\title{
Alexandre Fontaine
}

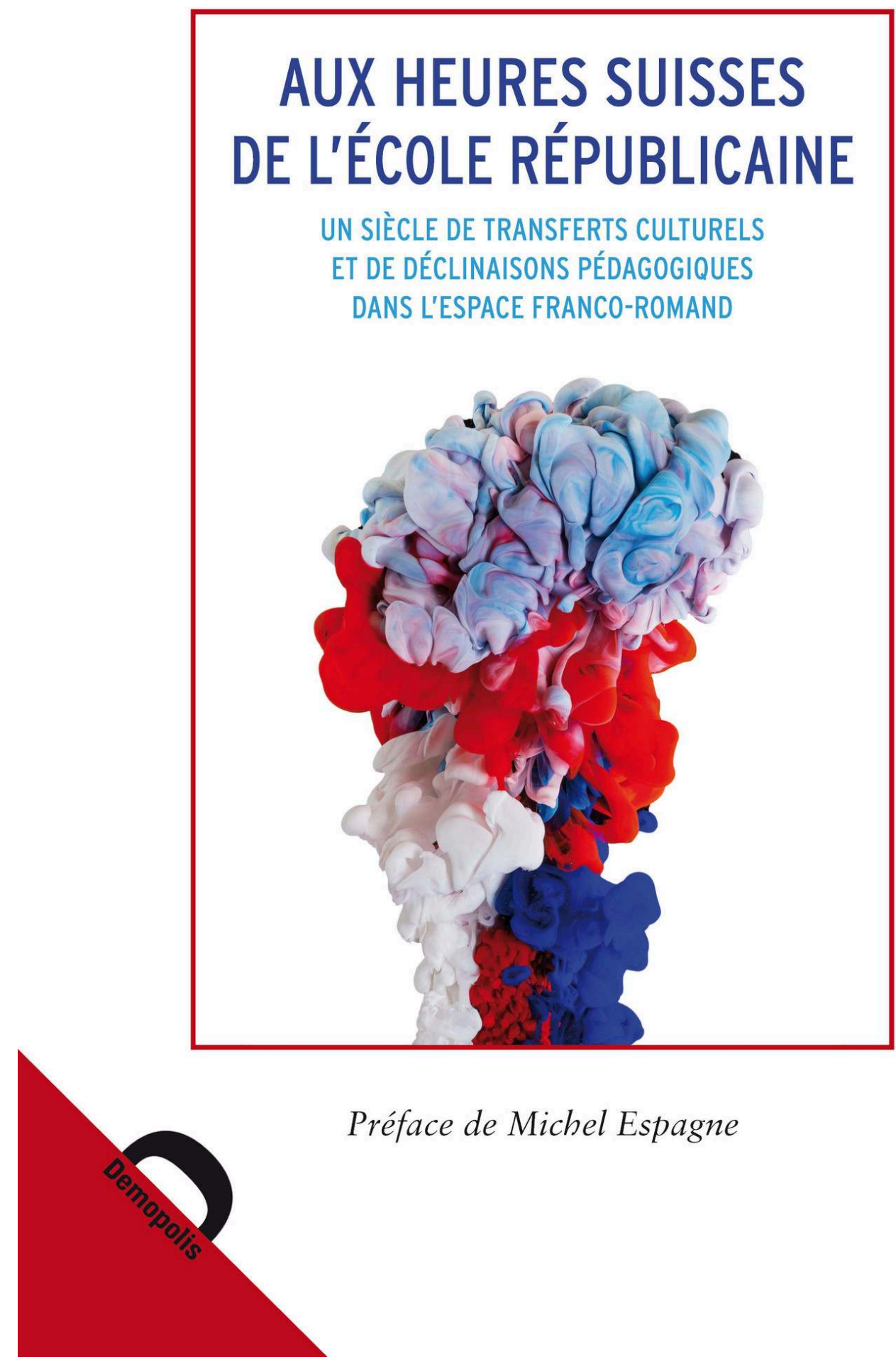




\section{Aux heures suisses de l'école républicaine}

Un siècle de transferts culturels et de déclinaisons pédagogiques dans l'espace franco-romand

\section{Alexandre Fontaine}

DOI : 10.4000/books. demopolis. 407

Éditeur : Demopolis

Année d'édition : 2015

Date de mise en ligne : 30 juin 2016

Collection : Quaero

ISBN électronique : 9782354571115

\section{prentation ebooks}

http://books.openedition.org

\section{Édition imprimée}

ISBN : 9782354570712

Nombre de pages : 316

\section{Référence électronique}

FONTAINE, Alexandre. Aux heures suisses de l'école républicaine: Un siècle de transferts culturels et de déclinaisons pédagogiques dans l'espace franco-romand. Nouvelle édition [en ligne]. Paris : Demopolis, 2015 (généré le 02 octobre 2020). Disponible sur Internet : <http://books.openedition.org/demopolis/ 407>. ISBN : 9782354571115. DOI : https://doi.org/10.4000/books.demopolis.407.

(C) Demopolis, 2015

Conditions d'utilisation :

http://www.openedition.org/6540 


\section{Alexandre Fontaine}

\section{AUX HEURES SUISSES DE L'ÉCOLE RÉPUBLICAINE}

UN SIÈCLE DE TRANSFERTS CULTURELS

ET DE DÉCLINAISONS PÉDAGOGIQUES

DANS L'ESPACE FRANCO-ROMAND

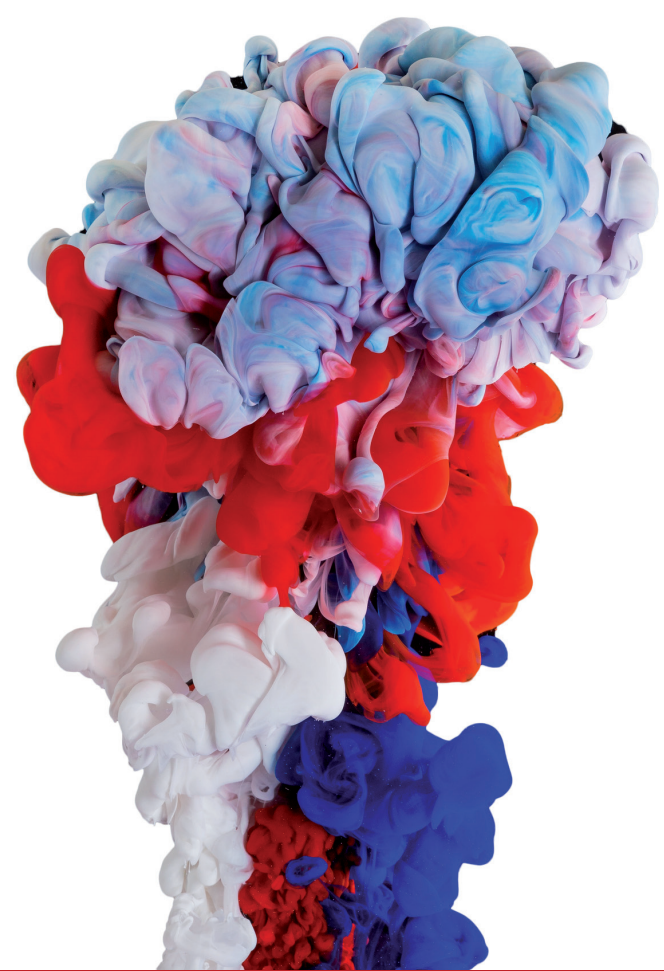

Préface de Michel Espagne

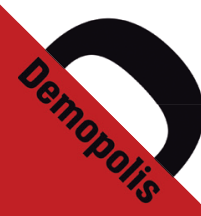



Cet ouvrage a été publié avec le soutien de :

la Fondation Ernst et Lucie Schmidheiny

la Maison de l'histoire de l'université de Genève

la Fondation du Père Girard à Fribourg (http://gregoiregirard.ch)

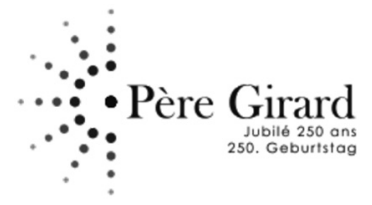

Ce travail a été écrit dans le cadre des thématiques de recherche du labex TransferS,

du domaine Allgemeine und Schweizer Geschichte der Neuzeit de l'université de Fribourg et de l'équipe Erhise de l'université de Genève

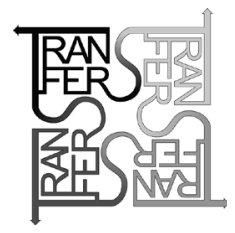




\section{AUX HEURES SUISSES DE L'ÉCOLE RÉPUBLICAINE \\ UN SIĖCLE DE TRANSFERTS CULTURELS \\ ET DE DÉCLINAISONS PÉDAGOGIQUES \\ DANS L'ESPACE FRANCO-ROMAND}




\section{«QUAERO »}

Collection dirigée par Jean-Christophe Tamisier

Hosham Dawod (dir.),

La constante "Tribu », variations arabo-musulmanes

Charles-Édouard Niveleau (dir.),

Vers une philosophie scientifique - Le programme de Brentano

Christian Ehrenfreund et Jean-Philippe Schreiber (dir.),

Les marranismes. De la religiosité cachée à la société ouverte

Christian Ghasarian,

Rapa, île du bout du monde, île dans le monde

Barbara Cassin, Danièle Wosny (dir.),

Les intraduisibles du patrimoine en Afrique subsaharienne

Pascale Rabault-Feuerhahn (dir.),

Théories intercontinentales. Voyages du comparatisme postcolonial

Michèle-H. Salamagne et Patrick Thominet (dir.),

Accompagner. Trente ans de soins palliatifs en France

Illustration de couverture:

Colorful Ink in Water $($ ) Lukas Gojda

(www.dreamstine.com)

(C) Éditions Demopolis, 2015

4, rue Scipion

75005 Paris

www.demopolis.fr

ISBN : 978-2-35457-071-2 


\section{ALEXANDRE FONTAINE}

\section{AUX HEURES SUISSES DE L'ÉCOLE RÉPUBLICAINE UN SIĖCLE DE TRANSFERTS CULTURELS ET DE DÉCLINAISONS PÉDAGOGIQUES DANS L'ESPACE FRANCO-ROMAND}

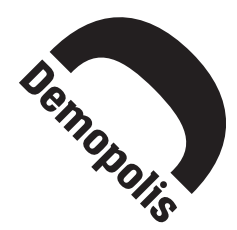



Pour Eya, Sonia et Olivier.

À la mémoire de mon père.

"Nous sommes tous des échos, échos d'innombrables échos. Les pensées de l'Inde, de la Judée, de la Grèce, de Rome, de la Germanie et des vieilles races celtiques se croisent dans nos pensées. Les uns sont plus Juifs, les autres plus Grecs, d'autres encore plus Germains; mais il y a de tout dans tous, et c'est ce mélange même qui fait la gloire et la richesse de notre civilisation moderne. Le plus pauvre esprit d'Europe est aujourd'hui paré des plumes d'une multitude d'espèces de paons. "

Eugène Rambert, Écrivains nationaux, 1874, p. 196. 



\section{Remerciements}

Cet ouvrage est le résultat d'une recherche doctorale menée en cotutelle internationale ${ }^{1}$. Il m'est particulièrement agréable de remercier toutes celles et ceux qui, à des titres divers, m'ont accompagné dans ce parcours de thèse. Ma dette la plus immédiate va aux professeurs Volker Reinhardt et Michel Espagne, qui ont dirigé mes recherches avec attention, rigueur et exigence. Je leur suis reconnaissant de m'avoir guidé vers des chemins intellectuels stimulants qui ont largement contribué à façonner ma formation scientifique.

Je tiens à dire ma gratitude à mes collègues de l'équipe de recherche en histoire sociale de l'éducation de l'université de Genève. Mes vifs et chaleureux remerciements vont également à mes collègues de l'UMR 8547 " Pays germaniques - transferts culturels » coordonnée par Michel Espagne, Pascale Rabault-Feuerhahn et Anne-Marie Thiesse (ENS-Ulm). Je suis redevable au Fonds national suisse de la recherche scientifique, qui par l'octroi d'une bourse de jeune chercheur m'a permis d'effectuer un séjour doctoral de dix-huit mois à l'École normale supérieure de la rue d'Ulm et de prolonger mes investigations dans plusieurs archives parisiennes ${ }^{2}$.

1. Transferts culturels et déclinaisons de la pédagogie européenne. Le cas franco-romand au travers de l'itinéraire d'Alexandre Daguet (1816-1894), université de Fribourg (Suisse) et de Paris 8, 2013. Soutenue le 5 juin 2013 à Fribourg devant le jury composé des professeurs: Volker Reinhardt (directeur, UNIFR), Michel Espagne (codirecteur, ENS Paris), Anne-Marie Thiesse (présidente, ENS Paris), Alain Clavien (président, UNIFR), Rita Hofstetter (UNIGE). Mention très honorable avec félicitations (Paris 8) et Summa cum laude (UNIFR).

2. Subsides FNS PBFRP1-127988 et PBFRP1-129474. Cette recherche a également bénéficié du soutien du FNS dans le cadre du projet Sinergia « Transformation des savoirs scolaires », FNS CRSII1-141826. 
J'exprime enfin ma reconnaissance aux organismes qui ont permis la publication de ce livre, à la fondation du Père Girard ${ }^{3}$, à la fondation Schmidheiny, à la Maison de l'histoire de l'université de Genève ainsi qu'à Sébastien Farré et Jean-Christophe Tamisier.

3. Nous suivrons dans ce livre I'usage qui s'est répandu de la graphie Père Girard au lieu du typographiquement correct père Girard. 


\section{Préface}

On sait que les outils intellectuels qui ont permis la construction d'une idéologie républicaine, celle qui a marqué la France depuis le milieu du $\mathrm{XIX}^{\mathrm{e}}$ siècle et continue à fournir le cadre de toute réflexion sur le lien social et la citoyenneté, ont été pour une large part forgés sur le territoire helvétique, lui-même servant souvent d'étape à des importations de la philosophie allemande. C'est en Suisse où il s'est réfugié que le traducteur de Kant Jules Barni élabore les principes d'un catéchisme républicain qui se combineront si aisément avec les principes d'autres germanisants réfugiés en Suisse, tel Edgar Quinet. La république laïque de Jules Ferry est tout particulièrement redevable à la Suisse d'impulsions essentielles dans le domaine de la pédagogie, celui où se constitue précisément l'unité nationale.

Au-delà d'une constatation à laquelle invite la prosopographie des émigrés français en Suisse durant le Second Empire, il importait d'analyser dans tous ses détails la circulation européenne de modèles pédagogiques et les efforts de réécriture auxquels elle donne lieu. C'est maintenant fait et bien fait grâce au travail d'Alexandre Fontaine qui a inauguré un nouveau style de recherche sur l'histoire de l'enseignement. Il a choisi comme premier fil directeur un historien et pédagogue de la Suisse romande: Alexandre Daguet, les quelques 3000 lettres de sa correspondance européenne et son journal l'Éducateur. Le projet exigeait d'éclairer les détails de réseaux franco-suisses et plus largement franco-germano-suisses qui sont au fondement d'une histoire culturelle européenne, pour comprendre comment les sciences de l'éducation sont nées au travers d'interactions internationales, pourquoi les fondements intellectuels de la $\mathrm{III}^{\mathrm{e}}$ République ont une dimension clairement internationale. Alexandre Fontaine a révélé que la méthodologie des transferts culturels, recherche attentive de communications oubliées entre des espaces nationaux et des dynamiques de réinterprétation, 
pouvait tout particulièrement s'appliquer au domaine pédagogique comme espace constitutif des phénomènes identitaires. Il fallait pour engager cette démonstration remonter jusqu'à la forte présence suisse à l'Académie royale des sciences de Prusse, observer qu'un des premiers inspirateurs de la pédagogie en Suisse, le père franciscain Grégoire Girard, avait été un lecteur particulièrement assidu de Kant.

Le parcours intellectuel d'Alexandre Daguet, au cœur de la construction d'une identité suisse, était particulièrement bien choisi, car on voyait apparaître les mécanismes de construction d'une culture suisse à partir de mécanismes d'importation et d'exportation francohelvétiques et germano-helvétiques. S'il y a en effet des éléments de biographie dans l'étude consacrée par Alexandre Fontaine à Daguet, il s'agit à l'évidence de la biographie d'un pays et d'une époque, de ce que l'on désigne par le terme de Gesellschaftsbiographie, de "biographie sociale ". Là encore, il convenait de choisir un corpus permettant de mettre en évidence le rôle spécifique de Daguet et le très large contexte dans lequel il s'inscrivait. En tant qu'historien, Daguet veut unir les cantons romands dans une fratrie régionale, ce qui le conduit à son Histoire de la Confédération suisse et à une attention particulière portée à Fribourg. Il est passionné par toutes les formes d'associations, qu'elles soient locales ou internationales et orientées vers un projet de paix universelle. C'est ainsi qu'on voit la société des instituteurs romands servir, avec l'aide de Daguet, de noyau à un projet d'association pédagogique universelle.

C'est dans ce contexte qu'il s'agissait d'observer la diffusion de l'œuvre des pédagogues allemands, Friedrich Fröbel ou AugustHermann Niemeyer. L'Éducateur est aussi un organe où l'on peut mesurer les équilibres internes à la Suisse, et on peut y voir l'apparition de contributions françaises comme celles de Gabriel Compayré. La pédagogie française va, de fait, progressivement devenir une projection d'expérimentations ou de théories suisses. La Suisse a été au XIX siècle un pays refuge, et c'est un des grands mérites du livre d'Alexandre Fontaine que de montrer tout ce que la pédagogie suisse doit à cette présence d'étrangers qui, à leur tour, ont fait essaimer en Europe et notamment dans la France de la III $^{\text {e }}$ République un modèle suisse réadapté aux caractéristiques du contexte d'accueil. L'amitié de Max Buchon et de Daguet, étudiée avec beaucoup d'attention est à cet égard très caractéristique. Très au fait de la culture allemande, le Salinois Max Buchon, qui se réclamait du fouriérisme, a été, un peu comme son compatriote le peintre réaliste Gustave Courbet, un protégé de 
Daguet et un actif médiateur entre Suisse et France. C'est Buchon qui contribua fortement à l'introduction du fouriérisme en Suisse romande. De Haller à Lavater, de Sulzer à Pestalozzi, de Zschokke à Gotthelf Daguet va chercher dans la littérature allemande l'inspiration nationale qui lui permettra de défendre la littérature suisse contre la prééminence française. Car il s'agit bien pour lui de déconstruire la littérature française en s'aidant de références allemandes ou alémaniques. Et pourtant le Dictionnaire de pédagogie de Ferdinand Buisson, comme les travaux pédagogiques de Gabriel Compayré, ces piliers de la réflexion française sur l'éducation laïque, ne peuvent être pleinement analysés qu'en lien avec le modèle de Daguet.

Le livre en vient de façon très naturelle à mettre en évidence des procédures de resémantisation à l'œuvre dans les transferts pédagogiques franco-suisses, qu'il s'agisse de la réinterprétation du cours de Girard, de la réappropriation du modèle de la gymnastique scolaire, des colonies de vacances, de la constitution de manuels suisses du citoyen français ou même de la circulation des modèles d'éducation musicale. Il apparaît, en conclusion, que la construction des systèmes pédagogiques nationaux résulte d'absorptions et de réinterprétations. On se prend à penser que l'approche engagée par Alexandre Fontaine de la circulation et de la réinterprétation des modèles pédagogiques dans des perspectives toujours liées à la construction d'ensembles nationaux trouverait facilement d'autres terrains d'application, par exemple dans la mise en place des systèmes d'enseignement propres aux pays africains ou asiatiques désireux de poser les bases d'un système culturel national. Elle présente en effet l'intérêt de dépasser radicalement le diffusionnisme pour mettre l'accent sur l'originalité liée à la réinterprétation d'un emprunt.

Michel Espagne, directeur du labex TransferS 



\title{
Introduction
}

\section{La pédagogie comme transfert culturel}

\author{
Qui dit pédagogie dit d'ailleurs quelque chose de \\ général, d'universel; on ne peut toucher à un sujet aussi \\ profondément humain et où chaque nation a dîu faire \\ des emprunts à l'autre, sans s'enquérir de la valeur \\ pédagogique de ces importations et de leur caractère \\ propre dans leur pays d'origine. \\ Alexandre Daguet, L'Éducateur, $1880^{1}$.
}

Comme le souligne l'éducateur suisse Alexandre Daguet, collègue et ami de Ferdinand Buisson à l'académie de Neuchâtel, la pédagogie occidentale s'est construite de manière collective, au prix d'innombrables emprunts transnationaux. Pensée globalement, elle est le fruit d'une " mobilisation générale » portée par divers acteurs singuliers et collectifs dès la fin du XVIII ${ }^{\mathrm{e}}$ siècle et regroupés dans des réseaux qui avaient pour but commun l'amélioration de l'éducation des masses peu à peu cristallisée - non sans résistance - sous la bannière " laïcitéobligation-gratuité ». Ce programme ambitieux a impliqué la mise en place de superstructures et de connexions internationales devant hâter l'avènement d'un " écolier-citoyen " instruit à la source d'une morale scolaire laïcisée et engagé à prendre sa place dans la nation pour servir au mieux les besoins de l'État: que l'on pense aux réseaux philanthropiques qui ont notamment pesé dans la diffusion de l'enseignement mutuel ou aux missions pédagogiques confiées à des spécialistes qui devaient rendre compte de l'état d'avancement du pays scruté et en

1. Alexandre Daguet, « Histoire critique de l'éducation en France, de Gabriel Compayré », L'Éducateur, 1/1880, p. 5. 
compiler les pratiques les plus efficientes ${ }^{2}$. Dès 1851 , les expositions universelles jouent par ailleurs un rôle nodal dans l'élaboration commune de normes identitaires mais aussi pédagogiques. À cet égard, Anne-Marie Thiesse souligne que " tout groupe national se montrait fort attentif à ce qu'accomplissaient ses pairs et concurrents, s'empressant d'adapter pour son propre compte une nouvelle trouvaille identitaire, étant à son tour imité dès qu'il avait conçu un perfectionnement ou une innovation ${ }^{3}$ ".

C'est pour ces raisons que l'on ne peut considérer l'école de Jules Ferry comme une invention made in France qui se serait élaborée en vase clos. Comme pour la plupart des espaces pédagogiques (Bildungsraum) ${ }^{4}$ qui se consolident durant le $\mathrm{XIX}^{\mathrm{e}}$ siècle, les structures scolaires mises en place sous la III $^{\mathrm{e}}$ République résultent d'un jeu complexe de transferts culturels, d'absorptions de savoirs étrangers et de retraductions personnalisées. Il suffit de parcourir le Catalogue noir instauré par Ferdinand Buisson dès 1886 pour constater l'étendue des références étrangères à partir desquelles l'école de Ferry s'est modelée. Ce passeport de la mémoire métissée de l'école républicaine recense tout ce que l'Europe pédagogique a produit de règlements, de programmes, de lois scolaires, de manuels ou d'ouvrages théoriques comme autant de pratiques susceptibles d'être appliquées ad usum Galliae.

La Suisse occupe une place de choix dans le transfert de savoirs scolaires vers Paris et la présence d'une minorité française dans le repli helvétique s'avéra déterminante dans la mise en place de ces translations. D'où l'intitulé de ce livre, dont le principal dessein

2. Voir Christophe Charle, « L'élite universitaire française et le modèle universitaire allemand (1880-1900) », in M. Werner et M. Espagne (éds.), Transferts. Les relations intellectuelles dans l'espace franco-allemand, Paris, Éditions recherche sur les civilisations, 1988, p. 346-358; Loïc Chalmel, Réseaux philanthropinistes et pédagogie au XVIII siècle, Berne, Peter Lang, 2004 ; Damiano Matasci, « Le système scolaire français et ses miroirs, Les missions pédagogiques entre comparaison internationale et circulation des savoirs », Histoire de l'éducation, n 125, 2010, p. 35-51.

3. Anne-Marie Thiesse, La création des identités nationales. Europe $X V I I^{e}-X X^{e}$ siècle, Paris, Seuil, 2001 [1999], p. 13. Voir également Brigitte Schroeder-Gudehus et Anne Rasmussen, Les fastes du progrès: le guide des expositions universelles, 1851-1992, Paris, Flammarion, 1992.

4. Lucien Criblez, Bildungsraum Schweiz, Berne, Haupt, 2008. Voir également Rita Hofstetter, Une école pour la démocratie. Histoire de l'école publique à Genève au XIXe siècle, Berne, Peter Lang, 1998; Jean-Michel Chapoulie, L'École et l'État conquiert la France. Deux siècles de politique scolaire, Rennes, PUR, 2010; Jean-Noël Luc, Philippe Savoie (éds.), « L'État et l'éducation en Europe, XVIII ${ }^{\mathrm{e}} \mathrm{XXI^{ \textrm {e } }}$ siècles », Histoire de l'Éducation, n 134, avril-juin 2012.

5. Une version numérisée est accessible sur http://www.bibliotheque-diderot.fr/bibliothequenumerique 
consiste à éclairer certaines références suisses de l'école républicaine. Si Pierre Rosanvallon a décelé un "moment suisse de la démocratie française $^{6}$ » qui s'étendrait globalement de 1890 à 1905, il existe une période qui s'avéra tout aussi décisive dans le processus de structuration des relations pédagogiques franco-romandes. En effet, suite au coup d'État du 2 décembre 1851 et à l'avènement du Second Empire, un nombre important d'opposantes et d'opposants à Louis Napoléon Bonaparte - les irréconciliables - s'exilent en Suisse jusqu'à l'amnistie de 1859 , sinon jusqu'à la proclamation de la III République le 4 septembre 1871. Que l'on pense à Edgar Quinet, installé à Veytaux près de Montreux entre 1858 et 1870 et à ses hôtes plus ou moins réguliers comme Jules Ferry, l'historien Jules Michelet, Georges Clemenceau ou dans une moindre mesure Adolphe Thiers en exil à Vevey. Que l'on pense également au divulgateur de Kant en France, Jules Barni, placé par Quinet à la tête de la chaire de philosophie de l'université de Genève dès 1861 et surtout à Ferdinand Buisson, la cheville ouvrière des grandes lois scolaires. Professeur à l'académie de Neuchâtel entre 1866 et 1870, il y sera bientôt rejoint par Jules Steeg et Félix Pécaut, deux autres piliers de l'école républicaine. L'intense travail d'observation de la démocratie suisse et de ses systèmes éducatifs laisse présager plus d'un emprunt. C'est ce qu'indique clairement Buisson, lorsqu'il évoque a posteriori son séjour neuchâtelois durant lequel il n'a cessé de réfléchir aux emprunts éducationnels susceptibles d'être acclimatés en France afin de relever la nation:

Comment s'y préparer mieux qu'en venant faire l'étude et l'apprentissage de la vie républicaine dans la plus ancienne démocratie de l'Europe? Pour la République française renaissante, l'éducation serait la première de toutes les réformes: où pourrait-on, mieux qu'en Suisse, en chercher l'inspiration, en recueillir les principes et la méthode? Et c'est ainsi qu'ayant eu le bonheur d'être admis, je m'installai à Neuchâtel bien plus, vous le voyez, en étudiant qu'en professeur. Observer à l'œuvre une démocratie vivante, en saisir l'âme dans l'école, puisque tant vaut l'école, tant vaut la nation, noter enfin les grands traits qu'un jour nous essaierons de reproduire chez nous, non pas par voie de copie servile, mais par l'élan des mêmes forces de liberté et de raison: telle fut, du premier au dernier jour, ma préoccupation constante ${ }^{7}$.

6. Pierre Rosanvallon, La démocratie inachevée: histoire de la souveraineté du peuple en France, Paris, Gallimard, 2000, p. 294.

7. Ferdinand Buisson, Souvenirs (1866-1916): conférence faite à l'Aula de I'université de Neuchâtel le 10 janvier 1916, Paris, Librairie Fischbacher, 1916, p. 11-12. 
De leur trajectoire helvétique, que retiendront ces proscrits, relégués hors d'une France dont ils repenseront bientôt la formule à l'aide de références empruntées entre Berlin et Moscou, entre Zurich et Genève? Que restitueront-ils de leur terre de proscription, si ce ne sont les outils qui serviront à renouer avec les idées des Lumières incarnées par Condorcet. Il serait bien présomptueux d'affirmer que la III ${ }^{\mathrm{e}}$ République trouve ses fondements en Suisse, surtout quand on connaît, depuis l'étude de Claude Digeon ${ }^{8}$, le poids de l'Allemagne dans le processus régénératif français. Toutefois, Patrick Cabanel a raison de rappeler que "la Troisième République est née aussi autour de la terrasse de Veytaux ${ }^{9}$ " et Pierre Ognier d'affirmer que la Suisse comme la Belgique ont révélé leur fonction de référence imaginaire, largement idéalisée ${ }^{10}$. Car on ne saurait trop montrer - et c'est là le pari de cet ouvrage - que c'est également de Suisse romande que s'est préparée, bien avant l'arrivée des républicains aux affaires d'ailleurs, la réactivation d'une pédagogie libérale-nationale qui aura un rôle déterminant dans le processus créatif et rassembleur de la nation française.

\section{Repenser la standardisation silencieuse des savoirs scolaires}

$\mathrm{Au}$ fur et à mesure de la consolidation des États-nations, on constate une gêne, sinon une défiance à assumer l'emprunt. Dans les années 1880, Félix Pécaut, figure titulaire de l'école républicaine et fondateur de l'école normale supérieure de jeunes filles de Fontenayaux-Roses, se demande "si dans le zèle que l'on montre à étudier les pays étrangers pour leur emprunter ce qu'ils ont de mieux en matière de pédagogie on ne risque pas de faire fausse route et d'égarer le génie français par ces imitations exotiques et contre-nature ${ }^{11}$ ".

Cette fidélité à la tradition ne s'accompagne nullement d'une diminution des circulations, bien au contraire. Mais concilier affirmation nationale et emprunt ne va pas de soi. On remarque que les autorités scolaires et politiques valorisent explicitement certains emprunts à

8. Claude Digeon, La crise allemande de la pensée française (1870-1914), Paris PUF, 1992 [1959].

9. Patrick Cabanel, Le Dieu de la République: aux sources protestantes de la laïcité (18601900), Rennes, PUR, 2003, p. 22.

10. Voir Pierre Ognier, L'école républicaine française et ses miroirs, Berne, Peter Lang, 1988.

11. Cité par Alexandre Daguet, «Pédagogie française et comparée », L'Éducateur, 10/1883, p. 163-164. 
opérer à l'international afin de légitimer leurs propres vues scolaires et orienter l'opinion publique pour précipiter leur réalisation à l'échelle locale ${ }^{12}$. Menant sa propagande en faveur de la création d'un musée pédagogique en France, Ferdinand Buisson s'alarme du fait que " tous les pays qui se préoccupent de l'instruction populaire possèdent aujourd'hui cette institution; le nôtre est le seul, ou peu s'en faut, qui ne la connaisse pas $^{13}$ ».

Une autre modalité liée au transfert demeure plus ambiguë. Lorsqu'une pratique pédagogique passe d'un contexte à l'autre (nations, régions, cantons, individus, etc.), on constate qu'elle est adaptée aux normes du contexte d'accueil afin d'y être greffée. Les médiateurs qui guident cette translation en façonnent une version singulière et autonome, souvent radicalement réinterprétée et qui autorise de ce fait la suppression de l'origine de l'emprunt. Gita Steiner-Khamsi notamment nous rend attentif à ces problèmes liés à la reterritorialisation de l'importation éducationnelle. Elle éclaire le processus hautement politisé de sélection des emprunts et convoque l'idée fort pertinente de nettoyage ${ }^{14}$. On remarque en effet que le succès et l'efficience de l'importation d'un savoir ou d'une méthode pédagogique dépendent de la capacité de ses médiateurs à en gommer plus ou moins grossièrement la généalogie. Jean Houssaye pointe également ce phénomène et explique que toute nouvelle pédagogie, " pour exister et s'imposer, se doit de s'opposer, et au besoin d'effacer, de passer sous silence, de diaboliser ${ }^{15}$ ". On ajoutera à ce constat que les autorités scolaires portaient une si grande énergie à s'approprier l'emprunt, à se le « faire soi », que celui-ci finissait par se confondre dans le panorama scolaire local et par un mécanisme de déni à en devenir une invention

12. Voir Bernd Zymek, Das Ausland als Argument in der pädagogischen Reformdiskussion: Schulpolitische Selbstrechtfertigung, Auslandspropaganda, internationale Verständigung und Ansätze zu einer vergleichenden Erziehungswissenschaft in der internationalen Berichterstattung deutscher pädagogischer Zeitschriften 1871-1952, Ratingen, Kastellaun, 1975; Philipp Gonon, « Learning from European Neighbours: The role of the State in defining of Institutional Policies - The Case of Switzerland », in Heikkinen A. (éds.), Vocational Education and Culture-European Prospects from Theory and Practice, 1995, p. 22-36.

13. Ferdinand Buisson, « Projet d'établissement d'un musée pédagogique », Manuel général de l'instruction primaire, 2 mars 1878, p. 85.

14. Gita Steiner-Khamsi, « Reterritorialisation de I'importation éducationnelle. Explorations de la politique de l'emprunt éducationnel », in Martin Lawn et Antonio Novoa (éds), L'Europe réinventée. Regards critiques sur l'espace européen de l'éducation, Paris, L'Harmattan, 2005, p. 103-128.

15. Jean Houssaye, « Pédagogies: import-export », Revue française de pédagogie, avril-juin 2006, p. 83-93. 
du cru. Ce processus de resémantisation et de nettoyage des filiations aboutit à ce que j'appellerai une standardisation silencieuse des savoirs scolaires ${ }^{16}$. Silencieuse parce que sous le couvert d'un processus d'acculturation plus ou moins radical, l'objet transféré est singularisé et perçu comme le fruit du génie national quand bien même on le retrouve décliné sous d'autres formes chez les voisins qui se targuent d'un discours similaire.

Les sciences de l'éducation - et c'est là un de leur principal atout - sont nées et se sont consolidées dans le sillage d'interactions internationales émanant traditionnellement du monde pédagogique, que l'on pense aux réseaux des jésuites et à leur Ratio Studiorum. On relèvera toutefois le caractère paradoxal de la naissance d'une science de l'éducation qui devient politiquement importante dans un contexte où l'universalisme lui-même devient une prétention nationale. Du reste, le fait que son fondateur Marc-Antoine Jullien, dit de Paris, soit également le père de l'éducation comparée ne fait que confirmer le constat du lien entre science de l'éducation et construction nationale. Dans le sillage de ses travaux, les historiens de l'éducation n'ont depuis cessé de s'interroger sur les systèmes scolaires pour définir leurs similitudes et différences, leurs avantages et inconvénients, leurs qualités et imperfections afin d'en importer les pratiques les plus efficientes ${ }^{17}$. En posant un regard rétrospectif sur cette histoire riche de deux siècles, Henk van Daele concède cependant que:

16. Florian Waldow a argumenté l'existence de silent borrowing, dans le contexte de son étude sur la construction du système scolaire suédois, voir « Undeclared imports : silent borrowing in educational policy-making and research in Sweden », Comparative Education, 45/4, 2009, p. 477-494. Je remercie Lucien Criblez qui m'a guidé vers ces développements.

17. On en trouvera une synthèse dans Jason Beech, « The theme of Educational Transfer in Comparative Education: a view over time », Research in Comparative and International Education, vol. 1, 1/2006, p. 2-13. Pour une vue plus détaillée, voir notamment Nicholas A. Hans, « Exportation of Educational Ideas », Journal of Educational Sociology, vol. 29, 7/1956, p. 274-281; Konstantin Ushinsky, « On National Character of Public Education », in A.I. Piskunov (éds.), K. D. Ushinsky: selected works, Moscow, Progress Publishers, 1975; Michael Sadler, « How Far Can we learn anything of practical value from the study of foreign systems of Education? », in J. Higginson (éds), Selections from Michael Sadler: studies in world citizenship, Liverpool, Dejall \& Meyorre, 1979; Marcelo Caruso et Heinz-Elmar Tenorth (éds.), Internationalisierung: Semantik und Bildungssystem in vergleichender Perspektive, Frankfurt am Main, Lang, 2002; David Phillips et Kimberly Ochs, Educational Policy Borrowing: historical perspectives, Oxford, Symposium Books, 2004; Jürgen Schriewer, « L'internationalisation des discours sur l'éducation: adoption d'une « idéologie mondiale » ou persistance du style de « réflexion systémique » spécifiquement nationale? », Revue française de pédagogie, 146/2004, p. 7-26; Jeremy Rappleye, « Theorizing Educational Transfer: toward a conceptual map of the context of cross-national attraction », Research in Comparative and International Education, 1/3, 2006, p. 223-240. 
La grande majorité des comparatistes de la première moitié de notre siècle $\left[\mathrm{xx}^{\mathrm{e}}\right.$ siècle] se limite à décrire, souvent d'une manière ethnocentrique, quelques systèmes nationaux d'enseignement en Europe occidentale et en Amérique du nord. S’inspirant des idées de Michael Sadler, James Russel et de Friedrich Schneider, ils sont tous convaincus que le système d'éducation de chaque pays, considéré - à tort! - comme une unité homogène, est le résultat typique de l'histoire nationale et du " caractère d'un peuple ${ }^{18}$ ».

Les spécialistes de l'éducation comparée sont donc conscients des promesses non tenues par une approche comparative qui n'a su proposer des explications convaincantes ${ }^{19}$. Jürgen Schriewer explique que « les évidences empiriques mises au jour par la comparaison ne permettent guère de corroborer les modèles explicatifs macrosociaux initialement posés ${ }^{20}$ ». Il s'agit également de répondre à de nouveaux défis liés à l'évolution même de la mondialisation. Dans ce sens, Schriewer constate que "les sociétés, les nations ou les civilisations [...] s'estompent derrière des amalgames complexes où se superposent des entités historico-culturelles et des interdépendances globales, des configurations particulières et des processus d'interpénétration civilisationnelle, la formation d'hybrides et des métissages culturels ${ }^{21}$ ». De cette prise de conscience nodale découle le fondement méthodologique de ce livre. Au lieu d'opposer des systèmes scolaires dans un jeu comparatiste qui présuppose de facto des aires culturelles closes ${ }^{22}$, je me suis plutôt interrogé sur les phénomènes d'inclusion pour montrer, sans dévaloriser les particularismes, qu'il existe une mémoire scolaire suisse de la France comme il existe une mémoire française de l'école suisse. En d'autres termes, j'ai essayé de déconstruire le caractère essentiellement national (ou cantonal pour la Suisse) à partir duquel sont traditionnellement présentées les histoires des instructions publiques que plusieurs générations d'historiens ont contribué à compartimenter.

18. Henk van Daele, L'éducation comparée, Paris, PUF, 1993, p. 108-109.

19. Jürgen Schriewer, « L'éducation comparée: un programme ambitieux face à de nouveaux défis », in P. Laderrière, F. Vaniscotte, L'éducation comparée: un outil pour l'Europe, Paris, L'Harmattan, 2003, p. 44. Voir également Mattei Dogan et Ali Kazancigil, Comparing Nations, Oxford \& Cambridge, Blackwell, 1994.

20. Ibid.

21. Ibid., p. 47.

22. Voir Michel Espagne, « Sur les limites du comparatisme en histoire culturelle », Genèses, 17, 1994, p. 112. 


\section{Décloisonner les espaces pédagogiques pour reformuler des connexions oubliées}

Volker Reinhardt a montré combien il s'avère essentiel, pour les nations européennes, de s'extraire de cette idée de Sonderfall (d'exception ou de cas particulier) pour apprendre à se représenter au sein d'un monde divers et métissé ${ }^{23}$. Cette recherche s'inscrit pleinement dans cette démarche, dans cette nécessité de réévaluer l'histoire des nations occidentales afin d'en éclairer les racines étrangères et en mesurer les dettes et les créances socioculturelles ${ }^{24}$. Ce travail paraît d'autant plus utile que nous traversons une période de crispation identitaire particulièrement profonde. Accepter que notre histoire soit aussi celle des autres constitue assurément un défi de taille pour l'ego-citoyen du xxi siècle. Autant de défis qui nous engagent à prolonger le travail de reconnaissance des réseaux d'héritages subtilement pointé par Michel Espagne:

On ne compte plus les caricatures très parlantes présentant l'Europe comme une forteresse dont les clivages internes sont réduits au point d'en être gommés, dont la diversité des mœurs et de langues parait oubliée, laissant en dehors de ses murs la véritable altérité, une altérité tellement inaccessible que, comme le soupçonne Édouard Saïd, la perception que nous en avons serait notre propre construction. À la vérité, des turqueries du XVII ${ }^{e}$ siècle à l'art nègre en passant par les persans de Montesquieu, le goût des jésuites pour la Chine ou l'égyptomanie napoléonienne, il se pourrait que des éléments extérieurs de la forteresse soient depuis bien longtemps des pierres de sa fondation même ${ }^{25}$.

Pour rendre compte de ces mécanismes d'emprunts, j'ai étudié ces échanges pédagogiques au travers de la notion de transfert culturel. Introduite par un groupe de chercheurs franco-allemands dans le milieu des années 1980, la question des transferts culturels continue d'être le point de convergence de recherches diversifiées mais dessinant un espace théorique et méthodologique commun répondant à un même souci d'aborder de façon nouvelle les imbrications culturelles ${ }^{26}$.

23. Neue Zürcher Zeitung am Sonntag, 28 août 2011, p. 14. Voir également Volker Reinhardt, Die Geschichte der Schweiz: von den Anfängen bis heute, München, Beck, 2011.

24. À cet égard, voir le Dictionnaire des étrangers qui ont fait la France dirigé par Pascal Ory, publié chez Robert Laffont en 2013.

25. Michel Espagne, «L'horizon anthropologique des transferts culturels - Introduction », Revue germanique internationale, 2004, p. 6.

26. On trouvera une présentation détaillée des projets en cours sur le site du laboratoire d'excellence labexTransferS (http://www.transfers.ens.fr). On trouvera une liste indicative des travaux de la Kulturtransferforschung dans la bibliographie en fin de volume. 
Encore peu employée par les historiens de l'éducation ${ }^{27}$, la méthodologie évolutive des transferts culturels a l'avantage de dépasser, tout comme le fait l'histoire globale, le cadre national pour mettre en avant l'idée de socle commun, d'osmose culturelle et placer la figure de l'étranger au centre du débat. Caroline Douki et Philippe Minard rappellent que « les compartimentages nationaux tendent en effet à escamoter ou rendre peu visibles tous les phénomènes d'interrelation et de connexions, en imperméabilisant les frontières, en détachant les objets des contextes et liens transétatiques ${ }^{28}$ ». Ainsi, pour les pères de la Kulturtransferforschung:

Le terme de transfert culturel marque un souci de parler simultanément de plusieurs espaces nationaux, de leurs éléments communs, sans pour autant juxtaposer les considérations sur l'un et l'autre pour les confronter, les comparer ou simplement les cumuler. Il signale le désir de mettre en évidence des formes de métissage souvent négligées au profit de la recherche d'identités, d'une recherche qui vise naturellement à occulter ces métissages, même lorsque les identités en résultent ${ }^{29}$.

Dans cette perspective, Monique Mombert, dans son étude sur l'enseignement de l'allemand en France, a fait le choix méthodologique « de ne pas comparer des données statiques, mais de chercher à saisir des dynamiques ${ }^{30}$ ", en suivant concrètement la trajectoire des emprunts au travers d'une analyse triple (sélection-médiation-réinterprétation). Quelles motivations, quels intérêts poussent en effet des

27. Voir Monique Mombert, L'enseignement de l'allemand en France 1880-1918. Entre «modèle allemand» et «langue de l'ennemi», Strasbourg, Presses Universitaires de Strasbourg, 2001; Danièle Tosato-Rigo, « Une didactique des droits de I'homme? Autour de quelques catéchismes républicains helvétiques », in Menschenrechte und moderne Verfassung. Die Schweiz im Übergang vom 18. zum 19. Jahrhundert. Akten des colloquiums an der Universität Freiburg, 18.-20. November 2010, Slatkine, Genève, 2012, p. 276-295; Christine Mayer, «Female education and the cultural transfer of pedagogical knowledge in the eighteenth century », Paedagogica Historica, 2012, 48/4, p. 511-526; Jean-François Goubet, Des maîtres philosophes? La fondation de la pédagogie générale par l'Université allemande, Paris, Garnier, 2012; Sarah Scholl, « « Soyez courageux et dociles! ». Les normes religieuses comme vecteur d'éducation au patriotisme en Suisse (1870 - 1914) », Revue suisse d'histoire, 3/2013, p. 343-363. Voir également Gita Steiner-Khamsi et Florian Waldow, Policy Borrowing and Lending in Education, World Yearbook of Education, Londres et New York, Routledge, 2012 et de la même, The global politics of educational borrowing and lending, Londres et New York, Teachers College, Columbia University, 2004.

28. Caroline Douki et Philippe Minard, « Histoire globale, histoires connectées: un changement d'échelle historiographique? », Revue d'histoire moderne et contemporaine, 5/2007, p. 10.

29. Michel Espagne, Les transferts culturels franco-allemands, Paris, PUF, 1999, p. 1.

30. Monique Mombert, op. cit., p. 12. 
instituteurs ou des cadres de l'instruction publique à importer une pratique pédagogique modelée ailleurs, celle-ci résultant parfois elle-même d'une ou de plusieurs translations antérieures? Quels acteurs singuliers ou collectifs assurent le processus de médiation et de retraduction? Quelle configuration prend le savoir transféré lorsqu'il change d'environnement culturel? Cet emprunt est-il toujours assumé ou est-il au contraire l'enjeu de résistances?

Afin d'aller vers des réponses à ces questionnements, j'ai tenté de réévaluer l'histoire des relations pédagogiques franco-suisses du $\mathrm{XIX}^{\mathrm{e}}$ siècle; il s'agissait d'être particulièrement attentif aux médiateurs pluriels qui se sont chargés, pour de multiples raisons, d'entreprendre le transfert de pratiques et de savoirs scolaires entre ces deux espaces bien plus interdépendants qu'il n'y paraît. Est-il besoin de le préciser, si j'ai choisi de faire des relations entre la France et la Suisse romande l'épicentre de cette recherche, il ne fait aucun doute qu'une analyse similaire pourrait être menée dans d'autres constellations, car à l'évidence le $\mathrm{XIX}^{\mathrm{e}}$ siècle pédagogique relève d'une dissolution manifeste des pratiques scolaires déclinées à tout vent entre les puissances européennes engagées dans un jeu de concurrences acharnées. Pour autant et comme on le verra à de nombreuses reprises, se polariser sur ces deux espaces implique nécessairement d'avoir l'Europe entière en ligne de mire. Car, que ce soit lors du processus de création de la nation française, comme celui de la région romande, c'est à partir du concert européen que ces deux espaces ont effectué leurs propres gammes, composées très souvent de consonances germaniques. Les travaux d'Ernest Gellner, de Benedict Anderson ou d'Anne-Marie Thiesse, qui a montré qu'il n'y a " rien de plus international que la formation des identités nationales ${ }^{31}$ ", sont là pour l'attester. Mieux encore, il aurait fallu considérer les circulations dans une perspective transcontinentale, afin de s'extraire de cet eurocentrisme pointé notamment par Jack Goody ${ }^{32}$. Car si l'on peut démontrer que l'école républicaine a construit son instruction publique, à l'instar des autres nations européennes, en absorbant pratiques et savoirs dans ce qui apparaît comme un socle commun de la pédagogie occidentale, alors il serait utile de faire réapparaître ces

31. Anne-Marie Thiesse, op. cit., p. 11. Voir Ernest Gellner, Nations et nationalisme, Paris, Payot, 1989 [1983]; Benedict Anderson, L'imaginaire national: Réflexions sur l'origine et l'essor du nationalisme, Paris, La Découverte, 2002 [1983].

32. Jack Goody, Le vol de I'histoire. Comment I'Europe a imposé le récit de son passé au reste du monde, Paris, Gallimard, 2010 [2006]. Voir également Pascale Rabault-Feuerhahn (éds.), Théories intercontinentales. Voyages du comparatisme postcolonial, Paris, Demopolis, 2014. 
filiations en contexte colonial, là où l'école semble, en tout cas de prime abord, la plus nationalisée ${ }^{33}$.

\section{Alexandre Daguet: entre nationalisme et universalisme}

L'historien et pédagogue romand Alexandre Daguet (1816-1894) sera notre guide dans ce travail de réévaluation ${ }^{34}$. Homme engagé dans tous les combats de son temps, historien de la nation, théoricien des idées éducatives, son activité scientifique est colossale: plus de mille contributions dans L'Éducateur, un Manuel de Pédagogie à succès (cinq éditions), une Histoire de la Confédération suisse traduite en trois langues et son Abrégé pour les écoles primaires réédité à seize reprises, ensemble auquel il faut adjoindre plus de cent cinquante articles historiques et une biographie de son maître le Père Girard publiée à titre posthume chez Fischbacher à Paris grâce à l'appui de cadres de l'école républicaine française.

Si la trajectoire et l'œuvre nationale de cet intellectuel sont bien connues $^{35}$, c'est plutôt la dialectique entre nationalisme et universalisme qu'il incarne que j'ai trouvé intéressant d'étudier. Car si son œuvre d'historien libéral-national est intégralement consacrée à l'appréhension des particularismes régionaux, cantonaux et nationaux de son pays, sa posture s'élargit et se décloisonne considérablement lorsqu'il devient rédacteur en chef de L'Éducateur, la revue des instituteurs romands fondée en 1865 . C'est au nom d'un principe d'universalité de la pédagogie émancipée des a priori ethnocentriques que Daguet façonne puis développe la phase éclectique de la pédagogie dixneuvièmiste romande. Consulté par l'élite scolaire française, un

33. Voir Julia Clancy-Smith, « L'école de la rue du Pacha à Tunis: I'éducation de la femme arabe et la plus « grande France »(1900-1914) 》, Clio. Histoire, femmes et sociétés, 12/2000, p. 33-55; Paul Aubin, « La pénétration des manuels scolaires de France au Québec. Un castype: Les frères des écoles chrétiennes, XIX $-X X X^{e}$ siècles », Histoire de l'éducation, 85/2000, p. 3-24; Daniel Rivet, Le Maghreb à l'épreuve de la colonisation, Paris, Fayard, 2010 [2002]; Rebecca Rogers, A Frenchwoman's Imperial Story: Madame Luce in Nineteenth-Century Algeria, Stanford, Stanford University Press, 2013; Benoît Falaize, Charles Heimberg, Olivier Loubes, L'école et la nation ( $3^{e}$ partie: l'école et la dimension impériale, p. 322-470), Paris, ENS Éditions, 2013; Barnita Bagchi, Eckhardt Fuchs, Kate Rousmaniere (éds.), Connecting Histories of Education: Transnational and Cross-Cultural Exchanges in (Post-) Colonial Education, Oxford \& New York, Berghahn Books, 2014.

34. On trouvera les principaux repères biographiques ainsi qu'une autobiographie inédite d'Alexandre Daguet dans les annexes I et II en fin de volume.

35. Les travaux et études consacrées à Daguet sont référencés dans la bibliographie. 
réseau se dessine autour de ce creuset romand qui jouit d'une certaine autorité et dont la revue fait l'objet d'emprunts et permet une large circulation des méthodes hors des frontières nationales. Inversement, $L^{\prime} E ́ d u c a t e u r$ se veut un ample réceptacle au sein duquel Daguet « essaie tout pour ne retenir que ce qui est bon ». L'essentiel de la pédagogie du moment y est traduit, exposé et réinterprété, formant par là même une mémoire infrastructurelle de la pédagogie occidentale. Ainsi, bien qu'il ait décliné l'appel de Ferdinand Buisson à édifier avec lui une " œuvre internationale d'éducation ", son rôle de passeur dans l'espace franco-romand fut important et reste à découvrir, tout comme les liens qu'il a entretenus avec les cadres de l'école française. Étudier sa correspondance, riche de plus de trois mille lettres, révèle un réseau resté inédit qui intègre des figures de premier plan tels Ferdinand Buisson, Jules Steeg, Gabriel Compayré, Édouard Charton, Max Buchon, Gustave Courbet, Hyacinthe Loyson, Jean-Jacques Rapet, Frédéric Passy, Gustave Vapereau, Charles Defodon, Charles Lucas ou encore Jean Macé. C'est donc d'une histoire de médiateurs et de transferts culturels dont il sera question dans cet ouvrage, afin de pointer le rôle décisif d'acteurs singuliers ou collectifs dans l'acculturation de savoirs scolaires entre la Suisse et la France. 
PREMIÈRE PARTIE

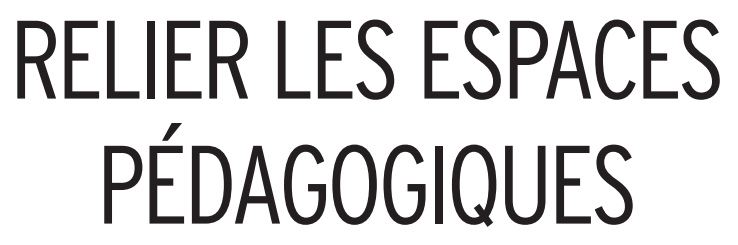





\section{1 \\ L'éveil d'une diplomatie scolaire}

Le $\mathrm{XVIII}^{\mathrm{e}}$ siècle se singularise par son ouverture considérable sur l'espace public. Les savants, les érudits, les philanthropes et les marchands jouissent de réseaux qui se sont substantiellement développés depuis la maitrise des quatre parties du monde ${ }^{1}$ engagée par les acteurs de la monarchie catholique (1580-1640) et la naissance d'une république mondiale des lettres vers la fin du Xvi ${ }^{\mathrm{e}}$ siècle $^{2}$. On évoquera par exemple le réseau constitué par les Suisses présents dans l'académie royale des sciences de Prusse, suite à son renouvellement de janvier 1744. Berlin, alors microcosme cosmopolite et capitale mondiale de la science, rassemble Leonhard Euler rapatrié de Saint-Pétersbourg par le président Maupertuis, les frères Bernoulli, Johann Georg Sulzer, Johann Caspar Lavater ou Johann Bernhard Merian ${ }^{3}$. La pédagogie s'inscrit pleinement dans ce tissu de circulations et l'on assiste, vers la fin du siècle, à l'émergence d'une "diplomatie scolaire » entendue comme un réseautage de plus en plus structuré constitué d'une élite en voyage et permettant les transferts de savoirs et de pratiques pédagogiques en Occident ${ }^{4}$.

1. Voir Serge Gruzinski, Les quatre parties du monde. Histoire d'une mondialisation, Paris, Éditions de la Martinière, 2004.

2. Voir Pascale Casanova, La république mondiale des lettres, Paris, Seuil, 2008 [1999].

3. Sur le réseau des Suisses à Berlin, voir Martin Fontius et Helmut Holzhey, Schweizer im Berlin des 18. Jahrhunderts, Berlin, Akademie Verlag, 1996; André Bandelier, Des Suisses dans la République des lettres. Un réseau savant au temps de Frédéric le Grand, Genève, Slatkine, 2007.

4. Voir Loïc Chalmel, La petite école dans l'école. Origine piétiste-morave de l'école maternelle française, Berne, Peter Lang; Florence Catherine, La Pratique et les réseaux savants d'Albrecht von Haller (1708-1777), vecteurs du transfert culturel entre les espaces français et germaniques au XVIII' siècle, Paris, Honoré Champion, 2012. 
Les idées pédagogiques s'exportent dorénavant d'Allemagne en Russie et se répandent dans toute l'Europe ${ }^{5}$. Nicolas Gabriel Clerc, dit Leclerc (1726-1798), savant français envoyé par Louis XV en mission à l'étranger, s'installe à Pétersbourg et y dirige les établissements de Catherine II avant de se charger de la traduction française des projets éducatifs de la tsarine qui devaient contribuer à faire émerger l'image d'une souveraine éclairée dans toute l'Europe ${ }^{6}$. De retour en France, Leclerc propose de ressusciter les idées novatrices du pédagogue allemand Johann Bernhard Basedow (1724-1790) et présente un plan d'éducation nationale à l'Assemblée constituante française ${ }^{7}$. Un moine préoccupé d'éducation dans la petite ville catholique de Fribourg en Suisse résume ce réveil d'une nouvelle conscience pédagogique née de la rupture fondamentale de 1789 et stimulée grâce à l'émergence d'une diplomatie scolaire résolument tournée vers les relations transnationales:

Le Russe, le Polonais et le Grec se portent vers l'Occident pour demander ce que l'on fait pour l'instruction de la jeunesse. L'Anglais sort de son île, avide de recueillir sur la terre ferme quelques nouvelles ressources pour sa chère jeunesse: le Français passe la mer, animé du même désir; il compare les écoles britanniques avec les écoles nationales pour composer son système amélioré. De retour sur le continent, il contemple avec satisfaction les modestes et touchantes institutions de la Hollande, les plus anciennes de toutes, et remonte le Rhin pour visiter la pensive Germanie. Nos Alpes sont comme le rendez-vous des voyageurs. Ici se fait l'échange de graves et bienveillantes pensées à la vue de nos rocs pelés, de nos glaciers, de nos riantes verdures et de nos belles eaux. Célèbre par deux grands noms, notre Helvétie est regardée comme une terre classique de l'éducation ${ }^{8}$.

5. Voir Michel Espagne, L'ambre et le fossile. Transferts germano-russes dans les sciences humaines XIX ${ }^{e}-X X^{e}$ siècle, Paris, Armand Colin, 2014; Danièle Tosato-Rigo, « Nobles russes en terre républicaine: les Golowkin », in Deux siècles de présence en Pays de Vaud: actes du colloque du 11 juin 2011, Slatkine, Genève, 2012, p. 68-80.

6. Voir Dominique Picco, « Le plan d'Ivan Betskoï pour l'Institut des demoiselles nobles de Smolny, modèle ou contre-modèle éducatif? », in F. Cadilhon, M. Combet \& M. FigeacMonthus (éds.), Construire l'éducation de l'Ancien Régime à nos jours, Presses universitaires de Bordeaux, 2009, p. 101-128.

7. Nicolas Gabriel Leclerc, Abrégé des études de I'homme fait, en faveur de l'homme à former, dédié aux représentants de la nation, Paris, Librairie Maradan, 1789.

8. Grégoire Girard, Discours de clôture du 9 septembre 1818 (1805-1822), Fribourg, Société fribourgeoise d'éducation, 1950, p. 67. 


\section{Le nouvel horizon du Père Girard}

Qui est donc ce moine franciscain, figure centrale mais également atypique des Lumières fribourgeoises du second XVIII siècle? Grégoire Girard (1765-1850), plus connu sous le nom de Père Girard, entre dans l'ordre des Franciscains en 1782 puis s'en va à Wurtzbourg suivre des études de philosophie et de théologie. Sa trajectoire et son œuvre sont bien connues, notamment grâce à la biographie dressée par son élève de prédilection, Alexandre Daguet, qui hérita des papiers du maitre lors de sa disparition. Soulignons toutefois que Daguet a cherché durant plus de quarante ans à éditer les Mémoires de son mentor en Suisse et ce n'est que grâce à l'appui de deux figures majeures de l'école républicaine, Ferdinand Buisson et Jules Steeg, que ses deux volumes paraitront à Paris chez Fischbacher en $1896^{9}$.

La bibliothèque nous en apprend davantage sur l'horizon intellectuel de Girard ${ }^{10}$. Le moine cénobite est en effet un grand lecteur de Kant: de la Critique de la raison pure à la Métaphysique des moeurs, ce ne sont pas moins de treize ouvrages du philosophe de Königsberg que Girard a lu et enseigné après son retour d'Allemagne. Girard s'attacha à l'étude des deux Raisons, qu'il devait propulser et défendre dans les milieux ultramontains fribourgeois via une interprétation pour le moins personnelle:

Le philosophe de Königsberg professe d'abord l'idéalisme et devient ensuite, comme il parait, un athée. Cependant, ce qu'il détruit d'une main, il le rétablit de l'autre. Parlant du devoir, il fait voir que la raison pratique nous ordonne la sainteté, sous promesse d'un bonheur proportionné au mérite; puis que cette sainteté et cette proportion ne sauraient avoir lieu sans l'immortalité et un Dieu tout-puissant; enfin, que la raison pratique nous oblige de croire à tous deux, bien que nous ne puissions rien en savoir. Cette philosophie n'est donc pas si immorale, elle n'est pas athée, comme on a voulu le dire; mais elle prend un chemin insolite pour arriver par la vertu à la religion. En vérité, c'est un beau chemin. C'est celui que prend l'innocence opprimée, qui, s'appuyant sur la conscience, en appelle au témoignage et à la justice du ciel ${ }^{11}$.

9. Alexandre Daguet, Le Père Girard et son Temps. Histoire de la vie, des doctrines et des travaux de l'éducateur suisse (1765-1850), 2 tomes, Paris, Librairie Fischbacher, 1896.

10. Voir Supplément du catalogue de la Société économique de Fribourg, Imprimerie L.-J. Schmid, 1858 (les ouvrages marqués d'une astérisque proviennent de la bibliothèque personnelle de Girard).

11. Ibid., p. 40. 
D’ailleurs, si François Azouvi et Dominique Bourel ont éclairé l'histoire d'une préréception de la philosophie de Kant en Suisse ${ }^{12}$, relayée notamment de l'académie de Berlin par Johann Bernhard Merian et diffusée dans les cercles protestants de Genève, on doit également relever l'existence d'un milieu kantien, certes d'importance moindre, au sein des catholiques libéraux suisses dont Girard fut assurément un animateur. Mais sont également à prendre en compte des adversaires ou des déçus du kantisme et en premier lieu Johann Georg Feder ou Friedrich Ludewig Bouterweck, proche de Friedrich Heinrich Jacobi que le moine de Fribourg a dévoré, tout comme l'œuvre du théologien catholique Jakob Salat. Parmi ses auteurs fétiches, on trouve également Friedrich Eduard Beneke, l'adversaire de Hegel. Girard se forme aux lumières écossaises avec Francis Hutcheson, Adam Smith et Adam Ferguson. Par ailleurs, Fichte, Christian Wolf, Schleiermacher et Herder complètent sa bibliothèque, où l'on doit relever la présence surprenante des Cuvres philosophiques de La Mettrie, du Nouveau regard sur la Société de Robert Owen, de la Morale d'Épicure, ainsi que des œuvres complètes de Lessing et de Schelling.

Le pédagogue Girard, très souvent comparé à son ami Pestalozzi, doit sa réputation, comme on le verra, à une déclinaison personnalisée de l'enseignement mutuel. Surtout, il participe à la protohistoire de la pédagogie, qui s'articule autour d'une multitude de connexions, d'absorptions et de transferts éducationnels pensés à l'international. C'est Marc-Antoine Jullien (1775-1848) qui, l'un des premiers, va convoquer les hommes d'école d'Europe occidentale afin de mener une étude comparative d'envergure, centrée dans un premier temps sur la constellation franco-suisse.

\section{Le transfert manqué de Jullien de Paris}

Bien que l'on ait hissé au pinacle Marc-Antoine Jullien en le proclamant père de l'éducation comparée et précurseur des organisations internationales, sa trajectoire demeure trouble ${ }^{13}$. Pierre de Vargas parle d'un « mystère Marc-Antoine Jullien » et rappelle qu'il incarne

12. François Azouvi et Dominique Bourel, De Königsberg à Paris. La réception de Kant en France (1788-1804), Paris, Vrin, 1991.

13. Pedro Rossello, Marc-Antoine Jullien de Paris, père de l'éducation comparée et précurseur du Bureau international d'éducation, Genève, 1943 et du même, Les précurseurs du BIE, un aspect inédit de l'histoire de l'éducation et des institutions internationales, Genève, BIE, 1943. 
" deux traditions ${ }^{14}$ ». Homme politique, on le retrouve aux côtés de Robespierre. S'étant retourné férocement contre les Girondins - et donc contre Condorcet -, il prend une part importante dans la Terreur pour suivre après Thermidor un cheminement politique peu limpide. Puis vient le virage. Jullien se façonne un destin de pédagogue suite à sa rencontre avec Pestalozzi à Yverdon et diffuse sa pensée en France dans un écrit substantiel publié en $1812^{15}$. Ainsi, la promotion de Jullien au cœur des sciences de l'éducation mériterait d'être rediscutée, en réinvestissant notamment sa trajectoire politique qui comporte nécessairement certaines clés de compréhension de l'œuvre pédagogique. On l'a dit, Jullien joue un rôle clé dans la fondation d'une "science de l'éducation » qu'il formule dans le sillage des recherches de Georges Cuvier, le promoteur de l'anatomie comparée ${ }^{16}$ :

L'éducation, comme toutes les autres sciences et tous les arts, se compose de faits et d'observations. Il paraît donc nécessaire de former, pour cette science, comme on l'a fait pour les autres branches de nos connaissances, des collections de faits et d'observations, rangées dans des tables analytiques, qui permettent de les rapprocher et de les comparer, pour en déduire des principes certains, des règles déterminées, afin que l'éducation devienne une science à peu près positive ${ }^{17}$.

Jullien souhaite relier les hommes préoccupés de relever les masses populaires par l'éducation en se consacrant à la création d'une commission spéciale d'éducation. Parfait symbole des idées de son temps, cette commission intergouvernementale fait résonance au fameux Conseil de Newton pensé au début du siècle par Saint-Simon ${ }^{18}$. Jullien fonde également la Revue encyclopédique (1819) afin d'assurer la circulation de savoirs entre les nations et ne cache pas à son ami suisse, le pédagogue et agronome Philipp Emanuel von Fellenberg (1771-1844) qu'il

14. Pierre de Vargas, « L'héritage de Marc-Antoine Jullien, de Paris à Moscou », Annales historiques de la Révolution française, 301/1995, p. 409.

15. Sur la trajectoire de Jullien, voir notamment Jacqueline Gautherin, « Marc-Antoine Jullien de Paris (1775-1848) », Perspectives: revue trimestrielle d'éducation comparée, vol. XXIII, 3-4/1993, p. 783-798; Marie-Claude Delieuvin, Marc-Antoine Jullien de Paris (1775-1848): théoriser et organiser l'éducation, Paris, L'Harmattan, 2003.

16. Jacqueline Gautherin, op. cit., (version du BIE, 2000) p. 3.

17. Marc-Antoine Jullien de Paris, Esquisse et vues préliminaires d'un ouvrage sur l'éducation comparée entrepris d'abord pour les vingt-deux cantons de la Suisse et pour quelques parties de l'Allemagne; susceptible d'être exécuté plus tard, d'après le même plan, pour tous les États d'Europe, Paris, L. Colas, 1817.

18. Claude-Henri de Saint-Simon, Lettres d'un habitant de Genève à ses contemporains, Paris, 1803. 
la considère comme une "sainte alliance des esprits élevés ${ }^{19}$ ". On sait par ailleurs qu'il approche le Père Girard à Fribourg dans le but de créer un bureau d'éducation qui ne verra jamais le jour ${ }^{20}$. Faut-il entrevoir cette entreprise comme un nouveau témoignage d'un Jullien " dévoré du besoin de reconnaissance, déployant une ingéniosité toujours renouvelée pour dire aux puissants ce qui peut à la foi leur plaire et les capter ? $^{21}{ }^{\prime}$. La question mériterait d'autres investigations. Jullien cristallise son projet international en 1817 par l'établissement d'un " hyperinventaire » des méthodes et des us scolaires en vigueur dans l'Ouest de l'Europe. Cette Esquisse et vues préliminaires d'un ouvrage sur l'éducation comparée entrepris d'abord pour les vingt-deux cantons de la Suisse se propose, comme l'indique son intitulé, de considérer la Suisse comme terrain d'étude préalable, à cause notamment de la variété de sa nature, de ses religions et de ses langues:

C'est donc à la Suisse que nous nous proposons d'appliquer, d'abord, notre instrument et nos tables d'observations. Nous sommes encouragés à entreprendre ce travail, à cause des résultats d'utilité qu'il doit procurer pour l'estimable nation suisse, appelée à donner en plus d'un genre de bons exemples à l'Europe, pour l'Europe elle-même, pour l'éducation et l'humanité22.

Toutefois, si cette analyse trouve ses marques et son cadre à partir du cas helvétique, extensible ensuite comme le pense Jullien à l'Europe entière, on ne cite que trop rarement le fait que l'étude comparée des cantons suisses devait en premier lieu provoquer des remèdes afin de soigner le système scolaire français:

C'est en France que l'amélioration de l'enseignement élémentaire est un besoin plus généralement senti. C'est là que la première idée de former des tables analytiques et comparatives de faits et d'observations sur l'éducation, a dû surtout paraître l'un des plus sûrs moyens de bien étudier en ce genre la nature du mal pour lui opposer les remèdes convenables. [...] On ne peut dissimuler que, chez cette même nation, l'instruction, mal dirigée et mal répartie, n'est pas encore descendue dans les

19. Pierre de Vargas, op. cit., p. 427.

20. Cité dans Marie-Claude Delieuvin, op. cit., p. 29. Voir également la lettre de Girard à Louis Perrot du 9 septembre 1817 dans Pierre Bovet, Écoles nouvelles d'autrefois. Louis Perrot et les débuts de l'enseignement mutuel en Suisse française, Genève, 1938, p. 36-37.

21. Pierre de Vargas, op. cit., p. 428.

22. Marc-Antoine Jullien de Paris, op. cit., p. 16-17. 
classes inférieures, [...] et n'a pas été appropriée aux véritables besoins des classes moyennes de la sociétée ${ }^{23}$.

En d'autres termes, l'étude comparative élaborée par Jullien doit permettre le transfert spécifique des méthodes et des procédés jugés comme les meilleurs de la Suisse vers la France. Or, il convient de souligner que toute la problématique du transfert culturel est cristallisée dans cette translation. En voulant imposer «la même éducation internationale pour tous ${ }^{24}$ ", Jullien omit deux invariants qui accompagnent nécessairement tout transfert éducationnel: le poids de la culture locale/régionale/nationale sur l'objet emprunté et surtout l'inévitable retraduction qui accompagne l'objet lors de son passage d'un contexte culturel à l'autre. On peut donc affirmer que cette entreprise théorique, sous ces conditions, était vouée à l'échec. Les philanthropes du premier $\mathrm{XIX}^{\mathrm{e}}$ siècle s'interrogèrent peu à peu sur les modalités des emprunts et $\mathrm{y}$ apportèrent des réponses décisives, en croisant et en déclinant les diverses méthodes étudiées sur le continent.

\section{L'école transnationale des philanthropes européens}

La pédagogie est une, et à part quelques dissemblances dans l'organisme scolaire, les manuels et les moyens d'instruction, elle est la même dans tous les pays civilisés. Or, d'où vient cette unité, cette communauté de principes et de méthodes, sinon de l'échange d'idées qui s'est opéré entre les peuples, vers la fin du XVIII ${ }^{\mathrm{e}}$ siècle d'abord, et ensuite au commencement de celui-ci, lorsque les bienfaits d'un âge de paix et de philanthropie eurent succédé aux convulsions terribles d'une période de guerres et de conquêtes?

Alexandre Daguet, L'Éducateur, $1867^{25}$

On ne soulignera jamais assez, avec Loïc Chalmel, le rôle décisif des réseaux philanthropiques préoccupés par les dangers de l'ignorance scolaire et pleinement engagés dans la mise en place de structures scolaires publiques fondées autour d'une conscience sociale nouvelle ${ }^{26}$. Dans sa thèse sur l'enseignement mutuel en Bretagne, Michel Chalopin

23. Ibid, p. 19-20.

24. Jean Houssaye, «Pédagogies: import-export 》, Revue française de pédagogie, avril-juin 2006, p. 88.

25. « Lettre au Conseil fédéral 》, L'Éducateur, 7/1867, p. 99.

26. Voir Loïc Chalmel, Réseaux philanthropinistes et pédagogie au XVIII siècle, Berne, Peter Lang, 2004. 
rappelle également que le début $\mathrm{du} \mathrm{XIX}^{\mathrm{e}}$ siècle fut surtout l'affaire de négociants, de propriétaires ou d'hommes de lois convaincus de l'importance du développement d'écoles du peuple, en d'autres termes une affaire de notables ${ }^{27}$. Ainsi, étudier les réseaux de la philanthropie nous engage de fait au cœur des circulations transnationales et pour le cas suisse nous invite à considérer certaines racines étrangères d'une pédagogie romande en chantier.

Lorsque le Zurichois Hans Caspar Hirzel (1751-1817) fonde, avec quelques amis médecins, la Société suisse d'utilité publique en 1810, l'éducation des masses relève déjà d'une préoccupation nodale. Il s'agit, d'une part, de combattre la pauvreté par l'instruction et d'éduquer par la diffusion d'une morale d'inspiration kantienne. D'autre part, à l'instar de Johann Caspar Zellweger (1768-1855), commerçant en textiles de Trogen, on s'attache également à assurer l'instruction spécialisée d'une classe commerçante qui ne trouve nullement son compte dans les contenus proposés jusque-là par les établissements classiques. En Suisse, les circulations transcantonales sont déjà bien établies et la Suisse romande ne tarde pas à être contaminée par ces idées issues de la bourgeoisie alémanique. En février 1826, le patriote Frédéric-César de La Harpe (1754-1838), ancien précepteur du tsar Alexandre $\mathrm{I}^{\mathrm{er}}$ de Russie, fonde la Société vaudoise d'utilité publique ${ }^{28}$. Dès ses débuts, celle-ci fait le choix de diffuser certaines méthodes pédagogiques hollandaises dans le canton, en créant à cet effet une des premières revues scolaires de Suisse française.

Ce transfert de procédés scolaires hollandais en Suisse est l'œuvre de Jacob Evert van Muyden-Porta (1781-1848). Protestant né à Utrecht, il obtient un doctorat en droit (1804) suite à quoi il séjourne en Allemagne, en Autriche puis en Italie. En 1809, il s'installe à Lausanne où il assume les fonctions de juge cantonal. Député libéral au Grand Conseil vaudois dès 1833, il s'implique avec conviction dans la commission chargée d'améliorer l'instruction publique. Cette réforme doit, selon lui, nécessairement s'inspirer du système scolaire de son pays d'origine. En août 1827, il fait lecture d'un Mémoire sur la Société hollandaise d'utilité publique dans lequel il met en exergue une série de réformes scolaires entreprises dans le but de répandre les lumières pour

27. Michel Chalopin, L'enseignement mutuel en Bretagne de 1815 à 1850, université de Rennes, thèse de doctorat, 2008, p. 3.

28. Voir Irène Herrmann, « La Harpe, la Suisse et la Russie: questions d'influence », in Olivier Meuwly (éds.), Frédéric-César de La Harpe 1754-1838, Lausanne, Bibliothèque historique vaudoise, 2011, p. 48-55. 
faire avancer la moralité du peuple. Dans sa conclusion, Muyden-Porta propose de suivre le canevas pédagogique proposé par la société Tot Nut van't Algemeen, arguant que " ce qui s'est fait avec tant de succès en Hollande, peut se faire également chez nous ${ }^{29}$ ". Une commission spéciale est créée afin d'intégrer concrètement ces méthodes et de tirer pleinement parti de l'expérience hollandaise. Elle fixe son attention sur trois objets principaux, dont on sait qu'ils ont obtenu d'excellents résultats dans leur contexte d'origine:

1. Procurer de bons livres élémentaires, soit pour les régens (sic), soit pour les élèves. À défaut, Van Muyden proposait la traduction de ceux que fournissent en abondance l'Allemagne, l'Angleterre et la Hollande;

2. Susciter la création de conférences de régents;

3. Instituer des Bibliothèques populaires, qui en Hollande avaient si radicalement amélioré les mœurs vulgaires des masses. ${ }^{30}$

Pour faciliter le transfert et diffuser ces méthodes hollandaises aux instituteurs du canton de Vaud, la commission propose la création d'une feuille mensuelle. Là encore, les Vaudois trouvent l'inspiration hors des frontières nationales et le Journal d'éducation à l'usage des instituteurs et des pères de famille, rédigé par l'instituteur Brousson dès janvier 1829, s'inspire du Journal d'éducation et d'instruction publié à Paris par le comte de Lasteyrie. Le périodique atteint rapidement les trois cents abonnés. Bien qu'il soit réservé en premier lieu aux instituteurs du canton, le rédacteur réclame vite "l'assistance et la coopération des amis de l'éducation à Genève, et dans les autres cantons ${ }^{31}$ ". À son lancement, Brousson publie une série d'articles sur les principes d'instruction civique et morale du Père Girard et reproduit des extraits de son Explication $d u$ plan de Fribourg ${ }^{32}$. Toutefois, c'est bien vers la Hollande que se focalisent les attentions, même si l'on se garde de tout plagiat servile:

Les écoles primaires hollandaises occupent peut-être aujourd'hui le premier rang parmi celles de l'Europe. Il sera donc intéressant d'entendre un homme instruit et qui connaît bien ces écoles nous entretenir de la marche qui y est suivie. Son intention n'est aucunement de prescrire une

29. Jacob Evert van Muyden-Porta, Mémoire sur la Société hollandaise d'utilité publique, présenté à la Société vaudoise d'utilité publique, dans sa séance du 2 août 1827, Lausanne, Imprimerie de Hignou Aîné, 1827, p. 13.

30. Ibid. p. 14.

31. Journal d'éducation, 1829, p. 6.

32. « Une première leçon de géographie et d'histoire », Journal d'éducation, 1829, p. 6-12. 
marche pareille aux écoles du Canton de Vaud, mais de faire connaître ce qui peut se faire et ce qui se fait ailleurs, afin qu'on suive ce qui paraîtra de bon exemple ${ }^{33}$.

Cet homme instruit, Van Muyden-Porta, retrace d'abord la vie et l'œuvre du pasteur Nieuwold, surnommé le Pestalozzi hollandais. Dans une série de cinq articles substantiels, il propose un agrégat de matériaux devant servir à la composition d'un manuel des instituteurs vaudois, essentiellement extrait d'ouvrages hollandais et allemands ${ }^{34}$. En se basant sur l'expérience batave encore, plusieurs instituteurs et notables réunis dans le village d'Apples le 22 novembre 1828 décident la formation d'une société d'enseignement. Il s'agit, par des rencontres périodiques, de s'éclairer mutuellement, de sortir ainsi de l'étude solitaire et d'améliorer les diverses techniques d'enseignement en vigueur. La réflexion sur l'introduction de bibliothèques populaires donne lieu à un élargissement des perspectives. L'étude comparative s'internationalise et l'on s'attache désormais à l'analyse des expériences réalisées en Europe occidentale. En France d'abord, où le pasteur Jean-Frédéric Oberlin a eu l'idée de diffuser une collection de livres d'éducation afin d'occuper les familles durant les soirées de la mauvaise saison. De l'Angleterre et de l'Irlande, on retient l'idée des bibliothèques ambulantes. En Saxe enfin, on étudie l'expérience de l'instituteur Kretschmann, dont la bibliothèque populaire fit le tour du petit pays d'Altenbourg et hâta l'instruction morale, intellectuelle et patriotique de ce canton.

Il est par ailleurs intéressant de constater que le Journal d'éducation joue le rôle de banc d'essai des diverses innovations pédagogiques formulées en Europe, selon un protocole établi. Il s'agit en premier lieu de compiler et de traduire ces méthodes grâce aux échanges épistolaires, aux voyages personnels ou à la presse, pour les diffuser dans le Journal. Dans un second temps, les instituteurs rendent compte de leurs expériences en publiant leurs observations et les divers moyens de se réapproprier la méthode en l'aménageant pour le contexte local.

33. « Note de la rédaction », Journal d'éducation, 1829, p. 49.

34. Jacob Evert van Muyden Porta, « Matériaux pour servir à la composition d'un Manuel des Régens (sic), en partie extrait d'ouvrages hollandais et allemands », Journal d'éducation, 1829, p. 49-57, 73-81, 97-103, 217-224, 241-246. Sur les manuels scolaires vaudois, voir Sylviane Tinembart, Le manuel scolaire de français, entre production locale et fabrique des savoirs. Le cas des manuels et de leurs concepteurs dans le canton de Vaud au XIXe siècle, thèse de doctorat, université de Genève, 2015 ainsi que Lionel Kaufmann, Autorité du discours-discours d'autorité: les manuels d'histoire vaudois (1938-1998), thèse de doctorat, université de Lausanne, 2013. 
Selon ce protocole, c'est par la reproduction d'un article tiré du Journal d'éducation et d'instruction publié à Paris par de Lasteyrie que l'on s'essaie à l'enseignement universel de Joseph Jacotot (1770-1840) dans le canton de Vaud. Ce procédé est toutefois rejeté, suite à l'expérimentation peu convaincante pratiquée par un instituteur du village du Sentier.

L'enseignement mutuel est également débattu dans le Journal et donne lieu à des appréciations contrastées. Il faut dire que Van Muyden-Porta fait partie du nombre de ceux qui ne se réjouissent pas de l'introduction de la méthode. Fait suffisamment curieux pour être cité, deux factions se constituent lors de la réunion annuelle de la Société d'utilité publique suisse à Lausanne en septembre 1830. L'enseignement mutuel est globalement défendu par les délégués romands. Inversement, de l'avis des membres alémaniques représentés par l'industriel Johann Caspar Zellweger et Van Muyden-Porta, l'équilibre parfait se trouve dans la combinaison des séminaires et des écoles-modèles propres à l'institution de Fellenberg et de son collaborateur Johann Jakob Wehrli (1790-1855) à Hofwyl:

Je ne crains pas d'affirmer que dans l'école de Hofwyl les jeunes gens apprennent tout ce qui leur est nécessaire; que l'instruction y est de manière à développer dans les élèves le sens moral et l'intelligence du droit et du devoir, si désirables dans les citoyens d'un pays de liberté; que dans cette école l'enseignement très diversifié, est cependant réglé avec une économie remarquable; enfin que les élèves-régens (sic), disciples de Wehrli, ont généralement les qualités que nous cherchons [...] Il ne s'agit donc, ce me semble, que de la question de savoir, comment et avec quelles modifications une pépinière de régens, telle que nous l'offre le séminaire ou école-modèle de Hofwyl, pourra être adaptée aux différentes localités de la Suisse ${ }^{35}$.

On le voit, une rupture notable apparait donc entre les pasteurs romands et les industriels ou commerçants alémaniques. Au-delà d'une simple crispation entre les entités culturelles du pays, c'est bien plus de l'extension de la mainmise utilitariste de la bourgeoisie commerçante sur l'éducation des masses dont il s'agit. Chaque camp tente de transformer les idées novatrices à son avantage et les multiples déclinaisons de l'enseignement mutuel en Europe semblent en être, à une plus large échelle, une parfaite illustration.

35. Actes de la Société suisse d'utilité publique. Réunion annuelle de Lausanne, 14 au 15 septembre 1830, Lausanne, Imprimerie des Frères Blanchard, 1831, p. 138. 


\section{De Madras à Fribourg: l'enseignement mutuel décliné}

L'enseignement mutuel incarne une méthode phare du premier $\mathrm{XIX}^{\mathrm{e}}$ siècle et a pour principe que des élèves incarnés en moniteurs instruisent leurs camarades et assistent le maître. Plusieurs historiens, à l'instar de Marcelo Caruso, ont analysé les multiples déclinaisons de ce système d'enseignement coopératif diffusé sur cinq continents, qui alimentent l'idée d'un socle commun de la pédagogie ${ }^{36}$. Dans le sillage de ces travaux, il est intéressant de se pencher sur le processus de transfert de l'enseignement mutuel d'Angleterre vers la France, puis sur sa diffusion vers la Suisse et l'Italie grâce au travail de lobbyisme opéré par des acteurs-connecteurs de tendance libérale. Ainsi voit-on l'Europe scolaire s'essayer à cette méthode venue de Madras pour la retraduire plus ou moins radicalement selon les besoins pédagogiques et politiques locaux et les aptitudes des éducateurs et des philanthropes qui en font la propagande.

Bien qu'un flou subsiste toujours sur les origines, françaises ou anglaises, de l'enseignement mutuel ${ }^{37}$, l'historiographie officielle privilégie le clergyman écossais Andrew Bell (1753-1832), qui eut l'idée de partager l'enseignement avec un de ses écoliers. Bell institutionnalise le self-tuition dans ses écoles de Madras dès 1789; il en fait la théorie et tente de le populariser à son retour à Londres en publiant $A n$ Experiment in Education made at the male Asylum in Madras (1797).

Le quaker anglais Joseph Lancaster (1778-1838) propose de son côté sa propre version du monitorial system, sans avoir eu

36. Voir notamment Marcelo Caruso \& Eugenia Roldan Vera, «Pluralizing Meanings: The monitorial system of education in Latin America », Paedagogica Historica, 6/2010; Marcelo Caruso, «The Persistence of Educational Semantics: Patterns of Variation in Monitorial Schooling in Colombia (1821-1844) », Paedagogica Historica, 41 (6), p. $721-744$ et du même, «Cheap, suitable, promising: monitorial schooling and the challenge of mass education in early liberal Spain (1808-1823) », Bordón, 65 (4), p. 33-45; Carlos Manique da Silva, Circulating the Monitorial System of Education: « The Portuguese Teacher Alexandre Luis da Cunha in the Atlantic World », in Caruso M., Koinzer T., Mayer C. \& Priem K. (éds), Zirkulation und Transformation. Pädagogische Grenzüberschreitungen in historischer Perspektive, Böhlau Verlag, 2014, p. 177-190.

37. En effet, M. Herbault semble avoir utilisé la méthode dans son école parisienne de I'hospice de la Pitié dès le milieu du XVIII' siècle, comme M. Paulet, irlandais d'origine, qui profita d'un soutien financier de Louis XVI pour fonder une maison d'éducation destinée aux enfants de militaires. Divisés en quatre groupes, ces petits officiers étaient dirigés par un enfant promu major, voir Fleming Voltelin van der Byl, Le chevalier Pawlet, éducateur oublié. Sa vie et son œuvre: son rôle et son importance dans l'histoire de I'Enseignement mutuel, Paris, Librairie Recueil Sirey, 1935. 
connaissance, soutient-il, des écrits de Bell: il y a en tout cas une divergence essentielle, concernant la composante religieuse à intégrer. Alors que Bell agence son système sur l'étude stricte de la religion anglicane, Lancaster n'enseigne aucun dogme et laisse son système ouvert à toutes les religions. Cette option de tolérance lui attire les foudres de l'Église anglicane et lui vaut diverses persécutions. Toutefois, le cadre rigoureux qu'a donné Lancaster à son système lui assure l'avantage en termes de popularisation. Lui-même s'engage personnellement dans son essaimage aux États-Unis (il meurt à New York en 1838); propagée par la Société pour la promotion du système lancastérien pour l'éducation des pauvres, fondée en 1808 , la méthode connaît une rapide et large diffusion, des États-Unis à la Sierra Leone, de Lisbonne au Cap de Bonne-Espérance, de la Nouvelle-Galles à Paris.

En France, l'introduction de l'enseignement mutuel est dictée en premier lieu par des contingences politiques. Il s'agit avant tout de restreindre la mainmise des frères des écoles chrétiennes sur la chose scolaire; la méthode anglaise, rebaptisée "enseignement mutuel» afin d'en gommer tant soit peu l'origine étrangère, est soutenue par un groupe de philanthropes libéraux particulièrement engagés en faveur de l'éducation des masses. Le philosophe de Gérando, CharlesPhilibert de Lasteyrie, Alexandre de Laborde, Edme François Jomard et l'abbé Gaultier fondent la Société pour l'instruction élémentaire en 1815 et créent peu après Le Journal d'éducation populaire, organe de propagande du système mutuel qui sera consulté dans toute l'Europe; l'abbé Gaultier, Jomard, Laborde et Jean-Baptiste Say visitent les écoles londoniennes de Bell et Lancaster et assurent le transfert de savoirs ${ }^{38}$. Globalement, l'enseignement mutuel répond aux exigences de cette élite libérale qui se donne pour mission, comme l'indique l'article premier des statuts de la société, de "former des hommes vertueux, amis de l'ordre, soumis aux lois, intelligents et laborieux ${ }^{39}$ ». Ce réseau franco-anglais s'avère suffisamment souple pour permettre certaines réadaptations. La Société centrale de Paris perfectionne par exemple les tableaux d'arithmétique créés par Lancaster ${ }^{40}$. Dans une

38. Marcelo Caruso, « Connecting men of progress. The international educational network of the French Société pour l'instruction élémentaire (1815-1850) » (accessible sur https: hu-berlin.academia.edu/MarceloCaruso).

39. Cité dans l'article « Société pour l'instruction élémentaire », édition électronique du NDP de 1911, p. 2.

40. Joseph Hamel, L'enseignement mutuel ou Histoire de l'introduction et la propagation de cette méthode par les soins du Dr Bell, de J. Lancaster et d'autres, Paris, L. Colas, 1818, p. 163. 
Europe soumise à l'emprise de la Sainte-Alliance, la pédagogie parvient à creuser son sillon sous les dehors d'une science foncièrement empirique, s'élaborant en réseaux. Philanthropes et membres du clergé expérimentent, amalgament et adaptent des systèmes pédagogiques exportés de Londres vers Paris, de Montauban vers Lausanne, Genève et Fribourg.

Ainsi l'enseignement mutuel, qui passe rapidement d'un contexte culturel à l'autre, se métisse sous des formes diverses et combinées. On s'essaie par exemple en France à fusionner la méthode de Pestalozzi et les principes de l'enseignement mutuel ${ }^{41}$. Curieux panachage, quand on sait que le pédagogue suisse fut un adversaire ardent du mutualisme. Néanmoins, un de ses anciens collaborateurs, le Vaudois François Barrault, qui avait tenté d'exporter sa méthode à Bergerac sur la demande de Maine de Biran, travaille à cette reformulation:

Barrault s'occupe maintenant à rechercher les moyens de fondre la méthode intuitive, et celle d'enseignement mutuel dans un seul corps de doctrine. Il a déjà composé des tableaux où se trouvent réunis les questions que les moniteurs doivent faire aux élèves et les réponses de ceux-ci. Dans ces réponses, l'enfant rend compte des raisons pour lesquelles il donne à toute question telle solution et non aucune autre. Par ce moyen, l'esprit s'exerce et se développe tandis que d'après la méthode d'enseignement mutuel, telle qu'elle est pratiquée dans toutes les écoles sans distinction, pour les leçons d'arithmétique, l'esprit des enfants reste constamment dans l'inaction, et n'apprend point à connaître les choses, mais seulement les signes par lesquels on les représente ${ }^{42}$.

L'enseignement mutuel se diffuse de France vers la Suisse grâce à l'écrit ainsi qu'à la propagande d'acteurs-connecteurs qui se déplacent dans toute l'Europe. Ainsi M. Frossard, fils du doyen de la faculté de Montauban, après avoir étudié la méthode dans l'école de Lancaster à Londres, fut le principal instigateur avec Frédéric-César de La Harpe des premières écoles mutuelles de Lausanne en juillet $1816^{43}$. À Genève, Charles Pictet de Rochemont (1755-1824), ancien militaire au service de France, propose de combiner les principes de gradation du travail propre au système lancastérien avec les idées de l'éducateur

41. Ibid., p. 170.

42. Ibid., p. 171-172.

43. Alexandre Daguet, Le Père Girard et son temps, op. cit., t. 1, p. 327. 
bernois Fellenberg dans sa propre école agricole de Lancy ${ }^{44}$. Mais c'est à Fribourg que le Père Girard va sans conteste en réaliser une des versions les plus efficientes, connue sous le nom de Girardines.

Le moine pédagogue a en effet découvert la méthode de Bell dans l'ouvrage du comte de Lasteyrie intitulé Nonveau système d'éducation pour les écoles primaires (1815). Mais rien ne serait plus inexact que d'imaginer qu'il ait mis en place à Fribourg une copie terme à terme des méthodes anglaises et françaises: "Ce n'est point une copie que nous voulions faire, les copies ne vont pas partout, et il n'est pas toujours bon de vouloir les faire ${ }^{45}$ ", souligne Girard en septembre 1816. Il adapte ces méthodes aux besoins de ses écoliers fribourgeois et aboutit dans son transfert triangulaire anglo-franco-romand à une réadaptation conséquente. Le moine pédagogue rééquilibre la méthode Lancaster - dont l'enseignement tout entier était remis aux élèves - par une distinction nette entre les objets d'études confiés aux moniteurs et ceux qu'il convient de réserver au maître ${ }^{46}$. Cette synthèse composite prit le nom d'enseignement mutuel gradué ou mixte. Dès juin 1816, elle est appliquée dans l'ensemble des quatre classes dirigées par Girard et procure rapidement des résultats appréciables, faisant dire à Pestalozzi qu' " avec de la boue, Girard a fait de l'or ». La déclinaison de Fribourg est dès lors prête à être à son tour exportée et reconfigurée dans plusieurs villes européennes.

\section{Les Girardines à l'heure européenne}

L'exemple de la diffusion des Girardines s'avère particulièrement approprié pour sonder les modalités d'une translation qui fut tant locale, transcantonale que transnationale. Si l'introduction de la méthode attire, à ses débuts, badauds et familles, ainsi que quelques responsables gouvernementaux, dès 1816, c'est toute l'Europe scolaire qui fait le pèlerinage de Fribourg pour étudier les écoles du moine cénobite, à commencer par Marc-Antoine Jullien et Andrew Bell

44. Voir Pierre Bovet, Écoles nouvelles d'autrefois. Louis Perrot et les débuts de l'enseignement mutuel en Suisse française, Genève, 1938, p. 34. Sur les enjeux de l'enseignement mutuel à Genève, voir Christian Alain Muller, « L'enseignement mutuel à Genève ou l'histoire de I'"échec" d'une innovation pédagogique en contexte, 1815-1850 », Paedagogica Historica, vol. 41-1/2, p. 97-119 ainsi que Rita Hofstetter, Les lumières de la démocratie. Histoire de l'école primaire publique à Genève au XIXe siècle, Berne, Peter Lang, 1998, p. 133-140.

45. Discours de clôture prononcés par le R. P. Grégoire Girard (1805-1822), Fribourg, Société fribourgeoise d'éducation, 1950 [1816], p. 48.

46. Alexandre Daguet, Le Père Girard et son temps, op. cit., t. 1, p. 309. 
(3 août 1816). En août encore, outre celle du prince du Danemark, du roi détrôné de Suède Gustave III ou de Casimir Périer, Girard reçoit la visite du Dr James Pillans (1778-1864) d'Édimbourg. Pillans a repris la direction d'une High School fondée par Lancaster, mais, en regard des nombreuses attaques, a intelligemment substitué le répétiteur au moniteur et introduit la méthode dans l'enseignement secondaire. Malgré un défaut de gradation, cette méthode Pillans fut propagée en Suisse française via la Bibliothèque universelle de Pictet de Rochemont et imitée par certaines écoles de Genève ${ }^{47}$. En février 1818, l'empereur Alexandre $\mathrm{I}^{\mathrm{er}}$ mandate le baron de Strandmann pour une mission pédagogique à Fribourg. Pestalozzi visite Girard le 6 juillet 1818. La même année, le cordelier reçoit un des grands penseurs du socialisme, Robert Owen, créateur d'un capitaliste paternaliste qu'il élabore aux commandes de ses fabriques de New Lanarck ${ }^{48}$. Owen a répondu à l'invitation de son ami genevois Charles Pictet de Rochemont qui l'emmène dans une tournée des figures pédagogiques européennes. Dans une lettre à Daguet, Owen souligne l'intérêt qu'il a trouvé à échanger avec le moine et relève les résultats très positifs de ses écoles consacrées à l'éducation des enfants pauvres ${ }^{49}$.

En Suisse aussi on s'intéresse à l'œuvre de Girard et à l'enseignement mutuel mixte. Des instituteurs viennent étudier la méthode, souvent pour plusieurs semaines. En décembre 1816, des régents du Jura prennent leurs quartiers à Fribourg, puis des enseignants de la ville de Berne arrivent en février 1819, avant ceux d'Argovie (avril 1820) et de Zurich (mai 1820). Il est par ailleurs intéressant de pointer l'intense travail de lobbyisme entrepris par le moine pédagogue. Dans une lettre qu'il adresse au révérend Walmesley, secrétaire de la National Society for the Education of the Poor, Girard indique avoir eu "quelque influence sur deux cantons voisins, ceux de Berne et Neuchâtel ${ }^{50}$ ". Il collabore par ailleurs avec un instituteur, Louis Perrot (1785-1865), chargé par la commission d'éducation de la ville de Neuchâtel d'étudier et de propager, le cas échéant, le système mutuel dans les écoles de l'ancienne cité prussienne. Perrot,

47. Grégoire Girard, Méthodes et procédés d'éducation, op. cit., p. 53.

48. Voir Marie Vergnon, Robert Owen, pédagogue de l'art industriel?, thèse de doctorat, université de Lorraine, 2013; Michel Onfray, L'eudémonisme social, Paris, Grasset, 2008, p. 177-214.

49. Lettre de Robert Owen à Daguet, Sevenoaks Park, $1^{\text {er }}$ janvier 1858, AEF, Fonds Daguet.

50. Cité dans Pierre Bovet, Écoles nouvelles d'autrefois. Louis Perrot et les débuts de I'enseignement mutuel en Suisse française, Genève, Institut J.-J. Rousseau, 1938, p. 27. 
qui parcourt la Suisse romande et rencontre les principaux artisans du mutualisme incarne un médiateur précieux. Le Père Girard l'a bien compris et il charge son allié de faire de la propagande pour la création d'un centre de communications pédagogiques susceptible de relier les défenseurs romands du mutualisme, qui pourrait s'agréger à la Société économique de Fribourg fondée sur l'initiative de Girard. Par ailleurs, le voyage d'études entrepris par Perrot demeure un excellent indicateur du processus d'installation d'une méthode pédagogique et du rôle central de ses réseaux d'influence. À l'été 1816, Perrot visite l'école mutuelle de Saint-Gervais à Genève, y rencontre Bell et traduit ses Instructions for Conducting Schools. En octobre, il examine l'école fondée à Lausanne par le Français Frossard. En février 1817, il entreprend son tour des écoles mutuelles romandes, passe trois semaines dans les trois principaux établissements genevois, puis étudie le système Girard à Fribourg avant de s'arrêter chez Pestalozzi à Yverdon. Ayant dressé un rapport élogieux sur le nouveau système, ce dernier le met à l'essai dès la rentrée suivante. Enfin, la commission neuchâteloise estime au début 1819 que la nouvelle méthode est entrée dans les mœurs.

Après avoir proposé cet aperçu de la diffusion plurielle du mode d'enseignement mutuel élaboré par le Père Girard, il nous reste à réfléchir à l'intérêt singulier que les éducateurs italiens ont voué à la déclinaison du cordelier fribourgeois, et à tenter d'expliquer ce qui s'apparente à un déferlement italien sur Fribourg. En premier lieu, on remarquera que la diplomatie scolaire était en vigueur dans le Nord italien bien avant la diffusion de l'enseignement mutuel. Il convient de mentionner l'exemple du père Moritz, envoyé en Prusse par le gouvernement lombard en 1785 pour y étudier les écoles normales, introduites plus tard par l'éducateur tessinois Francesco Soave (17431806). En revanche, c'est bien en Italie que la méthode mutuelle mixte élaborée par Girard fut la plus naturalisée, transférée par Bagutti à Milan, Raffaello Lambruschini et le marquis Ridolfi à Florence, Carlo Buoncompagni à Turin, Enrico Mayer à Livourne ou encore par la pédagogue genevoise Mathilde Calandrini qui va propager l'éducation populaire enfantine à Pise ${ }^{51}$. Or, un bref aperçu de la trajectoire politique de ces passeurs révèle l'enjeu spécifique de l'importation de l'enseignement mutuel en Italie. Le système devait, pour ces patriotes

51. Voir Daniela Vaj, « Une pédagogue genevoise méconnue: Mathilde Calandrini et la diffusion de l'éducation populaire enfantine dans I'Italie du Risorgimento », Société genevoise d'études italiennes, 1999, p. 287-310. 
en quête de risorgimento, faciliter la diffusion à grande échelle d'une propagande libérale-nationale, de surcroît dans des territoires longtemps soumis à l'occupation autrichienne ${ }^{52}$. Vers la fin de l'année 1818 , l'abbé tessinois Giuseppe Bagutti (1776-1837) se rend à Fribourg dans l'optique d'introduire l'enseignement mutuel dans plusieurs écoles de garçons de Lombardie. Au vu du succès de l'entreprise, une société fondatrice de l'enseignement mutuel se forme autour du comte et carbonaro Federico Confalonieri (1785-1846) afin d'instituer le mutualisme dans les écoles des filles. La déclinaison milanaise ayant trouvé un bon écho en Toscane, le marquis Cosimo Ridolfi (1794-1865) - fondateur du premier institut agricole d'Italie - visite Girard en 1820, dans le dessein de régénérer les écoles de la campagne florentine. On notera que Ridolfi symbolise, avec Giovan Pietro Vieusseux (1779-1863) et le pédagogue agronome Raffaello Lambruschini (1788-1874) le noyau de l'opposition libérale en Toscane. Or, ce dernier incarne le principal médiateur des idées éducatives de Girard dans la botte. En janvier 1836, il fonde la Guida dell'Educatore, éditée par Vieusseux, qui sert d'organe de presse aux girardistes italiens et facilite la propagation des idées de Girard et de Pestalozzi dans le Nord de l'Italie. On soulignera encore qu'Enrico Mayer, autre patriote du Risorgimento, visite Girard en septembre 1837 et publie ses principales appréciations dans la presse livournaise. En 1841, c'est le comte Carlo Buoncompagni (1804-1880), ministre de l'Instruction publique sous les rois CharlesAlbert de Sardaigne et Victor-Emmanuel II et acteur clé de la laïcisation du système éducatif en Italie, qui vient chercher conseil sur les bords de la Sarine:

Pendant les quelques jours que le chevalier Buoncompagni fut à Fribourg, il ne passa pas un jour sans aller frapper à la porte du pédagogue fribourgeois. Les entretiens de ces deux hommes d'élite, auxquels l'auteur de ce livre [A. Daguet] eut plus d'une fois le bonheur d'être admis, se passaient en questions de l'homme d'État italien et en réponses de l'éducateur suisse. Mais, de même que Cousin, Buoncompagni parut surtout frappé de la façon dont le Cordelier fribourgeois entendait la religion, et son introduction au catéchisme lui plut si fort qu'à son départ de Fribourg il pria le professeur Daguet d'en faire une copie et de la lui envoyer à Turin ${ }^{53}$.

52. Sur la diffusion de l'enseignement mutuel en Italie, voir Anna Ascenzi et Giuseppina Fattori, L'alfabeto e il catechismo. La diffusione delle scuole du mutuo insegnamento nello Stato Pontifico (1819-1830), Pise et Rome, università di Macerata, 2006.

53. Alexandre Daguet, Le Père Girard et son temps, op. cit., t. II, p. 225-226. 
L'œuvre de Girard reçoit donc un soutien particulièrement appuyé des pédagogues de l'Italie du nord, alors que l'Allemagne, comme l'indique Daguet, " le pays auquel Girard devait le développement de son génie et l'impulsion qui avait décidé de sa carrière, l'Allemagne, chose étonnante, devait rester la plus indifférente à son œuvre, de toutes les nations civilisées ${ }^{54} »$. Ce rejet s'explique en premier lieu par la condamnation unanime dont le mutualisme fut l'objet, alors représenté comme un «caporalisme dont on rit en Allemagne ${ }^{55}$ ». À cet égard, Victor Cousin indique que lors de son voyage en Germanie, «il n'a pas trouvé un seul pédagogue qui fût partisan de ce mode d'enseignement ${ }^{56}$ ». Il rapporte par ailleurs que Diesterweg, presque seul dans son pays, avait montré quelque goût pour l'enseignement mutuel. Mais après une visite des écoles danoises qui pratiquaient ce système, il le condamn[a] comme réduisant l'éducation du peuple à un pur mécanisme ${ }^{57}$. Il faut dire que la méthode, empruntée paradoxalement aux frères des écoles chrétiennes, s'avérait rébarbative et machinale ${ }^{58}$. Les élèves pouvaient entendre plus de deux cents commandements par jour, comme par exemple:

Entrée en classe, appel et prière

1. Pour obtenir un silence général: silence: un coup de sifflet;

2. Faire tourner les enfans (sic) vers le moniteur général: front: un coup de sonnette;

3. Faire mettre les enfans (sic) à genoux: un coup de sonnette;

4. Les faire relever: un coup de sonnette.

\section{Lecture}

1. Pour faire préparer les enfans (sic) à sortir des bancs: sortez: les bras écartés à la hauteur de la ceinture;

54. Alexandre Daguet, « Centième anniversaire de la naissance du Père Girard 》, L'Éducateur, 24/1865, p. 371. Sur la réception du mutualisme en Allemagne, voir Marcelo Caruso, « Locating Educational Authority: Teaching Monitors, Educational Meanings, and the Import of Pedagogical Models: Spain and the German States in the 19 th Century 》, in D. Phillips \& K. Ochs (éds.), Educational Policy Borrowing: Historical Perspectives, Oxford, Symposium Books, p. 59-87.

55. Alexandre Daguet, "La question scolaire devant le Grand-Conseil de Fribourg», L'Éducateur, 7/1870, p. 99.

56. Victor Cousin, De l'instruction publique en Allemagne, en Prusse et en Hollande, tome troisième, Bruxelles, Société belge de Librairie Hauan \& Cie, 1841, p. 248.

57. Ibid., p. 231-232.

58. Voir Bruno Poucet, « Petite histoire de l'enseignement mutuel: I'exemple du département de la Somme », Carrefours de l'éducation, 1/2009,n²7, p. 7-18 ainsi que Raymond Tronchot, L'enseignement mutuel en France de 1815 à 1833, les luttes politiques et religieuses autour de la question scolaire, université de Lille, thèse de doctorat, 1973, p. 182 sq. 
2. Les faire sortir des bancs: bancs: signe de la main droite portée de bas en haut ;

3. Envoyer les moniteurs de lecture prendre leurs bâtons: moniteurs de lecture, allez: un coup de sonnette ;

4. Faire aller les enfans (sic) en cercle: toute la classe, allez: un coup de sonnette;

5. Pour faire commencer la lecture: commencez: deux coups de sifflets;

6. Faire lire par cœur: lisez par cœur: deux coups de sifflets;

7. Faire ranger les enfans (sic) contre le mur: formez la ligne: un coup de sifflet. ${ }^{59}$

L'enseignement mutuel, encensé ou rejeté, traverse l'Europe et se décline au gré des visées philanthropiques ou politiques de ses médiateurs qui, dans le sillage de la tradition du Junkerfahrt, du grand tour, sillonnent le monde afin d'entrer en relation avec leurs pairs et d'étudier les divers systèmes éducatifs en vigueur. La démarche de Victor Cousin, figure sombre et toute-puissante de l'Université française, demeure à cet égard particulièrement significative, car elle exemplifie le vaste mouvement de compilations scolaires à partir duquel vont se forger les modèles dominants qui ont bâti l'école de ce continent.

\section{Les racines germaniques de l'éclectisme pédagogique francophone}

Avant l'importante mission pédagogique de 1831, Victor Cousin s'est rendu à trois reprises en Allemagne ${ }^{60}$. Dominique Bourel note qu'alors, en contact avec Hegel, Schelling ou Goethe, il devint " la tête de pont de la culture allemande à Paris, l'incontournable allié de tous les visiteurs ${ }^{61}$ ». C'est une des raisons pour lesquelles Guizot l'appelle à travailler à la régénération de l'école populaire française. Cousin initie une nouvelle mission en Allemagne et jette les bases d'une vaste compilation de données pédagogiques qui servira de prélude à la loi de 1833 . Cinq ans plus tard, Guizot le mandate à nouveau pour aller étudier sur place l'instruction publique des Pays-Bas, déjà visitée en 1811-1812 par

59. Joseph Hamel, L'enseignement mutuel ou Histoire de l'introduction et de la propagation de cette méthode par les soins du Dr Bell, de J. Lancaster et d'autres, Paris, L. Colas, 1818, p. $175-178$.

60. Après un premier séjour en 1817, un second en 1818, il y retourne en 1824 et y sera emprisonné.

61. Dominique Bourel, Souvenirs d'Allemagne, Paris, CNRS Éditions, 2011, p. 13. 
Georges Cuvier. Lois scolaires, règlements, visites d'établissements et discussions personnelles sont consignés dans deux rapports remis aux ministres respectifs.

Lorsque l'on examine ces deux missions, on constate premièrement que les diverses étapes s'avèrent particulièrement brèves. Par exemple, lors de son voyage en Prusse, Cousin part de Paris le 24 mai 1831, arrive à Francfort le 27, visite Weimar le 31, Leipzig le 2 et passe un mois à Berlin, du 5 juin au tout début de juillet. En Hollande, il s'arrête en moyenne un à deux jours par ville, sauf à Rotterdam où il séjourne deux semaines. Les journées de travail sont donc denses. Cousin s'organise pour rencontrer les principaux représentants scolaires, profitant d'ailleurs souvent du réseau développé en 1812 par Cuvier. Il apparaît également que les notes consignées par Cousin lors de son passage en Suisse sont bien menues. Sur à peine dix feuillets, on trouve quelques annotations éparses concernant les écoles de Genève et de Lausanne, datées de septembre 1837. Aussi, pour ne pas s'arrêter à ces quelques impressions de voyage, insuffisantes pour se donner une idée précise de la situation pédagogique de la ville étudiée, Cousin charge ses interlocuteurs de lui collecter de plus ou moins grandes quantités de documents, qui transitent ensuite via les ambassades et les chancelleries. C'est par exemple le cas lorsque Cousin visite l'école normale de Lausanne en septembre 1837 et charge le rénovateur de l'école vaudoise André Gindroz (1787-1857) d'amasser des documents dans les principales villes de Suisse romande:

J'ai le plaisir de vous annoncer l'expédition du petit ballot des documents pédagogiques que vous avez recueillis au milieu de nous, dans votre trop courte apparition: le paquet contenant la part de Fribourg, m'est revenu il y a 2 ou 3 jours. La chancellerie d'un autre canton a fait à cette expédition par l'intermédiaire de M. de Montebello; tout, je l'espère, vous arrivera en très bon état et promptement; l'expédition a eu lieu hier, j'ai eu à surmonter quelques petites difficultés; voilà la cause de ce petit délai. Le détour par Berne occasionnera encore quelque retard; mais le paquet vous parviendra intact; il échappera aux profondes investigations des douaniers. Une autre fois cependant je prendrai une voie plus simple; et la diligence est toujours ce qu'il y a de mieux. Il me cesse, Monsieur, à vous prier de me faire savoir si vous avez besoin d'un supplément d'information et je m'empresserai de vous satisfaire. Dans une note écrite rapidement mais exacte, j'ai donné les explications les plus indispensables; toutefois il serait bien possible qu'il y eût quelques omissions, ou des données insuffisantes. J'ai un autre envoi à vous faire, Monsieur; mais je ne ferai pas recours à 
votre ambassadeur; il faudra modestement se contenter de la diligence: on m'a renvoyé de Fribourg, votre chapeau... Je le ferai partir au plus tôt ${ }^{62}$.

$\mathrm{Au}$ travers de ces missions en Allemagne et en Hollande, c'est une res publica scolaire qui se met en mouvement. À mesure que son réseau s'agrandit, Cousin poursuit en filigrane la constitution d'une pédagogie éclectique qui tient sa source dans les travaux d'August Hermann Niemeyer (1754-1828). Né à Halle, Niemeyer se lie avec Lessing et surtout Klopstock qu'il rencontre à Hambourg en 1776. Suite à la défaite d'Iéna et la suppression de l'université de Halle, il est emmené à Paris et à son retour en 1807, Nolte l'appelle à participer à la création de l'université de Berlin. Parus en 1796, ses Grundsätze der Erziehung und des Unterrichts, dont la dernière édition date de 1828, vont dès lors nettement dominer la pédagogie allemande de la première moitié du $\mathrm{XIX}^{\mathrm{e}}$ siècle et attirer l'attention des voisins. Par cette démarche éclectique, Niemeyer souhaite " contribuer à faire connaître ce que le passé offre de vraiment méritoire, ainsi que les améliorations qui ont pu être réalisées depuis; de mettre à la portée des éducateurs et des maîtres de la jeunesse ce qui a été dit ou fait de meilleur dans tous les temps, et d'arriver ainsi à établir, sur la base de l'expérience, les règles solides de l'éducation et de l'enseignement ${ }^{63}$ ». Niemeyer ajoute encore qu'il s'agit « bien [de] se persuader qu'il n'existe pas plus, en pédagogie, de méthode unique et exclusive, qu'il ne peut exister en religion d'Église possédant seule le privilège de conférer le salut ${ }^{64}$ ». Il est par ailleurs intéressant de constater qu'entre 1841 et 1843 , le pasteur strasbourgeois Théodore Fritz publie une somme pédagogique en trois volumes considérée comme la première traduction française de la doctrine éclectique formulée par Niemeyer ${ }^{65}$. Fritz fait appel à Cousin dans le but de propager cet écrit en France:

J'ai l'honneur de vous transmettre les deux premiers volumes d'un ouvrage sur l'instruction, que je viens de publier. Cet ouvrage embrasse l'ensemble complet de la pédagogique (sic); il est, autant que je sache, le premier de ce genre en France et pourrait, à ce qu'il me semble, être utile

62. Lettre de A. Gindroz à V. Cousin, Lausanne, $1^{\text {er }}$ octobre 1837, BSFC, MSVC 231: correspondance générale, t. XVIII.

63. James Guillaume, « Niemeyer », NDP, 1911.

64. Ibid.

65. Théodore Fritz, Esquisse d'un système complet d'instruction et d'éducation et de leur histoire, avec indication des principaux ouvrages qui ont paru sur les différentes branches de la pédagogique, surtout en Allemagne, 2 vol., Strasbourg, 1841. 
à l'étude de cette partie. Il m'a semblé, et des juges assez compétents et impartiaux ont été de mon avis, qu'un pareil ouvrage devrait servir de base aux leçons de pédagogique qui doivent se donner dans les écoles normales. M. Cottard, recteur de l'académie de Strasbourg, en a écrit dans ce sens à M. le Ministre de l'Instruction publique. Je vous serais fort reconnaissant, si votre suffrage fut favorable à cette demande. M. le baron de Gérando a bien voulu m'écrire des lignes bien flatteuses sur mon travail; son jugement favorable m'enhardit à faire cette démarche auprès de vous ${ }^{66}$.

Si Victor Cousin, figure tutélaire de l'éclectisme ${ }^{67}$, n'a pas à notre connaissance donné suite à l'appel de son collègue strasbourgeois, l'Esquisse sera très largement diffusée en Suisse romande. Le Père Girard, son élève Alexandre Daguet et l'éducateur genevois FrançoisMarc-Louis Naville en feront grand cas dans la presse romande, parce qu'ils y voyaient avant tout l'occasion de légitimer l'éclectisme pédagogique dont ils se réclamaient:

Si la littérature scolaire de l'Allemagne est riche en histoires et en encyclopédies de l'éducation, il n'en est pas de même de la littérature scolaire de la France. À part quelques compositions incomplètes et un peu confuses, comme le Dictionnaire d'éducation de l'abbé Migne, le seul ouvrage vraiment intéressant qui nous soit tombé dans les mains est celui du pasteur Fritz, de Strasbourg (1843), que sa culture scientifique et l'avantage d'habiter une ville située aux confins de la France et de l'Allemagne avaient mis à même de s'initier au mouvement intellectuel des deux pays. Aussi, comme le faisait observer l'auteur de l'histoire littéraire de l'éducation morale et religieuse en France, M. Louis Burnier, l'ouvrage de M. Fritz est certainement ce que nous avons de plus complet dans notre langue en matière d'histoire de la pédagogie ${ }^{68}$.

Les raisons qui ont poussé ces éducateurs romands à opter pour l'éclectisme pédagogique s'expliquent assez aisément. Indéfiniment pris à partie par les ultramontains locaux, ils considéraient l'éclectisme comme l'unique moyen de s'extirper des querelles religieuses et politiques de leur temps:

"Essayez tout et retenez ce qui est bon ". Telle est et telle sera toujours notre devise sur ce terrain élevé et neutre de l'éducation, où nous

66. Lettre de T. Fritz à V. Cousin, Strasbourg, 29 janvier 1841, Bibliothèque de la Sorbonne, Fonds Cousin, MSVC 229: Correspondance générale, t. XVI.

67. Voir Jacques Billard, L'éclectisme, Paris, PUF, 1998.

68. Alexandre Daguet, « À propos de I'Histoire de la pédagogie de M. Paroz », L'Éducateur, 23/1869, p. 378-379. 
désirons nous maintenir à l'exemple de nos devanciers des précédents congrès, étrangers et supérieurs aux tiraillements des partis religieux et politiques qui divisent notre patrie et s'agitent autour de nous ${ }^{69}$.

D'ailleurs, il faut encore faire remarquer que si l'on considère le processus de mise en écriture de la pédagogie en Europe, l'œuvre de Niemeyer constitue un socle à partir duquel vont s'édifier les grandes histoires de la pédagogie du $\mathrm{XIX}^{\mathrm{e}}$ siècle et dont Friedrich Heinrich Christian Schwarz, Théodore Fritz, Jules Paroz ou Gabriel Compayré sont les héritiers. C'est donc dans le sillage de cette constellation pédagogique européenne qu'apparaît Alexandre Daguet. Avant de s'imposer comme un acteur central de la scène historique et pédagogique de son temps, il va devoir apprendre à évoluer dans les méandres politiques de sa ville natale et éluder en premier lieu un certain « problème français ".

69. Alexandre Daguet, « Circulaire du comité central de la Société des instituteurs de la Suisse romande aux membres du corps enseignant et aux amis de l'éducation dans la Suisse romande », L'Éducateur, 13/1874, p. 202. 


\section{2 \\ Daguet et le "problème français "}

Anne-Marie Thiesse fait observer que nationalisme, universalisme et internationalisme ne furent nullement contradictoires dans l'esprit des façonneurs de nos États-nations. Si cette dimension transnationale du processus de construction nationale ne relève certes pas de l'évidence, c'est parce que le processus de formation des communautés imaginées (développées par Benedict Anderson) est fondé sur son propre déni ${ }^{1}$. Alexandre Daguet, illustre parfaitement ce constat. Car si Daguet s'est investi dans sa cité comme historien national en déjouant un certain "problème français » pour mieux valoriser les particularismes de son pays, il fut également de ceux qui proposèrent la création d'une association pédagogique internationale lors de l'Exposition universelle de Paris en $1867^{2}$.

\section{Un milieu, des flux, une réaction}

Bien que certains de ses ascendants aient joué quelques rôles d'importance dans la société fribourgeoise des $\mathrm{XVII}^{\mathrm{e}}$ et $\mathrm{XVIII}^{\mathrm{e}}$ siècles, Alexandre Daguet (1816-1894) grandit dans une famille modeste du patriciat $^{3}$. Son père accumule les fonctions subalternes d'huissier d'État

1. Anne-Marie Thiesse, «Nations, internationalismes et mondialisation», Romantisme, n० $163,1 / 2014$, p. 18.

2. Certains développements de ce chapitre ont fait l'objet de publications: « Des livres pour fabriquer des Romands. Littérature scolaire, transferts culturels et élaboration collective des identités européennes au XIXe siècle, in P. Bühler, T. Bühler, M. Helfenberger \& F. Osterwalder (dir.), Erziehung in der europäischen Literatur des 19. Jahrhunderts, Bern, Haupt Verlag, 2014, p. 233-250; « Alexandre Daguet (1816-1894): une histoire pour les Fribourgeois. La fabrication d'un romand cantonal », $A F, 76 / 2014$, p. 47-56.

3. Voir la biographie en deux parties de Daguet dressée par Auguste Schorderet, « Alexandre Daguet et son Temps », $A F, 1 / 1920$, p. 1-14 et 2-3/1920, p. 49-86. 
et de vitrier pour de minces revenus qui s'évaporent parfois dans les jeux. Quant à sa mère, elle obtient un poste de confiance auprès d'une famille de la noblesse locale, dont un des membres, le baron et avoyer (premier magistrat dans certains cantons suisses) Charles Griset de Forell (1787-1860), parraine Alexandre lors de sa confirmation. On notera également l'alliance que les Daguet concluent en 1790 avec une prestigieuse famille française lors du mariage d'Étienne Pivert de Senancour, l'auteur d'Obermann, avec Marie-Françoise Daguet, parente éloignée d'Alexandre. Dans l'Europe de la Restauration, Fribourg est la capitale d'un des vingt-deux cantons de la Confédération restaurée ${ }^{4}$. Cette citadelle du catholicisme revient pour un temps aux mains des oligarchies patriciennes, mais la lutte pour le pouvoir, qui passe notamment par le contrôle des écoles publiques, est engagée par une bourgeoisie naissante. L'économie du canton, ballottée entre archaïsme et tentation moderne, demeure majoritairement agraire, la vie paysanne est encore hantée par le spectre de la disette.

La situation géographique de la maison paternelle, attenante au couvent des Cordeliers, facilite les contacts amicaux avec le Père Girard. Ainsi, le jeune servant de messe grandit dans l'environnement immédiat de ce pédagogue de renom, visité comme on l'a vu dès 1816 par les grandes figures de l'Europe scolaire. Toutefois, la fraction ultramontaine fribourgeoise, bientôt épaulée par l'évêque Jenny, attaque de front la forme personnalisée d'enseignement mutuel qui a construit la notoriété du moine. Huit ans d'une bataille pédagogique acharnée auront finalement raison de Girard, liquidé au terme de cette lutte paradigmatique. Il s'en ira à Lucerne et Daguet, âgé de sept ans, ne fera que paraître sur les bancs de l'école mutuelle l'année même de sa suppression en 1823 .

À l'automne 1827, orphelin de père, Daguet entre au collège SaintMichel, un établissement de la Contre-Réforme fondé par les jésuites à la fin $\mathrm{du} \mathrm{XVI}^{\mathrm{e}}$ siècle où les études sont gratuites. Il y acquiert une solide culture classique, un goût prononcé pour l'histoire où il excelle et la maîtrise du latin et de l'allemand. Cependant, on ne saurait trop souligner que ces huit années passées au collège européen de Fribourg, où plus de $70 \%$ des sept cents élèves du pensionnat des jésuites venaient des départements de l'Ouest et du Midi de la France, vont modeler

4. Sur I'histoire de Fribourg, voir Roland Ruffieux (dir.), Histoire du Canton de Fribourg, 2 vol., Fribourg, Imprimerie Fragnière, 1981; Francis Python (dir.), Fribourg, une ville aux $X I X^{e}$ et $X X^{e}$ siècles, Fribourg, Éditions La Sarine, 2007; Alain-Jacques Tornare, L'Histoire des Fribourgeois et de la Suisse, Bière, Éditions Cabédita, 2012. 
le libéralisme romantique du jeune homme ${ }^{5}$. Comme nombre de ses camarades, Daguet gardera sa vie durant une rancune tenace à l'égard de ses anciens maîtres, accusés de n'avoir pas su se consacrer aux aspirations de la cité: " quel intérêt réel des exotiques pouvaient-ils prendre à l'avancement moral et intellectuel de la république fribourgeoise et de la Confédération ${ }^{6}{ }^{\prime}$. Dans son essai consacré à la réorganisation de l'instruction publique, il décrit que:

L'esprit suisse et fédéral a été banni de nos écoles. Le vide rhétorique des jésuites, les tendances exclusives et intolérantes de l'obscurantisme, le cosmopolitisme implanté par le Pensionnat, et les corporations étrangères à nos mœurs et à notre politique républicaine, toutes ces funestes influences ont détruit, dans une partie de la jeunesse et parlant de la population fribourgeoise, l'amour de la patrie et des institutions helvétiques ${ }^{7}$.

De plus, Daguet déplore amèrement l'attitude sélective avec laquelle les jésuites traitent leurs étudiants, privilégiant les enfants issus de la noblesse française. C'est pourquoi les externes fribourgeois, délaissés et frappés par cette distinction de classe, se regroupent dans de petits cénacles patriotiques. Daguet se lie ainsi à quelques camarades dont le goût pour la patrie n'a été que médiocrement servi au collège. Ces jeunes gens se retrouvent dans les bois environnants pour célébrer une nature consubstantiellement helvétique au son de l'Ode sur les Alpes de Albrecht von Haller. Ils s'extasient devant le panorama des Préalpes en dévorant des passages de l'Histoire de la nation suisse de Johann Heinrich Daniel Zschokke. À dix-neuf ans, Daguet fonde et préside un petit cercle littéraire et national, baptisé du nom pompeux de Société guillimanienne. Ce choix n'est guère surprenant quand on sait que Franz Guillimann (1568-1612) fut l'historien qui affranchit Fribourg de l'anathème lancé par Heinrich Cornelius Agrippa (1486-1535) ${ }^{8}$, qui lors d'un séjour d'un an présenta la cité catholique comme "dépour-

5. Voir Olivier Meuwly, Les penseurs politiques du XIXe siècle. Les combats d'idées à l'origine de la Suisse moderne, Lausanne, Presses polytechniques et universitaires romandes, 2007, p. 61-91.

6. Alexandre Daguet, «Entretiens d'outre-tombe entre le P. Girard et le Président Laurent Frossard », L'Éducateur, 1/1875, p. 7.

7. Alexandre Daguet, Quelques idées pour la réorganisation de l'instruction publique dans le canton de Fribourg, Fribourg, L.-J. Schmidt, 1848, p. 7-8.

8. Au sujet du séjour d'Agrippa en Helvétie, on lira la notice d'Alexandre Daguet, « Cornélius Agrippa chez les Suisses », Archives de la Société d'histoire du canton de Fribourg, vol. 2, cahier 5, 1856, p. 132-170. 
vue de toute espèce de culture et de science ${ }^{9}$ ». On notera encore que de cette association estudiantine naquit la Société d'études, creuset du libéralisme fribourgeois post-Régénération. Daguet y réunit les principaux façonneurs d'une identité fribourgeoise de langue française: l'écrivain régional Louis Bornet (1818-1880), précepteur en Silésie et à Cracovie puis directeur des écoles de La Chaux-de-Fonds, le poète et avocat anticlérical Nicolas Glasson (1817-1864) ainsi que l'hégélien de gauche Pierre Sciobéret (1830-1876).

\section{L'héritage culturel français de Fribourg}

À lire les revendications de Daguet, pour qui «le Fribourg de la Restauration était un pays bourbonien plutôt que suisse ${ }^{10}$ ", on peut donc affirmer que l'émigration française de 1789, son antirépublicanisme, l'arrivée des troupes françaises et le carlisme affirmé des jésuites font de la Grande Nation le principal bouc émissaire de cette jeunesse libérale. Le Père Girard, témoin de l'afflux des émigrés, précise " qu'en général, les réfugiés français nous sortirent pour ainsi dire de notre pays. Nous respirions au milieu d'idées, d'usages et de passions étrangères, perdant de plus en plus ce que nous avions de suisse et pourtant, nous n'en avions pas de reste ${ }^{11}$ ». Lorsque les troupes napoléoniennes entrent dans Fribourg le 2 mars 1798, le couvent de Girard est transformé en une caserne française: " on était entré dans la bibliothèque de vive force et nous vîmes de nos livres jetés dans le feu ${ }^{12}$ ". Un mois plus tard, l'abrogation de l'ancienne Confédération, remplacée par une République helvétique "une et indivisible " constituée sur le modèle de la République française est vécue par ces patriotes comme un traumatisme. Auguste Schorderet, le biographe de Daguet, y voit une des origines du libéralisme suisse, qui s'apparente à un mot d'ordre d'affranchissement de la tutelle française, ce mouvement s'étant traduit dans les faits par un effort de régénération de l'esprit national et un élan de patriotisme ${ }^{13}$.

Pourtant, au-delà des passions, Georges Andrey a montré que les émigrés français de la première vague (1789-1815) furent loin

9. Alexandre Daguet, « Illustrations fribourgeoises », op. cit. p. 2.

10. Alexandre Daguet, Histoire de la Confédération suisse, t. 2, Genève-Bâle-Lyon, H. Georg Librairie-Éditeur, 1880, $7^{\text {ème }}$ édition, p. 530.

11. Grégoire Girard, Quelques souvenirs de ma vie avec des réflexions, Fribourg, Société fribourgeoise d'éducation, 1948, p. 45.

12. Ibid., p. 47.

13. Auguste Schorderet, « Alexandre Daguet et son Temps », AF, 2-3/1920, p. 60 sq. 
de confisquer la cité au détriment des indigènes. Il concède plutôt " qu'outre l'ostracisme qui a frappé les petites classes du tiers état, mendiants, vagabonds, paysans, ouvriers, on a vu que ceux qui ont bénéficié de l'asile, fussent-ils roturiers, nobles ou prêtres, n'ont pas manqué d'être l'objet, de la part du gouvernement, de tracasseries de tout genre et d'une certaine discrimination ${ }^{14}{ }$. Il indique par ailleurs que la dureté des temps et notamment la famine de 1816 a poussé Fribourgeois et émigrés à la coopération. De plus, il ne faut pas oublier qu'au moment où cette émigration française tente de s'agréger à la société fribourgeoise, deux mille colons (dont huit cents Fribourgeois) s'en vont quérir une vie meilleure dans le district de Cantagalo au Brésil ${ }^{15}$. Au-delà des obstacles mis à l'intégration des migrants français dans le tissu fribourgeois, l'exode brésilien de Nova Friburgo rappelle qu'au début du XIx ${ }^{\mathrm{e}}$ siècle, c'est la Suisse qui se débarrassait de ses propres citoyens devenus réfugiés économiques. Gérard Bourgarel attire l'attention sur le fait " qu'on érige cet exode en une sorte de poya (montée aux alpages) mythifiée, alors qu'en réalité il s'agit d'une quasi-déportation ${ }^{16}{ }$. Les contemporains relevaient déjà ces conditions déplorables. L'Alsacien Georges Joseph Schmitt, alors rédacteur du journal fribourgeois Le Confédéré, accusa les compagnies d'émigration de traiter les colons comme de la marchandise et dénonçait une véritable traite des blancs ${ }^{17}$.

Mais il y a plus. On ne saurait trop souligner que cette coexistence entre émigrés français et locaux va se doubler d'importations culturelles décisives pour le canton, à commencer par la réactivation de la langue française, elle-même déjà reléguée par l'allemande lors de l'entrée de Fribourg dans la Confédération en 1481 :

Nos relations constantes avec la France et l'influence des écrits de Rousseau sur notre bourgeoisie, à la fin du siècle dernier, avaient préparé de loin une transformation, activée encore par la présence de nombreux élèves français que comptait le pensionnat des jésuites. Le triomphe des idées libérales et démocratiques en 1830 marque l'avènement définitif

14. Georges Andrey, Les émigrés français dans le canton de Fribourg (1789-1815), Neuchâtel, Imprimerie Paul Attinger, 1972, p. 355.

15. Voir Martin Nicoulin, La genèse de Nova Friburgo: émigration et colonisation suisse au Brésil (1817-1827), Fribourg, Éditions universitaires, 1973.

16. Cité par Jan Pauchard, «L'histoire d'un exode suisse », L'Illustré, récupéré du site de la revue: http://www.illustre.ch/Nova-friburgo-bresil-1820-pro-fribourg_83469_html

17. Cédric Krattinger, L'idéologie de Georges Joseph Schmitt diffusée dans Le Confédéré (1854-1869). Entre radicalisme républicain et socialisme associationniste, université de Fribourg, mémoire de licence, 1997, p. 218. 
de la langue française devenue, semble-t-il, la langue littéraire du pays, le jour où elle en fut proclamée la langue officielle ${ }^{18}$.

Daguet impute la faiblesse du mouvement intellectuel de son canton «à ce contact, disons mieux, ce conflit de deux langues nées le même jour dans une cité à la fois romande et germanique, bourguignonne et souabe ${ }^{19}$ ». Il faut dire qu'avant d'être pensé comme un indéniable atout, ce bilinguisme fut souvent vécu comme problématique à Fribourg. À plusieurs reprises on songea à fermer les écoles allemandes. En connaissance de cause, Daguet indique qu'au début du $\mathrm{XIX}^{\mathrm{e}}$ siècle, "Girard concluait à leur suppression, soit pour faire cesser l'antagonisme alors assez vif des deux races, soit pour établir l'unité de culture $^{20}$ ». La question revint en 1861, mais Daguet, alors inspecteur d'école par intérim, se prononça contre la suppression. Pourtant, dès 1853, sa lointaine cousine Eulalie de Senancour ${ }^{21}$, la fille de l'auteur d'Obermann, affirme dans L'Émulation que "cette ville est devenue presque française par sa langue, sa littérature, ses usages et sa sociabilité. Depuis soixante ans, elle accueille nos réfugiés politiques de tout bord et ses habitants ont tellement multiplié leurs alliances au-delà des Alpes et du Jura surtout, qu'en vérité un Fribourgeois pur-sang devient chose rare $^{22} »$. Avec Paul Bondallaz, nous rappellerons également que " ces gens apport [ai] ent les usages, les coutumes, les manières, le parler de leur patrie d'origine. Lettrés, instruits, rompus aux belles manières, ils form [ai] ent avec les éléments de la société indigène cultivée une sorte d'élite intellectuelle ${ }^{23}$ ». Daguet n'a-t-il pas omis de reconnaître que cette élite métissée contribua au développement de la vie culturelle

18. Alexandre Daguet, Notice sur la vie et les travaux de la Société d'études de Fribourg, depuis sa fondation en 1838 jusqu'en 1854, Fribourg, L.-J. Schmidt, p. 38.

19. Alexandre Daguet, «Illustrations fribourgeoises », L'Émulation, 11/1842, p. 1. On notera qu'à la fondation de la ville en 1157, Berchtold IV de Zaehringen, de père souabe et de mère bourguignonne, hésita à adopter le roman ou l'alémanique comme langue officielle, faisant de Fribourg une ville bilingue « dès le berceau ».

20. Alexandre Daguet, « L'instruction publique à Fribourg », L'Éducateur, 14/1881, p. 216.

21. Eulalie de Senancour (1791-1873), fille d'Étienne Pivert de Senancour et de Marie-Françoise Daguet dont Alexandre est un parent éloigné. Née à Agy près de Fribourg, elle y vécut jusqu'en 1802, avant de rejoindre son père à Paris. Partagée entre ses deux identités, elle fera plusieurs séjours en Suisse. Elle meurt à Fontainebleau.

22. Cité par Philippe Gariel, « Eulalie de Senancour et ses amis fribourgeois, d'après sa correspondance inédite avec A. Daguet (1844-1857) », Revue de littérature comparée, 13/1933, p. 404.

23. Paul Bondallaz, « Le mouvement littéraire en pays fribourgeois vers 1850 », AF, 1/1919, p. $2-3$. 
locale, par l'instauration de plusieurs cercles et sociétés? On pense également à l'œuvre pédagogique des trappistes et des trappistines, certes fort critiquée par Girard, et à quelques personnalités qui arrivèrent sur les bords de la Sarine avec leurs ambitions propres. À cet égard, le cas du voltairien Louis-Valentin Prat est instructif. Cet ancien élève de l'École polytechnique de Paris, originaire de l'Aveyron, fut engagé par le conseil d'éducation de la ville pour prendre la direction de l'école moyenne centrale, un établissement fondé par les libéraux fribourgeois pour former la jeunesse aux différentes branches de l'industrie et du commerce. Symbole de hautes luttes, constamment attaquée par le parti conservateur et les partisans des jésuites, l'école moyenne se voulait une version des écoles primaires supérieures instituées en France par la loi Guizot de 1833 et c'est donc logiquement à Paris qu'on chercha son directeur. Prat fut finalement choisi de préférence à Émile Villemereux, professeur au collège Henri IV, dont les prétentions salariales se montrèrent trop élevées pour Fribourg. Autant d'énergies venues de l'étranger qu'il importe de prendre en compte pour mesurer la complexité des composantes en jeu dans la formation de la Suisse moderne.

Très critique du personnel de Saint-Michel, Daguet s'attache néanmoins au père Lückmeyer, un jésuite allemand en qui il voit " un des esprits les plus indépendants [qu'il] a rencontré, professeur de droit philosophique et dont les admirables leçons sur le droit naturel, contre le droit divin, contre l'esclavage, et pour la liberté de la presse excitèrent le courroux de bien des gens et déterminèrent son départ pour Dresde, où il sortit de l'Ordre et mourut peu après ${ }^{24}{ }$. Au sortir du collège, il suit le séminaire du professeur radical Jean-Marcelin Bussard (1800-1853), un avocat germanophile fervent promoteur de la pratique kantienne, de l'instruction du peuple et de l'abolition de la peine de mort. En 1836, il est appelé comme professeur d'histoire à l'école moyenne centrale.

C'est par des lectures assidues que Daguet parachève sa formation. À cette époque, le jeune professeur voue une admiration sans borne à l'histoire populaire et nationale de Zschokke et de Johannes von Müller, les chantres de la nation suisse. Il se retrouve pour un temps dans le romantisme radical d'Ignaz Paul Vital Troxler (1780-1866) ${ }^{25}$ et ne reste pas insensible aux thèses saint-simoniennes et socialistes. En

24. Alexandre Daguet, « Histoire de la pédagogie », L'Éducateur, 2/1870, p. 19.

25. Voir Daniel Furer, Gründervater der modernen Schweiz. Ignaz Paul Vital Troxler (17801866), université de Fribourg, thèse de doctorat, 2009. 
janvier 1845, Daguet écrit à son ami franc-comtois Max Buchon qu'il souhaite collaborer à la Démocratie pacifique de Victor Considerant ${ }^{26}$. Même si l'historien des lettres romandes Henri Perrochon clôt un peu vite la question en affirmant que « la prédication de Buchon n'eut pas grand succès [car] le côté religieux du fouriérisme effrayait Daguet ${ }^{27}$ ", on peut affirmer que ce dernier a servi pour un temps de connecteur entre les cercles francs-comtois et romands. Certes l'homme n'est pas toujours facile à cerner, notamment lorsqu'il écrit à Victor Cousin qu'il ne voudrait voir pénétrer à Fribourg « le Matérialisme, l'Athéisme, ni aucune de ces doctrines dégradantes qui tournent l'esprit de la jeunesse uniquement vers la terre et la jouissance physique ${ }^{28} »$. Mais on sait aussi que Daguet a affirmé " avoir été archi-révolutionnaire ${ }^{29}$ » dans une jeunesse nourrie de nombreuses lectures consacrées aux thèses socialistes (utopistes). Robert Owen fut l'une de ses références, vraisemblablement à cause de ses liens avec le Père Girard. En avril 1840, Daguet parcourt les Études sur les réformateurs contemporains ou socialistes modernes de l'économiste et homme de lettres français Louis Reybaud $^{30}$ et s'attarde sur Owen au sujet duquel il annote:

Études sur l'économiste Owen: l'homme est bon, sortant des mains de Dieu s'est dit J. J. - l'homme n'est bon, ni mauvais dit Owen, il est le jouet des circonstances dont on l'entoure; il devient mauvais, si elles sont mauvaises, bon si elles sont bonnes. Une bienveillance absolue sans restrictions et sans limites, une égalité tolérante, une grande liberté de mouvement, un retour vers les vérités éternelles dont l'homme porte les germes en lui, tels furent les premiers mots qu'il traduisit en mode d'action pour l'amélioration de New Lanarck ${ }^{31}$.

Suite à l'écrasement de la Commune de Paris (1871), Daguet fut l'hôte et le protecteur d'un autre Franc-comtois, le peintre Gustave Courbet (1819-1877). Incarcéré à la prison de Mazas du 30 juin à fin

26. «Tu me demandais dans ta dernière lettre comment tu pourrais te mettre en rapport avec la Démocratie pacifique. Je t'en ai envoyé un numéro. Si tu veux lui adresser des articles helvétiens, politiques, bien soignés je ne doute pas qu'ils ne soient bien accueillis » (lettre de M. Buchon à Daguet, Salins, 20 janvier 1845, AEF, Fonds Daguet).

27. Henri Perrochon, « Le Franc-Comtois Mac Buchon », op. cit. p. 19.

28. Lettre de Daguet à Victor Cousin, Fribourg, 15 août 1850, Bibliothèque de la Sorbonne, Fonds Cousin, MSVC 224: correspondance générale, t. XI.

29. Journal de Genève du 18 mai 1852, p. 1.

30. Louis Reybaud, Études sur les réformateurs contemporains ou socialistes modernes: Saint-Simon, Fourier, Owen, Paris, Librairie Guillaumin, 1839.

31. Alexandre Daguet, Notes de mes lectures d'avril 1840, AEF, Fonds Daguet. 
juillet 1871, celui-ci reçoit le soutien de Daguet qui tente d'intervenir à Paris auprès de l'ambassadeur de Suisse. Courbet n'étant pas citoyen helvétique, la diplomatie ne pourra donner suite à cet appel ${ }^{32}$. Son engagement politique et les poursuites engagées contre lui par l'État français après la Commune l'obligent à se réfugier en Suisse en juillet 1873. S'il s'installe à la Tour-de-Peilz sur les bords du Lac Léman, il peut compter sur l'aide de son protecteur comme il le confesse à sa sœur Juliette:

M. Daguet de Neuchâtel est le professeur de philosophie que j'avais connu à Fribourg avec Buchon (qui a bien fait de mourir). Il m'avait fait préparer une chambre chez lui en prévision de mon arrivée en Suisse. Elle est toujours à ma disposition. Il m'a envoyé l'autre jour un peintre, M. Bachelin, de ses amis que je connais aussi pour m'engager à aller quelque temps en Suisse. Il assure que les gens de Neuchâtel, de Berne, de Fribourg, m'attendent et me font leurs compliments ${ }^{33}$.

Notons que Courbet participa lui aussi à la pénétration des idées de Charles Fourier dans le canton de Fribourg. Marc Vuilleumier a montré que le passage de Victor Considerant à Genève a permis aux fouriéristes du cru de se rassembler. Un de ceux-ci, le peintre Auguste Baud-Bovy (1848-1899), installera un phalanstère dans le château de Gruyère, fréquenté notamment par Jean-Baptiste Corot et Courbet ${ }^{34}$.

Pour en conclure sur l'horizon intellectuel de Daguet, on notera encore qu'il est resté étranger à toute formation académique, même si l'idée d'un doctorat fut évoquée par Buchon, alors installé à Tübingen :

Mon cher, je reviens sur l'idée de ton doctorat. Tu devrais t'arranger de manière à pouvoir venir ici. Si tu dois rester à Lausanne cela ne te nuirait pas. Ici cela te coûtera 60 florins, $90 \mathrm{~F}$ de Suisse, plus un mémoire quelconque sur une question philosophique quelconque que tu ferais imprimer ou non avant de le remettre au recteur. On te donnerait le jour pour l'examen. Or, cet examen n'a pour but que de vérifier si celui qui se présente est réellement l'auteur du mémoire. On n'a donc pas besoin d'avoir la tête pleine d'idées en général. On a besoin seulement de posséder de

32. Lettre de la légation suisse de Paris à Daguet du 5 juillet 1871, AEN, Fonds Daguet.

33. Lettre de G. Courbet à sa sœur Juliette, 3 mars 1872, Correspondance de Courbet, Paris, Flammarion, 1996, p. 404.

34. Voir le numéro thématique de la revue Patrimoine fribourgeois consacré au château de Gruyères, $n^{\circ} 16$, décembre 2005. Sur les rapports entre Courbet et la Suisse, voir Laurence Madeline (dir.), Gustave Courbet, les années suisses, catalogue de l'exposition présentée au musée Rath de Genève, Versailles, Art Lys, 2014; Pierre Chessex, Courbet et la Suisse, Vevey, Säuberlin \& Pfeiffer, 1982. 
manière à la défendre un peu, l'idée que l'on a formulée soi-même. Je tiens

ces détails d'un examinateur qui est mon élève en français ${ }^{35}$.

Ce n'est que trente ans plus tard qu'il recevra une marque d'estime pour ses services d'historien national, en devenant docteur honoris causa de l'université de Berne. Pour autant, c'est bien par l'édification d'une littérature nationale et fribourgeoise qu'il débuta son œuvre patriotique.

\section{Une littérature suisse, rien que suisse?}

Nous possédons, avec La construction de la littérature romande de Daniel Maggetti et les travaux d'Alfred Berchtold, de Roger Francillon et de Doris Jakubec ${ }^{36}$, des études exhaustives sur le processus de structuration de la littérature romande. Si ces auteurs se sont essentiellement consacrés à l'étude des écrivains protestants - le protestantisme est un élément essentiel dans le mécanisme de dissociation d'avec la France - l'étude du mouvement initié par Daguet éclaire les ambitions d'intellectuels catholiques résolus à former un groupe littéraire capable de peser sur l'échiquier romand. D'ailleurs, on ne saurait trop le souligner, grâce à l'héritage de tolérance religieuse héritée du Père Girard et du chanoine Charles-Aloyse Fontaine (1754-1834) qu'il reprend à son compte, Daguet va réussir à imposer le mouvement littéraire de son canton en adoptant les principales thèses et revendications de ses collègues protestants. Cette démarche ressemble à un travail d'équilibriste, surtout quand on sait que nombre de littérateurs protestants, à l'instar d'Henri-Frédéric Amiel, délaissèrent les cantons catholiques en prétextant le retard de leur développement culturel et leur stérilité littéraire. Ces mêmes positions iréniques respectées par Daguet devaient d'ailleurs lui apporter bien des incompréhensions dans son propre canton: "Je vous ferais observer que si vous avez été attaqué des deux côtés opposés, c’est que vous êtes ni catholique, ni protestant dans vos

35. Lettre de Buchon à Daguet du 12 février 1847, AEN, Fonds Daguet.

36. Daniel Maggetti, L'Invention de la littérature romande 1830-1910, Lausanne, Payot, 1995; Alfred Berchtold, La Suisse romande au cap du XXe siècle. Portait littéraire et moral, Lausanne, Payot, 1966; Roger Francillon et Doris Jakubec (éds), Littérature populaire et identité suisse. Récits populaires et romans littéraires: évolution des mentalités en Suisse romande au cours des cent dernières années, Lausanne, L'Âge d'Homme, 1991; Roger Francillon, Histoire de la littérature en Suisse romande, 4 tomes, Lausanne, Payot, 1996-1999 et du même, De Rousseau à Starobinsky. Littérature et identité suisse, Lausanne, Presses polytechniques et universitaires romandes, 2011. 
écrits et qu'ainsi vous mécontentez tout le monde ${ }^{37}$ ", lui écrivit l'abbé Jean Gremaud en avril 1856.

Avec la publication de L'Émulation ${ }^{38}$ en septembre 1841, Daguet se donne les moyens de son ambition: doter le canton de sa première revue culturelle et susciter l'éveil d'une littérature réaliste fribourgeoise "longtemps étouffée sous le boisseau de la scholastique et du germanisme officiel ${ }^{39}$ ». Mais le principal mouvement vers l'autonomie romande passe indéniablement par une mise en cause symbolique et une mise à distance de la littérature française. Daguet entend restaurer le mouvement intellectuel fribourgeois dans une visée authentiquement populaire et nationale, en empruntant le kit identitaire forgé par la littérature alémanique, Pestalozzi, Gotthelf et Johann Martin Usteri en tête. Mais l'hypothèse peut être faite que malgré un verrouillage de façade, la littérature romande s'est élaborée autour d'une multitude de références métissées; c'est sous cette perspective que nous chercherons à éclairer ici ces importations culturelles, leurs enjeux comme leurs médiations.

Dans un portait dressé au sortir du collège, le poète gruyérien Nicolas Glasson écrit au sujet de son camarade Daguet que "son âme toute républicaine et ennemie des sujétions monarchiques n'a point trouvé à sympathiser avec nos grands auteurs ". Je crois, ajoute Glasson, que "c'est pour cette raison qu'il a plus de goût pour les autres littératures, l'allemande, l'italienne par exemple. Il y retrouve ses idées de liberté et d'indépendance. Cependant, comme elles ne peuvent satisfaire pleinement ses penchants, il en rêve une autre qui soit suisse et rien que suisse ${ }^{40} »$. Si Daguet, dans le sillage d'un de ses maîtres, le doyen Philippe-Sirice Bridel (1757-1845), va jouer pleinement la carte de l'helvétisation, peut-on pour autant parler d'une littérature exclusivement suisse? Anne-Marie Thiesse relève très justement que c'est «par l'observation mutuelle, l'imitation, le transfert d'idées et de savoir-faire que les intellectuels européens des différentes nations ont

37. Cité dans Alexandre Fontaine, « L'intellectuel fribourgeois Alexandre Daguet, un exemple de modération pour notre temps », Spectrum, 1/2010, p. 20.

38. Le bimensuel L'Émulation, recueil agricole, industriel, commercial, historique et littéraire, paraît chez Louis-Joseph Schmidt (fils d'un imprimeur alsacien qui vint s'établir à Fribourg vers 1786) de 1841 à 1846, puis dans une seconde phase de 1852 à 1856 . Sur I'histoire de la revue, on lira Jean-Maurice Uldry, L'Émulation (1841-1846 et 1852-1856). Analyse de la première revue culturelle fribourgeoise, mémoire de licence, université de Fribourg, 2003.

39. Alexandre Daguet, « Revue des principaux écrivains de la Suisse française, L'Émulation, 5/1856, p. 369.

40. Jeanne Niquille, « Un portrait d'Alexandre Daguet », NEF, 62/1929, p. 206. 
forgé, au cours du $\mathrm{XIX}^{\mathrm{e}}$ siècle, ce modèle commun de production des identités ${ }^{41}$ ». Daguet ne déroge pas à cette tendance. Bien au contraire, puisqu'il a largement comme il l'avoue « cultiv [é] les littératures étrangères, celles surtout qui, par leur génie patriotique et populaire, peuvent servir à vivifier l'étude de la nôtre en lui fournissant des termes de comparaisons et de nouveaux éléments ${ }^{42}$ ". Daguet et ses collaborateurs vont chercher l'inspiration bien au-delà des frontières cantonales pour multiplier les importations culturelles. Ainsi, la nécessité quasi obsessionnelle de se décentrer d'une littérature française perçue comme écrasante va favoriser la recherche d'autres filiations au sein des littératures européennes. On visite le monde par procuration dans L'Émulation, véritable organe d'ouverture, par l'entremise de récits de voyages ou de traductions des grands textes populaires. Certes, une poignée d'écrits sont porteurs de valeurs universelles et cherchent à faire tomber les préjugés. Daguet commente un article consacré à la fête de l'Aïd-elKebir à Constantinople qu'il reprend du journal L'Algérie: "Nous ne manquons pas de préjugés contre les Orientaux; l'ignorance où, malgré de récents travaux, nous sommes encore des mœurs, des usages et du caractère, distinctif des races orientales, les barrières qu'ont élevées, entre elles et nous, les différences de religion, tout a contribué à accréditer, à répandre parmi nous des erreurs qu'il est important de combattre $^{43}$." Malgré cela, l'histoire littéraire proposée par L'Émulation est essentiellement une histoire comparée au travers de laquelle l'intelligentsia libérale-nationale fribourgeoise accumule les juxtapositions transnationales perçues comme autant de repères identitaires. On en trouve un échantillon explicite dans le portrait croisé que Daguet dresse de la Suisse et de la Circassie: "C'est dans leur position politique surtout qu'on trouve beaucoup d'analogie. Elles ont l'une et l'autre pour voisin une monarchie puissante qui les convoite ${ }^{44}$. " On aime à se contempler dans le miroir de l'étranger, tout en créant " des références et des cautions intellectuelles dont la valeur est partagée au niveau européen $^{45}$ ». Bien davantage dictées par l'affirmation personnelle que par

41. Anne-Marie Thiesse, «La lente invention des identités nationales», Le Monde diplomatique, juin 1999, p. 12.

42. Alexandre Daguet, « Revue des principaux écrivains de la Suisse française », op. cit., p. 333-334.

43. Alexandre Daguet, « Fêtes de l'Aïd-el-Kebir à Constantine. Fantasia arabe », L'Émulation, 11/1843, p. 85, article reproduit de L'Algérie.

44. Alexandre Daguet, « La Suisse et la Circassie », L'Émulation, 17/1841, p. 7-8.

45. Daniel Maggetti, op. cit., p. 21. 
une réelle volonté de découverte des formes de l'altérité, les traductions répondent à un usage précis. À cet égard, Simone de Reyff rappelle que " l'altérité n'est féconde que dans la mesure où elle ramène le regard à sa propre identitét ${ }^{46}$ ». Si les collaborateurs de la revue en voyage, ou en exil, adressent des articles sur l'Ukraine, sur Damas ou sur Moscou, la comparaison n'a la plupart du temps d'autres fonctions que de légitimer les vues, sinon les fantasmes que ces écrivains projettent sur Fribourg. Lorsque Daguet traduit un fragment des Scènes de la vie d'un maître d'école de Gotthelf, "il ne s'en faut guère que le tableau de la vieille école bernoise ne soit aussi celui de la vieille école fribourgeoise avant $1830^{47}$ ». Il transcrit Luigi Cicconi ${ }^{48}$ car son épopée de la littérature italienne permet l'objectivation d'une littérature romande en recherche de validation: on y retrouve en effet une "domination française, domination étrangère et égoïste ", l'émergence d'une "poésie toute nationale » à la chute de Napoléon, suivie d'une redécouverte de Dante et des auteurs du $\mathrm{XIV}^{\mathrm{e}}$ siècle, dont "l'étude devait régénérer l'Italie, l'affranchir de toute influence étrangère et, en retrempant la langue à ses belles et vives sources, lui rendre, avec ses éléments primitifs, une nouvelle vie pleine de vérité, de beauté et d'avenir ${ }^{49}$ ". Somme toute, la revue culturelle fribourgeoise propose des fragments minutieusement choisis dans les littératures européennes pour nourrir les revendications romandes. Nul hasard donc si L'Émulation publie la première traduction du Tarass Bô̂lba de Nicolas Gogol dès octobre 1843, traduction réalisée par Adrien Grivet, ancien élève de Daguet, à partir de l'original russe plutôt que d'une traduction intermédiaire ${ }^{50}$. Daguet ne dissimule nullement ses nombreux emprunts. Au contraire, il les revendique et les justifie paradoxalement au nom d'une quête des particularismes:

Et quant aux emprunts que l'on peut faire aux littératures étrangères, si l'on a soin, dans ces sortes d'importations intellectuelles, de s'adresser de préférence aux littératures réellement populaires comme l'est en par-

46. Simone de Reyff, «L'"idéal favori" d'Alexandre Daguet ou les pages littéraires de L'Émulation », Cahiers du musée gruyérien, 5/2005, p. 35.

47. Alexandre Daguet, «Scènes de la vie d'un maître d'école par Jeremias Gotthelf », L'Émulation, 1/1852, p. 358 (traduction de Gotthelf, Leiden und Freuden eines Schulmeisters, 1838).

48. Luigi Cicconi (1804-1856), poète et patriote italien, séjourne cinq ans à Paris dès 1835 où il se liera avec Chateaubriand, Mickiewicz, Hugo et collaborera à la Gazette de France notamment.

49. Alexandre Daguet, « Des phases diverses de la poésie italienne et de sa mission actuelle (traduit de l'italien de Luigi Cicconi) », L'Émulation, 13/1846, p. 203.

50. Voir Rahel Willi, « Un regard sur la Russie », Cahiers du musée gruyérien, 5/2005, p. 51-56. 
tie celle de l'Allemagne, ou aux littératures vraiment nationales, comme le fut la littérature espagnole sous Philippe II, et comme l'est encore aujourd'hui la littérature italienne, ces emprunts, loin de nuire à l'idéal helvétique, aux lettres nationales, lui fourniront des points de comparaisons qui, en ajoutant de nouveaux éléments à ceux qu'elle possède, accroîtront son domaine, en augmentant sa vie ${ }^{51}$.

Dans ce sens, Manzoni et Niccolini ont beaucoup emprunté aux littératures étrangères et Daguet relève que "l'idée chrétienne elle-même, qui fait la base des doctrines littéraires de l'auteur de Carmagnola, est une idée française ou germanique, un emprunt fait à Chateaubriand, ou aux grands critiques de l'Allemagne ${ }^{52}$ ».

\section{S'émanciper du modèle culturel français}

Alexandre Daguet trouve en sa parente Eulalie de Senancour une médiatrice franco-romande particulièrement zélée. Cette Parisienne à moitié suisse se charge de faire connaître Fribourg dans la capitale française et parraine l'œuvre de son lointain cousin par plusieurs publications dans le Journal des femmes. Inversement, d'autres médiations jugées peu patriotiques ou trop cosmopolites sont dévalorisées, voire rompues. C'est le cas de l'auteur romantique Étienne Eggis ${ }^{53}$, protégé d'Arsène Houssaye à Paris et cousin de nos deux correspondants, dont les poèmes sont critiqués par Daguet et son beau-frère Xavier Kohler:

On sent, en lisant son volume, que l'âme du jeune Fribourgeois s'est bien ouverte à la poésie dans notre Suisse, mais qu'elle s'est épanouie sous un ciel étranger, en subissant deux influences marquées, celle de l'Allemagne et de la France; la première avec ce nébulisme (sic) trop commun aux auteurs d'outre-Rhin; la seconde avec la manière fantastique et sonore, qui distinguait la plus belle époque du romantisme ${ }^{54}$.

51. Alexandre Daguet, « Des phases diverses de la poésie italienne et de sa mission actuelle », op. cit., p. 201-202.

52. Ibid.

53. Étienne Eggis (1830-1867), né à Fribourg, il devient précepteur en Bavière, avant de s'établir à Paris. Porté par Arsène Houssaye, Eggis se fait connaître par ses recueils de poèmes. Incompris, il mène une vie de bohème, parcourt l'Europe et meurt de la tuberculose à Berlin en 1867. Voir Martin Nicoulin et Michel Colliard, Étienne Eggis, poète et écrivain, 1830-1867, Fribourg, Éditions de la Sarine, 1980 ainsi que Philippe Gariel, Fribourg et le romantisme: Étienne Eggis (1830-1867), Fribourg, Imprimerie Saint-Paul, 1930.

54. Xavier Kohler, «Revue bibliographique. En causant avec la lune, poésies par Étienne Eggis », L'Émulation, 1/1852, p. 121. 
On remarquera que la France, ou plutôt une certaine France, demeure exempte de ces emprunts. Daguet résume la pensée d'une génération dans sa Revue des principaux écrivains de la Suisse française:

Le grand mouvement littéraire dans la Suisse française date de la fin du siècle dernier. Genève alors donnait au monde Rousseau et Bonnet. Benjamin Constant naissait à Lausanne où séjournèrent Voltaire, Haller, Gibbon. Madame de Staël tenait à Coppet sa brillante cour composée de l'élite des penseurs et des écrivains de l'Europe, les deux Schlegel, Chateaubriand, Lewis, etc. L'auteur d'Obermann, M. de Senancour, égarait ses sombres rêveries sous les sapins d'Agiez, aux portes de Fribourg. Les Lettres neuchâteloises sortaient de la plume fine et spirituelle de Madame de Charrière. Ce sont là les noms saillants. D'autres noms aimables ou sérieux de littérateurs et de philosophes nous apparaissent à leur suite et nous rappellent les habitudes littéraires qui régnaient aux bords du Léman parmi les hautes classes de la société. Car la littérature était chose nobiliaire, aristocratique. À la ville, elle ne franchissait guère les salons de certaines rues privilégiées; à la campagne, elle se renfermait dans les villas et les gentilhommières ${ }^{55}$.

Les conclusions affichées par Daguet au sujet de cette littérature romande à la française sont sans équivoque: «Aussi, à peu d'exceptions près, qu'était cette littérature? Aucune pensée propre, aucun esprit patriotique, national, ne l'inspirait. C'était un écho affaibli, une imitation plus ou moins servile de la littérature parisienne ${ }^{56} »$ :

Notre Suisse française était un département de la France littéraire. Aujourd'hui même que par la richesse de ces productions littéraires et par le cachet original qui distingue une partie de ces œuvres, la Suisse française peut prétendre, comme la Belgique, à une certaine autonomie intellectuelle, nous voyons plusieurs de nos lettrés avec affectation à la remorque des idées et des formes étrangères. Mais il a de tout temps été permis de s'indigner contre cet esclavage, et de rechercher à relever le drapeau national en littérature comme en politique ${ }^{57}$.

Par cette posture, Daguet ne fait que s'inscrire dans un processus qui prend sa source dans le sillage de la Saint-Barthélemy (1572) et de la révocation de l'Édit de Nantes (1685), événements qui devaient durablement peser sur les consciences européennes et jeter l'opprobre

55. Alexandre Daguet, « Revue des principaux écrivains de la Suisse française », op. cit., p. 2. 56. Ibid.

57. Ibid. 
sur la pertinence du modèle culturel français ${ }^{58}$. Érudits britanniques et alémaniques s'unissaient bientôt afin de contrer l'hégémonie de ce dernier et de préparer l'offensive contre la culture unique (sic). Entre 1721 et 1723, Johann Jacob Bodmer et Johann Jacob Breitinger s'attaquent au saxon Johann Christoph Gottsched, thuriféraire des idées de Boileau, dans leur journal Die Diskurse der Mahlern. Les deux Zurichois se réclament d'une esthétique différente, incarnée par le quotidien The Spectator de Joseph Addison. Il s'agit bien, comme le précise Roger Francillon, de se distancer de l'influence prépondérante de la France en matière littéraire ${ }^{59}$. Et Anne-Marie Thiesse de conclure: «Espace britannique, espace helvétique: ce ne fut pas un hasard s'ils furent les deux plus ardents foyers de la lutte contre l'impérialisme culturel français. Ils étaient terre d'asile pour les victimes de son despotisme $^{60}$."

Lors de la première moitié du long $\mathrm{XIX}^{\mathrm{e}}$ siècle, l'école littéraire romande s'efforce de bâtir son identité et de réaliser son autonomie au travers d'attaques souvent agressives contre cette culture française jugée par trop aristocratique. Avec son Grand Saint-Bernard (1839), le Genevois Rodolphe Töpffer (1799-1846) caricature, dans la ligne de l'helvétisme du XVIII ${ }^{\mathrm{e}}$ siècle, la contagion des modes parisiennes sur les braves Genevoises qui se piquaient de littérature ${ }^{61}$. Se distancier de Paris pour mieux assumer une littérature que l'on souhaite autonome, telle est également l'ambition de Charles Gruaz lorsqu'il lance l'Album de la Suisse romande en 1843. François Vallotton rappelle à ce sujet l'orientation idéologique du journal, qui stipule que:

La Suisse romande doit, selon nous, avoir une littérature nationale; elle en est digne, elle en est capable. Sans doute la langue française étant la nôtre, la littérature française sera toujours la base de notre culture intellectuelle; mais placés dans des conditions tout à fait différentes, dotés d'institutions libres et de mœurs républicaines, échappant à la force de la centralisation parisienne, nous pouvons nous frayer une route qui soit mieux appropriée aux allures originales de notre caractère et de notre esprit $^{62}$.

58. Thomas Lau a remarquablement montré la redirection des élites suisses vers le modèle culturel hollandais suite à la révocation de l'Édit de Nantes dans "Stiefbrüder": Nation und Konfession in der Schweiz und in Europa (1656-1712), Köln, Böhlau, 2008.

59. Roger Francillon, De Rousseau à Starobinsky. Littérature et identité suisse, op. cit., p. 21.

60. Anne-Marie Thiesse, La création des identités nationales, op. cit., p. 32.

61. Roger Francillon, op. cit., p. 52.

62. François Vallotton, L'édition romande et ses acteurs 1850-1920, Genève, Slatkine, 2001, p. 69. 
On trouve d'ailleurs une pareille obsession indépendantiste chez un Daguet. En 1842, interpellé au congrès de Strasbourg par un savant qui lui fait remarquer que le peuple suisse est allemand, Daguet objecte que " le peuple suisse n'est pas allemand. Il est allemand, oui, en grande partie par la langue, par les mœurs, par les sympathies. Mais politiquement parlant, le peuple suisse est une nation souveraine. Elle n'appartient à personne. Elle n'est ni française ni allemande! Elle est elle! Et si jamais Français ou Allemand voulait attenter à son indépendance, elle retrouverait un Guillaume Tell ${ }^{63}$.

\section{Absorber la littérature populaire alémanique}

Ainsi, c'est dans le sillage des auteurs alémaniques que Daguet trouvera son Tell. De Haller à Lavater, de Sulzer à Pestalozzi, c'est bien outre-Sarine que Daguet puise l'inspiration nationale, afin de supplanter une littérature parisienne dont il ne cesse de décrier le caractère mondain :

Empreinte d'un autre esprit, d'un esprit plus national, la Suisse allemande se faisait déjà une place à part dans la littérature d'outre-Rhin par ses écrivains et ses penseurs. Trois noms surtout, ceux du grand Haller, de Jean de Müller et de Lavater personnifient l'idéal suisse proprement dit dans cette phalange des hautes intelligences à la fin du XVIII ${ }^{\mathrm{e}}$ siècle. On sait le beau rôle rempli par nos compatriotes dans le mouvement littéraire des pays germains, Bodmer et Breitinger imprimant aux lettres allemandes la direction qui seule pouvait les rendre fécondes et produire les chefs-d'œuvre qui ont immortalisé la terre de Klopstock et de Schiller; Albert de Haller créant le genre de la poésie descriptive sur les bords de l'Aar comme Salomon Gessner, celui de la poésie pastorale aux rives de la Limmat; Jean de Muller renouvelant entièrement le domaine de l'histoire, et Pestalozzi rajeunissait le champ de l'éducation, Sulzer celui de l'esthétique, et comme un Suisse allemand encore C. L. de Haller devait quelques années plus tard donner une nouvelle théorie de la politique, opposée à celle du contrat social, formulée par le Suisse français Rousseau ${ }^{64}$.

Rien d'étonnant donc à ce qu'il consacre la Suisse comme " une terre classique de la littérature populaire paysanne ", dont il dresse la trame historique dans un article paru dans L'Émulation de $1852^{65}$.

63. Gazette de Lausanne du 21 octobre 1842, p. 1.

64. Alexandre Daguet, « Revue des principaux écrivains de la Suisse française », L'Émulation, 1856, p. 2-3.

65. Alexandre Daguet, «Littérature populaire. Scènes de la vie villageoise en Suisse », L'Émulation, 1/1852, p. 65-74. 
Globalement, on résumera sa pensée en indiquant qu'avec Lienhard et Gertrude, Pestalozzi créée le roman villageois. Son successeur Johann Heinrich Daniel Zschokke (1771-1848), " Magdebourgeois de naissance, mais suisse par le cœur et par toute sa vie ", perpétue le mouvement avec le Village des Faiseurs d'or (Goldmacher-Dorf). Daguet lui reproche toutefois d'avoir utilisé la langue classique, le haut allemand et Zschokke se livre ainsi dans un style « trop idéal, trop attique, trop citadin [...] resté parfaitement classique et académique, en dépit de toutes les familiarités domestiques et villageoises de son récit ». Or, à l'inverse, ces défauts n'apparaissent nullement chez Johann Peter Hebel (1760-1826), auteur d'un recueil de poèmes ancestraux rédigés en dialecte badois, dont les " petits poèmes allemanniques (sic) sont d'une originalité puissante et étrange qui déconcerte le lecteur accoutumé à la fadeur élégante et monotone des idylles de Gessner et Florian ». Daguet encense tout autant le romancier bernois Jeremias Gotthelf, pseudonyme de l'écrivain bernois Albert Bitzius (1797-1854) notre «Walter-Scott campagnard" qui a osé parler la langue du peuple de l'Oberland et de l'Emmental:

Bitzius (Gotthelf) était un écrivain d'une certaine puissance et d'une véritable originalité. Peu de romanciers ont pénétré comme lui dans l'essence de la vie villageoise telle qu'elle se manifeste dans le plus populeux des cantons suisses ${ }^{66}$.

Pleinement conscient des potentialités identitaires de la culture orale et fermement inspiré par la littérature alémanique dialectale, c'est donc assez logiquement que Daguet tente d'imposer le patois dans L'Émulation. Dès le prospectus de 1841 , le comité de la revue ne dissimule nullement ses intentions et revendique qu'il "vouera quelques études à cette belle langue romande, riche de mille nuances inconnues à la langue classique ». Aussi, lorsque L'Émulation publie un poème de Louis Bornet en gruérin (1841) et que Daguet encourage l'usage de l'idiome roman en parallèle du français, cette possible projection d'une culture fribourgeoise bilingue déchaine les passions:

Nous les Fribourgeois, les Suisses romans (sic), nous avons deux langues. Le français d'abord, notre langue littéraire, langue de Racine et de Chateaubriand [...] Mais à côté de la langue classique, nous en avons encore une autre, langue vulgaire, pauvre petite langue, bien humble, se cachant dans les petits coins, aimant la campagne, mais vieil et doux

66. Alexandre Daguet, « Littérature populaire de Suisse », op. cit., p. 392. 
idiome, singulièrement naï, pittoresque, énergique, voix des vallées et des monts alpestres, bruit de cascades et de torrents, son de clochettes et de troupeaux, idiome pastoral comme on n'en vit guère, fait au foyer et bon enfant comme on n'en verra jamais, idiome mélodieux, qui nous endormait au berceau, nous fit sauter de joie sur les genoux de nos grand'mères, nous émerveille encore de ses Coraulés nocturnes, et idiome si mélancolique, si embaumé de l'air de la patrie qu'il donne la mort à l'armailli sur la rive étrangère ${ }^{67}$.

L'Émulation vit une brève mais féroce passe d'armes entre les partisans d'une production littéraire en gruérin et les défenseurs de la langue française classique, emmenés par le politicien Hubert Charles (17931882) qui s'est formé à Paris ${ }^{68}$. Selon lui, le français symbolise une langue pourvoyeuse de culture, de rationalisme et d'ouverture au monde. Les historiens qui ont traité de cette querelle linguistique indiquent que Charles et Daguet abrégèrent les hostilités pour ne pas mettre la pérennité de la revue en danger. La Suisse romande ne parviendra donc pas, à l'instar de sa sœur alémanique, à légitimer son propre idiome. Pourtant, quelques mois plus tard, Daguet impose, peut-être par provocation, sinon par fierté, un second idiome en opposition à la langue française en publiant un panthéon bolze $e^{69}$. Car qui mieux que les bolzes incarnent l'esprit populaire, avec leur idiome constitué dans la rue, fruit de l'exode des paysans du district alémanique de la Singine qui a contribué à peupler la basse-ville de Fribourg. Le mélange du français et du dialecte singinois a donné naissance à cet idiome commun. Roland Vonlanthen indique qu'il s'agit "d'un état d'esprit, un melting-pot de cultures franco-alémanique, campagnarde et urbaine. Des gens au caractère bien trempé et rebelles contre tout ce qui représente l'autorité ${ }^{70}{ }^{\text {». C'est }}$ pourquoi Daguet leur élève un panthéon, en exaltant leur autonomie:

Nos bolzes sont assez riches de leur propre fonds, sans être obligés à recourir à un emprunt quelconque. Les bolzes sont naturels de l'Uechtland, et qui plus est, de Fribourg seul. Les bolzes forment un peuple Autochtone. Entendez-vous bien, Autochtone ${ }^{71}$.

67. Alexandre Daguet, «De quelques essais dans le vieil idiome romand », L'Émulation, 10/1842, p. 7.

68. Voir Viviane Aeby, «Patois contre français. La querelle des "Tsévreis" », Cahiers du musée gruyérien, 5/2005, p. 39-44.

69. Alexandre Daguet, «Panthéon bolzique. Mémoires d'un sonneur de Saint-Nicolas », L'Émulation, 13/1843.

70. Voir Isabelle Eichenberger, « Nei, dasch zvüu, tu me connais! », article en ligne.

71. Alexandre Daguet, « Panthéon bolzique », op. cit., p. 103. 
Puis, après les bolzes, l'historien s'essaie à la constitution de deux autres panthéons littéraires. Le premier, dévolu à Fribourg, s'avère essentiellement militaire, puisque « le Fribourgeois est né soldat». En 1887 enfin, Daguet se fait le promoteur d'un Panthéon helvétique qu'il édifie sur l'exemple de la Walhalla constituée par Louis I ${ }^{\text {er }}$ de Bavière:

Depuis un demi-siècle et plus, nous rêvons, nous, pour la Suisse un Panthéon moins brillant, mais plus vraiment historique, un vrai temple de la gloire nationale où n'entreraient que les grandes individualités qui ont illustré réellement leur pays, dans les lettres, les arts et les sciences ou qui ont marqué dans l'Église et l'État par les services rendus. Ce temple serait placé comme la Walhalla sur une hauteur imposante qui dominerait tout le paysage. Mais les objections pleuvent lorsqu'il s'agit de la réalisation de ce beau rêve. L'argent d'abord, puis le choix du lieu et celui des personnages qui mériteraient de figurer dans ce temple de la mémoire ${ }^{72}$.

Dans son étude sur le réalisme et le romantisme en Suisse romande, Gonzague de Reynold distingue un double mécanisme structurel: le réalisme accorde aux régions et aux petites républiques nouvellement nées d'exister et de prendre conscience de leurs particularismes, de se constituer un esprit et des traditions. Quant au romantisme, il permettra aux cantons romands de s'attacher à la vieille Suisse. Ainsi, pour de Reynold, "il est naturel que le réalisme trouve surtout à s'exercer dans l'observation du milieu restreint de la cité, la patrie cantonale, et qu'on mette, en revanche, du romantisme dans l'effort de s' "helvétiser", lorsque l'on peint ou décrit les Alpes, lorsque l'on évoque l'histoire suisse $^{73}$ ». L'empreinte littéraire de Daguet peut donc se comprendre au travers de cette dialectique, cet équilibre entre romantisme national et réalisme régional. Autant de matriochkas patriotiques avec lesquelles il convenait de jongler et qui s'expliquent par les propriétés mêmes du fédéralisme suisse, partagé en trois niveaux politiques qu'il s'agissait de valoriser. Mais là encore, il ne s'agit nullement d'une spécificité helvétique, puisque l'on retrouve les mêmes phénomènes en France comme l'ont montré Anne-Marie-Thiesse et Jean-François Chanet dans leurs études sur les petites patries ${ }^{74}$. Il n'en reste pas moins, et c'est là

72. Alexandre Daguet, « Idée d'un Panthéon helvétique », L'Éducateur, 16/1887, p. 254.

73. Gonzague de Reynold, « Notre romantisme», La vie romantique au pays romand, Lausanne, Éditions Freudweiler-Spiro, 1930, p. 11.

74. À cet égard, Anne-Marie Thiesse a montré l'importance de la construction des identités locales dans le discours national, en éclairant la pédagogie de valorisation du local entreprise sous la III République. Voir A.-M. Thiesse, Ils apprenaient la France. L'exaltation des régions dans le discours patriotique, Paris, Éditions de la Maison des sciences de l'homme, 1997, ainsi que Jean-François Chanet, L'école républicaine et les petites Patries, Paris, Aubier, 1996. 
tout le paradoxe de cet homme, que Daguet historien national et littérateur s'est fait le pourfendeur de la France et, éducateur, n'a cessé de multiplier les correspondances et les amitiés outre-Rhône au nom de l'universalité de la pédagogie.

\section{Daguet pédagogue... et la France fut}

Sur les conseils du Père Girard, le jeune Daguet construit d'abord sa pensée pédagogique par l'étude des éducateurs allemands du XVIII ${ }^{\mathrm{e}}$ siècle. Ses premières références sont à chercher chez August Hermann Francke, Johann Bernhard Basedow, chez les catholiques Friedrich Eberhard Rochow et Johann Michal Sailer, chez August Hermann Niemeyer et Gustav Friedrich Dinter, les maîtres de l'école éclectique. Ainsi Daguet n'a été l'homme d'aucun système. Il a suivi sa vie durant le conseil d'une de ses maximes préférées: "Essayez tout et retenez ce qui est bon. " Il a ainsi poussé l'éclectisme et l'ouverture vers l'altérité dans des limites parfois difficilement tolérables pour ses contemporains, notamment lorsque les nations commençaient à se refermer sur elles-mêmes en dévalorisant les idées exotiques des voisins. Continuellement à l'affût de toute innovation, il s'est mis en relation avec ses homologues français. Restituer ces liens à partir de l'immense correspondance de Daguet est intéressant à plus d'un titre, car elle permet d'éclairer des réseaux effacés.

On l'a vu, c'est au congrès de Besançon, en septembre 1840, que Daguet fréquente pour la première fois le monde scientifique français et se lie avec le pestalozzien Marc-Antoine Jullien. En juin 1849, il se rapproche de Paris en devenant membre titulaire de l'Institut catholique Athénée universel, un centre de conférences sur les sciences et les techniques qui demeure également un lieu de rassemblement de l'opposition libérale au gouvernement. Daguet va par ailleurs forger des liens durables avec la Savoie, avant même qu'elle devienne française en 1860. En 1857, sur la proposition de Vincent Bouvard, il est nommé membre honoraire de l'association florimontane d'Annecy, puis de la Société savoisienne d'histoire et d'archéologie de Chambéry. Professeur au lycée impérial de cette ville, Bouvard s'est formé à Fribourg auprès du Père Girard. Rappelons que c'est un réseau tout à fait spécifique qui se met en place entre Fribourg et Chambéry, puisque Bouvard - "le père des Suisses en Savoie » - va se faire le protecteur des professeurs fribourgeois libéraux destitués sous le régime conservateur de 1857.

La guerre de 1870 déloge Jean Macé de Strasbourg, où il se consacre au soulagement des blessés, et le contraint à prendre le chemin de la 
Suisse. Le grand instigateur de la Ligue de l'enseignement, au nombre des fugitifs, s'arrête au bord du lac de Bienne, dans la première localité de langue française qu'il trouve sur sa route ${ }^{75}$. Il profite de ce séjour forcé à La Neuveville pour y donner une conférence et faire connaître sa Ligue. Il rencontre Daguet à Neuchâtel ${ }^{76}$, qui se fera dès lors un des principaux diffuseurs du credo associationniste de Macé en Suisse romande et son défenseur dans L'Éducateur:

Aussi l'œuvre de M. Macé a-t-elle fait son chemin, non seulement en France et en Algérie, mais en Belgique, en Italie, en Espagne, où il compte comme co-sociétaires des hommes comme Emilio Castelar, le recteur de l'académie De Castro et le populaire publiciste Firmin Caballero. La Ligue de l'enseignement mérite aussi toute la sympathie des instituteurs de la Suisse romande ${ }^{77}$.

De plus, il convient de s'arrêter sur la débâcle lors de la guerre franco-prussienne de l'armée de l'Est commandée par Charles Denis Bourbaki (1816-1897) et sur son internement en Suisse à la fin janvier 1871 : il favorisa un transfert de savoirs scolaires entre la Suisse romande et la France. James Guillaume, témoin des événements, raconte l'entrée des troupes françaises dans la ville de Neuchâtel:

Le 29 janvier et les jours suivants, j'assistai au lugubre défilé de l'armée Bourbaki, qui traversa presque toute entière la ville de Neuchâtel. Ce spectacle nous donna l'ineffaçable impression des atroces réalités de la guerre. Je vois encore les malheureux Français, lignards, zouaves, turcos, mobiles, dragons, descendant en une interminable colonne, incessamment renouvelée, la route des Terreaux, mornes, lamentables, affamés, écrasés de fatigue, les pieds presque toujours enveloppés de linges ou de paille. On ne pouvait pas, dans une ville de quinze mille habitants, loger trente à quarante mille hommes; la troupe bivouaquait où elle pouvait; la nuit venue, des soldats incapables de faire un pas de plus, restaient affalés dans la rue, sur les trottoirs, grelottants; j'en recueillis une trentaine, deux soirs de suite, dans le local de l'imprimerie; pendant ce temps, certains jeunes officiers, des bonapartistes assurément, sans s'occuper de leurs hommes, s'attablaient dans les cafés où la population, indignée, les huait. De toutes parts, les habitants s'empressaient pour soigner les blessés, les éclopés aux

75. Alexandre Daguet, «M. Jean Macé, à Neuveville, et la Ligue de l'enseignement en France », L'Éducateur, 20/1870, p. 307.

76. « Nous regrettons vivement qu'il n'ait pas jugé à propos de se fixer à Neuchâtel, où nous avons eu cependant l'occasion de le voir et de nous entretenir avec cet homme aussi intéressant que distingué », (A. Daguet, « M. Jean Macé, à Neuveville », op. cit., p. 307).

77. Ibid. 
pieds gelés, les malades, qu'on installa dans les écoles et dans un temple, transformés en infirmerie; chacun leur apportait des provisions, des vêtements, du linge, des chaussures. Au bout de quelques jours, la plus grande partie de l'armée avait été disséminée en différentes régions de la Suisse, et il ne resta à Neuchâtel et aux environs que quelques milliers d'hommes. Ces pauvres gens avaient apporté avec eux toutes sortes de maladies, entre autres la petite vérole noire, qui sévit pendant plusieurs mois à Neuchâtel. Les membres de l'Internationale furent parmi les plus zélés à se dévouer comme infirmiers volontaires; et quelques-uns d'entre eux, qui se trouvèrent avoir la vocation, se transformèrent pendant un certain temps en infirmiers professionnels, rétribués par la ville ${ }^{78}$.

Stéphane José Gaggero a analysé le zèle déployé par les autorités scolaires romandes pour occuper et scolariser ces soldats français ${ }^{79}$. En février 1871, le conseil d'État du canton de Vaud décide de leur organiser des conférences afin de pourvoir à leur instruction. À raison d'une heure par jour, des professeurs et des intervenants bénévoles dispensent des cours d'histoire, d'hygiène et de morale républicaine: " on leur développa les premiers principes de l'instruction civique, on exposa la Constitution qui régit la Suisse, sa situation politique, industrielle, commerciale, son organisation intérieure, civile et militaire ${ }^{80}$ ». On observe un déroulement similaire à Genève, où le régent Paul Pautry donne des cours de trois heures et demie par jour à une centaine d'internés. Ces leçons servent également de laboratoire pédagogique durant lesquelles le régent teste notamment diverses méthodes de lecture. Pareille situation à Fribourg, où tous les établissements d'instruction publique ont été évacués par les indigènes et ont servi à l'internement des militaires français. À cet égard, Daguet espère un transfert des valeurs républicaines vers la France:

Si les tristes événements qui viennent de s'accomplir, ont été généralement nuisibles à la cause de l'instruction populaire, espérons au moins que le séjour momentané de 85000 soldats français en Suisse, aura pour conséquence le développement des institutions démocratiques en France. En général, les internés ont su apprécier les bienfaits de la liberté dont nous jouissons dans notre heureux pays; ils ont compris que la paix, la prospérité et le bonheur d'un peuple, sont facilités grandement par la République. Puissent-ils, de retour dans leurs foyers, transmettre

78. James Guillaume, L'internationale: documents et souvenirs (1864-1878), t. II, III partie, chap. VI, p. 2.

79. Voir Stéphane José Gaggero, Politique d'accueil de l'armée Bourbaki, février-mars 1871, université de Neuchâtel, mémoire de master, 2010, notamment p. 58-70.

80. Rapport Davall, cité par Stéphane José Gaggero, op. cit., p. 61. 
à leurs compatriotes les idées qu'ils ont puisées en Suisse, en se rappelant toutefois que la démocratie sans l'instruction est une chimère ${ }^{81}$.

La guerre de 1870 mit indirectement Daguet en relation avec l'économiste Frédéric Passy, qui recevra en 1901 le premier prix Nobel de la paix avec Henri Dunant. Passy découvre en effet un article de Daguet dans le Progrès de Bruxelles. Interpellé par son plaidoyer contre la guerre franco-prussienne ${ }^{82}$, il lui écrit afin de reproduire ses lignes dans l'organe de la Société française des amis de la paix. Cet échange est à l'origine d'une amitié et d'une correspondance de plus de vingt ans, basée sur la conviction commune qu'une régénération de la société est possible via l'éducation pacifiste de la jeunesse: "La lutte est plus que jamais entre la barbarie et la civilisation; et c'est à l'éducation de l'enfance qu'appartient la perte ou le salut de la Société européenne ${ }^{83}$ " écrit Passy en 1871. C'est que ce promoteur de l'instruction populaire demeurait particulièrement attentif à ce qui se faisait en Suisse française. En 1871, afin de mieux faire connaître la pédagogie romande en France, il propose à Daguet de soumettre L'Éducateur aux instituteurs français via le canal de la fameuse bibliothèque Franklin ${ }^{84}$.

Suite au traumatisme de 1871 et au passage de Ferdinand Buisson à Neuchâtel, on note une évolution dans les rapports qu'entretient Daguet avec la France. Dorénavant, c'est essentiellement avec le monde protestant qu'il correspond. Il faut notifier qu'une erreur de Gustave Vapereau, qui l'introduit en France dans L'année littéraire de 1868 en tant qu' " historien dévoué au protestantisme ${ }^{85}$ " va achever d'établir sa réputation. Daguet rencontre probablement Henri Bordier (1817-1888) durant l'été 1863, lorsque ce dernier passe par Fribourg pour se rendre à Munich. Cet historien protestant, diplômé de l'École nationale des chartes, quitta comme Michelet son poste d'archiviste aux Archives nationales par opposition à Napoléon III, mais aussi afin de constituer la Bibliothèque du protestantisme français. À cet effet, il avait l'habitude de séjourner chaque été à Genève et de mener ainsi

81. Alexandre Daguet, « Correspondance de Fribourg », L'Éducateur, 8/1871, p. 121-122.

82. Alexandre Daguet, «La guerre de 1870. L'Humanité recule, instituteur, as-tu fait ton devoir? », L'Éducateur, 18/1870, p. 273-274.

83. Lettre de F. Passy à Daguet, Pornic, 16 avril 1871, AEN, Fonds Daguet.

84. Lettre de F. Passy à Daguet, Neuilly-sur-Seine, 3 avril 1871, AEN, Fonds Daguet.

85. Gustave Vapereau, L'année littéraire et dramatique ou Revue annuelle des principales productions de la littérature française et des traductions des œuvres les plus importantes des littératures étrangères, classées et étudiées par genres, Paris, Hachette, 1868, p. 255-256. 
des recherches pour travailler sur une nouvelle édition de La France protestante (1877-1888), restée inachevée. Bordier profita largement des connaissances historiques de Daguet, leurs échanges se focalisant d'ailleurs sur les mythes fondateurs de la Suisse dont Bordier s'était fait une petite spécialité. C'est lui qui recommande le célèbre publiciste Édouard Charton (1807-1890) à son ami. Le fameux rédacteur du Magasin pittoresque souhaite en effet se rendre en Suisse romande afin d'étudier divers systèmes scolaires cantonaux:

Je suis persuadé que M. Édouard Charton n'aura pas moins de plaisir à vous entendre. Toutefois le but de son voyage est de recueillir des renseignements et non des compliments. Presque tous ceux qui savent lire connaissent le Magasin Pittoresque et peuvent croire sans peine que celui qui dirige depuis 40 ans cette excellente publication a été toute sa vie préoccupé de pédagogie. C'est donc un de vos confrères, mon cher Professeur, jadis élève de Pestalozzi et du Père Girard. Je n'ai pas besoin de plus longue introduction pour être persuadé que Monsieur Charton et vous aurez tous deux plaisir à causer ensemble et je vous recommande seulement de boire à ma santé. Ne vous gênez pas pour placer dans vos entretiens la démagogie à côté de la pédagogie, car $\mathrm{M}$. Charton siège à notre Assemblée nationale de Versailles sur des bancs dont le rouge peut $s^{9}$ harmoniser avec votre républicanisme ${ }^{86}$.

Charton visite les écoles neuchâteloises le 8 mai 1873, au titre de délégué cantonal de la Seine-et-Oise et de député. Son affectation récente au musée pédagogique (1872) prononcée par Jules Simon n'est certainement pas étrangère à ce bref séjour d'études. Il passe un jour et demi dans l'ancienne cité prussienne, y rencontre Daguet ainsi qu'un libraire et visite le musée ${ }^{87}$. Le lendemain il est à Lausanne et écrit à sa femme: " J'ai passé utilement plusieurs heures: mais j'espère bien en apprendre plus ici sur l'instruction primaire. Le professeur Daguet m'a donné quelques mots de recommandation ${ }^{88}$. " À partir de cette rencontre, les deux érudits échangent une amitié sincère et complice. Charton va publier plusieurs textes de son confrère suisse dans le Magasin pittoresque: "Mon intention est de vous faire d'autres emprunts: je serai toujours heureux de vous citer. Nous avons, ce me semble, même but

86. Lettre de H. Bordier à Daguet, Paris, 5 mai 1873, AEN, Fonds Daguet.

87. Lettre de É. Charton à sa femme Hortense, Neuchâtel, 9 mai 1873, in Édouard Charton, Correspondance générale 1824-1890, vol. II, éditée et annotée par Marie-Laure Aurenche, Paris, Honoré Champion Éditeur, 2008, p. 1638.

88. Ibid, p. 1639. 
et mêmes sympathies ${ }^{89}$ ", lui écrit-il en février 1875 . Cette unité de vues s'explique par l'intérêt que les deux hommes vouent à l'œuvre du Père Girard. Rappelons que Charton fut le rédacteur du Bulletin de la société pour l'instruction élémentaire qui fit connaître l'enseignement mutuel sur le continent. Après 1848, ce saint-simonien fut appelé par Hippolyte Carnot au poste de secrétaire général du ministère de l'Instruction publique. Or, Carnot tenta de naturaliser la pédagogie de Girard en France. Nul hasard, donc, si Charton quémande à plusieurs reprises quelques textes du cordelier auprès de Daguet:

Avez-vous publié votre livre sur le P. Girard? En ce moment, j’ai soif de tout ce qui se rapporte à cet excellent homme: mais il est extrêmement difficile de se procurer ses écrits: les uns ne sont plus dans le commerce, les autres sont dans des recueils, qu'on ne trouve pas aisément. La notice de M. Ernest Naville est bonne, mais bien courte. Je ne compte que sur vous ${ }^{90}$.

Mais c'est son Manuel de pédagogie, publié chez le frère de James Guillaume, qui intéresse Charton:

Je suis ravi de votre manuel. C'est le meilleur de tous ceux que je connais. J'ai passé presque toute ma journée à le lire et à en faire des extraits. Je ne vois pas une seule de vos considérations qui ne me paraisse juste. Vous avez réveillé en moi le regret que j'ai eu longtemps de ne pas m'être fait instituteur: j'avais, je crois, la vocation. Je vous citerais plus d'une fois ${ }^{91}$.

Avant qu'il soit refondu dans un ouvrage en 1871, on rappellera que ce cours fut diffusé dans L'Éducateur en quarante-cinq livraisons, espacées entre 1865 et 1868 . De ce fait, Daguet a touché la moitié $\mathrm{du}$ corps enseignant romand et a pu poser sa vision sur la manière d'appréhender la pédagogie en Suisse romande. Pour autant, c'est de France qu'il reçoit des messages enthousiastes. Bonaventure Berger, le directeur du musée pédagogique, lui fait savoir que «[son] Manuel de pédagogie est au nombre des ouvrages de [la] Bibliothèque circulante et il est très demandé ${ }^{92}$ » et Charles Defodon lui écrit:

Vous ne m'avez pas envoyé votre Manuel de pédagogie, et je le regrette d'autant plus que, d'après une table des matières que j'ai trouvée dans un catalogue de la librairie Sandoz, il me semble que je pourrais en faire usage dans mon cours à l'École normale, et me donner ainsi l'agréable

89. Lettre de É. Charton à Daguet, Versailles, 10 février 1875, AEN, Fonds Daguet.

90. Lettre de É. Charton à Daguet, Versailles, 18 mai 1875, AEN, Fonds Daguet.

91. Lettre de É. Charton à Daguet, Versailles, 20 avril 1873, AEN, Fonds Daguet.

92. Lettre de B. Berger à Daguet, Paris, 2 mai 1882, AEN, Fonds Daguet. 
occasion d'en recommander la lecture à mes jeunes Normaliens; je pense que je pourrais de même en dire de temps en temps quelques mots dans le Manuel général. J'espère donc que vous voudrez bien m'en adresser un exemplaire ${ }^{93}$.

À partir de 1877, et plus encore après l'accession de Buisson à la direction de l'instruction primaire en février 1879, Daguet joue le rôle de référence suisse pour les pédagogues de la $\mathrm{III}^{\mathrm{e}}$ République. En mai 1878, peu avant l'Exposition universelle, l'inspecteur général Guillaume Jost vient chercher des renseignements auprès de Daguet:

Mon ami, M. Defodon, rédacteur de notre Manuel de l'enseignement primaire, m'autorise à me recommander de lui pour vous demander un renseignement sur la Suisse, et, le cas échéant, un service [...]. Je dois préparer en vue de l'Exposition universelle un travail sur l'histoire, le développement, les résultats, la situation actuelle des conférences d'instituteurs en France et à l'étranger, et il me semble que sous ce rapport la Suisse occupe une place honorable pour le développement de cette institution si utile aux instituteurs, et peut être citée comme exemple ${ }^{94}$.

Clovis Lamarre, administrateur du collège Sainte-Barbe, vient s'enquérir de renseignements analogues: "Je dois publier chez M. Delagrave, éditeur, une vingtaine de volumes sur les nations qui prennent part à l'exposition, et j'ai pensé qu'il serait agréable à un citoyen de la Suisse de rédiger lui-même le travail qui concerne son pays $^{95}$."

À soixante ans, Daguet s'est peu à peu imposé comme une tête de pont de la pédagogie franco-romande. Quand bien même le Conseil fédéral décide en dernier lieu de ne pas l'envoyer à Paris pour examiner l'Exposition universelle de 1878, il est élevé au rang d'officier d'académie sous le ministère Bardoux le 3 janvier 1879. Si Daguet a vécu un cheminement scientifique tourmenté dans son pays, marqué par deux exils ${ }^{96}$, c'est davantage à l'international qu'il s'est fait un nom. Ferdinand Buisson n'y est pas étranger, lui qui a constamment diffusé et valorisé les écrits de son collègue en France. Avant de devenir la cheville ouvrière de l'école républicaine, Buisson a trouvé refuge en

93. Lettre de C. Defodon à Daguet, Paris, 17 septembre 1874, AEN, Fonds Daguet.

94. Lettre de G. Jost à Daguet, Paris, 29 mai 1878, AEN, Fonds Daguet.

95. Lettre de C. Lamarre à Daguet, Paris, 20 février 1878, AEN, Fonds Daguet.

96. Persécuté par les ultramontains fribourgeois, il quitte sa ville natale pour diriger l'école normale de Porrentruy dans le Jura bernois entre 1843 et 1848. En 1866, il s'installe définitivement à Neuchâtel où l'académie l'a nommé professeur d'histoire et de pédagogie. 
Suisse romande, comme beaucoup d'autres irréconciliables. Mélangés aux autres réfugiés européens présents dans le repli helvétique et aux intellectuels du cru, ces proscrits français seront les acteurs mais aussi les premiers spectateurs d'une Suisse moderne en construction et dont James Guillaume résume l'émulation:

Si nous pouvions bavarder, je vous raconterais une foule d'anecdotes et de détails, je vous ferais revivre tout ce milieu neuchâtelois de 1856 à 1866, où le hasard des circonstances avait amené tant de personnalités intéressantes: les Français Versigny, Cantagrel, Chaudey, Erdan, Pascal Duprat, Pierre Leroux, $\mathrm{M}^{\mathrm{lle}}$ Clémence Auguste Royer (la traductrice de Darwin); les Allemands Karl Vogt et Édouard Desor, Moleschott, Gressly (Soleurois), l'Américain T. Barker, puis les champions du protestantisme libéral français d'alors: Félix Pécaut, Albert Réville, Jules Steeg et leur disciple F. Buisson, etc., etc. ${ }^{97}$

Dès 1852, ce sont donc des exilés soucieux de recueillir des références spécifiques qui s'organisent dans leur fourmilière helvétique. Edgar Quinet incarne à l'évidence la figure tutélaire des irréconciliables en Romandie, la conscience de la France hors de France.

97. Cité par Marc Vuilleumier, « James Guillaume, de l'esprit libertaire dans la I ${ }^{\text {re }}$ Internationale », http://www.increvables-anarchistes.org/articles/themes/biographies/james-guillaume 


\section{3 \\ Des irréconciliables en Romandie}

Nous étions, en France, un groupe de jeunes républicains "irréconciliables » nourris de la lecture des Châtiments, abhorrant l'homme et le régime du 2 décembre. Nos maîtres, avec Victor Hugo, c'étaient ceux qu'on appelait «les proscrits » et le premier de tous, Edgar Quinet, que nous allions saluer d'un pieux enthousiasme dans son exil de Veytaux.

Ferdinand Buisson, Souvenirs, $1916^{1}$

Sous le Second Empire, la Suisse est perçue de manière tout à fait contrastée. Pour les républicains français qui s'y installent suite au coup d'état du 2 décembre 1851 et prennent par là même le surnom d'irréconciliables, elle est symbole de liberté; d'autres la fustigent de manière plutôt véhémente. Dans la Revue des Deux Mondes, SaintRené Taillandier énonce en 1852 que la Suisse actuelle incarne "un des foyers les plus actifs de la perversité et de la corruption sociale, l'asyle (sic) des enfants perdus de l'athéisme germanique ${ }^{2}$ ». Arthur de Gobineau s'inscrit dans d'analogues perspectives et écrit de Berne à Tocqueville: "La position centrale de la Suisse en fait un club permanent des réfugiés les plus agressifs pour nous, pour l'Italie et pour l'Allemagne ${ }^{3}$.» Relativement peu étudié, ou de manière indirecte, le rôle des proscrits et des réfugiés européens fuyant la répression

1. Ferdinand Buisson, Souvenirs (1866-1916). Conférence faite à l'Aula de l'université de Neuchâtel le 10 janvier 1916, Paris, Librairie Fischbacher, 1916, p. 10.

2. Cité par Alexandre Daguet, « Littérature populaire », L'Émulation, 1/1852, p. 69.

3. Correspondance d'Alexis de Tocqueville et d'Arthur de Gobineau, in Alexis de Tocqueville, CEuvres complètes, t. IX, Paris, Gallimard, 1959, p. 168. 
antilibérale d'Allemagne, d'Italie et de France, mériterait une étude globale sur la durée, afin de disséquer leur réelle implication dans l'élaboration de la Suisse moderne. Réclamée dès les années 1970 par l'historien suisse Marc Vuilleumier, l'entreprise n'est pas aisée et reste sujette à maintes résistances ${ }^{4}$. Alain-Jacques Tornare fait remarquer que «ce qui était insupportable déjà à l'époque, c'était le poids de l'étranger dans la formation, la réalisation de la Suisse ${ }^{5}$ ». Que l'on pense pourtant à l'itinéraire helvétique des frères Ludwig et Wilhelm Snell, qui émigrent en Suisse alémanique en 1824. Il ne fait nul doute que le projet de constitution libérale (mémorial de Küssnacht) proposé par Ludwig Snell a profondément pesé sur la rénovation de l'État comme sur l'avènement du radicalisme suisse ${ }^{6}$. Il en va de même du réfugié politique italien Pellegrino Rossi (1787-1848), le rapporteur de la commission chargée d'élaborer un projet d'acte fédéral lors de la Régénération. Blaise Extermann a par ailleurs souligné le rôle des réfugiés dans la structuration de l'enseignement de l'allemand en Suisse romande, en suivant l'itinéraire de figures marquantes comme Stephan Born, Hermann Krauss ou le catholique Jean Kleiser ${ }^{7}$. Il ne s'agit bien évidemment pas, dans ce chapitre, de dresser une histoire totale des émigrés ayant séjourné en Suisse romande. On se concentrera plutôt sur une minorité, les irréconciliables français, regroupés autour d'Edgar Quinet. Si certains d'entre eux, à l'instar de Max Buchon, possédaient déjà une certaine expérience de la Suisse avant le coup d'État, la plupart des figures majeures de la proscription du 2 décembre y affluent entre 1852 et 1858 :

4. Marc Vuilleumier, «Quelques jalons pour une historiographie du mouvement ouvrier en Suisse », Cahiers Vilfredo Pareto, Genève, t. XI, 29/1973, p. 5-35. Voir également du même, Histoire et combats. Mouvements ouvriers et socialisme en Suisse 1864-1960, Lausanne, Éditions d'en Bas et collège du travail, 2012.

5. Alain-Jacques Tornare, « Cinq dates qui ont changé la Suisse », L'Hebdo, mis en ligne le 25.07.2012.

6. Voir Olivier Meuwly, Les penseurs politiques du 19e siècle. Les combats d'idées à l'origine de la Suisse moderne, Lausanne, Presses polytechniques et universitaires romandes, 2007, p. 68-69 ; Anton Scherer, Ludwig Snell und der schweizerische Radikalismus (18301850), Freiburg, Paulusdruck, 1954 ; Stefan G. Schmid, « Ludwig Snell : ein Revolutionär in Küsnacht », Küsnachter Jahrheft, 45/2005, p. 67-75.

7. Blaise Extermann, Une langue étrangère et nationale. Histoire de l'enseignement de I'allemand en Suisse romande (1790-1940). Neuchâtel, Éditions Alphil, 2013. 


\begin{tabular}{lcc} 
Proscrits & Lieux & Durée \\
\hline Jules Barni (1818-1878) & Genève & $1861-1870$ \\
\hline Ferdinand Flocon (1800-1866) & Lausanne & $1851-1866$ \\
\hline François Auguste Bruckner (1814-1876) & Lausanne & $1857-1876$ \\
\hline Pascal Duprat (1815-1885) & Lausanne & $1856-1865$ \\
\hline Clémence Royer (1830-1902) & Lausanne & $1860-1865$ \\
\hline Pierre Leroux (1797-1871) & Lausanne & $?-1869$ \\
\hline Edgar Quinet (1803-1875) & Veytaux & $1858-1870$ \\
\hline Victor Versigny (1819-1872) & Neuchâtel & $1851-1864$ \\
\hline François-Jean-Félix Cantagrel (1810-1887) & Neuchâtel & $1857-1859$ \\
\hline Georges Joseph Schmitt (1813-1875) & Fribourg & $1852-1870$ \\
\hline Max Buchon (1818-1869) & Berne & $1851-1859$ \\
\hline Jean-Baptiste-Adolphe Charras (1810-1865) & Bâle & $1858-1865$ \\
\hline Victor Chauffour (1819-1889) & Bâle & $1852-1859$ \\
\hline Marc Dufraisse (1811-1876) & Zurich & $1855-1870$
\end{tabular}

Comment s'insèrent-ils dans le tissu helvétique et comment s'organisent leurs réseaux? Ont-ils joué un rôle de médiation entre leur patrie d'origine et leur terre d'accueil ? On abordera ces questions à travers l'itinéraire du Salinois Max Buchon (1818-1869) dont l'amitié avec Alexandre Daguet demeure minutieusement consignée dans une correspondance de plus de trente lettres qui s'étend de 1841 à 1868 . Buchon fut, avec le peintre Gustave Courbet, l'un des deux FrancsComtois accueillis et protégés par Daguet suite au 2 décembre pour l'un, et à la Commune de Paris pour l'autre. On soulignera surtout que Buchon entreprit, à l'instar de Daguet et grâce à ses séjours en Suisse et en Allemagne, un travail de déconstruction de la littérature française par la médiation d'une littérature germano-alémanique populaire et réaliste. De plus, l'itinéraire de ce passeur interculturel nous invite à réfléchir au rôle et à la condition de l'exilé en Suisse romande, comme à celui des intellectuels des provinces françaises. En effet, revendications romandes en Suisse et provinciales en France s'avéraient globalement connexes. Ainsi, Paris, cœur de la France, ne pouvait battre sans l'apport du sang des provinces pensées comme l'incarnation de la nation ${ }^{8}$.

8. Daniel Maggetti, L'Invention de la littérature romande 1830-1910, Lausanne, Payot, 1995, p. 121. 


\section{Entre les rives, Max Buchon}

Qui se cache derrière ce médiateur passionné, ce personnage complexe dont l'itinéraire se résume dans une de ses formules: "L'Allemagne, voilà toujours mon rêve au point de vue de l'art et Fourier mon oracle (sic), au point de vue de la croyance ${ }^{9}$ ? " Curieusement, les études ${ }^{10}$ consacrées à Max Buchon contrastent par leur nombre avec l'attitude modeste et réservée de cet auteur dont Frédérique Desbuissons montre qu'il n'a jamais véritablement cherché à s'imposer à Paris ${ }^{11}$. Bien davantage que la gloire personnelle, c'est sa passion pour la médiation interculturelle qui a guidé son existence. Buchon n'a cessé de multiplier les points de contact, s'incarnant en courtier d'idées entre les espaces germanique et latin. La connaissance de l'altérité le poussait continuellement à exhorter ses amis français à ouvrir les yeux vers l'extérieur: "Allez donc voir ce qui se passe en Russie, en Angleterre, en Hollande, en Allemagne, partout; et vous comprendrez combien ils ont de glorieux complices au dehors, ceux de nos artistes qui s'appliquent si intrépidement à l'interprétation de la vie moderne ${ }^{12}$."

Natif de Salins tout comme Victor Considerant, Max Buchon fréquente le petit séminaire d'Ornans avec son lointain cousin Gustave Courbet. Son père, un ancien officier d'Empire, l'envoie dès 1834 à Fribourg en Suisse chez les jésuites de Saint-Michel, comme il est de bon ton dans les familles franc-comtoises, surtout depuis les ordonnances de juin 1828 promulguées sous le ministère Martignac. Buchon fréquente rapidement le cercle des patriotes libéraux-nationaux et se lie avec deux de ses condisciples, Alexandre Daguet et le poète gruyérien Nicolas Glasson. Rappelé par son père trois ans plus tard, Buchon revient à Salins sans diplôme. Ce premier séjour helvétique s'avère toutefois déterminant, puisque le Franc-Comtois y fonde l'ambition de consacrer sa vie à l'écriture. Les rentes léguées par sa mère facilitent un

9. Lettre de M. Buchon à Daguet, Salins, 9 novembre 1844, AEN, Fonds Daguet.

10. Voir notamment la thèse de Hugo Frey, Max Buchon et son œuvre, Besançon, Imprimerie de l'Est, 1940 et celle de Janine Joliot-Anguenot, Max Buchon, romancier réaliste et régionaliste, université de Besançon, 1980. Sur l'œuvre littéraire de Buchon, voir Rudolph Zellweger, Les débuts du roman rustique: Suisse, Allemagne, France, 1836-1856, Paris, E. Droz, 1941 et l'introduction de Frédérique Desbuissons dans Max Buchon, Le réalisme. Discussions esthétiques recueillies et commentées, La Rochelle, Rumeurs des Âges, 2007.

11. Frédérique Desbuissons, op. cit., p. 14.

12. Max Buchon, CEuvres choisies, Paris, Sandoz et Fischbacher, 1878, p. 3. 
engagement littéraire qui le mène d'abord à Milan en repassant par la Suisse, puis en Allemagne.

Royaliste et dévoué d'abord à un romantisme pondéré ${ }^{13}$ - il avait publié un recueil dédié à la duchesse d'Orléans ${ }^{14}$ - la découverte de l'Allemagne et de ses poètes rustiques hâte sa conversion littéraire et politique. Vers la fin de l'an 1844, Buchon consacre ses premières traductions aux Poésies alémaniques de Johann Peter Hebel (17601826). Initié au dialecte par le Badois Scheibel, un ouvrier ébéniste qu'il rencontre à Salins, il s'attache ensuite à la traduction ${ }^{15}$ de quatre références majeures qui lui permettent d'embrasser l'ensemble de la poésie populaire germanique:

Je m'en suis tenu à ces quatre poètes-là parce qu'ils m'ont paru représenter chacun une manière bien distincte de la poésie allemande. Hebel, d'abord, ne ressemble à personne! Uhland le légendaire, et le libéral résume parfaitement pour nous autres Français la manière de Brentano. Koerner personnifie toute la clique de 1813, Arndt, Schenkendorf et Rückert. Tandis que M. Heine me semble être pour l'Allemagne ce qui est à la France notre Alfred de Musset ${ }^{16}$.

En janvier 1845, ses ambitions littéraires se précisent et il écrit à son ami Daguet: "Je voudrais me faire une petite spécialité de l'Allemagne et de la littérature allemande, dont on ne connaît en France que des noms. Je t'avoue que je suis tout honteux, moi qui ne vis que de littérature, de ne connaître Hebel par exemple que depuis quelques mois et Uhland depuis 2 ans ${ }^{17}$ ! » Malgré les encouragements d'un ami médecin qui l'incite à tenter sa chance à Baden Baden, il publie finalement ce recueil chez lui à Salins ${ }^{18}$. En filigrane se dessine l'ambition médiatrice de Buchon: la culture et le progrès doivent rapprocher les deux rives

13. Hugo Frey, op. cit., p. 33.

14. Alexandre Daguet, « Nécrologie de Buchon », L'Émulation, 1/1870, p. 13.

15. Sur la traduction de la poésie allemande en langue française, voir notamment Michel Espagne, «La fonction de la traduction dans les transferts culturels franco-allemands aux XVIII ${ }^{e}$ et XIX siècles. Le problème des traducteurs germanophones », Revue d'histoire littéraire de la France, n³, 1997, p. 413-427; Henri Van Hoof, Histoire de la traduction en Occident, Paris, Éditions Duculot, 1991; Christine Lombez, La traduction de la poésie allemande en français dans la première moitié du XIXe siècle. Réception et interaction poétique, Tübingen, Max Niemeyer Verlag, 2009.

16. Lettre de M. Buchon à Daguet, Salins, 20 janvier 1845, AEN, Fonds Daguet.

17. Ibid.

18. Max Buchon, Poésies allemandes de J.-P. Hébel, Th. Koerner, L. Uhland, H. Heine, Salins, Imprimerie de G. Mareschal, 1846. 
du Rhin et il escompte, malgré " tant de fâcheuses et gratuites préventions » que "les voies de fer aideront bientôt à ce rapprochement si désirable ${ }^{19} »$.

Buchon prend ses quartiers à Tübingen vers la fin 1846 et réalise ainsi son rêve allemand. Il fréquente rapidement le philologue Karl Moritz Rapp (1803-1883), qui consacre une élogieuse recension de ses Poésies allemandes dans les Annales du présent (Jahrbücher der Gegenwart) de février $1847^{20}$. Buchon professe des leçons de français et approche ainsi plusieurs personnalités de l'Université. Non sans sarcasme, il confie à Daguet qu'il a " pour élève le professeur Vischer, professeur d'esthétique, et le privat-docent Schwegler, deux amis de Zeller, tous deux hégéliens, qui ont dû savoir, de l'érudition en masse; cela patauge dans le grec et l'hébreu, comme dans du vrai duvet, cela se croit libre penseur ${ }^{21}$ ". Il y fait également la rencontre d'un ami de Daguet, le Neuchâtelois Félix Bovet (1824-1903)22. Celui-ci l'encourage à aller visiter Ludwig Uhland, réputé pour ses colères monumentales. À Tübingen, Buchon n'a vraisemblablement d'autres ambitions que ses traductions, envoyées au fur et à mesure à l'éditeur neuchâtelois Wolfrath qui les écoule dans sa Revue suisse.

Très actif politiquement dès son retour à Salins, élu conseiller municipal, Buchon s'engage avec les radicaux bisontins pour l'élection de Ledru-Rollin à la présidence de la République. Amené au fouriérisme par Victor Considerant vers 1838, puis disciple de Proudhon, il tombe sous le coup d'un mandat d'arrêt au lendemain du coup d'État du 2 décembre 1851. Il trouve refuge chez Daguet à Fribourg, puis s'installe à Berne. Dans la capitale helvétique, il projette un temps d'entreprendre la traduction complète en prose des poésies de Heinrich Heine $^{23}$, mais la découverte du Banerndichter bernois Albert Bitzius (1797-1854), connu sous le pseudonyme de Jeremias Gotthelf, l'incite à se vouer à d'autres projets ${ }^{24}$. Gustave Courbet séjourne quelque temps à Berne en septembre 1854, alors que Champfleury (1821-1889) rejoint

19. Ibid., p. 11.

20. Voir Max Buchon, Hébel et Auerbach. Scènes villageoises de la Forêt-Noire, Paris, Borrani et Droz, Berne, Dalp, 1853, p. XIII-XIV.

21. Lettre de M. Buchon à Daguet, Tübingen, 12 février 1847, AEN, Fonds Daguet.

22. Sur la relation épistolaire entre Bovet et Buchon, voir Henri Perrochon, Un ami d'Alexandre Daguet et de Félix Bovet, op. cit., p. 208-210.

23. Lettre de M. Buchon à Daguet, Berne, 13 janvier 1854, AEN, Fonds Daguet.

24. Sur Gotthelf, voir le chantier consacré aux commentaires de son œuvre, dirigé notamment par Marianne Derron et Christian von Zimmermann (www.gotthelf.unibe.ch). 
Buchon dans la capitale helvétique en juin 1855. De ces rencontres naît l'idée de composer un essai sur le réalisme, que Buchon publie bientôt dans L'Indépendant de Neuchâtel tenu par Victor Versigny, un autre irréconciliable exilé en Suisse ${ }^{25}$.

En outre, le Franc-Comtois s'initie au bärntütsch (dialecte bernois) avec une vieille dame sensible à ses charmes. Il publie ses Nouvelles bernoises à Paris et à Berne en 1854, mais son public tarde à se faire entendre. Amer, Buchon souffre de l'incompréhension de son entreprise de médiation: "Je ne chercherai à éditer le Gotthelf en Suisse qu'en désespoir de cause [...] je peux faire plus d'argent peut-être qu'en France, mais si je ne réussis pas à faire accepter Gotthelf à Paris, dans 50 ans, il n'y sera toujours pas plus connu qu'aujourd'hui ${ }^{26}$. » Il faut dire que ses traductions rencontrent une réception contrastée. Daguet, par exemple, n'hésite pas à utiliser le terme de trahison: "Je puis dire trahir, malgré la fidélité et le talent remarquable de la traduction, car un poète comme Hebel ne peut être lu et goûté dans toute sa suavité qu'en allemand et dans le dialecte même qui a donné naissance à ses inimitables créations ${ }^{27}$. " Il y avait donc de la témérité à vouloir traduire du dialecte alémanique en français, alors que Buchon voyait dans ce procédé un acte innovant ${ }^{28}$.

\section{Autour d'un transfert triangulaire}

L'écrivain romantique Charles Magnin, originaire de Salins comme Max Buchon, avait prédit que le XIx ${ }^{\mathrm{e}}$ siècle serait l'âge de l'esthétique ${ }^{29}$. S'essayer à un bilan littéraire de Max Buchon implique obligatoirement d'analyser son œuvre sous le prisme d'une médiation esthétique opérée entre l'Allemagne, la Suisse et la France. Comme l'indique Hugo Frey, c'est au-dehors, à l'étranger, que Buchon demandait le secret du

25. La publication se fait en vingt-cinq livraisons entre le 7 décembre 1855 et le 21 mars 1856. Le recueil est publié à cent exemplaires à Neuchâtel chez Attinger la même année.

26. Lettre de M. Buchon à Daguet, Salins, 5 janvier 1858, AEN, Fonds Daguet.

27. L'Émulation, 13/43, p. 105.

28. « Le mode des traductions que j'ai entreprise n'a été employé par personne; et nous ne pondrons en français que quelques traductions en prose de quelques bien rares morceaux allemands. Voilà le charme de ce qui entre autre a été cru bien longtemps intraduisible en vers, j'en suis persuadé » (lettre de M. Buchon à Daguet du 9 novembre 1844, AEN, Fonds Daguet).

29. Cité par Jean-Louis Cabanès (dir.), Romantismes, I'esthétique en acte, Paris, Presses universitaires de Paris-Ouest, 2009. 
réalisme ${ }^{30}$. Nourri des poèmes rustiques de Hebel, d'Auerbach, de Körner ou de Gotthelf, il tenta d'imposer une esthétique nouvelle en important les outils culturels des poètes alémaniques qu'il souhaitait naturaliser dans une France qu'il jugeait en retard: "En 1843, les paysanneries littéraires plus ou moins frelatées qui nous ont inondés depuis, n'étaient point écloses. Nos plus grands maîtres en étaient encore, ou peu s'en faut, à essayer le paysage littéraire. Sous ce rapport, les poésies allémaniques (sic) les avaient triomphalement devancés d'environ quarante ans ${ }^{31}$. " À l'image de littérateurs romands comme Rodolphe Töpffer ou Henri-Frédéric Amiel, le Franc-Comtois se livre à un travail de nettoyage en soulignant l'impéritie des Parisiens à ressentir l'âme helvétique: "Ces badauds de Paris, ils ont pour eux sans doute l'aménité des formes, la mélodie du langage, la désinvolture des manières, mais eux, ils n'ont pas comme vous une patrie. Ils n'ont vu la nature, ils ne l'ont étudié qu'au jardin du Luxembourg, au coin de la rue où ils sont nés ${ }^{32}$. " À Fribourg et plus généralement en Suisse française, Buchon suscita, non sans résistance, le passage d'une littérature ancrée dans un classicisme modéré à une littérature réaliste, davantage axée sur la tradition locale, ses divers acteurs ainsi que sur des particularismes qu'il s'agissait d'exalter. Pour autant, sa tentative de révéler Gotthelf en France prête à un constat mitigé. Paris n'était vraisemblablement pas préparée à accueillir le réalisme souvent outrancier d'un Gotthelf. À ce sujet, même un Daguet concédait que:

Les paysans de Gotthelf sont de vrais paysans. Mais pendant que les paysans de Pestalozzi font du bien à l'âme, d'où vient que ceux de Gotthelf nous répugnent parfois et nous crispent les nerfs. C'est que tout en peignant la misère morale du peuple, Pestalozzi, on le sent, aimait ce dernier de tout son cœur et ne se complaisait jamais dans le spectacle de son égoïsme et de sa bassesse ${ }^{33}$.

Il n'est donc pas étonnant que Champfleury, lui-même sceptique envers l'importation de cette littérature bernoise, ait pu déclarer que «M. Bitzius ne serait jamais lu en France, sauf dans les librairies protestantes de la rue Basse-du-Rempart ${ }^{34}{ }^{2}$. Néanmoins, la principale contribution de Buchon se révèle dans l'édification d'un trait d'union entre la

30. Hugo Frey, op. cit., p. 80.

31. Max Buchon, CEuvres choisies, op. cit., p. 175.

32. Lettre de M. Buchon à Daguet, Salins, 7 décembre 1841, AEN, Fonds Daguet.

33. Alexandre Daguet, «Littérature populaire de Suisse », op. cit., p. 392-393.

34. Cité par Hugo Frey, op. cit., p. 100. 
Suisse, l'Allemagne et la France. Abreuvé à la source de ces trois cultures, il semble que son œuvre - aussi fragile et éclatée qu'elle soit - aboutit à un positionnement original. Obnubilé par la volonté de rapprocher ces espaces, Buchon les repense selon une formulation dénationalisée. De ce fait, il fait partie de ces exilés qui, à force de se nourrir des cultures qu'ils visitent et absorbent, à force de vouloir jeter des ponts, finissent par n'être compris ni d'un côté, ni de l'autre, et sont rejetés à cause de leurs positions médianes et par trop tolérantes. Par ailleurs, le parcours de Buchon s'apparente à une quête d'outils susceptibles de soigner son pays, d'où son intention de semer un peu de Suisse en France. Ce sera encore le cas en 1868, lorsqu'il signale à son ami Daguet son projet d'écrire une Histoire suisse à l'intention de ses compatriotes:

J'ai à te parler de choses plus sérieuses, je suis tellement préoccupé de la Suisse, comme contraste avec nos turpitudes françaises incurables, qu'il m'est venu, il y a quelque temps, l'idée d'un livre bien curieux qui serait à faire, et qui serait, je le crois très utile et très nouveau en France à savoir : la Suisse, historique, politique, industrielle, scientifique et artistique. Plus j'avance et plus je me confine dans cette certitude que notre public ne sait rien de la Suisse ${ }^{35}$.

Cette Histoire suisse ne paraîtra jamais, la disparition de Buchon en 1869 ayant laissé cette publication à l'état de brouillon. Dans le sillage de Buchon, il convient de mentionner d'autres proscrits, restés dans l'ombre des grandes figures de l'exil et oubliés aujourd'hui, qui servirent leur patrie d'adoption dans des conditions particulièrement difficiles et contribuèrent à l'amélioration des conditions de vie dans leur pays d'accueil ${ }^{36}$. Amédée Saint-Ferréol, établi à Genève, fait remarquer que beaucoup d'entre eux trouvèrent un emploi grâce à l'implantation d'une nouvelle ligne de chemin de fer dans le canton de Vaud:

Tous les réfugiés politiques ne se tirent d'ailleurs pas trop mal d'affaire, grâce surtout au chemin de fer de Lausanne. Par l'influence de l'ingénieur Lalane, l'ami de Guinard, des Cavaignac, ils s'y sont placés en assez grand nombre, pour que les Vaudois appellent la légion étrangère, le groupe de travailleurs français employés dans leur canton ${ }^{37}$.

35. Lettre de M. Buchon à Daguet, Salins, février 1868, AEN, Fonds Daguet.

36. Voir Jean Batou, Mauro Cerutti et Charles Heimberg, Pour une histoire des gens sans Histoire. Ouvriers, excluEs et rebelles en Suisse ( $x x^{\mathrm{e}}-\mathrm{xx}{ }^{\mathrm{e}}$ siècles), Lausanne, Éditions d'en Bas, 1995.

37. Amédée Saint-Ferréol, Impressions d'exil à Genève, Brioude, Imprimerie Chouvet, 1877, p. 153. 
L'ingénieur des chemins de fer Charles Bergeron (1809-1883), d'origine bressane comme Quinet, réside à Lausanne entre 1862 et 1873. Il prend la direction de l'Ouest-Suisse (ligne LausanneFribourg-Berne). Étant appelé de par ses fonctions à parcourir l'Europe, il assure le lien entre les proscrits de Suisse et ceux de Londres et de Bruxelles, en même temps qu'il renseigne ses compatriotes sur l'état d'esprit en France ${ }^{38}$. Le républicain socialiste Pierre Vésinier est également actif dans les chemins de fer. Expulsé de Genève, il se fixe à Sion en Valais où il travaille, tout en s'adonnant au commerce d'ouvrages hostiles à l'Empire et de publications licencieuses ${ }^{39}$. Le député Victor Versigny (1819-1872), farouche opposant à la loi FallouxParieu sur l'enseignement, se fixe à Neuchâtel suite au 2 décembre où il se marie avec la petite-fille de Babeuf. Avec Gustave Chaudey, il rédige L'Indépendant, un journal radical neuchâtelois particulièrement lié aux intérêts du franco-suisse - la ligne reliant Pontarlier à Neuchâtel - dont Versigny fut l'administrateur. On y retrouve encore Pierre Malardier (1818-1894), instituteur nivernais, député républicain socialiste de 1848 à 1851, qui d'Angleterre entre en Suisse plus ou moins clandestinement ${ }^{40}$. Socialiste de type associationiste et patriote, il donne des leçons et participe à des réunions préparatoires du soutien à la Commune, ce qui lui vaudra une condamnation à quinze ans de prison.

\section{Edgar Quinet et son cercle}

Au lendemain du coup d'État du 2 décembre 1851, un grand nombre d'exilés, à l'instar de Victor Hugo ou d'Edgar Quinet, afflue dès le 12 décembre dans la capitale belge. Ils doivent peu à peu se résoudre à tirer un trait sur cette France confisquée qu'ils ne reverront au mieux qu'en août 1859 , suite à l'amnistie proclamée par Napoléon III. Selon la formule de Madame de Staël, " être en exil, c'est être condamné à se survivre ». Il s'agit donc avant tout de se recréer une existence. Par conséquent, pour survivre, la majorité d'entre eux se reconvertissent en collaborateurs de la presse belge ou, comme Marc Dufraisse ou Victor Versigny, intègrent le professorat public. Dans ces conditions, l'entraide s'avère cruciale et les

38. Marc Vuilleumier, « Georges Joseph Schmitt », op. cit., p. 75.

39. Ibid.

40. Ibid. 
rassemblements solidaires se multiplient dans la maison de Quinet. On y croise l'éditeur Pierre-Jules Hetzel, Étienne Vacherot, Victor Chauffour, Victor Versigny. Cette proximité patriotique s'avère précieuse, car René Maurice rappelle qu'à Bruxelles, l'accueil est hostile. Léopold $\mathrm{I}^{\text {er }}$ n'a pas oublié qu'après l'avènement de la République en février 1848, les mêmes ont tenté de renverser la royauté belge ${ }^{41}$. Toutefois, Maurice fait remarquer que pour être toléré à l'étranger, avoir de la fortune aide: contrairement aux futurs exilés de la Commune, ceux du coup d'État, pour la plupart issus de la bourgeoisie, n'en manquaient point ${ }^{42}$.

Affectés par les mauvaises conditions météorologiques de Bruxelles, les Quinet se résolvent à trouver une autre terre d'adoption. Ils traversent la Suisse allemande durant l'été 1857 puis celui de 1858. De passage à Zurich, lors de ce second séjour, ils rencontrent Ferdinand Flocon et la famille de Marc Dufraisse qui les encouragent à venir s'installer sur les bords de la Limmat. Selon Hermione Quinet, une installation en Suisse allemande est impossible, car « l'obstacle invincible c'est l'allemand. Mon mari tenait à venir dans un pays de langue française, au milieu d'une population parlant français ${ }^{43}$ ». Pourtant, au lieu de rentrer en Belgique, les Quinet mettent le cap sur le lac Léman. Ils s'établissent pour un temps à Amphion, mais Dufraisse revient à la charge: "Non, il ne faut pas vous fixer sur la côte catholique de Savoie; il faut préférer à cette terre papale et monarchique le sol anti-papal et républicain des Vaudois ${ }^{44}$. " Ainsi, le $1^{\text {er }}$ novembre 1858 , ils prennent leurs quartiers dans leur maison de Veytaux, près de Montreux et du château de Chillon, pour un long exil qui durera plus de dix ans:

L'exil, peine terrible, vraie mort civile, châtiment dû aux traîtres; il remplacerait admirablement la peine de mort. L'exil efface l'exilé du souvenir de ses concitoyens, du cœur de ses parents; l'exil paralyse chez la plupart les facultés créatrices; toute carrière est brisée. Le commerçant, l'avocat, le notaire, l'avoué, le médecin, arrachés à leur centre d'action, ne peuvent exercer leur profession dans une société indifférente et même hostile. Le père de famille voit avec effroi l'avenir de ses enfants; s'il les

41. René Maurice, La fugue à Bruxelles. Proscrits, exilés, réfugiés et autres voyageurs, Paris, Éditions du Félin, 2003, p. 166 et 171.

42. Ibid., p. 217.

43. Hermione Quinet, Mémoires d'exil, nouvelle série, Paris, Armand Le Chevalier, 1870, p. 148.

44. Ibid., p. 149. 
garde près de lui, l'éducation morale est sauvée, sans doute, mais le lien avec le pays est rompu. Il ne mariera pas ses filles. Qui épouserait la fille d'un proscrit? Cela ne s'est pas vu une seule fois en huit ans d'exil ${ }^{45}$.

Malgré tout, les Quinet semblent avoir apprécié leur terre d'adoption. Hermione avoue même qu' " après la France, nul lieu sur la terre ne [lui] causa un attendrissement aussi doux que le lac Léman, vu pour la première fois dans la matinée du 5 septembre $1858^{46}$ ».

Sylvie Aprile rappelle «qu'entrer en exil, ce n'est pas seulement franchir une frontière, c'est entrer aussi dans de nouvelles communautés d'hommes et de femmes, se confronter aux autres habitants et autorités des pays d'accueil, c'est enfin se créer une mémoire, un imaginaire, des rites et une morale ${ }^{47}$ ". C'est exactement ce qu'Edgar Quinet entreprend. Il se trouve rapidement au centre d'un réseau de visites, d'amitiés et de correspondances, que ce soit avec les indigènes comme avec les autres proscrits ${ }^{48}$. Ainsi, durant leur exil à Veytaux, les Quinet se rendent régulièrement à Genève, où ils rencontrent des intellectuels de premier plan:

Toutes les idées, tous les systèmes qui agitent l'Europe pensante, ont leur écho parmi nous. De Bungener à Adolphe Pictet, de Merle d'Aubigné à Sayous et à Amiel, de $\mathrm{M}^{\mathrm{me}}$ de Gasparin à Marc Monnier et à Victor Cherbuliez, on rencontre toutes les nuances de la foi et du doute. Aujourd'hui, c'est moins l'uniformité qui nous menace que la dispersion. La trame de la pensée genevoise se complique et ses fils se croisent en sens divers ${ }^{49}$.

Quinet se lie avec les naturalistes Jules Pictet de la Rive et Adolphe Pictet, et surtout avec le philosophe Ernest Naville (18161906), le fils de l'éducateur, avec qui il discute les principales thèses de la Révolution et de la Création. Quinet est introduit à la Société de lecture de la ville et se rapproche de Jacques Adert, le directeur du Journal de Genève. Pendant l'été 1869, il rencontre la comtesse polonaise Revitzka, amie d'Adam Mickiewicz ainsi que le philosophe

45. Hermione Quinet, Mémoires d'exil (Bruxelles-Oberland), Paris, Librairie internationale, 1868 , p. 8.

46. Ibid., p. 155.

47. Sylvie Aprile, Le siècle des exilés. Bannis et proscrits de 1789 à la Commune, Paris, CNRS Éditions, 2010, p. 12.

48. Je m'appuie ici sur la recherche de Marcel Du Pasquier, Edgar Quinet en Suisse. Douze années d'exil (1858-1870), Neuchâtel, La Baconnière, 1959, qui retrace de manière remarquablement documentée les relations d'Edgar Quinet avec les intellectuels romands et français, ainsi que les visites qu'il reçut à Veytaux.

49. Rodolphe Rey, cité dans Marcel Du Pasquier, op. cit., p. 69. 
socialiste et révolutionnaire russe Alexandre Herzen ${ }^{50}$. Si, pour Quinet, Genève incarne indéniablement le centre névralgique des échanges savants en Suisse romande, il n'en refuse pas moins à deux reprises les propositions du gouvernement genevois d'accepter une chaire à l'académie. N'ayant que peu de sympathie pour le régime de James Fazy et soucieux de se consacrer pleinement aux œuvres qu'il médite (Merlin l'enchanteur, La Révolution), il décline une première offre en 1852 et propose la candidature du gendre de Michelet. Il réitère son refus en 1859, mais profite de l'occasion pour placer Jules Barni à la tête de la chaire d'histoire générale et de philosophie ${ }^{51}$.

Quinet se lie également à quelques Vaudois, dont l'historien Louis Vuillemin qui l'invite à participer à une séance de la Société d'histoire de la Suisse romande en 1868. Lors de son arrivée à Montreux, Quinet retrouve avec une émotion toute particulière l'un de ses plus chers amis, le peintre suisse Charles Gleyre (1806-1874) ${ }^{52}$ qu'il avait rencontré en Italie vers 1830. Quinet fréquente également le philosophe lausannois Charles Secrétan (1815-1895), disciple de Schelling, qu'il croise lors d'une promenade aux alentours de Chillon en compagnie de Pierre Leroux, un des pères du socialisme. Ce dernier mène à dire vrai une vie de misère à Lausanne. Secrétan se préoccupe beaucoup de sa santé et le fait savoir à Mme de Pressensé: "Si ses anciens amis saintsimoniens, si les Pereire, les Michel Chevalier, si les collaborateurs du

50. Sur les liens entre Herzen et Quinet, voir Michel Mervaud, « Amitié et polémique: Herzen critique de Quinet », Cahiers du monde russe et soviétique, vol. 17, n²1, janvier-mars 1979, p. 53-79. Voir également Marc Vuilleumier, « En 1849, un écrivain russe à Genève: Alexandre Herzen et James Fazy », musées de Genève, 32/1963, p. 11-14 et du même, « Révolutionnaires de 1848 et exilés. Carl Vogt, Herzen et la Suisse », Autour d'Alexandre Herzen. Révolutionnaires et exilés du XIX siècle. Documents inédits, Études et documents publiés par la Faculté des Lettres de l'université de Genève, section d'histoire, vol. 8, 1973, p. 9-252.

51. Sur la trajectoire de Jules Barni, voir Mireille Gueissaz, « Jules Barni (1818-1878) ou I'entreprise démopédique d'un philosophe républicain moraliste et libre-penseur », Les bonnes mœurs, 1994, p. 215-244.

52. Charles Gleyre (1806-1874), entre à l'École des beaux-arts à Paris en 1825, puis dans I'atelier de Louis Hersent. Dès 1828, il effectue un voyage en Italie qui aboutit en 1834 à une rencontre avec John Lowell, riche industriel américain, qui I'engage comme dessinateur pour une tournée autour du monde. II retrouve Paris en 1838 en ramenant avec lui des centaines de dessins et des aquarelles. En 1843, il a un succès incontestable grâce à son chef-d'œuvre, Les illusions perdues (conservé au musée du Louvre). Gleyre reprend ensuite l'atelier de Paul Delaroche, qu'il dirige pendant plus de deux décennies et qui est le lieu de formation de deux générations de peintres suisses, tels Albert Anker ou François Bocion, ainsi que, dans les années 1860, des jeunes impressionnistes français Auguste Renoir, Alfred Sisley, Frédéric Jean Bazille et Claude Monet. Lors de I'Exposition universelle de Paris de 1867, il organise le pavillon suisse (tiré de l'article biographique de William Hauptmann dans le Dictionnaire historique de la Suisse, version du 12.07.2007, www.dhs.ch). 
Globe les Rémusat, les Sainte-Beuve savaient que cet homme plein de talent, après tout, a froid et faim, il me semble qu'ils feraient pourtant quelque chose ${ }^{53}$. » À cet égard, on soulignera également que Ferdinand Buisson implore Quinet de participer à une collecte de fonds entreprise en sa faveur par Marc Dufraisse.

C'est donc une constellation qui se structure autour de Quinet. Nous venons de citer Marc Dufraisse, dont Jaurès rappelle qu'il fut « un des premiers propagandistes de l'Association ouvrière, le collaborateur de Proudhon au Peuple ${ }^{54}$ ". Après un passage en Belgique, Dufraisse est nommé dès l'automne 1855, professeur de législation comparée à l'École polytechnique fédérale de Zurich, récemment fondée. Il a pour collègue un autre réfugié, l'architecte allemand Gottfried Semper (1803-1879). Il doit cette position à la recommandation de Quinet auprès de l'homme politique radical genevois Abraham Louis Tourte, membre du conseil directeur du Polytechnicum ${ }^{55}$. Également soutenu par le "sage de Veytaux ", Anatole Dunoyer obtient la chaire d'économie de l'université de Berne. Il y a tout lieu donc de rappeler avec Marc Vuilleumier, "la part immense que les réfugiés et, d'une manière générale, les étrangers [ont pris] à l'enseignement secondaire et supérieur helvétique ${ }^{56}$ ». Par ailleurs, on l'a dit, Jules Barni occupe la chaire d'histoire générale à Genève dès 1861 où il donne son cours sur les Martyrs de la libre pensée. Divulgateur de Kant, homme de toutes les entreprises, Marcel Du Pasquier affirme qu'il «a exercé une action politique plus directe que Quinet dans notre pays ${ }^{57}$ ».

Enfin, au-delà des exilés qui ont pu poser leurs bagages en Suisse, la maison des Quinet est un point de ralliement des pèlerins de l'exil et d'une jeune garde républicaine restée en France, qui se rend de temps à autre sur les bords du Léman. Georges Clemenceau, alors jeune étudiant en médecine, visite le maître de Veytaux début octobre 1864 en compagnie de Charras. En 1867 défilent Gabriel Monod puis Adolphe

53. Lettre de C. Secrétan à Mme de Pressensé, 7 février 1868, citée dans Marcel Du Pasquier, op. cit., p. 59.

54. Voir Albert Thomas, « Le Second Empire (1852-1870) 》, in Jean Jaurès, Histoire socialiste, t. X, Paris, Jules Rouff, p. 86.

55. Voir Marc Vuilleumier, « Georges Joseph Schmitt, le Confédéré de Fribourg et les Républicains français. Documents inédits », tirage à part de la Revue suisse d'histoire, 24/1974, p. 89.

56. Marc Vuilleumier, Immigrés et réfugiés en Suisse : aperçu historique, Zurich, Pro Helvetia, 1992, p. 19.

57. Marcel Du Pasquier, op. cit., p. 94. 
Joanne, le fameux éditeur des guides touristiques du même nom. Jules Ferry rencontre pour la première fois Quinet le $1^{\text {er }}$ septembre 1866. En 1867 , il assiste au congrès international de la paix et de la liberté de Genève, où il rencontre un certain Ferdinand Buisson, qui deviendra son bras droit dès son accession au ministère en 1879 et l'un des principaux médiateurs dans l'espace franco-suisse.

\section{La Suisse française de Ferdinand Buisson}

Des doutes importants subsistent quant à la première destination de Ferdinand Buisson à son arrivée en Suisse ${ }^{58}$. S'est-il rendu dans la petite ville de Payerne, où son oncle Édouard Deribaucourt était pasteur depuis 1859? Ou fut-il accueilli par Jules Barni, arrivé dans la cité de Calvin en 1861? On sait que Barni dirige son ami vers Veytaux, où il est reçu par Quinet le 25 juillet 1866 . Revenant sur cette rencontre, Hermione relève les synergies qui réunissaient les deux proscrits et écrit que "ce jeune homme était plus sympathique à nos idées que tout autre ${ }^{59}$ ". Quinet et Barni le pressent à se présenter à Neuchâtel, où les anciens auditoires où Charles Secrétan professait la philosophie s'apprêtent à être transformés en académie ${ }^{60}$. Après que Buisson eut remporté le concours malgré son jeune âge, le gouvernement neuchâtelois le nomme professeur de philosophie, de littérature comparée, de psychologie et de logique. Le 28 septembre 1866, il reçoit le télégramme suivant: "Nommé unanimité - F 3200 - Envoyez-moi immédiatement programme du cours pour $66-67^{61}$. " L'acte de nomination de Buisson précise par ailleurs qu'il est engagé en même temps qu'un autre professeur bien connu en Suisse, l'historien libéral-national Alexandre Daguet ${ }^{62}$. Voici donc Buisson et Daguet engagés conjointement dans la même aventure, insérés dans une nouvelle équipe académique prestigieuse composée tant de professeurs émigrés que suisses:

58. Sur sa trajectoire et son œuvre, voir Samuel Tomei, Ferdinand Buisson (1841-1932) : protestantisme libéral, foi laïque et radical-socialisme, 2 vol., Paris, Institut d'études politiques de Paris, 2004.

59. Hermione Quinet, Mémorial d'exil, cité par Patrick Cabanel, Le Dieu de la République. Aux sources protestantes de la laïcité (1860-1900), Rennes, PUR, 2003, p. 24.

60. Ferdinand Buisson, Souvenirs (1866-1916), op. cit., p. 11.

61. "Télégramme de nomination, signé Monnier », département des manuscrits de la Bibliothèque de la Société pour I'histoire du protestantisme français, Fonds Buisson, papiers personnels, carton $n^{\circ} 1,022$ Y.1.04.

62. Daguet a été nommé professeur d'histoire générale et archéologie, histoire nationale, langue et littérature française (Histoire de l'université de Neuchâtel, t. 2 : la seconde académie, Hauterive, Attinger, 1994, p. 60). 


\begin{tabular}{|ll}
\hline Cyprien Ayer & économie politique et statistique, géographie comparée, grammaire \\
\hline Étienne Born & langue et littérature allemandes \\
\hline Édouard Desor & géologie et paléontologie \\
\hline Louis Favre & lecture expressive et dessin mathématique \\
\hline Georges Grisel & dessin artistique \\
\hline Adolphe Hirsch & astronomie et physique du globe \\
\hline Aimé Humbert & pédagogie et instruction civique \\
\hline Alfred Junod & gymnastique \\
\hline Charles Kopp & physique, chimie élémentaire et mathématiques moyennes \\
\hline Richard Monsell & langue anglaise \\
\hline Frédéric Sacc & chimie \\
\hline Charles Vouga & physiologie et anatomie comparée, géographie physique \\
\hline Adolphe Neumann & philologie grecque et latine \\
\hline Charles Lardy & droit pénal \\
\hline Henri Jacottet & procédure civile \\
\hline
\end{tabular}

Engagé pour six ans ${ }^{64}$, Buisson partage son temps entre ses cours à l'académie, la préparation de sa thèse sur Castellion et de nombreuses recherches dans les combles de l'Antistitium à Bâle, dans les salles basses de l'hôtel de ville à Genève ou dans les archives de Zurich. Il se marie avec sa cousine Pauline Emma Deribaucourt à Payerne dans la Broye vaudoise et devient rapidement père de deux enfants. Buisson prend ainsi pied dans la société romande et construit ses réseaux. Il livre à la Bibliothèque universelle un article sur « Le matérialisme et les sciences » qui paraît en août 1868 et rencontre à cette occasion Eugène Rambert et Edmond Tallichet. Il reconduit l'expérience quelques mois plus tard et propose cette fois-ci un texte intitulé « Les origines de la liberté religieuse en Suisse. Fragment de l'histoire du protestantisme au $\mathrm{XVI}^{\mathrm{e}}$ siècle, d'après des documents ignorés ou inédits ${ }^{65}$ ". Ainsi se prépare un autre événement - un scandale retentissant - qui va placer Ferdinand Buisson au centre des attentions en Suisse romande:

Il faut avouer qu'il est extraordinaire de voir aujourd'hui une population se passionner pour des débats théologiques, mais c'est qu'à côté

63. Histoire de l'université de Neuchâtel, op. cit., p. 60.

64. Journal de Genève du 13 mars 1869, p. 3.

65. Journal de Genève du 20 décembre 1868, p. 4. 
de la question de la foi, il y a aussi celle du sentiment national qui est vivement froissé de voir un jeune homme, étranger à la Suisse, se poser comme but le bouleversement de notre Église, où, grâce à Dieu, depuis de longues années, il régnait une paix parfaite ${ }^{66}$.

Il ne s’agit pas ici de traiter de la question théologique soulevée par les conférences romandes de Buisson, déjà étudiée par les spécialistes ${ }^{67}$. Nous souhaitons plutôt, par une analyse de la presse romande et des Souvenirs de James Guillaume notamment, mesurer l'impact de ces conférences de Buisson en Suisse romande. Le 5 décembre 1868, dans la salle du Grand Conseil à Neuchâtel, Buisson donne une conférence intitulée "Une réforme urgente dans l'instruction primaire ». Une foule importante s'y presse. Les nombreux auditeurs ont encore en souvenir le remarquable Cours de littérature que Buisson avait donné fin 1867 à Neuchâtel, puis à Lausanne à partir du 20 janvier $1868^{68}$. Aimé Humbert, recteur de l'académie, rassurait encore les esprits au sujet du cours de son collègue:

L'expérience faite à Neuchâtel permet de rassurer complètement les personnes qui pourraient craindre de s'engager ou de conduire leurs pupilles dans une excursion littéraire embrassant la poésie, le théâtre, le roman, l'éloquence, la presse, l'histoire, la critique, tout le mouvement intellectuel de la France, durant les trente-sept dernières années. D’un autre côté, l'on apprendra aussi avec plaisir que la prudence du professeur n'affaiblit nullement la franchise de ses appréciations, l'énergie de ses opinions, la chaleureuse expression de ses sympathies. Sa parole est militante, son éloquence est de l'action ${ }^{69}$.

Ce n'est donc plus ce professeur prudent que l'on découvrit quelques mois plus tard. Car grande fut la stupeur, au sein des instituteurs et institutrices présents, piqués par l'intitulé de cette conférence soutenue par la Société d'utilité publique, lorsque Buisson s'attaqua à l'histoire sainte:

66. Journal de Genève du 23 janvier 1869, p. 1.

67. On consultera en premier lieu la thèse de Anne-Claire Husser, Du théologique au pédagogique. Ferdinand Buisson et le problème de I'autorité, ENS de Lyon, 2012; Patrick Cabanel, Les Protestants et la République de 1870 à nos jours, Paris, Éditions Complexe, 2000; Vincent Peillon, Une religion pour la République. La foi laïque de Ferdinand Buisson, Paris, Seuil, 2010; Pierre Ognier, Une école sans Dieu? L'invention d'une morale laïque sous la III République (1880-1895), Toulouse, Presses universitaires du Mirail, 2008.

68. « Cours en douze séances sur la littérature française contemporaine (poésie, théâtre, roman; éloquence, histoire, critique et philosophie) », voir la Gazette de Lausanne du 6 janvier 1868, p. 4. 69. Lettre d'Aimé Humbert du 2 janvier 1868, Gazette de Lausanne du 6 janvier 1868, p. 3. 
Les instituteurs, institutrices et élèves s'y poussèrent en foule, mais grand fut l'ébahissement et la douleur d'un bon nombre, lorsque la conférence annoncée sous un titre aussi anodin et sous le patronage de la Société d'utilité publique, se transforma en une attaque à fond contre la divinité et la sainteté de l'Ancien-Testament. Le public fut si outré de ce procédé que le nom de l'imprudent professeur fut bientôt dans toutes les bouches et que la conférence de M. le professeur Godet sur la sainteté de l'Ancien-Testament, qui eut lieu peu de jours plus tard, fut transformée par l'enthousiasme des auditeurs en une protestation éclatante ${ }^{70}$.

Grossièrement résumé, le projet de Buisson consistait à remplacer l'histoire sainte par l'histoire de l'humanité. C'est dans son Manifeste du Christianisme libéral ${ }^{71}$ publié début 1869 dans l'imprimerie du frère de James Guillaume, que Buisson synthétise les contours de la rénovation théologique qu'il entend susciter en Suisse romande et résume par cette devise:

Nous voulons donc: Une Église sans sacerdoce.

Une religion sans catéchisme.

Un culte sans mystères.

Une morale sans dogmatique.

Un Dieu sans système obligatoire. ${ }^{72}$

James Guillaume assiste à la conférence du 5 décembre 1868 et prie Buisson de répéter ce plaidoyer (sic) au Locle. D’abord prévu le 9 décembre, l'événement a finalement lieu le $16^{73}$. La venue de Buisson arrange particulièrement Guillaume et contribue aux intérêts des socialistes loclois. En faisant cause commune avec Buisson, on souhaite avant tout récupérer des adhérents dans les rangs des radicaux désabusés. C’est ce qui se produit, puisque le conseiller d'État Eugène Borel - futur collaborateur du Dictionnaire de pédagogie - se rapproche de Guillaume. De plus, le Dr Hirsch, collègue de Buisson à l'académie, se réconcilie avec le libertaire neuchâtelois, dans l'espoir d'une lutte conjointe contre l'ennemi commun, le clergé ${ }^{74}$. Enfin, un camarade d'étude de Guillaume aborde Charles Kopp, professeur de chimie à l'académie, pour lui faire

70. Gazette de Lausanne du 22 janvier 1869, p. 1.

71. Manifeste du Christianisme libéral, Neuchâtel, Imprimerie G. Guillaume fils, 1869.

72. Ibid. p. 14-15.

73. Sur la conférence de Buisson au Locle, voir James Guillaume, L'Internationale, documents et souvenirs, t. I, lère partie, chap. XII, p. 3-8.

74. Voir James Guillaume, L'Internationale, documents et souvenirs, t. I, II partie, chap. III, p. 1-3. 
connaître les intérêts du groupe socialiste du $\operatorname{Locle}^{75}$. La première conférence dans cette cité horlogère obtient un franc succès et Guillaume prie Buisson de revenir y parler de ses conceptions théologiques ${ }^{76}$. À cette occasion, c'est à nouveau un professeur de l'académie, le royaliste Auguste Jaccard, qui intervint non sans scrupule pour demander à la municipalité l'autorisation de faire usage du temple. Ainsi, il faut souligner l'appui substantiel que Buisson trouva parmi ses collègues. D'ailleurs, lorsqu'il lance en mars 1869, L'Émancipation, organe du christianisme libéral pour la Suisse romande, on sait qu'Édouard Desor et Adolphe Hirsch contribuent à cette feuille hebdomadaire ${ }^{77}$.

Malgré la résistance qui s'organise dans les rangs des protestants orthodoxes romands ${ }^{78}$, Buisson poursuit ses conférences à la Chauxde-Fonds et au Locle, puis à nouveau à Neuchâtel, où il reproche à ses détracteurs d'avoir fait d'un problème pédagogique une question théologique. Le mercredi 25 janvier 1869, Buisson est à Genève où il répète sa conférence sur "L'histoire sainte dans l'instruction primaire ". Deux jours plus tard, on doit changer de salle car une foule immense se presse pour écouter le tribun sur la question du christianisme libéral. À nouveau, la contre-offensive s'organise et, le jeudi 4 mars, les pasteurs Barde et le célèbre polémiste Félix Bungener (1814-1874) défendent le protestantisme orthodoxe face au principal intéressé. Si la presse relève globalement la bonne tenue des débats, une attaque ad nominem touche toutefois Buisson. On lui reproche en effet d'avoir provoqué ce séisme parce qu'il se savait sur le départ. Buisson nie et s'en explique ainsi:

À la fin de l'année dernière, spontanément et dans le simple désir de rentrer en France où mon titre d'agrégé me donnait droit à une chaire de philosophie dans un lycée, j’ai demandé mon congé aux autorités de Neuchâtel qui ont mis ma place au concours. Ce concours ayant été clos sans qu'on m'eût désigné un successeur, le Conseil d'État, sur le préavis du Conseil académique, m'a demandé de reprendre et de conserver aussi longtemps que je le pourrais mes fonctions à l'académie ${ }^{79}$.

75. Kopp propose de donner une conférence aux ouvriers du Locle au Cercle international (16 janvier 1869). Un résumé de cette conférence, intitulée « Le socialisme jugé par la science moderne », se trouve dans James Guillaume, L'Internationale, t. I, II partie, chap. III, p. 4-5.

76. Buisson reviendra au Locle pour y répéter une conférence donnée à Neuchâtel sous le titre de « Profession de foi du protestantisme libéral ».

77. Patrick Cabanel, Le Dieu de la République, op. cit., p. 53.

78. Voir, entre autres, Jules Paroz, La Bible en éducation, réponse à la réforme urgente de M. le professeur Buisson : conférence donnée à Neuchâtel le 18 janvier 1869, Neuchâtel, Samuel Delachaux libraire-éditeur, 1869.

79. Journal de Genève du 13 mars 1869, p. 3. 
Son départ avorté, Buisson va redoubler de zèle pour imposer son mouvement d'émancipation dans le giron romand. Il enrôle des théologiens libéraux comme Albert Réville, Louis Leblois ou Athanase Coquerel fils. La venue de deux autres personnages, qui assureront des fonctions importantes dans le gouvernement de Ferry, mérite d'être soulignée. Jules Steeg arrive le 9 octobre 1869 à Neuchâtel, mais repart pour des raisons de santé le 16. Il est remplacé par Félix Pécaut, qui débarque dans l'ancienne cité prussienne le 31 octobre $^{80}$. Le 27 janvier 1870, Pécaut commence une série de conférences au Temple du Bas de Neuchâtel, devant un auditoire de près de 2000 personnes, sur la "religion du miracle et de l'autorité de la libre conscience ». Le père de James Guillaume écrit à son fils:

M. Pécaut [...] a traversé toute la France, par ces froids rigoureux, pour venir appuyer le mouvement d'émancipation des intelligences, commencé à Neuchâtel et qui va s'étendre à toute la Suisse romande; car on ne peut plus en douter, l'heure est venue, et les cantons français vont enfin entrer à leur tour dans cette voie de libéralisme religieux où les ont précédés de plusieurs années la plupart des cantons allemands ${ }^{81}$.

À l'heure du bilan, on voit donc que les conférences de Buisson ont fait grand bruit en Suisse romande et suscité un vrai débat théologique qui fut assurément apprécié par ses adversaires, de Philippe Godet à Félix Bovet, de Jules Paroz à Félix Bungener. Mais finalement, dans la presse suisse, il ressort de cette entreprise que Buisson s'est battu sur des questions qui ne relevaient point ou peu de la réalité neuchâteloise, sinon romande. En date du 10 mars 1869, le rédacteur du Journal de Genève dresse le bilan suivant:

M. Buisson, avec sa réforme urgente dans l'instruction primaire, s'est fourvoyé à Genève comme à Neuchâtel, en ce sens que l'enseignement religieux n'occupe aucune place officielle dans nos écoles. Nos régents peuvent être protestants, catholiques, incrédules, sans que cela compromette en rien leur position, et s'ils s'occupent d'histoire sainte, ce n'est que dans la mesure où elle se rattache à l'histoire de l'humanité. Le Consistoire seul, sous sa responsabilité, en dehors des heures de classe, et seulement pour les enfants dont les parents le désirent, fait donner, par des chapelains désignés par lui, des leçons d'histoire sainte, tantôt sur l'Ancien, tantôt sur le Nouveau Testament. S'il y a des réformes à

80. II repartira de Neuchâtel le 2 février 1870.

81. Lettre de Georges Guillaume à son fils James, 27 janvier 1869, in James Guillaume, L'Internationale, documents et souvenirs, t. I, II partie, chap. III, p. 7. 
faire, c'est au corps ecclésiastique qu'il faut s'adresser; mais la question pédagogique reste intacte, aussi bien que le principe de liberté ${ }^{82}$.

Le rédacteur conclue par ces mots: "Enfin, nous avons écouté avec attention, nous avons lu avec soin, et nous n'avons découvert ni dans ce qu'a dit, ni dans ce qu'a écrit M. Buisson, rien qui fut absolument nouveau. " On trouve pareille positionnement dans la Gazette de Lausanne: "M. Buisson, après avoir préludé par demander la réforme urgente dans l'enseignement primaire, s'enhardit toujours plus et finit par exposer le système de protestantisme libéral, ne paraissant pas se douter que ce qu'il appelait une nouveauté était pour la bonne partie de son public une vieillerie ${ }^{83}$."

Voilà pour les faits et les tendances que l'on retrouve dans la presse romande. Qu'en est-il réellement, alors que de retour à Neuchâtel en 1916, Buisson lui-même parlera d'un fait de jeunesse, abordé « avec plus d'ardeur que de circonspection » alors qu'il était « tout pénétré de la théorie révolutionnaire [d]Edgar Quinet ${ }^{84}$ " ? Pierre Caspard a mis en relation les revendications de Buisson avec les réalités scolaires observables à l'époque de son séjour neuchâtelois. Par une analyse détaillée de la place et des enjeux de religion dans la formation des maîtres, il conclut que la réforme urgente souhaitée par Buisson a déjà été en grande partie réalisée ${ }^{85}$. D'autre part et comme on l'a déjà aperçu dans les critiques parues dans la presse romande, si l'histoire sainte était encore présente dans le cursus scolaire des Neuchâtelois, elle n'était plus dispensée par les enseignants. Patrick Cabanel propose un autre argumentaire, tout aussi pertinent. Selon lui, Buisson a agi certes sur le terrain romand, mais tout en pensant à la France. Dans une lettre du 24 avril 1869, Quinet lui écrit qu' « il serait beau que ce fût Neuchâtel qui éveillât Paris ${ }^{86}$ ". Georges Guyau réactivera cette idée d'une propédeutique neuchâteloise au cas français en 1899 : «M. Buisson, Steeg et Pécaut délaissèrent leur petit cénacle de Neufchâtel (sic), encore assoupi dans le demi-sommeil du protestantisme orthodoxe, pour venir

82. Journal de Genève du 10 mars 1869, p. 1.

83. Gazette de Lausanne du 23 janvier 1869, p. 1.

84. Ferdinand Buisson, Souvenirs (1866-1916), op. cit., p. 13.

85. Pierre Caspard, « Un modèle pour Ferdinand Buisson ? La religion dans la formation des maîtres à Neuchâtel (XIXe siècle) », in Jean-François Condette, Éducation, religion, laïcité ( $X V I^{e}-X X{ }^{e}$ s.). Continuités, tensions et ruptures dans la formation des élèves et des enseignants, Lille, Centre de gestion de l'Édition scientifique, 2010.

86. Correspondance d'Edgar Quinet, cité par Patrick Cabanel, Le Dieu de la République, op. cit., p. 66. 
éveiller Paris du sommeil catholique et pour prendre le gouvernail de l'esprit français ${ }^{87}$. »

\section{À la recherche du peuple introuvable ?}

L'intitulé du présent chapitre, "Des irréconciliables en Romandie », fait droit à une assertion qui demande à être explicitée. En effet, le terme Romandie fait aujourd'hui encore débat et c'est pourquoi Georges Andrey en a récemment redéfini les contours ${ }^{88}$. Il indique que le toponyme apparaît dans la Tribune de Lausanne en 1919, dans un article de Maurice Porta qui souligne: "Beaucoup de choses nous lient et nous lieront toujours à nos grands cousins d'outre-Jura. Cependant sommes-nous français? Non pas. Nous sommes nousmêmes, la Romandie ${ }^{89}$. " Presque un siècle après les premières tentatives d'indépendance littéraire (et identitaire), voilà encore et toujours cette nécessité - d'autres diront ce complexe - de s'autonomiser par rapport au grand voisin d'outre-Jura. Le terme Romandie permet de soulever une question de fond. Car, si l'on se réfère au chapitre précédent, c'est bien dans une Romandie, c'est-à-dire dans un espace créé à partir de codes et de références métissées, mais foncièrement hostiles au modèle français, que les proscrits trouvent refuge. Pourtant, si l'on sait que les ouvriers français vont parfois faire l'objet de stigmatisation, les grandes figures de la proscription furent chaleureusement accueillies en Suisse romande. Qu'on évoque simplement l'hommage rendu par les chanteurs vaudois sous les fenêtres des Quinet, ou les funérailles que les Bâlois offrirent au colonel Charras, il s'avère que les proscrits n'ont jamais connu l'animosité toute théorique que l'on retrouve dans les textes programmatiques de l'intelligentsia romande du milieu du XIX ${ }^{\mathrm{e}}$ siècle. Au fond, ils ont été accueillis en semblables, en républicains.

Nous avons vu précédemment le mécanisme par lequel le catholique Daguet a tenté de régénérer la société fribourgeoise. Chacune de ses entreprises avait pour corollaire la déconstruction de l'héritage français, par l'activation de références alémaniques faisant du peuple l'unité fondamentale de la société helvétique. Croyant fermement que « la démocratie

87. Georges Guyau, L'école d'aujourd'hui, I, Paris, Perrin, 1899, p. 73.

88. Georges Andrey, La Suisse romande, une histoire à nulle autre pareille !, Pontarlier, Cabédita, 2012, p. 209-305.

89. Voir L'Hebdo, n 42, 18 octobre 2012, p. 49-50. 
sans les lumières est un fléau ${ }^{90}$ ", Daguet s'est attelé à un vaste travail d'instruction des masses, en faisant de Girard et de Pestalozzi - le fondateur du roman populaire selon lui - les deux figures tutélaires de son action pédagogique. De ce fait, on peut se demander si les irréconciliables, Quinet, Buisson et Barni en tête, n'ont pas entrepris pour la France ce qu'un Daguet a suscité pour Fribourg. N'ont-ils pas convoqué en Suisse une certaine idée du peuple, tout fascinés qu'ils étaient par l'acuité patriotique des petites gens qu'ils rencontraient? Au sujet de Quinet, Marcel Du Pasquier souligne que « notre pays lui offrait le réconfortant spectacle d'une démocratie authentique. Il aurait voulu, pour le sien, l'école laïque et populaire réalisée chez nous, et s'étonnait, avec beaucoup d'étrangers, du développement intellectuel des gens simples ${ }^{91}$ ». On rajoutera que cette étude du peuple suisse ne se fixa pas sans une certaine idéalisation, exprimée notamment par ces considérations d'Hermione Quinet:

La culture de ces paysannes est vraiment surprenante [...] Il n'est pas rare de les entendre causer littérature; il y en a qui connaissent les Méditations de Lamartine, Le dimanche, après le culte, elles rapportent de la bibliothèque communale quelques livres d'histoire de M. Guizot, les Girondins de Lamartine, l'Histoire de mes idées, surtout les romans populaires d'Urbain Olivier. Le paysan vaudois cause politique, administration avec une aussi parfaite connaissance des choses qu'un conseiller d'état suisse. Comment en serait-il autrement? Il est le souverain; dès son enfance, à l'âge de douze, il a déjà appris en classe le manuel des droits et des devoirs du citoyen vaudois. Ces hommes, ces enfants, que vous rencontrez dans la rue chargés d'instruments de travail, portent au cœur le sentiment de leur souveraineté et de leur affranchissement d'esprit, grâce à la république, grâce à l'école ${ }^{92}$.

D’autres importations culturelles explicites nous incitent à persévérer dans cette hypothèse. Par exemple, peu après l'accession de Buisson à la direction de l'enseignement primaire, les ténors de l'école républicaine diffusèrent l'intégralité du «Comment Gertrude instruit ses enfants ${ }^{93}$ » dans la Revue pédagogique, comme pour mieux faire pénétrer l'essence

90. Voir Alexandre Daguet, « Chronique neuchâteloise », L'Éducateur, 19/1888, p. 314.

91. Marcel Du Pasquier, La Suisse romande terre d'accueil et d'échanges. Évocations au cours de trois siècles, Lausanne, Éditions SPES, 1966, p. 148.

92. Hermione Quinet, Mémoires d'exil (Suisse orientale-Bords du Léman), Paris, Armand Le Chevalier Éditeur, 1870, p. 223-224.

93. Voir Heinrich Pestalozzi, Écrits sur la méthode. Volume V. Comment Gertrude instruit ses enfants (introduction de Michel Soëtard et commentaires de Loïc Chalmel et Danièle TosatoRigo), Le Mont-sur-Lausanne, LEP, 2013. 
de la méthode pestalozzienne en France ${ }^{94}$. Il est donc vraisemblable que ces théoriciens de la société française aient tenté de saisir ce fameux peuple introuvable ${ }^{95}$ en scrutant le corps et l'âme de la démocratie suisse.

94. Heinrich Pestalozzi, « Comment Gertrude instruit ses enfants », traduction du Dr Darin, Revue pédagogique, second semestre de 1880, p. 1-13, 140-159, 435-447, premier semestre de 1881, p. 408-420, second semestre de 1881, p. 25-33 et premier semestre de 1882, p. 1-10. 95. Selon la formule de Pierre Rosanvallon, Le peuple introuvable, Paris, Gallimard, 1998. 


\title{
DEUXIÈME PARTIE
}

\author{
INTERNATIONALES \\ DE L'ÉDUCATION ET \\ SAVOIRS SCOLAIRES \\ MÉTISSÉS
}





\section{4 \\ Internationaliser, propager, contrôler}

Dès la moitié du $\mathrm{XIX}^{\mathrm{e}}$ siècle, les synergies et les échanges internationaux s'accélèrent. Les enseignants, ou tout du moins leurs élites pensantes, s'inscrivent pleinement dans cette dynamique d'internationalisation, à l'instar des ouvriers qui se fédèrent au sein de l'Association internationale des travailleurs à Londres en 1864, ou encore des scientifiques européens qui se dotent de nouveaux lieux de savoirs ${ }^{1}$. La Suisse occupe une place importante dans ce processus, notamment avec la création de la Croix-Rouge en 1864, de l'Union postale universelle fondée à Berne en 1874 et comme on le verra dans ce chapitre de la Ligue internationale de la paix et de la liberté instituée par les républicains français installés dans le repli helvétique. De nouvelles grand-messes se succèdent sur le continent comme autant de lieux de production du savoir mais également comme moyens privilégiés de diffuser et surtout de contrôler les articulations d'une rénovation pédagogique dès lors amplifiée à l'échelle continentale.

\section{La Ligue internationale de la paix et de la liberté}

Les congrès de la Ligue internationale pour la paix et la liberté - à ne pas confondre avec la Ligue internationale de la paix fondée en mai 1867 par Frédéric Passy - naissent dans la poudrière du printemps 1867, lorsque Napoléon III se préoccupe de rattacher à la France le

1. Voir Pascale Rabault-Feuerhahn et Wolf Feuerhahn, «La fabrique internationale de la science. Les congrès scientifiques de 1865 à 1945 », Revue germanique internationale, 12/2010, CNRS Éditions ; Anne Rasmussen, L'Internationale Scientifique (1890-1914), thèse d'histoire sous la direction de Jacques Julliard, EHESS, 1995, 2 volumes. 
Luxembourg, également convoité par la Prusse ${ }^{2}$. Dans un contexte de guerre imminente, le rédacteur du journal nantais Le Phare de la Loire, Évariste Mangin, propose en mai 1867 de réactiver l'idée d'un congrès pour la paix, après celui de Paris en 1849 et celui de Francfort en 1850, afin de convoquer une nouvelle réunion sur le sol helvétique. Des républicains français, parmi lesquels Louis Blanc, Victor Hugo, Edgar Quinet, Charles Lemonnier, Élysée Reclus ou Jules Barni, rédigent un Manifeste publié dans la presse européenne. Plus de dix mille adhésions sont consignées, suite notamment à un vaste travail de lobbying effectué par le démocrate badois Armand Goegg, l'époux de Marie Goegg-Pouchoulin dont on verra le rôle central au sein de la Ligue. Le saint-simonien Charles Lemonnier (1806-1891) résume l'héritage et l'horizon programmatique de la Ligue, dont il fut un des principaux acteurs et organisateurs:

La Ligue suit directement la tradition de la Révolution européenne de 1789 ; elle est la fille de Kant et se porte pour héritière de la philosophie du XVIII ${ }^{\mathrm{e}}$ siècle; elle ne s'est point contentée d'affirmer que le seul moyen pratique de fonder la paix était de constituer, en regard de la République helvétique et de la République des États-Unis d'Amérique, une fédération analogue parmi les peuples d'Europe ${ }^{3}$.

Une foule considérable se presse à Genève, du 9 au 12 septembre 1867, pour écouter Garibaldi, invité d'honneur du comité central. Notons qu'il fallut déplacer la date d'ouverture du congrès, initialement prévu le 5 septembre, à cause de l'assemblée de l'Association internationale du travail (AIT) qui se tint à Genève du 2 au 7 septembre. Marx, peu favorable, fit savoir que s'il était permis aux délégués de participer au congrès de la paix et de la liberté à titre personnel, il n'était pas souhaitable que l'AIT y soit représentée.

Ce premier congrès de la Ligue est présidé par Pierre Jolissaint (1830-1896), un ancien élève d'Alexandre Daguet devenu leader de la section de St-Imier de la ${ }^{\text {Ìre }}$ Internationale, l'irréconciliable Jules Barni en assumant la vice-présidence. Comme le rappelle ce dernier, le but recherché est de jeter les bases d'une vaste confédération devant relier les peuples émancipés d'Europe, afin d'aboutir à la constitution

2. Voir Philippe de Vargas, Le congrès de la paix et de la liberté de 1869 à Lausanne, université de Lausanne, mémoire de licence, 1961; Martine Brunet, « Ferdinand Buisson, la guerre et la paix », Theolib, 2011, p. 119-131.

3. Charles Lemonnier, Les États-Unis d'Europe, Paris, Librairie de la Bibliothèque démocratique, 1878 , p. 108-109. 
des États-Unis d'Europe ${ }^{4}$. Or, il ne fait nul doute que l'exemple de la Suisse confédérale offre la structure idéale du système à propager:

Notre idée s'appuie, d'ailleurs, sur une réalité vivante qui peut servir à la fois de modèle et de noyau à l'organisation de l'Europe. Je veux parler de la Suisse, où notre ligue a pour cette raison même établi son siège. La Suisse ne comprend-elle pas vingt-deux États indépendants, appartenant à des nationalités et parlant des langues diverses? Et ces vingt-deux États ne forment-ils pas une Confédération qui, en laissant à chacun son autonomie, les unit pour le règlement et la défense de leurs intérêts communs, et entretient entre eux l'harmonie et la paix ? Et bien! c'est ce système qu'il s'agit d'étendre à l'Europe entière. Ce que la Suisse est en petit, il faut que l'Europe le devienne en grand, si elle veut extirper à jamais de son sein le fléau de la guerre et des armées permanentes $^{5}$.

Ainsi, un demi-siècle après l'étude comparative de Jullien, la Confédération helvétique se retrouve à nouveau promue au rôle de laboratoire miniaturisé d'une Europe que l'on souhaite à son image. Barni valide la faisabilité de cette projection en prenant pour témoin l'histoire même de la Confédération:

Celui-là eût passé pour un insensé qui, à l'époque où les trois cantons forestiers formèrent le premier noyau de la Confédération helvétique, aurait prédit ce que deviendrait un jour la Confédération. À la vérité, il a fallu des siècles pour achever cette œuvre; mais c'étaient des siècles de ténèbres et de barbarie. La civilisation marche aujourd'hui plus vite, et j'en trouve la meilleure preuve dans l'exemple de la Confédération helvétique ${ }^{6}$.

$\mathrm{Au}$ terme de l'évènement, les congressistes votent en faveur de la création d'un journal. L'hebdomadaire Les États-Unis d'Europe paraîtra à partir du 5 janvier 1868 en deux éditions, l'une en allemand, l'autre en français et emprunte son titre à tirade du patriote italien Carlo Cattaneo (1801-1869), écrivant vers la fin 1848 : Avremo pace, quando avremo li stati uniti d'Europa ( "Nous aurons la paix lorsque nous aurons les États-Unis d'Europe »).

4. Voir la préface de Jules Barni, Annales du congrès de Genève (9-12 septembre 1867), Genève, Vérésoff et Garrigues, 1868, p. VIII.

5. Discours de Jules Barni, Bulletin officiel du congrès de la paix et de la liberté de 1869 , Lausanne, Association typographique, 1869, p. 9.

6. Ibid., p. 10. 


\section{Les États-Unis d'Europe et la question de l'éducation}

Parmi plusieurs articles consacrés à la chose pédagogique, l'un d'eux, sous la plume d'un certain Jean le pédagogue propose quinze ans avant l'ouverture d'une chaire de sciences de l'éducation à la Sorbonne, occupée par Henri Marion la création de facultés pédagogiques. Théoriquement, celles-ci s'articuleraient autour de l'étude anthropologique, dont le mécanisme physico-psychologique développé par Pestalozzi représenterait l'élément clé. La faculté pédagogique tournerait autour de trois axes:

1. L'étude de l'homme et de ses forces y serait la chose principale;

2. Les branches spéciales n'y seraient enseignées qu'en tant qu'elles sont des manifestations des forces humaines ou qu'elles constituent à leur tour des moteurs de ces forces;

3. Le mode d'enseignement dans une faculté de pédagogie devrait être lui-même pédagogique, générateur de force d'après la méthode socratique de Pestalozzi, dans une étroite communion, se livrant ensemble dans une douce intimité aux plus nobles aspirations et préparant le levain de renaissance pédagogique pour des académies entières. ${ }^{7}$

Plusieurs autres causes viennent s'agréger à la Ligue et s'invitent régulièrement dans son journal, notamment celle de l'éducation des filles et la cause féministe. Dans le premier numéro de janvier 1868, Clémence Royer (1830-1902) demande l'admission et le concours des femmes au sein de la Ligue. Cette philosophe et scientifique nantaise s'installe en Suisse à Cully en 1856, puis à Lausanne où elle donne à l'académie un cours sur la philosophie de la nature (1859) réservé aux femmes. Auteure de la première traduction française De l'origine des espèces de Darwin, elle introduit l'œuvre du naturaliste anglais en France dès 1862. Sa demande va au-devant des souhaits de Royer, pour laquelle il est absolument nécessaire que les femmes concourent à l'idée de paix et rejoignent en grand nombre la Ligue, car " elles seules peuvent lui donner la puissance d'une popularité générale, la puissance de la vogue, le concours imposant de l'opinion universelle ${ }^{8} »$.

7. Jean le Pédagogue, « De la création des facultés pédagogiques 》, Les États-Unis d'Europe, n० 15,12 avril 1868, p. 60.

8. Clémence Royer, « La Ligue et les femmes », Les États-Unis d'Europe, n 1, 6 janvier 1868, p. 4. 
Marie Goegg-Pouchoulin (1826-1899), proche des réfugiés politiques allemands et notamment du chef révolutionnaire badois Armand Goegg qui deviendra son mari, réagit à la proposition de sa consœur et propose, dans le numéro suivant, de créer une Association internationale des femmes connectée à la Ligue internationale de la paix et de la liberté ${ }^{9}$. En phase avec la revendication de l'égalité des sexes dans la formation, dans la vie professionnelle ainsi que sur le plan juridique, l'éducation des filles y figure au premier plan. Il s'agit de regrouper les femmes dans des clubs locaux afin de former des cercles de lecture qui, sur le modèle des cercles d'hommes, offriront l'attrait de lectures instructives sous forme de journaux, de feuilles périodiques, de revues, de livres sur l'éducation. De plus, la féministe genevoise insiste pour que "les privilégiés de l'éducation et de l'instruction [considèrent] comme un devoir impérieux [de] faire part à d'autres moins favorisées qu'elles, de ce qu'elles ont appris, vu et observé ${ }^{10}$ ». Première présidente du comité directeur de cette ligue féministe basée à Berne dès 1868, Goegg-Pouchoulin doit toutefois s'en retirer en 1871 à cause de positions que l'on jugeait par trop extrémistes. Par son engagement, elle n'en a pas moins posé les fondations de la Ligue internationale des femmes pour la paix et la liberté fondée par Jane Addams en 1931.

\section{L'entrée de Ferdinand Buisson sur la scène internationale}

Un an après l'assemblée de Genève, on se réunit à nouveau à Berne du 21 au 25 septembre 1868. Le deuxième congrès de la Ligue est présidé par Carl Vogt (1817-1895), médecin et naturaliste allemand qui s'est réfugié en Suisse à cause de ses idées libérales-démocrates. Si Vogt est connu pour avoir pris une part importante dans la fondation de l'université de Genève, il l'est également en tant qu'adversaire des thèses de Marx et des communistes qu'il fait passer pour des faussaires et des maîtres-chanteurs. Aussi ce congrès de Berne se déroule-t-il dans un climat de fortes tensions; une vingtaine de collectivistes libertaires, parmi lesquels se trouvent Bakounine et James Guillaume, démissionnent et décident de créer l'Alliance internationale de la démocratie

9. Marie Goegg, « Proposition de créer une Association internationale des femmes, en connexion avec la Ligue de la paix et de la liberté », Les États-Unis d'Europe, $\mathrm{n}^{\circ}$ 10, 8 mars 1868 , p. 38.

10. Ibid. 
socialiste. Déjà amoindrie par les positions des pacifistes purs opposés à toute prise de position contre les gouvernements établis et ce départ des collectivistes, la ligue voit son maintien même fortement remis en cause. Certains congressistes, à l'image de Jean-Aristide Claris, un exilé de la Commune installé à Genève, incrimine son radicalisme bourgeois : «Pour opposer la ligue des peuples à la ligue des rois, et fonder les États-Unis d'Europe, il fallait chercher, tout d'abord, à se concilier les peuples. » Claris relève encore que « le chiffre relativement élevé de ses cotisations annuelles en fait une sorte d'association aristocratique dont l'accès est interdit au prolétaire. De là, l'isolement où elle se trouve à cette heure et le peu de sympathie que lui ont vouée les travailleurs ${ }^{11}$ ". L'affaire est reprise en main par Barni, qui propose la présidence d'honneur du congrès suivant, fixé à Lausanne en septembre 1869 , à Victor Hugo. C'est lors de ce congrès que Ferdinand Buisson, resté actif au sein de la Ligue malgré le départ de son ami James Guillaume, expose ses idées sur l'instruction, dans un discours resté célèbre, intitulé «L'abolition de la guerre par l'instruction ».

À Lausanne, le " fils spirituel du républicain Barni ${ }^{12}$ » prend position contre toute phraséologie. Il ne s'agit pas de mettre en place des mesurettes, mais bien d'œuvrer via la Ligue à un changement de perspectives radical, en ayant constamment en ligne de mire la transformation des masses par l'instruction. Les points principaux de son discours peuvent se hiérarchiser en quatre volets principaux. Tout d'abord, il est nécessaire de forger les conditions d'une "réforme ou plutôt d'une révolution européenne ${ }^{13}$ " qu'il juge décisive pour établir dans le monde la paix définitive. Il s'interroge sur les instruments à disposition pour extirper la guerre du domaine des esprits et assène que « le grand levier, le grand ressort à mettre en mouvement, c'est l'instruction. Par l'instruction, on peut réformer la nation dans le citoyen et le citoyen dans l'enfant; et c'est jusque-là qu'il faut remonter, si nous voulons atteindre le mal dans son germe ${ }^{14}$ ».

Dans un deuxième temps, plusieurs interlocuteurs définissent l'opinion publique comme un référent fondamental du discours sur la

11. Jean-Aristide Claris, La proscription française en Suisse 1871-1872, Genève, Imprimerie Blanchard, 1872, p. 36.

12. Selon I'expression de Pierre Nora, citée dans Vincent Peillon, Une religion pour la République. La foi laïque de Ferdinand Buisson, Paris, Seuil, 2010, p. 20.

13. Ferdinand Buisson, « L'abolition de la guerre par l'instruction », Les États-Unis d'Europe, $n^{\circ} 16,19$ avril 1868, p. 62.

14. Ibid. 
paix; il s'agit de l'utiliser "afin de chasser loin de l'esprit des enfants le "Dieu des armées", le dieu des Napoléon ${ }^{15}$ ». Rappelons qu'en 1867 à Genève, Pierre Jolissaint a fait remarquer qu' "il existe à côté des armées permanentes une force non moins imposante qui est appelée à devenir la reine du monde, c'est l'opinion publique. Si ce n'est pas la reine du présent, ce sera inévitablement la reine de l'avenir ${ }^{16}$ ». Deux ans plus tard, à Lausanne, Buisson semble avoir retenu le mot de Jolissaint, quand il affirme que "nous sommes ici pour exercer une pression sur l'opinion publique ${ }^{17}$ ». Selon lui, voilà l'outil qui permettra de conquérir «ces quelques millions de Français qui labourent la terre et travaillent dans les ateliers [...] et qui n'ont encore eu ni le temps ni le moyen de s'imprégner de toutes ces grandes idées ${ }^{18}$ ». Il s'agit donc de s'écarter des idées élevées répandues dans la grande presse, pour se préoccuper davantage des besoins du peuple. Obnubilé par la nécessité de la résistance par l'action, Buisson conclut qu'il est impératif, " au foyer, à l'école, sur la place publique, de travailler et former l'opinion publique ${ }^{19}{ }$. Cela dit, c'est justement dans cette perspective de renversement de l'opinion publique qu'il faut comprendre les fameuses tirades prononcées par Buisson dans son discours de Lausanne, certes rédigé dans la hâte dans le train qui le ramène d'Italie et qu'il payera cher tant ses adversaires sauront les évoquer à des moments stratégiques ${ }^{20}$. Que ce soit le « je voudrais un Voltaire occupé pendant cinquante ans à tourner en ridicule rois, guerres et armées " et surtout le "habituer les enfants à se dire: un uniforme c'est une livrée, et toute livrée est ignominieuse, celle du prêtre et celle du soldat, celle du magistrat et celle du laquais ${ }^{21}$ ", c'est toujours une foi dans la possibilité d'un changement radical par l'éducation qui est invoquée par Buisson, afin d'inverser l'imaginaire belliqueux en un idéal pacifiste dans l'opinion publique:

Ce n'est pas seulement dans les assemblées populaires, dans les journaux, dans les congrès, c'est dans les mœurs publiques qu'il faut combattre et

15. Bulletin officiel du congrès de la paix et de la liberté de 1869, op. cit., p. 43.

16. Annales du congrès de Genève (9-12 septembre 1867), Genève, Vérésoff et Garrigues, 1868, p. 146.

17. Bulletin officiel du congrès de la paix et de la liberté de 1869, op. cit., p. 40.

18. Ibid., p. 41.

19. Ibid., p. 43.

20. Voir Martine Brunet, « Ferdinand Buisson, la guerre et la paix », op. cit., p. 130-131.

21. Bulletin officiel du congrès de la paix et de la liberté de 1869, op. cit., p. 42-43. 
extirper le militarisme. Il faut le combattre dans des habitudes en apparence insignifiantes, mais qui règnent partout et qui ont une influence incalculable sur l'éducation individuelle. Il faut le combattre dans le goût qu'on a pour l'uniforme; il faut que la mère de famille indique de bonne heure à l'enfant cette idée, que les armes, qu'un sabre, un fusil, un canon, c'est un des instruments qu'il faut considérer des mêmes yeux que nous considérons, au château de Chillon, par exemple, les instruments de torture employés il y a quelques siècles. C'est sur l'éducation matérielle qu'on détruira la première racine du militarisme et l'on ne verra plus des milliers de badauds aller contempler une revue, on ne verra plus cette admiration pour les grades, pour l'épaulette, pour l'uniforme ${ }^{22}$.

En troisième lieu, Buisson invite à une mobilisation générale des esprits. Il s'agit de répandre ces saines idées de justice, de solidarité et d'humanité "à grands flots, par les livres, par les brochures, par les journaux, par les conférences, par toutes les voies ouvertes ou qu'on peut s'ouvrir, les répandre avant tout dans la famille et dans l'école [...] par une éducation foncièrement démocratique ${ }^{23} »$. Buisson conçoit que c'est là une œuvre immense, " une nouvelle conversion du monde » qui ne peut seule se concevoir que par un dévouement personnel et total. Il juge enfin que ce changement radical ne sera entrepris ni par les gouvernements, car " ils ne le veulent pas ", ni par la marche providentielle du progrès sur laquelle on ne peut compter. L'instruction s'impose pour Buisson - et pour les défenseurs d'une éducation libertaire que sont Guillaume et Bakounine avec lesquels il a noué des liens personnels ${ }^{24}$ - comme l'unique remède, mais un remède qui doit incarner l'action et s'incarner dans l'initiative personnelle: "Le remède c'est vous, c'est moi, c'est nous tous qui le possédons ${ }^{25}$. " Par conséquent, « instruire le peuple, c'est rendre impossible dans un avenir prochain la guerre au dehors, comme la tyrannie au dedans. Instruire le peuple, c'est faire des républicains et avouons-le franchement, faire des républicains c'est le plus sûr et c'est encore le plus court moyen de faire des républiques ${ }^{26}$ ».

22. Ibid., p. 42.

23. Ferdinand Buisson, « L'abolition de la guerre par l'instruction », op. cit., p. 63.

24. Voir à ce titre Martine Brunet, « Ferdinand Buisson et James Guillaume, une histoire d'amitié... », La révolution prolétarienne, n 777, juin 2012; Christiane DemeulenaereDouyère, Paul Robin (1837-1912): un militant de la liberté et du bonheur, Paris, Publisud, 1994 et de la même auteure, « Ferdinand Buisson et l'innovation pédagogique: I'exemple de I'Orphelinat Prévost de Cempuis », Journée d'étude sur Ferdinand Buisson, 30 mai 2000.

25. Ferdinand Buisson, « L'abolition de la guerre par l'instruction », Les États-Unis d'Europe, $\mathrm{n}^{\circ} 17,26$ avril 1868, p. 66.

26. Ibid. 
Obsédé par l'idée d'une réforme des consciences par le bas, Buisson clame qu' "il n'y a pas de plus grandes réformes sociales que celles qui sont comprises, voulues et faites par le peuple lui-même ${ }^{27}$ ». En cela, il rejoint son maître Quinet, pour qui le réveil du peuple est une condition sine qua non de la paix sur le continent: " les peuples ne se relèveront [que] quand ils auront acquis la conscience de leur chute » assène Quinet lors du congrès de Genève. Ainsi, « il faut que les hommes cessent d'être des machines et redeviennent des hommes. Il faut que les peuples cessent d'être des troupeaux et redeviennent des peuples ${ }^{28}$ ".

Ironie de l'histoire ou preuve de la concurrence acharnée à laquelle se livrent les principaux acteurs engagés dans les internationales de l'éducation, alors que Buisson marque de sa verve le congrès de Lausanne et propose de faire de la Ligue « une sorte de société internationale pour l'organisation universelle de l'éducation démocratique 29 ", son ami Alexandre Daguet travaille à la fondation d'une association pédagogique universelle qu'il est allé proposer aux instituteurs français lors de l'Exposition universelle de 1867.

\section{Le pari manqué de l'Association pédagogique universelle ${ }^{30}$}

Si la mission politique et sociale de la Suisse, au milieu des grandes nations qui l'entourent, est une mission de paix, de neutralité, de médiation, de bienfaisance, le rôle de la pédagogie suisse ne serait-il pas de servir d'intermédiaire et de trait d'union entre les systèmes d'éducation du Nord et du Midi ? N'est-ce pas là un des caractères essentiels de ce programme de fédération universelle, proclamé à Paris en 1867, discuté et voté à Genève, et dont la réalisation définitive doit faire l'objet de la dernière séance de ce congrès ${ }^{31}$.

27. Ferdinand Buisson, « L'abolition de la guerre par l'instruction », $n^{\circ} 16$, op. cit., p. 62.

28. Edgar Quinet, « Discours », in Annales du congrès de Genève (9 au 12 septembre 1867), op. cit., p. 164.

29. Ibid.

30. Ce volet consacré à l'Association pédagogique universelle a fait l'objet d'une publication : « Entre ambitions universalistes et concurrences internationales. Retour sur le pari manqué de I'Association pédagogique universelle (1863-1900) », Histoire de l'éducation, n 139, septembre-décembre 2013.

31. Discours d'Alexandre Daguet Iors du congrès de St-Imier, in Compte-rendu du Ve congrès scolaire de la Société des instituteurs de la Suisse romande tenu à Saint-Imier les 20, 21 et 22 juillet 1874, Saint-Imier, Imprimerie Ernest Grossniklaus, 1874, p. 64. 
S'interrogeant sur les liens étroits mais aussi, au premier abord, paradoxaux entre le monde globalisé que nous connaissons et la réactivation intense des références au national, Anne-Marie Thiesse souligne que l'internationalisme du second $\mathrm{xIx}^{\mathrm{e}}$ siècle "valide le nouveau principe du monde des nations [par lequel] l'internationalité intellectuelle et culturelle est célébrée, mais où dans le même temps sont affirmés des esprits nationaux spécifiques qui divisent l'art et la science en unités radicalement distinctes et concurrentes ${ }^{32}$ ». Portée par Alexandre Daguet et la Société des instituteurs de la Suisse romande, l'Association pédagogique universelle, dont la création est décidée en 1872, a en effet facilité la mise en réseau, sous diverses formes, des défenseurs d'une pédagogie libérale-nationale et anticléricale devant faciliter l'avènement d'un réseau d'envergure ayant pour but de travailler à l'avènement de l'écolier-citoyen. Bien qu'il s'agisse d'une tentative manquée, dans le sens où l'association n'aboutira pas à la constitution d'une structure internationale stable sur le long terme, cette entreprise internationale demeure un maillon constitutif important de l'histoire du mouvement associatif pédagogique européen.

\section{"Instituteurs de tous les pays, unissez-vous!"}

Comme le rappelle Michel Onfray, c'est Flora Tristan (1803-1844) qui, cinq ans avant le Manifeste du Parti communiste de Marx et Engels, exhorte dans L'Union ouvrière (1843) les prolétaires à s'unir fin d'aboutir à l'union universelle des ouvriers et des ouvrières ${ }^{33}$. Les enseignants suisses participent également à cette poussée internationaliste et s'associent afin de valoriser leur position et de construire un socle commun en matière d'éducation. Si les régents alémaniques se mobilisent au sein du Schweizerischer Lehrerverein (Société pédagogique de Suisse allemande) dès 1849 , les instituteurs romands éprouvent rapidement le besoin de s'unir et de s'autonomiser par rapport à leurs confrères alémaniques. C'est lors de la cinquième réunion du Lehrerverein à Berne, en octobre 1863, que quelques enseignants provenant de la Suisse française, "se sentant un peu perdus au milieu de sept cents collègues germains $^{34}$ ", décident de se regrouper afin d'échanger leurs préoccu-

32. Anne-Marie Thiesse, « Nations, internationalismes et mondialisation », Romantisme, n० 163, 2014, p. 23.

33. Cité dans Michel Onfray, L'eudémonisme social, Paris, Grasset, 2008, p. 34. Voir également Flora Tristan, L'Union ouvrière, Paris, 1844 [1843], p. 4.

34. Alexandre Daguet, « Rapport sur l'origine et la marche de la Société des Instituteurs de la Suisse romande », in Rapport sur la deuxième session de l'assemblée générale des instituteurs de la Suisse romande réunis le 6 août, Fribourg, Imprimerie Marchand, 1866, p. 7. 
pations pédagogiques. Un comité d'initiative est formé et la fusion des enseignants romands avec ceux du Lehrerverein est un temps envisagée. Le projet est vite délaissé tant la langue allemande demeure un fossé infranchissable:

La Suisse allemande peut déjà nous présenter les bienfaits d'une association pédagogique. Certes, nous n'eussions pas mieux demandé, pour la facilité de notre tâche, que de nous joindre à elle et de profiter ainsi de ce qui existe. Mais, après avoir mûrement étudié la chose, il nous est apparu qu'il serait de toute impossibilité de réunir dans une même assemblée les instituteurs des diverses langues de la Suisse. En effet, il ne peut être question de faire entrer dans une société de langue allemande des hommes qui n'en comprennent pas le premier mot, qui ne pourront ainsi prendre part en connaissance de cause aux délibérations, et dont le nombre d'ailleurs sera toujours dominé par la majorité qui les environnera. Nous pourrons d'ailleurs nous allier en tout temps avec nos frères allemands; ce que nous réclamons ici, c'est le maintien de notre individualité. D'autre part, ce qui importe surtout d'avoir avec eux, c'est une communauté d'intentions. Or, notre programme est le même $\mathrm{e}^{35}$.

De ce fait, quelque deux cent cinquante enseignants réunis en assemblée à Neuchâtel le 26 septembre 1864 fondent la Société des instituteurs de la Suisse romande (SIR) à laquelle se rallient les sociétés pédagogiques cantonales préexistantes. On ne saurait trop relever l'importance de ce regroupement des sociétés cantonales en un faisceau unique, quand on sait combien la prééminence des cantons en matière d'instruction est prégnante sur le territoire helvétique ${ }^{36}$. Quelques indices nous montrent cependant que cette nouvelle société ne fit pas l'unanimité. En effet, il existe une autre Suisse romande pédagogique, également guidée par un Fribourgeois, l'abbé Raphaël Horner (1842-1904), directeur de l'école normale d'Hauterive, qui n'ambitionne nullement de s'inscrire dans cette société régionale jugée par trop libérale et antichrétienne. C'est pourquoi Fribourg fonde sa propre société cantonale en novembre 1871, crée son organe, le Bulletin pédagogique et décide six ans plus tard de quitter la SIR qu'elle ne rejoindra qu'en 1969. Jean-Marie Barras rappelle

35. Ernest Savary, La Société pédagogique de la Suisse romande (1864-1914). Notice historique à l'occasion du jubilé cinquantenaire de cette société, Lausanne, Imprimeries réunies, 1914 , p. 7.

36. Voir Rita Hofstetter, « La Suisse et l'enseignement aux XIXe-XXe siècles. Le prototype d'une "fédération d'États enseignants"? », Histoire de l'éducation, n 134, avril-juin 2012, p. $59-80$. 
à ce sujet que "si les idées pédagogiques que présentera le Bulletin seront le plus souvent novatrices, voire d'avant-garde, l'idéologie en sera carrément conservatrice ${ }^{37}$ ».

Il faut également souligner qu'à peine six mois après cette union régionale, les projets intercantonaux de la SIR se doublent d'une ambition internationaliste soutenue par l'adversaire de Horner. Car si Daguet se fait d'abord connaître par son œuvre d'historien et promeut comme on l'a déjà évoqué une vision particulariste de la nation suisse, ses conceptions pédagogiques s'avèrent très clairement universalistes. Accompagné de quelques membres fondateurs de la SIR, il profite de l'Exposition universelle de 1867 pour intégrer la Suisse romande dans le concert pédagogique européen.

\section{Un projet universaliste aux racines franco-romandes}

Le mouvement naît en mars 1865, quand le président de la SIR Frédéric Villommet interpelle son collègue parisien M. Pilate, membre de la conférence des institutrices et instituteurs protestants de la Seine: "Pourquoi ne pourrions-nous pas avoir des congrès internationaux aussi bien que les économistes, les légistes, les ouvriers. Nous aimerions à vous voir prendre l'initiative... Il va sans dire que la première réunion aurait lieu à Paris ${ }^{38}$. " Par ces mots, Villommet donne l'impulsion à un projet d'association internationale qui répond à plusieurs préoccupations. La guerre austro-prussienne et les tensions entre la France et la Prusse suite à la victoire de celle-ci à Sadowa poussent en effet l'Europe scolaire à s'interroger sur les vertus pacificatrices de l'éducation. En août 1866 à Fribourg, les instituteurs romands rassemblés lors de leur premier congrès pédagogique officialisent le projet d'envoyer une délégation à Paris lors de l'Exposition universelle afin d'y étudier l'exposition scolaire et de susciter la création d'une association internationale d'instituteurs. Les principaux acteurs de l'école primaire romande composent la délégation présidée par Daguet. Tous collaborent à L'Éducateur et la plupart d'entre eux jouissent déjà de leur propre réseau avec le monde pédagogique français. Jules Paroz (1824-1906), ancien élève de Daguet et créateur de l'école normale évangélique de Grandchamp, a vu sa revue L'Éducateur populaire, fondée en 1848, absorbée par L'École normale de Pierre Larousse dès

37. Jean-Marie Barras, Au temps de l'école normale. D'Hauterive à Fribourg : chronique, contexte et témoignages, Fribourg, Imprimerie Saint-Paul, 2005, p. 40.

38. Lettre du 15 mars 1865, tirée de Rapports sur l'exposition scolaire de Paris en 1867, Lausanne, Imprimerie Borgeaud, 1868, p. V. 
$1859^{39}$. Il profite d'ailleurs de son séjour parisien pour lancer la publication de son Histoire de la pédagogie chez Charles Delagrave. Daguet a déjà rencontré Pierre-Philibert Pompée ${ }^{40}$ - le principal interlocuteur des Suisses à Paris - lorsque celui-ci visita les écoles de Girard à Fribourg.

Le 22 août 1865, la délégation romande assiste, sur l'invitation du ministre Duruy, à l'une des fameuses conférences de la Sorbonne organisées pour le perfectionnement des instituteurs français présents à Paris lors de l'Exposition universelle ${ }^{41}$. Daguet fait ressurgir les liens franco-suisses, avant d'argumenter les fondements universels et les enjeux de son projet:

Il y a entre nous, Messieurs et chers amis, plus d'un lien, plus d'un motif de rapprochement. Sans parler de la communauté de langue et du légitime pouvoir qu'exerce sur les esprits la riche et belle littérature française, qui est aussi la nôtre, n'y a-t-il pas pour tous les instituteurs identité de but, d'efforts, d'aspirations? Ne désirons-nous pas tous former une jeunesse intelligente, éclairée, généreuse, pénétrée du même amour du bien et du beau, du saint enthousiasme de Dieu, de l'humanité et de la patrie? En dépit de toutes les différences que peuvent mettre entre les peuples la nationalité et la diversité des méthodes, un fonds commun subsiste; c'est qu'il n'y a qu'une éducation comme il n'y a qu'une humanité ${ }^{42}$.

Daguet conclut par un appel à la formation d'une association internationale placée dans le sillage des idées des Lumières françaises:

Les grands principes qui unissent les peuples et les hommes n'ont jamais été affirmés avec plus de puissance et plus d'éclat que dans les grandes assemblées françaises qui ont proclamé la liberté et l'égalité civile et politique à la fin du dernier siècle. Ne serait-il pas beau, ne serait-il pas glorieux pour vous et pour nous, Messieurs, et chers collègues, de voir sortir de nos délibérations communes une institution qui fût le trait d'union des divers peuples, et réunit les instituteurs de tous les pays en congrès international.

39. Voir chapitre 5 et Jules Paroz, Mémoires d'un octogénaire, Porrentruy, Éditions du Précarré, 1981, p. 161 ainsi que le compte-rendu de Pierre Caspard dans Histoire de l'éducation, 1981, vol. 13, n¹, p. 95-96.

40. Pierre-Philibert Pompée (1809-1872) fut le directeur de l'école primaire supérieure municipale Turgot à Paris et le fondateur de l'école professionnelle d'Ivry. Médiateur dans I'espace franco-suisse, il étudia en Suisse la méthode Pestalozzi et rencontra le Père Girard (et Alexandre Daguet) à Fribourg. Lors de l'Exposition universelle de 1867, il fut désigné, grâce à ses bons rapports avec V. Duruy, pour faire partie du jury international des récompenses comme membre de la classe 90.

41. Voir Anne Rasmussen, « Les Congrès internationaux liés aux Expositions universelles de Paris (1867-1900) », Cahiers Georges Sorel, 7/1989, p. 23-44.

42. Rapports sur l'exposition scolaire de Paris en 1867, op. cit., p. VIII. 
C'est à la fondation de ce congrès que j'ose vous convier et la délégation suisse serait heureuse d'y contribuer pour sa faible part ${ }^{43}$.

Pierre-Philibert Pompée souscrit au projet et dans le sillage de la proposition suisse, indique par ailleurs vouloir mettre en place une exposition pédagogique internationale permanente à Paris, afin que les instituteurs de France puissent venir étudier à loisir les progrès susceptibles d'être importés dans leurs classes ${ }^{44}$. Cela étant dit, il faut souligner combien les structures nationales sur lesquelles doit reposer cette association internationale sont disparates et inégalement développées, ce qui fait dire à Daguet:

Peut-être l'idée souriait-elle au fond médiocrement à l'administration française; peut-être aussi ne pouvait-elle rien avoir de pratique dans une assemblée composée d'instituteurs venus de provinces éloignées et qui n'avaient jamais entendu parler d'une institution de ce genre; peut-être encore, et c'est des trois versions la plus probables, les chefs de l'instruction publique en France pensèrent-ils sagement qu'avant de songer à une réunion internationale, c'est-à-dire des divers peuples, il était nécessaire de commencer par organiser une société générale des instituteurs français ${ }^{45}$.

Soucieuse de présider à la destinée de cette association, la délégation suisse propose de se servir des congrès pédagogiques romands comme point de rencontre des divers délégués qui proviennent de toute l'Europe et même des colonies ${ }^{46}$.

\section{Une entreprise supervisée par la Suisse française}

Remise ainsi à l'ordre du jour du deuxième congrès de la SIR en août 1868 à Lausanne, la question est timidement traitée, d'autant que le spectre du choléra a retenu chez eux la plupart des invités étrangers.

43. Ibid., p. VIII-IX.

44. Ibid., p. 137-138.

45. Ibid., p. XIV.

46. Les principaux délégués qui fréquentent les congrès romands et participent à I'élaboration des statuts de I'Association pédagogique universelle sont pour I'Italie, Vincenzo de Castro, professeur émérite de I'université de Padoue et membre du conseil-directeur de l'Association nationale pour l'éducation du peuple ainsi que J.-O. Mellé, professeur de belles-lettres à Turin; pour la Belgique, Jean-Joseph Campion, président de la fédération des instituteurs belges; pour la France, Charles Defodon, secrétaire de la Société pour I'instruction élémentaire à Paris, MM. Merle et Masson, instituteurs ainsi que François-Joseph Gastu, maire d'Alger et son adjoint d'El Biar; pour la Hollande, J.-F. Humalda, inspecteur de la province de Frise; pour la Grèce, M. Frédéricos, secrétaire du ministère de I'Instruction publique et ses adjoints MM. Lascaris et Grégorias; pour la Russie, M. Smolian, inspecteur des écoles sibériennes et M. Swekowski, professeur à Kiev. 
Néanmoins, les messages d'appui reçus pour l'occasion laissent à penser que l'entreprise possède déjà un début de réseau, en partie constitué à Paris grâce à l'appui de personnalités comme Jules Simon, Albert Le Roy, André Rousselle, tous trois membres de la Société pour l'instruction élémentaire, Pierre-Philibert Pompée et Adrien Guerrier de Haupt, le rédacteur de L'union des instituteurs. Notons encore que la Société centrale des instituteurs belges, représentée par Emmanuel van Driessche, instituteur franc-maçon impliqué dans les activités de la Ligue de l'enseignement, Pierre Wynen, président de la Société des instituteurs privés d'Anvers et le libre-penseur Jean-Joseph Campion, gérant de la revue pédagogique Le Progrès bruxellois ainsi que la Societa pedagogica italiana et son président Giuseppe Sacchi s'agrègent à ce premier réseau et se retrouvent lors des assemblées romandes.

Deux ans plus tard, lors du congrès neuchâtelois de 1870, la déclaration de guerre à la Prusse sonne momentanément le glas de toute idée d'union internationale. C'est donc lors des congrès de Genève (1872) et de Saint-Imier (1874) que la question d'une association internationale revient au centre des préoccupations. La vocation internationale dont jouit la Rome protestante a une incidence certaine dans la reprise $\mathrm{du}$ dialogue et du projet de fondation de l'Association pédagogique universelle. Pourtant, cet optimisme de façade n'efface en rien les obstacles qui surgissent lors de l'assemblée. Les effets de la guerre francoprussienne se font sentir. Certains, comme l'instituteur vosgien Masson ou le professeur italien Pietro Preda, collègue de Daguet et de Buisson à l'académie de Neuchâtel, proposent d'exclure l'Allemagne. Preda soumet l'idée de fonder « pour le moment et en attendant mieux, une association des instituteurs de race latine, qui comprendrait les pays où l'on parle français, italien et espagnol ${ }^{47}$ ". La réponse de Daguet est sans équivoque:

Ce que nous voulons, ce n'est donc pas une fédération partielle, exclusive. Surtout pas d'exclusion de l'Allemagne qui est avec la Suisse la terre classique de la pédagogie rationnelle et le berceau de l'invention de Gutenberg, sans lequel la diffusion actuelle des lumières eût été impossible. C'est le propre de tous les Nabuchodonosors français et allemands d'être éblouis de leurs victoires. Mais la haine de la France et de l'Allemagne, toute vivace qu'elle soit, ne sera pas éternelle, et si des représentants de ces deux grandes nations doivent se rencontrer et se tendre une main fraternelle, c'est à coup sûr sur le terrain neutre de la science et de

47. Compte-rendu du IV congrès scolaire de la Société des instituteurs de la Suisse romande tenu à Genève les 29, 30 et 31 juillet 1872, Genève, Imprimerie Taponnier et Studer, 1872, p. 83. 
l'éducation. [...] Quoi qu'il advienne, ouvrons toutes grandes les portes de l'Alliance pédagogique. Il y aura déjà assez de difficultés de détail, d'obstacles financiers à vaincre. Ceux qui viendront à nous, Français ou Allemands, seront des hommes de cœur, élevés au-dessus des haines de race et de nation. Acceptons-les tous: paix aux hommes de bonne volonté sur la terre ${ }^{48}$.

On mesure ici le caractère pacificateur que Daguet attribue à la pédagogie, eu égard au premier chef aux tensions internationales. Relevons au passage que ce sera également via le canal de la pédagogie que l'inspecteur strasbourgeois Guillaume Jost, invité au XXVI ${ }^{\mathrm{e}}$ congrès des instituteurs allemands de Darmstadt en décembre 1885, tendra une main réconciliatrice à l'Allemagne: "Nous pouvons différer en politique, mais en ce qui concerne l'éducation populaire, nous ne connaissons pas de frontières. Il n'y a pas de pédagogie spécifiquement allemande, italienne, française et celui-là n'est pas un pédagogue qui croit n'avoir rien à apprendre chez les autres peuples ${ }^{49}$. "

Enfin, les discussions sur la terminologie à adopter pour nommer l'association s'avèrent houleuses. Plusieurs intitulés sont discutés: "Association universelle des instituteurs ", "Société pédagogique universelle » ou encore «Ligue universelle d'enseignement ». Daguet défend même l'utilisation délicate de "Société internationale " et s'attache à faire taire certaines rumeurs suggérant qu'en Italie, " on a cru qu'il s'agissait d'une espèce d'internationale poursuivant des idées révolutionnaires ${ }^{50}$ ". L'assemblée aboutit finalement à un consensus et ses membres proclament, à l'unanimité, la création de l'Association pédagogique universelle:

Le congrès scolaire, réuni à Genève le 31 juillet 1872, décide à l'unanimité la création d'une Association pédagogique universelle. Pour atteindre son but, le congrès charge son bureau d'adresser immédiatement un appel aux Sociétés pédagogiques des différents pays. Cet appel sera signé par le bureau du congrès actuel et par les délégués étrangers présents. Dès que trois sociétés de pays différents auront donné leur adhésion au projet de la Société pédagogique universelle, elles désigneront des délégués pour s'entendre sur la constitution même de la Société et pour aviser aux meilleurs moyens d'atteindre le but ${ }^{51}$.

48. Ibid., p. 84

49. Alexandre Daguet, « Pédagogie de I'Allemagne », L'Éducateur, 1/1886, p. 6.

50. Compte-rendu du Ve congrès scolaire, op. cit., p. 98.

51. Compte-rendu du IV congrès scolaire, op. cit., p. 88. 
Cependant, deux ans plus tard, dans un rapport qu'il rédige pour préparer les débats du congrès de Saint-Imier de 1874, l'instituteur vosgien Masson réitère son vœu de voir naître une association des membres du corps enseignant " de race latine ". Son collègue, M. Vion, appelle quant à lui à la création d'un bulletin élaboré sous l'égide de la France et voué à terme à devenir l'organe de l'enseignement laïque. Selon lui, un grand congrès constituant pourrait avoir lieu l'année suivante, à Pâques, à Paris, à l'occasion du congrès de géographie ${ }^{52}$. On se trouve ici en face d'une des rares contestations du leadership romand, que Daguet va réprimander d'une manière plutôt autoritaire, sinon arrogante:

Nous aimerions bien pouvoir partager la confiance de M. Vion quant à la part que prendra son pays à notre œuvre, mais il nous semble que la question de débuter par la France est un peu prématurée et même hasardée. Il sera donc plus prudent, à notre avis, de tenir ailleurs le premier congrès dont il s'agit. Il ne suffit pas que l'esprit d'association existe dans un pays; il faut de plus qu'il soit encouragé et non comprimé. Nos collègues de la France, bien disposés d'ailleurs à nous prêter un concours efficace, ne le pourront que par un zèle soutenu et une grande persévérance à réclamer pour eux le droit de réunion qu'on leur conteste, et qui seul peut donner essor à leurs légitimes aspirations ${ }^{53}$.

Le congrès de Saint-Imier de 1874 marque ainsi le début des désillusions pour Daguet, qui ne dissimule plus son irritation. Le troisième jour, au moment d'aborder la question internationale, le temple où se tient le congrès se vide de ses instituteurs, peu concernés semble-t-il par ces préoccupations internationales: "Soit que cette question n'intéressa pas au même degré que les autres, soit qu'on trouva trop long le terme de trois jours, le temple était presque désert quand on traita ce sujet et l'auditoire réduit à 40 ou 50 personnes ", peut-on lire dans le Journal de Genève du 29 juillet 1874. Lorsqu'on s'essaie timidement à une ébauche de statuts, la montée des intérêts nationaux, la volonté de tirer la couverture à soi marque un coup d'arrêt définitif au projet universaliste romand. Les tractations s'enlisent, n'aboutissent finalement qu'à des résultats très mitigés. Enfin, durant les préparatifs pour le congrès de Fribourg de 1877, l'inactivité de la commission chargée de traiter la question pousse Daguet à donner le coup de grâce. Cette entreprise s'avère en fait, selon lui, " un idéal impossible à réaliser dans les circonstances présentes, ou

52. Compte-rendu du ve congrès scolaire, op. cit., p. 91.

53. Ibid. 
comme une utopie généreuse éclose au souffle exhilarant et enthousiaste des expositions universelles ${ }^{54}$ ". En dépit de cet échec, cette association va perdurer sous une autre forme: à cette tentative avortée de rassemblement physique va se substituer une communauté fort puissante à travers les publications. Le réseau occidental de la pédagogie libérale-nationale va dès lors, selon la fameuse formule de Norbert Elias, "étendre ses chaînes d'interdépendance ${ }^{55}$ » à l'emploi massif de la presse et des revues afin de traduire, transférer et diffuser les éléments d'un système éducatif pensé de manière collective - et de ce fait de plus en plus standardisé - dans le but d'ôter définitivement à l'Église le monopole de l'enseignement public.

\section{L'association est morte, vive l'association!}

C'est dans cette perspective que Daguet s'attelle à la constitution d'un réseau européen de la presse pédagogique, qu'il appelle ainsi de ses vœux :

Si la fédération universelle par voie de congrès et de délégués est difficile à établir et à pratiquer, il n'en est pas de même de la fédération qui s'opère par la voie des journaux et de l'échange d'idées qu'elle établit entre les éducateurs et écrivains pédagogiques non seulement de l'Europe, mais des deux hémisphères.

C'est à cet échange surtout que nous pensions dès l'origine de notre Société et son organe, et nous n'avons rien négligé pour le créer, l'étendre à tous les peuples civilisés, à commencer par ceux dont la langue est généralement comprise et même à ceux dont la langue n'est connue que de quelques initiés. Les idées lumineuses ne sont pas l'apanage d'une seule nation ou de certains peuples, pas plus que d'un ou de plusieurs individus. Il ne faut rien mépriser, rien négliger. Puis, vous pouvez être utiles et apporter des lumières à ceux qui ne vous en donneraient pas. Quoi de plus beau d'ailleurs, de plus profitable et de plus touchant que ces relations de peuple à peuple, d'esprits à esprits, de corps enseignant à corps enseignant, d'un bout du monde à l'autre? Si l'humanité doit jamais former une grande famille, c'est assurément par l'école que doit commencer cette fusion des divers groupes de l'humanité qu'on nomme les nations ${ }^{56}$.

54. Alexandre Daguet, « Un mot sur la question de la fédération universelle », L'Éducateur, 9/1876, p. 135-136.

55. Norbert Elias, La société des individus, Paris, Fayard, 1991.

56. Alexandre Daguet, « Revue de la presse pédagogique en Europe et aux États-Unis et relations de L'Éducateur à l'étranger », L'Éducateur, 19/1876, p. 290. 
Ainsi, dès le milieu des années 1870, Daguet propose régulièrement dans L'Éducateur une revue de la pédagogie européenne, c'està-dire des pays avec lesquels son journal est en relation par l'échange de leurs numéros. Si la pratique du courrier international n'est pas neuve et fut déjà pratiquée antérieurement par d'autres revues, les acteurs de ce réseau font de la presse pédagogique un point de rencontre et un élément médiateur fondamental de la diffusion d'une pédagogie libérale-nationale - essentiellement anticléricale - dont on peut reconstituer la constellation à partir du réceptacle offert par L'Éducateur. Dès ses premières semaines de publication en 1865 , ce dernier était entré en relation avec la revue Patria e Famiglia du pédagogue lombard Giuseppe Sacchi, avec El Magisterio Espanol dirigé par le pédagogue Emilio Ruiz de Salazar ainsi qu'avec Los Annales de primera ensenaza rédigées par Mariano Carderera, directeur de l'instruction publique au ministère du Fomento à Madrid et par ailleurs rédacteur dans le premier Dictionnaire de pédagogie de Buisson ${ }^{57}$. Grâce à la traduction, plusieurs articles qui le plus souvent sont choisis pour légitimer des politiques scolaires locales, jouissent d'une diffusion européenne et facilitent la circulation de savoirs pédagogiques dans l'espace occidental ${ }^{58}$. Ces processus de transferts laissent apparaître des situations d'osmose et d'assimilation de savoirs qui transitent via les revues pour être adaptés par leur contexte d'accueil. Comme le relève Daguet, "les feuilles étrangères ne se bornent pas à échanger avec nous; elles nous citent souvent, empruntent ou traduisent nos articles ${ }^{59}$ ». L'Allgemeine Deutsche Zeitung de Darmstadt réserve une place de choix aux articles de fond de L'Éducateur. L'anticlérical Christian Jessen reproduit in extenso plusieurs articles romands dans ses Freien pädagogischen Blätter publiées à Vienne. Dans les années 1871-1872, L'Éducateur entre en relation avec deux revues libérales anglaises, le School-board Chronicle et l'organe de la National-Education-League, toutes deux imprimées à Londres. Avide

57. Voir Patrick Dubois, Le Dictionnaire de pédagogie et d'instruction primaire de Ferdinand Buisson. Répertoire biographique des auteurs, Paris, INRP, 2002, p. 51. L'édition de 1911 est accessible en ligne sous http://www.inrp.fr/edition-electronique/lodel/dictionnaire-ferdinandbuisson

58. Voir Béatrice Haenggeli-Jenni, Alexandre Fontaine et Patrick Bühler, « Une circulation des idées pédagogiques sur papier. Presse d'éducation, transferts et trajectoires transnationales des savoirs (1850-2000) », Revue suisse des sciences de l'éducation, numéro thématique, 36/1, 2014.

59. Alexandre Daguet, « Les jardins de l'enfance et l'école de Chantepoulet à Genève. Conférences pédagogiques données par M. Sante Polli, directeur de l'École normale de Milan », L'Éducateur, 14/1868, p. 220-223. 
de faire connaître en Suisse les livres élémentaires de l'Union américaine, Daguet initie une collaboration avec Journal of Education de Boston en 1872. Ces échanges transnationaux, progressifs, suscitent la mise en place d'un réseau spécifique des revues pédagogiques, un lobby international regroupant les représentants d'une pédagogie éclectique et anticléricale.

\begin{tabular}{lll} 
Revues & Rédacteurs & Orientations \\
\hline L'Éducateur & A. Daguet & Catholique libéral, maçon \\
\hline Schweizerische Lehrerzeitung & J.-U. Rebsamen & Protestant libéral \\
\hline L'Educatore della Svizzera italiana & G. Ghiringhelli & Chanoine radical \\
\hline Le Progrès de Bruxelles & J.-J. Campion & Libre penseur, maçon \\
\hline Le Manuel général de l'instruction primaire & C. Defodon & Catholique libéral \\
\hline Revue pédagogique & F. Buisson & Protestant libéral \\
\hline Patria e Famiglia & G. Sacchi & Patriote italien, libéral \\
\hline Enrico Pestalozzi o l'Educazione nuova & V. di Castro & Patriote italien, libéral \\
\hline Freien pädagogischen Blätter & C. Jessen & Libéral anticlérical \\
\hline School Board Chronicle (London) & A. Bikkers & Libéral, maçon \\
\hline De Vekker (La Haye) & M. Lallemand & Libéral \\
\hline Los Annales de primera ensenaza & M. Carderera & Libéral \\
\hline El Magisterio Espanol & E. Salazar & Libéral \\
\hline
\end{tabular}

Revues européennes en relation avec L'Éducateur (1865-1890)

La communauté de langue entre la Suisse romande et la France va de fait privilégier les échanges et les métissages pédagogiques entre les deux espaces ${ }^{60}$. Peu après son retour à Paris en 1870, Buisson fait la publicité de L'Éducateur dans le Bulletin pour l'enseignement élémentaire de Paris:

L'Éducateur est une solide et consciencieuse revue pédagogique publiée par les instituteurs de la Suisse romande. Parmi les nombreuses feuilles que nous parcourons, aucune ne contient des articles plus substantiels. Comme le Progrès, l'Éducateur n'est pas exclusif; il recueille de tous les côtés les renseignements, les faits, les livres, les méthodes: aussi est-il d'une lecture tout à fait profitable pour l'instituteur qui aime sa pro-

60. Voir Laurier Turgeon (dir.), Regards croisés sur le métissage, Laval, Les Presses de I'Université, 2003. 
fession et qui s'intéresse à tout ce qui se fait, au près et au loin, pour l'éducation du peuple ${ }^{61}$.

De son côté, Daguet fait savoir dans L'Éducateur que les ministres de l'Instruction publique et des Cultes qui se sont succédés en France de Victor Duruy à Jules Simon, ont gratifié sa revue de l'envoi régulier $\mathrm{du}$ Bulletin administratif de leur département ministériel ${ }^{62}$. Comme souvent en Suisse, on cherche à légitimer les entreprises locales par l'approbation symbolique et le cachet de l'étranger. C'est dans cette perspective que le comité de rédaction de L'Éducateur adresse sa revue à plusieurs personnalités françaises. Victor Hugo accuse réception d'Hauteville-House le 18 avril 1869:

Absorbé par des travaux urgents, je n'ai pu vous remercier plus tôt de votre excellente lettre. Voir le peu que je fais si bien compris, et par de telles intelligences, serait pour moi une douce récompense, si une récompense m'était due; mais je suis loin de le penser. Le devoir, c'est là ce que je tâche de faire. Hors de là, je ne suis rien. Vous m'envoyez votre utile journal, je le lis avec intérêt et je vous prie de croire à toute ma cordialité ${ }^{63}$.

En outre, de nombreux articles sont reproduits dans des revues pédagogiques françaises: dans le Manuel général de l'instruction publique de Charles Defodon, dans l'Union des instituteurs d'Adrien Guerrier de Haupt ${ }^{64}$ ou dans le Bulletin pour l'enseignement élémentaire de Paris. Mais à l'évidence, c'est Ferdinand Buisson qui va s'attacher à faire connaître L'Éducateur en France et même beaucoup plus loin :

Je vous avais demandé l'article Éducateur pour le 29 avril. Si vous pouviez m'envoyer d'ici à 8 jours à défaut de cet article une note d'une page ou deux au plus sur l'origine du journal, ses fondateurs, son mode de publication, ses principales séries de travaux pédagogiques, etc., je pense qu'il vous serait agréable de profiter d'une bonne occasion que je puis

61. Ferdinand Buisson, « L'Éducateur de la Suisse romande », Bulletin pour l'enseignement élémentaire de Paris, juin-juillet 1871.

62. Alexandre Daguet, « Revue de la presse pédagogique en Europe et aux États-Unis et relations de l'Éducateur avec l'Étranger », L'Éducateur, 19/1876, p. 294-295.

63. Réponse de Victor Hugo à Monsieur Biolley, président de la SIR, in Compte-rendu du Congrès pédagogique de Neuchâtel en 1870, Neuchâtel, Imprimerie G. Guillaume Fils, 1870, p. 37-38.

64. Le congrès scolaire de Lausanne. Rapport sur la troisième session de l'assemblée générale des Instituteurs de la Suisse romande réunis les 5 et 6 août 1868, Lausanne, Imprimerie Borgeaud, p. 8. 
vous offrir. Je ferais imprimer cet article-là dans un nouveau spécimen que je vais faire adresser à tous les journaux pédagogiques dont je sais l'existence en Europe et en Amérique. Ce serait donc un moyen de notoriété assez bon mis à votre portée. Vous me comprenez bien ${ }^{65}$.

Buisson s'intéresse particulièrement aux problématiques romandes développées dans les articles de fond de la revue et dans ce sens concède à Daguet: "Je n'ai pas besoin de vous dire que de mon côté je serais heureux d'avoir l'occasion, dans mon service d'inspecteur, de faire connaître et apprécier ici une publication où les Français en particulier auraient tout à apprendre ${ }^{66}$." Ce sont d'ailleurs ces mêmes réseaux que Ferdinand Buisson va réactiver et utiliser afin de lancer son propre projet international.

\section{Buisson et l'élaboration d'une pensée sur l'éducation internationale}

Afin d'imposer et de légitimer sa vision internationale de l'éducation, Buisson dut non seulement trouver les moyens de rassembler les instituteurs européens mais également concevoir une théorie générale des nouveaux rapports entretenus par les nations européennes naissantes ${ }^{67}$. Il faut dire qu'il avait longtemps réfléchi à ces questions depuis le premier congrès de la Ligue internationale de la paix et de la liberté de Genève en 1867; sa pensée est résumée dans un article intitulé L'instruction et l'éducation internationale ${ }^{68}$ qui paraît à Paris et à Berne en 1905. Buisson prend pour prémisse la concurrence de l'élément national avec l'international comme "trait caractéristique de la civilisation à l'heure où nous sommes ». De ce fait, il apparaît essentiel que l'école éduque l'homme non seulement à son milieu, mais lui fasse également découvrir l'importance croissante des relations internationales ainsi que les progrès des échanges humains à l'échelon

65. Lettre de F. Buisson à A. Daguet, sans lieu ni date, Archives de l'État de Neuchâtel, Fonds Daguet.

66. Ibid.

67. Klaus Dittrich donne une analyse de l'œuvre de médiation transnationale de Buisson dans « Appropriation, Representation and Cooperation as Transnational Practices: The Example of Ferdinand Buisson », in Isabella Löhr et Roland Wenzlhuemer, The Nation State and Beyond: Governing Globalization Processes in the Nineteenth and Early Twentieth Centuries, Springer, 2013, p. 149-173.

68. Ferdinand Buisson, L'instruction et l'éducation internationale, Paris et Berne, bureau de la Grande Revue, Ligue internationale de la paix et de la liberté, 1905. 
international, qu'ils soient de nature commerciale ou scientifique. Au côté idéal, voire utopique, s'adjoint une autre vision, paradoxale, que l'enfant doit également éprouver:

Nous ne devons pas lui laisser ignorer que cet idéal est encore loin d'être réalisé; et, qu'en attendant qu'il le soit, chaque nation pouvant avoir encore à se défendre à main armée, tout citoyen est tenu de répondre à l'appel de sa patrie et de remplir virilement et courageusement le devoir militaire comme la première des obligations que la loi lui impose envers son pays ${ }^{69}$.

Selon Buisson, c'est ce paradoxe qui doit être enseigné à la jeunesse européenne. Le jeune Français, comme l'Allemand ou l'Italien doit "vivre le cœur plein des visions de la paix internationale qui seront un jour la réalité générale sur cette terre, mais l'œil attentif, l'âme tendue et roidie pour répondre au premier signal si la patrie [1]appelle ${ }^{70}$ ». Buisson initie son raisonnement en partant d'un fondement anthropologique et prend en compte la dualité de l'égoïsme instinctif et de l'altruisme qui lui fait contrepoids. Cet équilibre permet ainsi à l'homme d'accepter sa soumission au pacte social: "Il se subordonne jusqu'à un certain point à la famille d'abord, première cellule de la société; puis successivement et progressivement à une toute petite agglomération de familles, clan, tribu, gens ${ }^{71}$. » En cela, Buisson annonce en quelque sorte Benedict Anderson et sa communauté imaginée ${ }^{72}$, en affirmant que: "C'est la forme minuscule de la patrie [qui] s'étend et passe à l'état de groupement dépassant les limites où s'arrêtent la connaissance directe des relations de parenté et le souvenir des liens du sang ${ }^{73}$."

S'il est un point intéressant de ce développement, c'est celui des phases successives de la construction des sociétés que Buisson emprunte à Jean Izoulet (1854-1929). Ce normalien, secrétaire particulier de Paul Bert et détenteur de la chaire de philosophie sociale au Collège de France où il sera remplacé à sa mort par Marcel Mauss, explique que "chaque fois que le cercle s'agrandit, il y a une crise du patriotisme ». Ainsi, le devoir envers la petite patrie d'hier semble

69. Ibid., p. 18.

70. Ibid., p. 9.

71. Ibid., p. 11.

72. Benedict Anderson, L'imaginaire national. Réflexions sur l'origine et l'essor du nationalisme, Paris, La Découverte, 2002 [1983].

73. Ferdinand Buisson, L'instruction et l'éducation internationale, op. cit., p. 11. 
remis en question, compromis ou nié par l'avènement d'une patrie plus grande. Buisson admet le caractère paradoxal de ces fusions: «Quelle invraisemblable entreprise que de faire évanouir ces patriotismes concrets et historiques, souvent opposés, plus souvent inconnus et indifférents les uns aux autres, le normand et le breton, le bourguignon et l'armagnac, le flamand et le provençal, pour en faire un jour l'âme française et la patrie française ${ }^{74}$.» D'Izoulet, Buisson reprend également la théorie d'un patriotisme de superposition structuré en cinq strates successives: le patriotisme municipal, provincial, national, continental et le dernier global ou planétaire. Dans cette perspective, l'humanitarisme est perçu comme une onde élargie du patriotisme et cet argumentaire est repris par Buisson pour affirmer que l'éducation internationale n'est ni antipatriotique, ni antinationale, ni même antimilitaire:

Elle n'exagère ni ne diminue le rôle de la patrie, le rôle des patries de l'espèce humaine. Elle sait qu'il n'y a pas d'humanité là où il n'y a pas de patrie, mais elle sait aussi que les patries tendent à s'humaniser et qu'elles finissent, comme on l'a dit, par communier dans l'espèce. Le patriotisme d'hier, c'était la haine des autres patries, celui de demain ce sera presque un interpatriotisme $e^{75}$.

Soucieux d'insérer la France dans le mouvement pédagogique international, Buisson entre en scène au moment où son ancien collègue suisse s'apprête à donner le coup de grâce à son projet universaliste. En 1877, il écrit à Daguet:

Une lettre de M. Campion m'encourage à faire auprès de vous une démarche qui ne sera peut-être pas plus heureuse que les précédentes. Il s'agit de ce fameux projet de société ou alliance internationale des instituteurs et amis de l'enseignement. Ce projet est né je crois à Genève, est-il enterré? Si oui n'en parlons plus. Sinon, y aura-t-il à Fribourg cette année une séance consacrée à l'étude de la question? Vous savez que j'avais songé à la création d'une société (internationale) d'études pédagogiques. [...] Il paraît que les instituteurs de la Suisse romande et vous leur grand inspirateur vous ne croyez plus devoir encourager ce projet. Soit. Peut-être la chose ne se fera-t-elle pas! Du moment qu'une voix aussi importante que celle de la Suisse manque à ce concert, il n'y a qu'à renoncer à l'idée. D'ailleurs nous autres Français nous ne demandons ni ne songeons, quoique nous ayons peut-être une autre réputation

74. Ibid., p. 13-14.

75. Ibid., p. 15. 
en Suisse, à nous annexer les sociétés étrangères. Au contraire si vous créez votre société ou alliance universelle, nous serons bien aisés d'y rentrer à la place qu'il vous plaira de nous assigner. Nous travaillons en ce moment à une certaine suite et dans un esprit pratique à l'amélioration de nos institutions scolaires. Et nous éprouvons le besoin de nous instruire, de nous informer, de nous tenir au courant de ce qui se fait de bon au près et au loin. Si donc il était possible de profiter du congrès de Fribourg pour un rapprochement à titre quelconque, fut-il même borné à l'établissement d'un échange régulier de communications et de renseignements entre les écoles de divers pays, je me ferais un plaisir d'aller à ce congrès et d'en suivre les travaux, si toutefois les étrangers peuvent y assister ${ }^{76}$ ?

Rappelons-le, Buisson avait déjà réfléchi à la constitution d'une organisation internationale, souhaitant faire de la Ligue de la paix et de la liberté " une sorte de société internationale pour l'organisation universelle de l'éducation démocratique ». Si la réponse de Daguet nous est inconnue, il semble que celui-ci ait interprété les mots de Buisson comme une ingérence et réagi contre cette volonté, de la part de son ancien collègue, de renverser la situation à son avantage comme Buisson l'évoque dans une autre lettre:

Vous vous méprenez sur le sens de ma proposition, si vous n'y voyez rien qui puisse donner ombrage à L'Éducateur et à la Société suisse. Au contraire, il s'agit de répondre à l'appel international de Genève et de Saint-Imier et de fonder quelque chose en conséquence d'un commun accord. Je vous en écrirai plus long sur ce sujet que je crois de nature à vous intéresser si je venais de voir ici M. Sandoz, qui est au courant de mes vues et intentions. Il vous en parlera et j'espère vous convaincra qu'il y a une envie bonne et utile à faire, où la Suisse ne peut refuser son concours à la France. ${ }^{77}$

Ces échanges, marqués en filigrane par de tenaces batailles d'ego, ne se soldent par aucune réalisation concrète. Buisson s'essaiera une seconde fois à la réactivation du projet au tournant du $\mathrm{XIX}^{\mathrm{e}}$ siècle, dans le sillage de la fédération des amicales de France, créée en 1900, qui précède et constitue par ailleurs un terrain favorable à l'émergence

76. Lettre de F. Buisson à A. Daguet, sans lieu ni date, mais il s'agit assurément d'une lettre envoyée dans le courant de 1877, année du congrès de Fribourg, Archives de l'État de Neuchâtel, Fonds Daguet.

77. Lettre de F. Buisson à A. Daguet, sans lieu ni date (courant 1877), Archives de l'État de Neuchâtel, Fonds Daguet. 
du syndicalisme enseignant ${ }^{78}$. Dans le Manuel général de l'instruction primaire du 13 juin 1903, un comité d'action constitué pour l'occasion dévoile le programme d'une excursion des membres de l'enseignement primaire français en Helvétie ${ }^{79}$. Celle-ci doit marquer le début des grandes excursions pédagogiques en Europe, patronnées notamment par Buisson, Gabriel Compayré et Émile Levasseur. Ce qu'il convient surtout de souligner, c'est que ces organisateurs avaient pour intention de provoquer la constitution d'un comité international d'études pédagogiques afin d'établir des liens entre tous les instituteurs d'Europe. Ernest Savary, auteur d'une notice historique rédigée à l'occasion du jubilé cinquantenaire de la Société pédagogique de la Suisse romande, souligne à cet égard que "pendant l'été 1903, les instituteurs de la Suisse romande reçurent la visite d'une caravane de leurs collègues français qui venaient visiter notre pays et nous proposer la création d'une Union internationale d'instituteurs. Le projet fut accueilli avec empressement par les dirigeants de notre association mais, rentrés dans leurs foyers, les maîtres français oublièrent complètement ce qu'ils nous avaient proposé ${ }^{80}$ ! » En dépit de cette nouvelle déconvenue, il n'en demeure pas moins que ces diverses expériences de rapprochements internationaux constitueront un socle sur lequel les acteurs de l'éducation occidentale pourront s'appuyer après le premier conflit mondial pour réactiver et parachever cette lente mise en réseau, non sans provoquer d'ailleurs de substantiels avancements au niveau local.

\section{Échec global, avancées locales}

De fait, l'analyse de ces tentatives manquées permet de mieux comprendre les raisons des échecs constitutifs du mouvement associatif européen du second $\mathrm{xIx}^{\mathrm{e}}$ siècle. Tout d'abord, le manque de moyens financiers a lourdement pesé sur l'avenir de l'Association pédagogique universelle. Ensuite, il eût été nécessaire que tout pays qui souhaitait y prendre part disposât déjà d'un réseau de sociétés cantonales, régionales ou départementales. On l'a vu, Buisson ne s'est concrètement engagé dans le mouvement international

78. Voir Loïc Le Bars, « Amicales et syndicats dans l'enseignement primaire (1901-1919) », in Danielle Tartakowsky et Françoise Tétard, Syndicats et Associations. Concurrence ou complémentarité?, Rennes, PUR, 2004, p. 37-46.

79. « Excursion des Membres de l'enseignement primaire en Suisse du 5 au 11 septembre 1903 », Manuel général de l'instruction primaire, n²4, 13 juin 1903, p. 282.

80. Ernest Savary, op. cit., p. 35-36. 
qu'après la création de la fédération des amicales de France (1900) et l'avènement de structures locales et régionales sur lesquelles il pouvait légitimement reposer ses ambitions ${ }^{81}$. Enfin, il faut pointer la multiplicité des internationales de l'éducation qui, pour survivre, se vouent tout au long du second $\mathrm{XIX}^{\mathrm{e}}$ siècle une concurrence acharnée. Rappelons qu'en 1868, le professeur Hermann Karl von Leonhardi et la frœbélienne $\mathrm{M}^{\text {me }}$ de Marenholtz-Bülow fondent l'Allgemeine Erziehungsverein dans le but d'engendrer une Confédération internationale des amis de l'éducation. Cette concurrence s'accroît encore avec la création d'une Société internationale, composée d'une cinquantaine d'instituteurs suisses, badois et bavarois. Fondée le 18 mai 1872 à Rorschach dans le canton de Saint-Gall, cette association est appuyée par la Schweizerische Lehrerzeitung (Revue des instituteurs de Suisse allemande) et s'incarne de fait comme le contrepoids germanique de l'entreprise romande.

Toutefois, et malgré l'échec de l'Association pédagogique universelle, on prend conscience en France de l'importance des réunions internationales et de la nécessité de rassembler les instituteurs dans des structures départementales, regroupées ensuite dans un faisceau national. L'idée fait son chemin et en 1885, le maire du Havre Jules Siegfried convoque un congrès international d'instituteurs. Mais c'est davantage au plan national que ce rassemblement permet des avancées, lesquelles seront poursuivies lors du congrès convoqué à Paris en 1887 . Une résolution tendant à la constitution, dans chaque département, d'une société autonome et amicale des instituteurs y est votée, la fédération de ces sociétés devant aboutir à l'Union amicale des instituteurs de France ${ }^{82}$. Il faut souligner que ce mouvement français de fédération départementale, combattue par le ministre Eugène Spuller au nom de la souveraineté et de l'unité nationales, s'inspire des sociétés pédagogiques belges et romandes, auxquelles

81. Sur I'histoire des amicales et du syndicalisme enseignant, voir M. T. Laurin (Maurice Tortillet), Les instituteurs et le syndicalisme (amicales et syndicats d'instituteurs), Paris, Librairie des sciences politiques et sociales, 1908; Frédéric Mole, L'école laïque pour une République sociale. Controverses pédagogiques et politiques (1900-1914), Rennes, PUR, 2010; Loïc Le Bars, « Amicales et syndicats dans l'enseignement primaire (1901-1919) », in Danielle Tartakowsky et Françoise Tétard, op. cit., p. 37-46 et dans le même volume, Bruno Poucet, « Association et syndicalisme dans l'enseignement privé dans la première moitié du $X X^{e}$ siècle », p. 107-116 ainsi que Jean-Paul Martin, « Ligue de l'enseignement, Amicales et Syndicats d'instituteurs sous la Troisième République », p. 361-370.

82. Voir l'article « Congrès d'instituteurs, congrès pédagogiques », Nouveau Dictionnaire de pédagogie et d'instruction primaire, édition électronique, www.inrp.fr. 
l'éducateur franc-maçon Gustave Francolin (1835-1899), fondateur de l'école de sociologie, consacre plusieurs notices dans Les congrès d'instituteurs ${ }^{83}$. Née des discussions du Havre, cette feuille paraît dès novembre 1885 afin de légitimer la création d'une fédération des instituteurs français. Il faudra néanmoins attendre l'arrivée au pouvoir des républicains radicaux et le vote de la loi de 1901 sur les associations, pour voir les amicales se multiplier en toute légalité ${ }^{84}$. Ainsi, l'histoire des internationales de l'éducation doit aussi se penser au travers de ses maillons successifs antérieurs, même si la plupart d'entre eux se sont soldés par des échecs. Heinz-Gerhard Haupt souligne avec raison le danger d'écrire une histoire des interconnexions qui ne prendrait en compte que ses succès ${ }^{85}$. La mise en perspective de cet essai manqué d'Association pédagogique universelle rappelle que la lente constitution des internationalismes éducatifs demeure le fruit d'ardents combats, de concurrences nationales, de rivalités d'ego et de jeux diplomatiques fort subtils.

83. Les congrès d'instituteurs. Comptes-rendus des congrès pédagogiques internationaux, nationaux et régionaux, des conférences cantonales, des associations syndicats, unions et fédérations d'Instituteurs (gérant: G. Francolin), Paris, Imprimerie L. Hugonis, 1885-1889.

84. Bertrand Geay, Le syndicalisme enseignant, Paris, La Découverte, 2005 [1997], p. 32-57.

85. Heinz-Gerhard Haupt, « Une nouvelle sensibilité : la perspective transnationale », Cahiers Jaurès, no 200, avril-juin 2011, p. 178. 


\section{5 \\ Connexions franco-romandes et bigarrures pédagogiques}

Dans Les quatre parties du monde, Serge Gruzinski développe un argumentaire fort pertinent sur la manière de penser l'interrelation et les phénomènes de métissages. Sensible à l'idée de cloisonnement, il fait remarquer que « des différences et des distances souvent exagérées, réifiées et parfois même imaginées de toutes pièces finissent par enterrer les continuités, escamoter les coïncidences ou les passages qui rendaient viable au jour le jour la coexistence entre les êtres et les sociétés ${ }^{1}$ ". Avisé de ce constat, il s'agira donc de placer ici les phénomènes de circulations et de métissages au centre de la discussion, afin d'éclairer les multiples connexions pédagogiques qui se concrétisent dans l'espace franco-romand du long XIX ${ }^{\mathrm{e}}$ siècle.

\section{Quand la France recrutait du made in Switzerland}

On pourrait croire que, durant la période de construction identitaire romande, toute implication avec les milieux parisiens pouvait être perçue d'un mauvais œil. Roger Francillon précise à dessein que « les écrivains qui, tels Victor Cherbuliez ou Édouard Rod, ont préféré s'installer à Paris pour y faire carrière, sont regardés avec méfiance et considérés un peu comme des "traîtres" à la patrie romande ${ }^{2}$ ". Alain Clavien, dans sa thèse sur les Helvétistes, a cerné ce rapport "trouble et ombrageux » entretenu par les intellectuels romands avec Paris, fait d'attirance et de rejet:

1. Serge Gruzinski, Les quatre parties du monde. Histoire d'une mondialisation, Paris, Éditions de La Martinière, 2004, p. 33.

2. Roger Francillon, De Rousseau à Starobinsky. Littérature et identité suisse, Lausanne, Presses polytechniques et universitaires romandes, 2011, p. 63-64. 
Attirance, parce que Paris offre la possibilité de s'évader du cadre restreint du champ romand, de court-circuiter certaines instances de légitimation romandes: même s'il fait bon accueil à la production suisse, le public romand n'en lit pas moins les succès parisiens avec empressement. Rejet parce que cette reconnaissance de l'autorité parisienne revient à accepter une situation de dominé, une relation asymétrique, ce que les intellectuels dominant le champ littéraire romand refusent évidemment ${ }^{3}$.

L'appel d'une vie meilleure, comportant ses hypothétiques rêves de gloire, a pourtant tenté plus d'un Romand ${ }^{4}$. Parmi les trajectoires les plus accomplies, on citera celle du Fribourgeois Victor Tissot (1844$1917)^{5}$. Après des études de droit à Fribourg-en-Brisgau, Tübingen, Leipzig et Vienne, Tissot passe un an dans la capitale française où il collabore à la rédaction du Dictionnaire de Larousse ainsi qu'à celle du Dictionnaire universel des contemporains de Vapereau, impulsant l'entrée de quelques Suisses dont celle de son ami Alexandre Daguet. Au passage, on notera que ce dernier, alors rédacteur de L'Éducateur, prévoyait de fonder un Journal d'éducation récréatif avec Tissot, alors de passage à Paris entre 1866 et 1867 :

Je n'ai pas oublié le projet dont vous m'avez entretenu une fois à Fribourg, celui de fonder ensemble un Journal d'éducation récréatif. J'étudie les gens ici, chaque soir, dans les cabinets de lecture, et je pense que vous pourriez tenter quelque chose qui aurait chance de succès, nous ne nous adresserions pas seulement en Suisse, mais aussi à la France, à l'Allemagne, etc. Depuis que je me suis lancé dans la librairie, j'en connais un peu les ficelles, et surtout le secret de mettre en état une publication nouvelle. Comme vous le disait Cherbuliez, et comme me le rappelait dimanche Houssaye, un journal d'éducation bien rédigé et formant volume chaque année est l'entreprise littéraire qui court le moins de risques ${ }^{6}$.

Rappelé au pays en 1867, Tissot entre à la Gazette de Lausanne et lance en 1871 les suppléments littéraires hebdomadaires qu'il déclinera

3. Alain Clavien, Les Helvétistes: intellectuels et politique en Suisse romande au début du siècle, Lausanne, Éditions d'en bas, 1993, p. 14-15.

4. Sur le sujet, on lira Jean-Daniel Morerod (dir.), Les Romands et la Gloire, Actes du colloque de Lausanne du 17 novembre 2001, Société d'histoire de la Suisse romande, 2006.

5. Voir François Pharisa, « Victor Tissot entre succès et polémiques 》, $A F$, 76/2014, p. 57-68; Serge Rossier, « Victor Tissot (1845-1917). Un homme d'affaires littéraires », Cahiers du musée gruyérien, 2009, p. 31-48; Alain Bosson, « Victor Tissot, auteur à succès dans le Paris de la Belle Époque », Cahiers du musée gruyérien, 2009, p. 49-54.

6. Lettre de V. Tissot à Daguet, Paris, 1867, AEN, Fonds Daguet. 
en France lorsqu'il deviendra rédacteur en chef du Figaro entre 1888 et 1893. Tissot se fixe dans la capitale française en 1874 et s'y forge rapidement une audience internationale grâce à la publication de ses Voyages au pays des milliards (1875) vendus à plus de 100000 exemplaires (quarante éditions en deux ans). Claude Digeon dira de lui qu'il a "donné un nouveau visage de l'Allemagne ${ }^{7}$ » en France.

Les pédagogues aussi vont trouver grâce dans l'hexagone, emportant avec eux des références pédagogiques essentiellement germaniques. Au début du XIX ${ }^{\mathrm{e}}$ siècle, ce sont essentiellement des éducateurs protestants que l'on fait venir à Paris. Ainsi, le théologien Adam Vuillet (18141892), formé à l'académie de Lausanne, est appelé dès 1844 à diriger l'École normale protestante de Paris (1844-1858). Il commence à y publier ses manuels d'histoire et de géographie qui ont contribué à répandre le goût et l'étude de ces sciences. Frédéric Gauthey (17951864), un artisan du Réveil, enseigne également plus de dix-huit ans en France. Après avoir fondé l'école normale du canton de Vaud en 1833, il accepte la direction de celle de Courbevoie de juillet 1846 à sa mort en 1864. On sait que la Société pour l'encouragement de l'instruction primaire parmi les protestants de France songeait à créer une école capable de former des instituteurs sous le cachet de l'Église évangélique, raisons pour lesquelles on se rapprocha de ce spécialiste de Pestalozzi :

La grande question, celle d'où dépendait l'avenir de l'institution, était le choix du directeur. Le nom de Gauthey était honorablement connu par ses publications et par la position qu'il avait occupée en Suisse. Un de ses anciens élèves, instituteur à Paris, le désigna à M. le pasteur Montandon. D'ailleurs, plusieurs membres du comité le connaissaient personnellement [...] L'ami de Pestalozzi, de Girard, de Vinet, de Fellenberg, consentit à venir dispenser à de jeunes Français les trésors de son savoir, de sa piété et de son expérience. Pour se mettre en règle avec l'administration, et d'après l'avis de Victor Cousin, alors ministre, il consentit à subir, à Besançon, un examen d'instituteur ${ }^{8}$.

$\mathrm{Si}$ ces éducateurs ont répandu des innovations pédagogiques dans leur patrie d'exil, d'autres collaborations franco-romandes y contribuèrent tout autant. Ce fut notamment le cas pour l'éducateur

7. Claude Digeon, La crise allemande de la pensée française 1870-1914, Paris, PUF, 1959, p. 322.

8. Souvenirs du Pasteur L. F. F. Gauthey, directeur des écoles normales du canton de Vaud et de l'école normale de Courbevoie près Paris, publiés par la Société des livres religieux de Toulouse, Toulouse, 1869, p. 58. 
protestant Jules Paroz (1824-1906), spécialiste de Pestalozzi ${ }^{9}$ et de la méthode intuitive, qui reçut en 1858 à Berne la visite de Pierre Larousse $^{10}$. Le grammairien parisien venait prier son confrère suisse de fusionner son journal avec sa propre revue L'École normale. Rappelons qu'en novembre 1848, Paroz fonde une modeste feuille pédagogique, L'Éducateur populaire, qui permet une diffusion transcantonale des principes pestalozziens auprès des instituteurs romands. Outre un aspect financier intéressant, la coopération avec Larousse encourage Paroz à rédiger une Histoire universelle de la pédagogie qui sera publiée par livraisons dans L'École normale dès $1858^{11}$. De passage à Paris lors de l'Exposition universelle de 1867, l'éducateur protestant tente de convaincre Larousse de publier une version allégée de son Histoire universelle. Absorbé par la tâche, l'auteur du Grand Dictionnaire décline l'offre et l'œuvre de Paroz paraît chez Charles Delagrave dès 1872 (cinq rééditions successives et des traductions en russe, grec, roumain, italien, espagnol, et partiellement en allemand). Cette somme lui vaudra une renommée européenne et les considérations du ministre de l'Instruction publique française Victor Duruy ${ }^{12}$. Paroz est également approché par l'éditeur Charles Delagrave pour participer à l'aventure de la Revue pédagogique, dirigée par un compatriote, James Guillaume, qui lui fait savoir que " [son] autorité est grande en France et [ses] bons conseils seront entendus et suivis ${ }^{13}$ ». On notera encore que l'inspecteur général Jean-Magloire Baudouin, observateur avisé des écoles helvétiques ${ }^{14}$, propose à Paroz de prendre la direction d'une école secondaire fondée par de riches propriétaires allemands aux portes de Paris. Celui-ci consigne dans ses Mémoires

\footnotetext{
9. Paroz publia en 1879 son cours de pédagogie qu'il intitula L'École primaire. Cahier de pédagogie d'après les principes de Pestalozzi ; il s'agissait des résultats de trente années d'études passées essentiellement à la compréhension et à la diffusion de l'œuvre de Pestalozzi, mais aussi des divers systèmes qu'il alla étudier en France, en Prusse, en Wurtemberg, dans le Grand-Duché de Bade ainsi qu'en Suisse allemande.

10. Julien Bourquin, Des portes qui s'ouvrent ou la vie de Jules Paroz (1824-1906), Neuchâtel et Paris, Delachaux et Niestlé, 1954, p. 118-119.

11. Voir L'École normale, 1858-1859, p. 1, 17, 33, 69, 84, 113, 177, 193, 225, 237, 289, 369.

12. Duruy souhaitant bénéficier de ses conseils, l'invita à lui adresser un mémoire sur les rapports entre l'instruction et les progrès de la moralité. Voir Julien Bourquin, op. cit., p. 119. 13. Ibid., p. 157.

14. Jean-Magloire Baudoin (1818-1882), docteur de I'université d'léna, observa les écoles professionnelles de Suisse lors d'une mission mandatée par Victor Duruy en 1863 et participa au congrès de Neuchâtel en 1870. Baudoin fut également envoyé à Constantinople en 1866 afin d'étudier plusieurs écoles spéciales turques fondées sous le patronage de la France.
} 
qu'il aurait accepté le poste si M. Baudouin s'était rendu chez lui comme promis à la veille du congrès de la SIR à Neuchâtel (1870): " il a peut-être craint mes principes évangéliques ${ }^{15}$ " écrit-t-il sournoisement. Toutefois, sachant Daguet désespéré à Fribourg, placé par le nouveau gouvernement conservateur à un poste peu en adéquation avec ses ambitions et ses qualités, il écrit à son ancien professeur:

Vous m'avez parlé hier de difficultés, etc., que vous auriez à Fribourg, de votre désir de le quitter, si une chance favorable se présentait. Cette pensée ne cesse de me poursuivre et c'est elle qui me met la plume à la main: je souffre de vous sentir dans une position qui ne répond ni à vos besoins, ni à vos talents. Dernièrement, $\mathrm{M}$. Baudoin (sic), inspecteur général à Paris, et précepteur dans la famille du duc d'Orléans, a demandé un directeur à M. Sandoz pour une école secondaire que de riches Allemands de Paris ont ouverte à Bourg-la-Reine, près de Sceaux; c'est à un quart d'heure de la capitale en chemin de fer. On offrait le logement et 3000 à $3600 \mathrm{~F}$ [...]. Voilà donc un poste avantageux, me semble-t-il, pécuniairement parlant. M. Baudoin veut un directeur au courant des méthodes allemandes. Vous serez certainement mieux qualifié que moi pour ce poste, et je viens vous y rendre attentif, si vos difficultés, comme les miennes, sont d'une nature pécuniaire. Je vous verrais avec peine quitter la Suisse, il me semble même que cela ne doit pas se faire, et je m'accuse de trahison en vous écrivant; mais on est quelquefois obligé de faire ce qu'on n'aimerait pas faire ${ }^{16}$.

Si Daguet n'accepte ni ce poste, ni les autres propositions qu'on lui fait en Suisse et en Belgique ${ }^{17}$, il reçoit quelques années plus tard une proposition fort attrayante. Son ancien collègue et ami Ferdinand Buisson l'appelle à le rejoindre à Paris pour élever une œuvre internationale d'éducation:

Ce sont ces mêmes articles qui valaient au rédacteur en chef de votre feuille, de la part de M. Buisson, aujourd'hui directeur de l'Instruction primaire de la République française, la proposition flatteuse de s'associer à lui pour la publication de l'œuvre internationale d'éducation que méditait alors cet auteur du Dictionnaire universel de la Pédagogie [...] Mon refus, dans cette circonstance, fut dicté par mon attachement

15. Julien Bourquin, op. cit., p. 119.

16. Lettre de J. Paroz à Daguet, Berne, 8 octobre 1865, AEN, Fonds Daguet.

17. En 1846, Daguet décline l'appel du gouvernement vaudois à la chaire d'histoire à l'académie de Lausanne. En 1864, il refuse la direction des écoles primaires et industrielles de la Chaux-de-Fonds. En 1875, il pense pour un temps prendre la direction d'une école de Bruxelles mais y renonce finalement. 
à l'œuvre nationale commencée par vous, avec vous, et qu'il eût fallu interrompre pour concourir dignement à l'entreprise de mon ancien collègue à l'écadémie de Neuchâtel ${ }^{18}$.

Daguet décline à nouveau cette offre et argumente ce choix en invoquant la fidélité que son collègue Eugène Rambert (1830-1886) voua à son pays lorsqu'il refusa "de se fixer à Paris et déclina les propositions brillantes qui lui avaient été faites pour l'attacher à la Revue des Deux Mondes ${ }^{19}$ ". Pourtant, malgré sa haute conscience patriotique, Daguet envisagea l'exil parisien. Il a sans doute fallu cette mise en garde de Henri-Frédéric Amiel et l'avertissement procuré par l'exemple scabreux de Juste Olivier qui avait suivi Sainte-Beuve dans la capitale française, pour flétrir ses adultères patriotiques:

Une transplantation à Paris m'apparaît comme riche en déboires sans nombre, quand on n'a plus trente ans et qu'on n'a pas la flexibilité de dos, de langue et de caractère nécessaire pour se faire de puissants protecteurs. Je vous en prie, regardez à cinq fois avant de prendre ce parti. Juste Olivier qui l'a pris à la fleur de l'âge et qui avait beaucoup de circonstances favorables, s'en est mal trouvé cependant et l'a toujours regretté. Quelles que soient les amertumes possibles de votre situation en Suisse, elles sont probablement un mal moindre que celles dont abondent les émigrations tardives. D'ailleurs, si vous avez des ennuis ou des jaloux ou des ingrats dans votre pays, c'est pourtant en Suisse que vous avez vos partisans, vos appréciateurs, vos amis, les services rendus, toutes les attaches qui soutiennent, tous les appuis qui réconfortent. Vous me permettez bien de vous dire ingénument mon impression, laquelle, j'en conviens, est sans valeur puisque j'ignore vos motifs et vos chances. Mais ce sont les craintes d'un $\mathrm{ami}^{20}$.

Amiel clôt l'affaire en inscrivant dans son Journal intime: "Le pauvre cher homme est, paraît-il, usé à Neuchâtel. Il songe à un établissement à Paris! C'est stupéfiant ${ }^{21}$. " C'est par conséquent un autre Romand, James Guillaume, qui occupera le poste proposé à Daguet,

18. Alexandre Daguet, « Rapport sur la marche de l'Éducateur », L'Éducateur, 17/1882, p. 259.

19. Alexandre Daguet, « Eugène Rambert », L'Éducateur, 24/1886, p. 377. Eugène Rambert (1830-1886) fut professeur ordinaire de littérature française à l'académie de Lausanne (18551860), puis à l'École polytechnique fédérale de Zurich (1860-1881) et à nouveau à Lausanne (1881-1886). Médiateur entre la Suisse allemande et la Suisse romande, il a traduit avec son épouse les nouvelles de Gottfried Keller.

20. Lettre de H.-F. Amiel à Daguet, Genève, 15 novembre 1879, Bibliothèque de Genève, Salles des manuscrits, Archives Amiel 92, Ms fr 3092.

21. Henri-Frédéric Amiel, Journal intime, t. XII, Lausanne, L'Âge d'Homme, 1994, p. 223. 
même si Ferdinand Buisson dut s'y reprendre à deux reprises et que des circonstances personnelles hâtèrent l'exil du Neuchâtelois en mai 1878.

\section{James Guillaume, un Neuchâtelois à Paris}

James Guillaume (1844-1916) naît en février 1844 à Londres ${ }^{22}$. Sa famille paternelle, active dans le monde horloger du Valde-Travers, détient une succursale dans la capitale britannique. Neuchâtel, ancienne cité prussienne devenue républicaine lors de la révolution de 1848, rappelle toutefois le père de James qui s'occupe dès lors essentiellement de politique. Après avoir fréquenté les écoles de la cité, le jeune homme s'installe à Zurich en septembre 1862. Autrefois sceptique envers ces enseignants qu'il n'écoutait jamais, il se passionne au contact de deux professeurs allemands réfugiés en Suisse, le philologue Hermann Köchly (1815-1876) et le célèbre professeur d'esthétique Friedrich Theodor Vischer (1807-1887). De retour en pays neuchâtelois, il passe fin 1864 l'examen du professorat des écoles industrielles et enseigne à l'école industrielle du Locle jusqu'en 1869. Cette première incursion réelle dans le monde ouvrier s'avère décisive. Désireux de se consacrer tout entier à l'instruction du peuple, il organise des cours du soir pour les apprentis, puis des conférences d'histoire afin d'élever les connaissances générales des ouvriers jurassiens. Parallèlement, il poursuit ses lectures: Feuerbach, Darwin, Fourier, Louis Blanc ou Proudhon qu'il considérait d'ailleurs comme un sophiste dans sa jeunesse. C'est au contact des révolutionnaires européens rencontrés lors des congrès de l'AIT et du congrès de Genève (1867) de la Ligue de la paix et de la liberté que sa pensée prend toute sa profondeur. Sa rencontre avec Bakounine ne fait que confirmer ses vues. Ses activités militantes ne restent pas sans conséquence sur sa situation personnelle, puisqu'il est renvoyé de son poste de professeur au milieu de l'été 1869 et vit ensuite de petits boulots ${ }^{23}$. Sa renommée de dangereux révolutionnaire, qui le poursuit, l'incite à hâter son départ pour Paris, de peur de perdre le

22. Pour davantage de précisions sur l'itinéraire de James Guillaume (1844-1916), voir Marc Vuilleumier, « James Guillaume, sa vie, son œuvre », in L'internationale: documents et souvenirs, Paris, Lebovici, 1985, vol. 1 (1864-1872), p. I-LVII; Dorothea Roth, « James Guillaume: seine Jugend in Neuenburg (bis 1862), sein Studium in Zürich (1862-1864) und seine Begegnung mit dem Sozialismus (1868) », Schweizerische Zeitschrift für Geschichte, 15/1965, p. 30-86.

23. Après avoir travaillé dans l'imprimerie de son frère jusqu'en 1872, il survit grâce à quelques traductions et leçons particulières. 
travail de traduction que lui promet une maison d'édition parisienne. Guillaume part seul le $1^{\text {er }}$ mai 1878, jour d'ouverture de l'Exposition universelle. Dans une lettre à sa femme, il explique:

Il m'est bien difficile de le dire par lettre toutes les idées que j'ai relativement à Paris et à nos futurs arrangements... Je pense d'abord, qu'il m'est impossible de continuer à vivre à Neuchâtel: je n'y trouverai plus de travail; c'est donc la question du pain, en tout premier lieu, qui me pousse à Paris. Il y a deux autres questions encore dont je ne te parle qu'en passant, mais qui ont pour moi, comme tu sais, beaucoup de valeur: 1. mon développement intellectuel: à Neuchâtel j'étouffe et je m'abrutis, je ne fais pas de mes facultés l'usage que je dois en faire;

2. mon devoir comme socialiste ${ }^{24}$.

Deux raisons principales ont donc poussé Guillaume à rejoindre Paris: ses engagements avec une grande maison d'édition parisienne, sans doute Hachette, ainsi que l'effervescence socialiste qui commençait à exciter la population ouvrière de Paris où se trouvaient déjà Andrea Costa (1851-1910) et Pierre Kropotkine. Deux jours après son arrivée dans la capitale, on retrouve Guillaume à la tâche. Il va pouvoir, enfin, se consacrer à sa période historique favorite ${ }^{25}$ et retourner aux sources de l'éducation sous la Révolution française afin de réenchanter le paradis perdu des hommes de la III $^{\mathrm{e}}$ République. À Paris, on découvre un homme radieux, qui écrit en date du 3 mai "se sentir dans sa vraie patrie ", avant de poursuivre quelques jours plus tard:

Je t'écris de la Bibliothèque nationale, en attendant qu'on m'apporte les livres que j'ai demandés pour travailler... J'ai déjeuné au Palais Royal, à deux pas; et ensuite, en fumant ma cigarette dans le jardin, au milieu des fillettes qui jouaient, je pensais à la joie que la nôtre aurait à courir là, sous ces arbres, autour de ces pièces d'eau; et je pensais aussi: c'est dans ce jardin qu'a commencé la Révolution française; c'est monté sur une chaise comme celle sur laquelle je suis assis que Camille Desmoulins a appelé le peuple aux armes la veille de la prise de la Bastille ${ }^{26}$.

24. James Guillaume, L'Internationale: documents et souvenirs, t. IV, Paris, Stock, 1905, p. 304. 25. « Depuis longtemps j'avais le désir d'aller vivre à Paris, pour être plus à portée de me livrer aux recherches historiques sur la Révolution française qui toujours - et déjà lorsque j'étais étudiant à l'université de Zurich - avaient occupé ma pensée », in James Guillaume, L'Internationale: documents et souvenirs, t. IV, op. cit., p. 304.

26. Lettre de Guillaume à sa femme, mai 1878, in James Guillaume, L'Internationale: documents et souvenirs, t. IV, op. cit., p. 325. 
Cette thèse d'une renaissance personnelle et intellectuelle parisienne semble d'ailleurs se confirmer avec le temps. Le cadre tolérant, laïc, dans lequel il évolue aux côtés de Buisson semble lui convenir parfaitement :

Par M. Buisson, j'ai fait peu à peu la connaissance d'à peu près toutes les personnes qui ont un nom ou une fonction importante dans l'instruction publique; on me fourre de temps en temps dans une commission, et j'y vais siéger sans scrupule, attendu qu'il ne s'agit que de pédagogie et non de politique. J'ai conservé une entière liberté de langage avec M. Buisson et ceux que je connais, et je m'en trouve très bien; on sait ce que je pense, on ne me demande que ce qui est compatible avec mes idées. Tout ce monde-là est tolérant en raison même de son intelligence, du moment qu'on a reconnu que vous n'êtes pas un imbécile, on vous traite avec sympathie; en Suisse au contraire, on ne me pardonnait pas de n'être pas un imbécile: c'était là mon grand crime ${ }^{27}$.

Concernant les contingences de sa vie parisienne, Guillaume raconte qu'il aurait pu devenir professeur de grec à l'école Monge, sous les auspices du philosophe Joseph de Bagnaux (1831-1882) et du grammairien Wierzejski, s'il n'était entré au service de Ferdinand Buisson pour œuvrer au cœur du Dictionnaire de pédagogie et d'instruction et de la Revue pédagogique ${ }^{28}$. L'historiographie s'accorde sur son rôle de cheville ouvrière de l'ouvrage, qui ne fut d'ailleurs pas un secret pour les contemporains: Buisson a multiplié les remerciements et les témoignages de reconnaissance à son fidèle bras droit:

C'est à James Guillaume que j'ai dû de pouvoir publier, il y a trente ans, un ouvrage qui, à cette époque, apportait à la France un véritable trésor de documents et de matériaux pour l'œuvre scolaire que la République allait entreprendre. Le Dictionnaire de pédagogie mettait sous les yeux de tous un tableau complet de la législation et des institutions scolaires du monde entier, en même temps que des études originales sur l'histoire des doctrines sur les doctrines elles-mêmes. Quiconque est au courant de ce qui s'est fait pour l'école en France sous la Troisième République, sera d'accord avec nous pour dire qu'une place est due, et une des plus grandes, dans l'histoire de notre éducation nationale, une place aussi dans l'estime et la reconnaissance publiques à cet homme qui, au rebours des autres, a mis son point d'honneur dans le silence, dans le

27. Lettre de Guillaume à sa mère, 1881, citée par Marc Vuilleumier, « James Guillaume, de l'esprit libertaire dans la première Internationale (AIT) » (version électronique consultable sous http://www.increvables-anarchistes.org/articles/themes/biographies/james-guillaume).

28. James Guillaume, L'Internationale: documents et souvenirs, t. IV, Paris, Stock, 1905, p. 325. 
travail et dans l'obscurité voulue, à ce grand et modeste éducateur des éducateurs français ${ }^{29}$.

La laïcité à la française a donc particulièrement convenu à James Guillaume et l'a même fait grandir en quelque sorte. Marc Vuilleumier rappelle combien ses proches amis parisiens ont contribué à le diriger vers certaines grandes entreprises, notamment Lucien Herr, «lequel, inlassablement, le poussa à rédiger son œuvre majeure: les quatre volumes de l'Internationale, Documents et souvenirs (1864-1878), qui parurent de 1905 à $1910^{30} »$.

\section{Les Suisses du Dictionnaire de Buisson}

Réinvesti depuis une dizaine d'années par les historiens de l'éducation, le Dictionnaire de Pédagogie et d'instruction primaire de Buisson a évolué du statut de lieu de mémoire reconnu, mais finalement peu exploité, à celui de source de première main ${ }^{31}$. Si l'on évoque les Suisses du Dictionnaire, c'est à l'évidence à James Guillaume que l'on pense immédiatement. Toutefois, huit autres Helvètes sont approchés par Buisson et figurent de ce fait sur la liste des collaborateurs pressentis pour la première édition de $1878^{32}$. Trois d'entre eux ne livreront aucun article. C'est le cas de Raphael Horner, leader du mouvement pédagogique catholique à Fribourg et directeur du Bulletin pédagogique ${ }^{33}$. Si Buisson pense pour un temps l'engager, non sans demander conseil à Daguet $^{34}$, il semble que ce dernier ait réussi à éliminer du projet son principal opposant de Fribourg. Buisson lui en rendit compte: «Vous savez

29. Ferdinand Buisson, « Hommage à James Guillaume », Vie ouvrière, 20 février 1914, p. 214. 30. Marc Vuilleumier, « James Guillaume, de l'esprit libertaire dans la première Internationale (AIT) », article en ligne (http://www.pelloutier.net/glossaire/detail.php?id=72).

31. Voir Patrick Dubois, Le « Dictionnaire » de Ferdinand Buisson: aux fondations de l'école républicaine, Bern, Peter Lang, 2002; Laurence Loeffel, Ferdinand Buisson, apôtre de l'école laïque, Paris Hachette, 1999; Daniel Denis et Pierre Kahn (sld.), Nouveau regard sur l'école républicaine: enquête sur les disciplines dans le Dictionnaire de pédagogie de Ferdinand Buisson, Paris, CNRS Éditions, 2003.

32. Selon la liste proposée par Patrick Dubois, op. cit., p. 241-243.

33. Sur la trajectoire fribourgeoise de l'abbé Horner, on lira Valérie Lussi Borer, Formations à l'enseignement et science de l'éducation. Analyse comparée des sites universitaires de Suisse romande (fin $d u x x^{e}$ - première moitié $d u x x^{e}$ siècle), thèse de doctorat, université de Genève, 2008, p. 65-128.

34. « $Y$ a-t-il effectivement une Société, un groupe, une association fribourgeoise derrière le Bulletin pédagogique de Hauterive ? M. Horner m'offre quelques articles. Que me conseilleriez-vous ? », (lettre de F. Buisson à Daguet, Paris, sans lieu ni date, AEN, Fonds Daguet. Voir également L'Éducateur, 9/1880, p. 131. 
assez mes idées pour ne pas me supposer une grande tendresse pour l'abbé Horner ou tout autre ultramontain. J'ai eu tort de mettre son nom sur la liste puisqu'on y attribue (sic) le sens que vous dites; je l'ai fait par honnêteté, sans y attacher la moindre importance ${ }^{35}$. " Par ailleurs, s'il est difficile d'argumenter sur les causes de l'ajournement de la collaboration du Fribourgeois Magnin, professeur à Wiesbaden, s'agissant de Xavier Ducotterd (1836-1920), un autre Fribourgeois exilé en Allemagne, les choses sont d'autant plus complexes à cerner qu'il s'apprêtait à livrer un article de grande portée consacré à l'intuition:

Du reste je n'ai pas renoncé à un article sur Herbart. C'est un travail que je ferai aussitôt que j'aurais achevé celui dont je me suis chargé pour M. Buisson de Paris, pour lequel vous travaillez aussi. Je traite le mot: intuition ${ }^{36}$.

Le parcours de ce disciple de Karl Volkmar Stoy (1815-1885), spécialiste de l'Anschauung, qui a tenté de propager le système de Herbart dans l'espace francophone, est digne d'intérêt ${ }^{37}$. En 1861, Daguet trouve un poste de précepteur dans un pensionnat de jeunes gens de Wiesbaden pour cet ancien étudiant particulièrement zélé. C'est donc dans le Hesse que Ducotterd conçoit et publie sa fameuse méthode pour l'apprentissage intuitif de la langue française en tant que seconde langue, basée sur les seize tableaux de Wilke, qu'il tentera d'institutionnaliser dans l'Europe francophone ${ }^{38}$ :

Je vais commencer avec un ami allemand un ouvrage basé sur le principe de l'intuition pour l'enseignement de l'allemand en pays français. J'ai déjà l'assentiment du ministre de l'Instruction publique de Belgique, M. Vanhumbeck. J'ai aussi soumis mon projet à M. Ferry; je vais en faire de même auprès des gouvernements de Neuchâtel, de la Suisse française en général. L'ouvrage doit être fini pour le mois d'avril prochain ${ }^{39}$.

Ducotterd enseigne ensuite à Bürgstadt, en Saxe royale et termine sa carrière au gymnase catholique de Francfort. Avant cette dernière étape, il fait un passage par Heidelberg où Stoy vient de prendre ses quartiers. Il s'agit d'une rencontre décisive puisqu'il se convertit dès ce

35. Lettre de F. Buisson à Daguet, Paris, sans lieu ni date, AEN, Fonds Daguet.

36. Lettre de X. Ducotterd à Daguet, Francfort, 19 octobre 1877, AEN, Fonds Daguet.

37. Voir la notice de Jean-Marie Barras, Au temps de l'école normale, Fribourg, Imprimerie Saint-Paul, 2005, p. 177-180.

38. Xavier Ducotterd, Die Anschauung auf den Elementarunterricht der französischen Sprache angewendet. Nach den 16 Wilke'schen Bildern, Wiesbaden, Verlag vom Limbarth, 1868.

39. Lettre de X. Ducotterd à Daguet, Francfort, 7 octobre 1881, AEN, Fonds Daguet. 
jour à la psychologie d'après les principes de Herbart et s'affiche en disciple de Stoy qui lui ouvre les colonnes de l'Allgemeine Deutsche Schulzeitung. Ducotterd s'engage à diffuser les principes de l'herbartisme en Suisse romande, notamment par l'envoi d'une série d'articles à L'Éducateur. En 1871, il soutient l'idée d'un système pensé comme un tout organique, "qui renferme les conditions nécessaires de son futur développement contre un éclectisme autoritaire, subjectif et éphémère ${ }^{40} »$. Ardent défenseur de l'éclectisme pédagogique, Daguet publie malgré tout l'article de Ducotterd, non sans faire remarquer que " la thèse qu'on va lire est dirigée contre l'éclectisme pédagogique que L'Éducateur a fait profession de suivre jusqu'à ce jour, de préférence à un de ces systèmes exclusifs dont l'auteur se déclare le champion, pour faire prévaloir celui auquel il a voué ses sympathies, le système Herbart, représenté par M. Stoy ${ }^{41}$ ». Dès 1874 , les relations semblent se crisper entre Daguet qui se sent négligé en termes d'articles et Ducotterd qui constate amèrement que la Suisse romande reste imperméable à la psychologie d'outre-Rhin. Aussi en novembre 1878 écrit-il à Daguet:

Pourquoi, cher Rédacteur, ne fait-on dans notre pays aucun effort pour rompre avec une psychologie surannée, mythologique et stérile, au moyen de laquelle on ne saurait résoudre aucun problème psychologique, ni aucune question pédagogique? Car enfin la pédagogie, comme science, ne peut être en réalité que le corollaire de la psychologie et que l'application des lois de celle-ci à la pratique.

Avant de conclure:

Mais à quoi bon m'étendre sur des choses que, chez nous, on est accoutumé à considérer comme des brouillards ou des spéculations nébuleuses d'outre-Rhin, qui m'exposeraient à passer auprès de vous pour un einseitigen Systemenmenschen. Malgré cela je dirai encore mon dernier mot: c'est que, si en Allemagne, il y a des brouillards dans certaines sphères, il y en a chez nous de plus épais encore qu'il faudrait sérieusement chercher à dissiper, à commencer par les ténèbres dans lesquelles la psychologie y est encore plongée. Une réforme sur ce terrain ouvrirait à la pédagogie des voies fraîches et toutes nouvelles sur lesquelles le perfectionnement et les progrès de nos méthodes d'enseignement se feraient avec beaucoup plus de facilité et avec des succès jusqu'ici inconnus ${ }^{42}$.

40. Xavier Ducotterd, « Systèmes et éclectisme 》, L'Éducateur, 15/1871, p. 225-231; 16/1871, p. $241-245 ; 18 / 1871$, p. $273-278$.

41. Ibid, p. 225.

42. Daguet publie cette lettre de X. Ducotterd dans L'Éducateur, 24/1879, p. 406-407. 
Rien d'étonnant donc à ce que Ducotterd ait pris ses distances avec Daguet pour se rapprocher des ultramontains fribourgeois. Il visite Raphaël Horner à l'été 1882 et déclare que " les idées pédagogiques de Horner se parvenaient (sic) avec les miennes sur beaucoup de points. Il paraît être grand partisan de la pédagogie allemande; il y avait même du Herbart et du Stoy dans ses arguments ${ }^{43}$ ». L'absence de sources nous empêche de documenter les raisons particulières de la suppression de Ducotterd de l'équipe des collaborateurs du Dictionnaire. Il est néanmoins envisageable que Daguet ait intercédé une nouvelle fois auprès de Buisson pour écarter son ancien étudiant, de plus en plus proche de l'ultramontanisme fribourgeois ${ }^{44}$.

Si l'on se préoccupe maintenant des collaborateurs suisses qui ont effectivement livré des articles au Dictionnaire, il faut souligner en premier lieu que Buisson a décidé de soumettre l'organisation générale de la partie helvétique à Daguet:

Maintenant si vous aviez loisir pour prendre une tâche un peu plus lourde, je serais très enchanté de vous confier la direction de toute la partie suisse dont je n'ai pas encore disposée, sauf quelques articles promis par M. Aimé Humbert, de Kinkelin, etc. Il y a d'ailleurs quelques sujets théoriques ou historiques qui doivent vous intéresser et que je vous confierais bien volontiers pour peu que vous me les signaliez, sûr d'avancer que les lecteurs seraient heureux de mon choix. Touchez-m'en un mot à l'occasion s'il vous plaît et veuillez vous mettre en mesure le plus tôt possible de m'envoyer les bonnes pages que j'attends ${ }^{45}$.

Le statisticien bâlois Hermann Kinkelin (1832-1913) ne livrera finalement aucun écrit. Quant à Daguet, il publie quatre articles, dont le plus important est consacré à son mentor le Père Girard. Curieusement, il semble qu'il ait même demandé à figurer personnellement dans le Dictionnaire:

Comme vous n'êtes pas encore mort (Dii omen avertant), je ne peux vous consacrer un article à la lettre $\mathrm{D}$ du dictionnaire pédagogique. C'est dommage, j'aurai plaisir à dire tout le bien que je pense de vous mais je le dirai dans le rapport sur l'exposition, dont je suis hélas, chargé. Pourquoi ne feriez-vous pas quelque article en fin de C ou en $\mathrm{D}$ pour

43. Lettre de X. Ducotterd à Daguet, Francfort, 22 octobre 1885, AEN, Fonds Daguet.

44. « Ainsi, vous le voyez, cher directeur, ce ne sont pas les ultramontains qui m'ont fait catholique, mais bien les adversaires du catholicisme, ennemi mortel du catholicisme » (lettre de X. Ducotterd à Daguet, Francfort, 7 août 1886).

45. Lettre de F. Buisson à Daguet, Paris, sans lieu ni date, AEN, Fonds Daguet. 
que votre nom arrive avant la lettre G (Girard). Voulez-vous me faire Comenius (long article) pour le 20 janvier ou Crevier (court) pour le $1^{\text {er }}$ février ou Crousaz ( 15 février) ou quelques suisses importants ${ }^{46}$ ?

C'est Auguste Demkès, directeur de l'école primaire communale de la rue des Batignolles, qui se charge finalement de l'article "Crevier » et James Guillaume de l'article «Crousaz ». Daguet rédige encore une brève notice sur l'anthropologue suisse Alexandre-César Chavannes, une note sur les "congrès pédagogiques de Suisse » ainsi qu'un article conséquent sur Comenius, cosigné par la fröbelienne genevoise Caroline Progler. Or, à en croire Buisson, qui montre là à quel point il était sensible à l'actualité pédagogique et scientifique, leur travail ne semble pas avoir pas tenu toutes ses promesses:

Vous allez recevoir votre Comenius, et vous vous plaindrez mais à tort. Vous aviez rédigé toute la partie biographique sans tenir compte de l'ouvrage tout récent de Lindner qui a changé considérablement de dates et même de faits jusqu'ici admis. J'ai été obligé de le refaire en entier. Le reste, ce qui vous reste, est d'ailleurs l'important, c'est l'appréciation pédagogique $^{47}$.

Comme Daguet, la majorité des collaborateurs suisses du Dictionnaire de Pédagogie et d'instruction sont des anciens collègues de Buisson rencontrés à l'académie de Neuchâtel. À commencer par son recteur, Aimé Humbert (1819-1900) dont l'itinéraire fut allemand, japonais puis suisse. Formé à l'académie de Lausanne puis à Tübingen, Humbert fréquente le cercle du poète souabe et ami d'Uhland Karl Mayer ${ }^{48}$. Président de l'Union horlogère fondée en 1858, il est dépêché en 1862 par le gouvernement suisse au Japon comme envoyé extraordinaire pour conclure le premier traité de commerce nippo-suisse ${ }^{49}$. À son retour, il est appelé à Lausanne par son ami Louis Bridel à la direction d'un pensionnat de jeunes Espagnols convertis au protestantisme par Manuel Matamoros ${ }^{50}$. Recteur de la nouvelle académie

\section{Ibid.}

47. Ibid.

48. Karl Mayer appartient à l'école poétique souabe (Schwäbische Dichterschule) qui fédéra les poètes romantiques de Tübingen autour de Justinus Kerner et de Ludwig Uhland.

49. En ethnologue, Humbert rapporte ses souvenirs nippons dans Le Japon illustré, 2 vol., Paris, Hachette, 1870. Voir également Joseph Allimann, Pour le commerce, la civilisation et le christianisme ! : Aimé Humbert, instigateur du débouché japonais pour l'industrie suisse (1859-1862), mémoire de master, université de Neuchâtel, 2009.

50. Manuel Matamoros Garcia (1834-1866) est considéré comme le fondateur du protestantisme espagnol. 
de Neuchâtel dès 1866 , il y occupe également un poste de professeur de pédagogie et d'instruction civique ${ }^{51}$. À la fin de son rectorat, il continue à y enseigner la littérature française jusqu'à ce que la maladie le contraigne à prendre sa retraite en 1893. Dans le Dictionnaire, il signe les articles "Francke » et "Fellenberg ", dont il avait déjà produit une version dans la Galerie suisse d'Eugène Secrétan (1880). Par ailleurs, le Fribourgeois Cyprien Ayer (1825-1884), ancien élève de Daguet avec lequel il se brouille vers 1857, est engagé comme professeur d'économie politique, géographie comparée, géographie générale et grammaire générale dès l'ouverture de l'académie de Neuchâtel à l'automne 1866. Herdérien convaincu, germanophile et plutôt hostile à la France, Ayer élabore une théorie des races historiques dans laquelle il assigne à la Suisse "le point de contact des deux races et des deux civilisations ${ }^{52}$ ». C'est toutefois pour ses compétences grammaticales que Buisson le recrute, puisqu'il signe une série d'articles comprenant " analyse grammaticale (complétée par des exercices de synthèse) ", « contraction ", « dérivation » et "genre ». Édouard Desor (1811-1882) enseigne lui aussi la géologie et la paléontologie à l'académie dès 1866 , et signe l'article «blocs erratiques ». Scientifique d'envergure mondiale, il présida le premier congrès international d'anthropologie et d'archéologie, qui se tint à Paris en $1868^{53}$. Buisson recrute également Eugène Borel (1835-1892), un politicien et avocat neuchâtelois qui a fait ses études à Munich et Heidelberg et était devenu conseiller fédéral en 1872, à l'âge de trente-sept ans. En charge du département des postes et télégraphes, il fut l'acteur principal de la naissance de l'Union postale universelle (1874) qui s'établit selon ses souhaits dans la capitale helvétique. Borel rédige l'article "Suisse » dans l'édition de 1887. On peut d'ailleurs se demander pourquoi celuici n'a été confié à Daguet, auteur d'une Histoire de la Confédération suisse aux multiples rééditions et traduite en plusieurs langues.

Nous terminerons ce panorama des Suisses du Dictionnaire de Pédagogie et d'instruction avec le Neuchâtelois Georges Calame, né

51. Histoire de l'université de Neuchâtel. Tome 2 : la seconde académie (1867-1909), Hauterive, G. Attinger, 1994, p. 60.

52. Cyprien Ayer, « Les nationalités et les États de l'Europe en 1861 », Revue suisse, 1861, p. 331. Voir également l'analyse de Daniel Maggetti, L'invention de la littérature romande 18301910, Lausanne, Payot, 1995, p. 145-148.

53. Voir Marc-Antoine Kaeser, « Une science universelle ou "éminemment nationale" ? Les congrès internationaux de préhistoire (1865-1912) », Revue germanique internationale, 12/2010, p. 17-31; du même auteur, L'univers du préhistorien. Science, foi et politique dans I'œuvre et la vie d'Édouard Desor (1811-1882), Paris, L'Harmattan, 2004. 
à la Chaux-de-Fonds le 13 mai 1849. Ancien secrétaire de la Revue critique, il devient professeur à l'école Monge à Paris. On sait que Calame fut un ancien élève de l'École des hautes études en archéologie orientale, ce qui explique qu'il ait signé un article consacré aux écoles arabes-françaises. Il livre également une brève notice sur le père du sport éducatif anglais Thomas Arnold et une biographie importante du pédagogue allemand Gustav Friedrich Dinter.

Il se confirme ainsi qu'une communauté pédagogique transnationale prend forme des deux côtés du Rhône et que les échanges tant humains qu'intellectuels abondent dès le milieu du $\mathrm{xIx}^{\mathrm{e}}$ siècle. Alexandre Daguet, par sa position centrale de rédacteur en chef de L'Éducateur et de guide de l'école romande devient, avec l'appui de Buisson, un marchepied vers la pédagogie suisse. L'élite scolaire française fréquente également les congrès romands et s'y forme. Les cadres de l'école de la République, à l'instar des inspecteurs généraux, étudient et parcourent la Suisse en quête de pratiques et d'innovations susceptibles d'être réinterprétées dans leur propre pays.

\section{En mission dans les congrès suisses}

Le premier congrès des instituteurs de la Suisse romande se tient à Fribourg (1866) et a pour fonction essentielle de créer du relationnel entre les instituteurs romands. Il s'agit d'estomper les préventions et autres stéréotypes cantonaux encore particulièrement prégnants, notamment entre les cantons catholiques et protestants. L'esprit de corps qui règne lors de ces rencontres est remarqué par les visiteurs étrangers. M. Heinemann, instituteur protestant de Paris, membre de la Société des institutrices et des instituteurs du département de la Seine, relève au sujet du congrès de Saint-Imier de 1874 :

J'aurai beaucoup de choses à raconter à mon retour. Je parlerai à mes collègues de votre solidarité, de votre amitié et surtout de la manière distinguée dont vous savez exercer l'hospitalité. À Paris nous n'avons pas les mêmes prérogatives que vous. D'abord il nous manque l'esprit de corps et nous sommes trop peu nombreux. Nous avons besoin de travailler comme vous le faites, à l'instruction de notre population qui est bien ignorante, bien plus ignorante qu'en Suisse ${ }^{54}$.

Par ailleurs, il faut dire que les villes qui accueillent ces congrès se transforment pour l'occasion. Le décorum grandiose et solennel de ces

54. Compte-rendu du Ve congrès scolaire de la Société des Instituteurs de la Suisse romande tenu à Saint-Imier les 20, 21 et 22 juillet 1874, Saint-Imier, Imprimerie E. Grossniklaus, 1874, p. 49. 
fêtes a, à l'évidence, permis de valoriser l'image du corps professoral dans l'opinion publique; les visiteurs sont frappés par cette mise en scène inédite.

Le congrès de 1870 , qui a lieu à Neuchâtel les 20 et 21 juillet 1870 , se tient dans des circonstances singulières puisqu'il débute, on l'a déjà vu, au lendemain de la déclaration de guerre française à la Prusse. Cette conférence marque l'entrée en scène d'un passeur emblématique de la pédagogie franco-romande. Il s'agit de Charles Defodon (1832-1891), rédacteur en chef du Manuel de l'instruction primaire et délégué de la Société pour l'instruction élémentaire:

J'y suis venu comme délégué de la Société pour l'instruction élémentaire de Paris, d'une Société qui date aujourd'hui de cinquante-cinq ans; qui, fondée dans de tristes jours où notre pays était envahi par l'étranger, avait compris dès lors que le seul moyen de relever un peuple, c'est de l'instruire, et qui depuis n'a cessé de poursuivre ce but, malgré toutes les difficultés et malgré les résistances. Et puis, je suis venu à vous, j’oserai le dire, en mon propre nom. Rédacteur en chef d'un journal scolaire qui tient à honneur de suivre les doctrines des Pestalozzi et des Girard, de vos illustres compatriotes [...] j'ai voulu, après avoir visité les expositions scolaires de la France, répondre à l'invitation que vous nous aviez faite en 1867, en visitant et en étudiant l'exposition solaire de la Suisse romande, persuadé que je trouverais dans cette visite et dans cette étude l'occasion de bien des observations et de bien des rapprochements intéressants et utiles ${ }^{55}$.

À partir de cette visite neuchâteloise, cet ancien secrétaire de Victor Cousin s'impose comme la principale tête de pont, avec Buisson et Daguet, des relations pédagogiques entre la Suisse romande et Paris. Spécialiste des questions scolaires internationales, notamment grâce à son rôle-clé dans la réalisation de l'exposition scolaire à Paris en marge de l'Exposition universelle de 1867, Defodon est ensuite régulièrement délégué par Hachette pour visiter les expositions scolaires départementales ou étrangères ${ }^{56}$. Ses visites aux congrès romands de 1870, 1872, 1874 et 1884 sont systématiquement rapportées et commentées dans le Manuel de l'instruction primaire.

55. Compte-rendu du congrès pédagogique de Neuchâtel en 1870, et rapport sur l'exposition scolaire de la Suisse romande, Neuchâtel, Imprimerie G. Guillaume Fils, 1870, p. 51.

56. Voir l'article « Charles Defodan (sic) » (on n'a curieusement jamais corrigé cette coquille), NDP, http://www.inrp.fr/edition-electronique/lodel/dictionnaire-ferdinand-buisson/document. php? id $=2523$ 
Un autre Français à moitié suisse par son séjour sur les bords du Léman à Nyon ${ }^{57}$ est présent, comme Defodon, à Saint-Imier en juillet 1874. Fondateur de la Société d'éducation de Lyon, Jean Georges Hoffet (1803-1877) appartient à une famille protestante originaire de Strasbourg. Parfaitement bilingue, il administre des prédications aux ouvriers allemands et suisses établis à Lyon. Il y préside d'ailleurs la Société de moralisation et de secours pour les ouvriers alsaciens, suisses et allemands, fondée pour empêcher la démoralisation presque inévitable des ouvriers qui arrivaient à Lyon sans connaître la langue française ${ }^{58}$. Fasciné par l'utilité des congrès romands, Hoffet souhaite importer le concept outre-Rhône: "En France, l'idée n'a malheureusement pas encore pu être exécutée. J'ai l'entière conviction que sans des conférences pédagogiques, jamais les instituteurs ne pourraient faire les progrès qu'ils devraient faire ${ }^{59}$ ".

En 1880, Ferdinand Buisson mandate Bonaventure Berger (18261890), le premier directeur du musée pédagogique et de la Bibliothèque centrale de l'enseignement primaire, pour assister au congrès des instituteurs de la Suisse allemande à Soleure. Deux ans plus tard, c'est l'inspecteur Guillaume Jost, originaire de Strasbourg et dont Daguet relève à plusieurs reprises l'excellence de l'allemand, qui assiste à celui de Bâle:

Depuis longtemps nos gouvernements ont l'habitude d'envoyer à l'étranger des délégués chargés d'étudier l'organisation des écoles, les méthodes d'enseignement, toutes les questions administratives, financières, pédagogiques qui intéressent le progrès de l'instruction élémentaire. Nous voulons savoir comment les nations voisines comprennent ces questions, et comment on fait passer dans la pratique les règles de la pédagogie théorique. Nous suivons en cela l'antique maxime: Prüfet alles und behaltet das Beste (examinez tout et retenez ce qui est bon). Mais c'est surtout depuis 1871, depuis l'établissement définitif du gouvernement républicain, que ces questions sont devenues vitales pour nous, car, comme l'a dit un de nos grands esprits, c'est dans la puissance de l'éducation que réside la force d'une république [...] Quel pays, Messieurs, se prête mieux que le vôtre à ces enquêtes? Quel pays a fait plus pour l'instruction du peuple? Dans quel pays nous sentons-nous plus à l'aise, nous Français, qu'au milieu de ce peuple libre, habitué depuis

57. Alexandre Daguet, « Nécrologie », L'Éducateur 16/1877, p. 246.

58. Charles Defodon, « Nécrologie », Manuel général de l'instruction primaire, n²6, 30 juin 1877, p. 246.

59. Compte-rendu du Ve congrès scolaire, op. cit., p. 51. 
longtemps à la liberté dont il a fait un si noble usage? [...] M. Fallières, notre ministre de l'Instruction publique, a visité récemment ces écoles de Bâle, et c'est certainement à elles qu'il a songé quand il a dit, hier, dans une fête scolaire à Moissac: Les palais de la démocratie, ce sont les écoles ${ }^{60}$.

On sait par ailleurs que Berger profite de son passage en Suisse pour visiter les écoles de plusieurs cantons en 1880 et que Jost parcourt une partie du pays en 1881. Ces missions sont à l'origine de la programmation d'excursions scolaires dans les pays voisins en faveur des élèves-maîtres français ${ }^{61}$. En 1883, Ferdinand Buisson et Georges Dumesnil se rendent à Zurich pour visiter l'exposition nationale suisse ${ }^{62}$. À l'évidence, les congrès des instituteurs suisses vont rapprocher les hommes d'école romands de leurs collègues français et contribuer à parfaire les connaissances des systèmes pédagogiques germaniques de ces derniers. Au fur et à mesure des rencontres, des liens se créent et des coopérations se dessinent, faisant de la Suisse une sorte d'intermédiaire entre le Nord et le Midi.

\section{Un trait d'union entre le Nord et le Midi}

La Suisse, par sa position au centre de l'Europe et au confluent des races latine et germanique, semble prédestinée à devenir de plus en plus le trait d'union entre les grands peuples qui l'entourent ${ }^{63}$.

Quel fut le rôle de la Suisse (romande) dans le passage de savoirs pédagogiques en France? On peut en premier lieu penser qu'il était pratique, pour des pédagogues français peu à l'aise avec la langue allemande, de transférer chez eux des méthodes germaniques préalablement traduites et expérimentées dans le giron romand. De plus, il est probable que la Romandie a joué pour la France le rôle de "sas de décontamination ${ }^{64}$ " des idées allemandes dans le sens où il

60. Discours de G. Jost au Lehrertag de Bâle de 1884, reproduit dans A. Daguet, « Le Lehrertag de Bâle et le comité romand », L'Éducateur, 23/1884, p. 354.

61. Alexandre Daguet, « Chronique scolaire », L'Éducateur, 13/1882, p. 205.

62. Alexandre Daguet, « L'exposition nationale de Zurich, jugée par M. Dumesnil, conseiller d'État de la République française », L'Éducateur, 1885, p. 98-100. Voir également Pierre Centlivres, « Expositions nationales et nation helvétique. La quête d'identité », Revue européenne des sciences sociales, t. XLIV, 135/2006, p. 123-143.

63. « Convocation au congrès d'instituteurs de Neuchâtel (1870) 》, Le Manuel général de I'instruction primaire, $\mathrm{n}^{\circ} 28,9$ juillet 1870, p. 550.

64. J'emprunte cette idée à Anne-Marie Thiesse, entretien avec l'auteure, ENS-Paris, juin 2011. 
s'avérait plus aisé de puiser des savoirs pédagogiques en Suisse que chez l'ennemi allemand, même si les contacts et les missions restèrent conséquents entre les deux pays rivaux. Ce qui est certain, c'est que la Suisse s'est imposée durant le XIX ${ }^{\mathrm{e}}$ siècle comme un intermédiaire, sinon comme un passeur entre les cultures du nord et du sud de l'Europe.

Culturellement, il est intéressant de constater qu'à partir des années 1840 et de la rupture du lien forcé avec la France proclamée par des auteurs comme Henri-Frédéric Amiel, Eugène Rambert ou Joseph-Marc Hornung, l'élite romande s'accorde sur un point: la Romandie - et la Suisse plus généralement - incarnent une posture médiane au sein du concert des nations européennes. Daniel Maggetti propose dans sa thèse une synthèse détaillée de ce repositionnement stratégique et explique qu'au début du siècle, avec des auteurs francophiles comme Alexandre Vinet, Jean-Jacques Porchat ou Juste Olivier, la Suisse romande demeurait fortement dépendante de Paris. Ainsi, "l'absence de référence à l'Allemagne montre qu'on n'attribue pas encore à la Suisse française ce statut de nation intermédiaire calqué sur la représentation de l'Helvétie, et destiné à la détacher de la France ${ }^{65}$ ". Le fait que des intellectuels comme Amiel - formé à Berlin - ou son ami Daguet se soient nourris de références essentiellement germaniques marque une rupture. Dès lors, pour Amiel comme pour son rival Joseph-Marc Hornung, la Suisse doit jouer le rôle d'intermédiaire entre la France et l'Allemagne ${ }^{66}$. La pensée du belge Lucien Jottrand (1804-1877) s'avère encore plus explicite, puisqu'il fait de la Suisse romande la messagère des valeurs protestantes en France ${ }^{67}$. Daguet indique que "c'est à nous Suisses français ou romans (sic), à colliger tous ces avantages des deux civilisations et à servir de trait d'union aux diverses nationalités ${ }^{68} »$. De ce fait, n'est-il pas étonnant de constater la responsabilité quasi prophétique qu'il assigne à la pédagogie de son pays:

Si la mission politique et sociale de la Suisse, au milieu des grandes nations qui l'entourent, est une mission de paix, de neutralité, de média-

65. Ibid., p. 40.

66. Amiel développe cette idée dans son texte programmatique Du mouvement littéraire dans la Suisse romane et de son avenir, Genève, Imprimerie E. Carey, 1849.

67. Daniel Maggetti, op. cit., p. 125 sq.

68. Alexandre Daguet, « Union de la Suisse française et de la Suisse allemande », L'Éducateur, 14/1869, p. 219. 
tion, de bienfaisance, le rôle de la pédagogie suisse ne serait-il pas de servir d'intermédiaire et de trait d'union entre les systèmes d'éducation du Nord et du Midi ${ }^{69}$ ?

Dans cette perspective, il n'est pas rare de voir Daguet intervenir en médiateur paternaliste lors de tensions franco-allemandes. Il réagit par exemple à une attaque de Célestin Hippeau contre les Allemands parue dans L'École nouvelle: « Nous ne ménageons pas les Allemands, quand ils offensent la langue française et font du teutonisme. Mais le chauvinisme ne vaut pas mieux et devrait avoir disparu des journaux scolaires, comme il a disparu d'un grand nombre d'organes de la presse politique ${ }^{70}$. "Dans l'imaginaire européen se fixe peu à peu l'image d'une Suisse qui apporte son crédit à l'élaboration culturelle européenne, comme l'exprime l'ancien président de la République espagnole Emilio Castelar:

Les cités républicaines sont celles qui ont le plus contribué à l'éducation de l'espèce humaine [...] Athènes lui a donné ses statues, Rome ses lois, Florence les arts de la Renaissance, Gênes, la lettre de change pour le commerce, Venise, les glaces, Pise, la loi du pendule, Strasbourg, l'imprimerie. Tout le mouvement intellectuel de la France au Xvi ${ }^{\mathrm{e}}$ siècle eût été perdu, s'il n'eût trouvé un asile à Genève; sans la Hollande, l'Angleterre devenait réactionnaire avec les Stuarts. Zurich a exercé une grande influence sur le mouvement intellectuel de l'Allemagne. Là ont séjourné Schelling et Fichte; là écrivirent Klopstock et Gessner; là encore brillait le théologien, le physionomiste Lavater; c'est là aussi qu'est né Pestalozzi ${ }^{71}$.

Mais on ne saurait trop souligner combien cette position médiane de la Suisse va en faire une plateforme des idées pédagogiques occidentales. Dans ce sens, sa presse pédagogique incarne un réceptacle hybride qui s'est nourri des questionnements et des innovations pédagogiques de son temps.

69. Compte-rendu du Ve congrès scolaire, op. cit., p. 64.

70. Alexandre Daguet, « Pédagogie et Encyclopédie françaises 》, L'Éducateur, 10/1880, p. 148. 71. Alexandre Daguet «Pestalozzi et la Suisse loués par Emilio Castelar », L'Éducateur, 2/1876, p. 17-18. 



\section{6 \\ L'Éducateur et ses références pédagogiques mêlées ${ }^{1}$}

Dès le milieu du Xviıi ${ }^{\mathrm{e}}$ siècle, l'usage intensif de la presse d'éducation stimule la circulation de savoirs pédagogiques dans une Europe scolaire en construction. Les méthodes se discutent, s'échangent et s'adaptent en fonction des besoins des contextes particuliers. Alain Choppin rappelle avec raison que les revues pédagogiques ont longtemps occupé les fonctions de livre du maître ou du professeur, et tenu par là même un rôle déterminant ${ }^{2}$. Pierre Gaspard le souligne: "La presse constitue un maillon indispensable dans la connaissance de ce qu'a été, pendant près de deux siècles, le système d'enseignement, car elle présente à la fois l'espace où se déploient et le point où se focalise tout un ensemble de théories et de pratiques éducatives d'origine tant officielle que privée ${ }^{3}$.»

L'échange massif de savoirs scolaires sur le continent laisse à penser que la plupart des revues pédagogiques se sont muées en interprètes d'une pédagogie toujours davantage métissée. Ce constat s'avère particulièrement probant pour L'Éducateur - l'organe de la Société des instituteurs de la Suisse romande (SIR) - qui peut être considéré comme un lieu de mémoire interculturelle pour diverses raisons. Il s'agit en premier lieu de souligner l'exceptionnelle ouverture internationale que son premier rédacteur, Alexandre Daguet, a insufflé à son contenu. Le périodique regorge en effet de références étrangères et dans cette

1. Certains développements de ce chapitre ont fait l'objet d'une publication : « Une revue à l'affût du monde (1865-1890) ? L'Éducateur comme relais des transferts et métissages pédagogiques en Suisse romande », Revue suisse des sciences de l'éducation, 36/1, p. 17-34.

2. Alain Choppin, « Le manuel scolaire, une fausse évidence historique », Histoire de l'éducation, 117/2008, p. 42.

3. Pierre Caspard (dir.), La presse d'éducation et d'enseignement, XVIII siècle-1940, t. I, Paris, INRP, Éditions du CNRS, 1981, p. 8. 
perspective, interroger la masse importante d'articles et de recensions consignées sur la France fait sens. Bien entendu, la réciproque se vérifie clairement. La bibliothèque de Jean-Jacques Rapet (1805-1882), qui est à l'origine de la constitution du musée pédagogique, est par excellence un lieu de mémoire français de la pédagogie suisse. Acheté par l'État (loi du 5 juin 1880), le fonds de cet éminent spécialiste de la pédagogie helvétique constitue une collection unique au monde, surtout en ce qui concerne les ouvrages relatifs à la pédagogie suisse dès lors instituée comme référence en France par Ferdinand Buisson ${ }^{4}$. Que l'on se remémore aussi les dizaines d'articles reproduits dans le Manuel général de l'instruction primaire par Charles Defodon (1832-1891) pour rendre compte des congrès romands auxquels il participait activement. De ce fait, le chercheur intéressé par les conférences pédagogiques suisses trouvera davantage d'informations sur le sujet dans la presse d'éducation française que dans les revues romandes. Cet usage transmémoriel des revues mérite donc d'être souligné. Lieu de mémoire interculturelle, L'Éducateur l'est également pour d'autres raisons. Sous le Second Empire, il a servi de fenêtre de dialogue pour des instituteurs français touchés par la censure. Dans cette perspective, analyser les références plurielles et métissées de L'Éducateur laisse apparaître, en filigrane, les grands traits d'une histoire romande de l'éducation française.

\section{Dieu-Humanité-Patrie}

Lors de la publication du numéro initial en janvier 1865 , le comité directeur de L'Éducateur ne cache pas son ambition de supplanter les revues cantonales existantes afin de constituer un monopole: "Cette union est nécessaire encore si l'on désire (et on doit le désirer) que la feuille de la Suisse romande l'emporte sur les feuilles purement cantonales qui l'ont précédée dans la carrière ${ }^{5}$. " Il faut dire que dès les années 1850, des voix se font entendre pour lutter contre tout esprit cantonaliste. Qui mieux qu'Alexandre Daguet pouvait mener cette œuvre de médiation? Intellectuel doué d'un savoir encyclopédique, historien national, Daguet théorisa la pédagogie libérale-nationale romande du second $\mathrm{XIX}^{\mathrm{e}}$ siècle et œuvra pour le rassemblement corporatif des instituteurs de Suisse française.

4. Voir Alexandre Fontaine et Damiano Matasci, « Centraliser, exposer, diffuser : les musées pédagogiques et la circulation des savoirs scolaires en Europe (1850-1900) », Revue germanique internationale, CNRS Éditions, 20/2015.

5. L'Éducateur, 1/1865, p. 3. 
L'Éducateur - toujours en activité aujourd'hui sous la forme d'un mensuel - paraît du temps de Daguet le premier et le quinze de chaque mois et se divise en deux parties principales: une première consacrée aux articles de fond, théoriques et une seconde dévolue à la correspondance, aux notices bibliographiques et aux comptes-rendus. Une partie pratique fait son apparition en 1869 , avec des exercices de mathématiques ou des dictées à utiliser directement en classe. Daguet réserve une place importante à l'étude des trajectoires de pédagogues illustres, présentées aux conducteurs de la jeunesse comme autant d'exemples à suivre. Le rédacteur en chef privilégie surtout " ceux qui ne furent pas seulement des théoriciens de cabinet comme Montaigne, Locke et Rousseau, mais de véritables éducateurs en théorie et en pratique, à l'exemple de Pestalozzi et de Girard, dont les noms forment le principal décor de cette enceinte ${ }^{6}$ ». Centré sur ces deux éducateurs qui sont à l'origine de la Suisse pédagogique, L'Éducateur a toutefois été pensé par Daguet comme une fenêtre ouverte sur les divers systèmes étrangers, comme un lieu d'ouverture qui sert avant tout à élargir l'horizon des instituteurs romands. Daguet promeut l'éducation d'un corps professionnel qu'il veut armer en termes de méthodes pédagogiques. C'est pourquoi il entreprend la diffusion d'une theoria éclectique, seule susceptible selon lui d'instituer un code commun dans chaque partie de la Suisse romande et arracher ainsi l'instituteur à son isolement:

La lecture d'une feuille pédagogique bien dirigée fait à l'esprit de l'instituteur l'effet d'une eau pure et savoureuse à celui qui a soif. L'intelligence est avivée, le savoir accru, la méthode perfectionnée, le cœur agrandi et ennobli. Quel est l'instituteur qui ne serait satisfait de voir ce que les autres font, ce qui se passe autour de lui et au-delà, de quelles questions on s'occupe et quels progrès s'accomplissent. Il y a cependant des instituteurs qui ne lisent aucun journal scolaire et ne s'inquiètent pas le moins du monde de ce qui se fait en pédagogie. Ils tiennent leur école demain comme hier et ne pensent même pas qu'ils aient à apprendre quelque chose: ils taxent de théories creuses ou arbitraires tout ce qui est en dehors de leur horizon ou contrarie leur routine, oubliant le fameux mot de Goethe, le coryphée de la littérature allemande: «Qui n’avance pas recule. " Nous ajouterons: Celui qui n'a pas l'habitude de porter ses regards au-delà de la banlieue où il se trouve, devient myope et sans cœur

6. Alexandre Daguet, « Coup d'œil sur la marche et les tendances de L'Éducateur », L'Éducateur, 18/1870, p. 277.

7. Alexandre Daguet, « Mission de la presse scolaire : l'importance de cette dernière pour I'instituteur », L'Éducateur, 4/1880, p. 50. 
Entre 1865 et 1890, L'Éducateur possède un nombre d'abonnés relativement stable, ce qui équivaut à une moyenne de 1200 tirages. Il touche ainsi la moitié du corps enseignant romand et est consulté par plusieurs personnalités de l'Europe pédagogique (F. Buisson, G. Compayré, G. Sacchi, J.-J. Campion, V. di Castro, K. V. Stoy, etc.). Il emprunte sa devise Dieu-Humanité-Patrie à l'école cantonale de Fribourg dirigée par Daguet entre 1848 et 1857, devise qui imprime le cadre idéologique de sa ligne rédactionnelle. Signalons encore que L'Éducateur a la particularité d'être une revue itinérante, changeant de lieu et de maison d'édition tous les deux ans et parcourant ainsi les principales villes de Suisse romande.

Lors de la constitution de la première équipe rédactionnelle, Daguet cherche avant tout à s'entourer de personnalités "fiables ». Il s'agit de prendre toutes les précautions afin de ne pas répéter l'expérience douloureuse de l'école cantonale de Fribourg, où les luttes politiques entre les membres du corps enseignant ont jeté le doute sur ses capacités à diriger une équipe pédagogique. Fort des apprentissages retenus lors de ce qui s'apparente à une fronde, le noyau initial des collaborateurs de la revue regroupe, pour l'essentiel, des anciens étudiants de Daguet proches des milieux libéraux-nationaux catholiques et protestants, parmi lesquels on trouve Auguste Biolley, Alexis Bourqui, Joseph Rey, l'herbartien Xavier Ducotterd et Jules Paroz. Ainsi, contrairement à un Ferdinand Buisson qui a dû jongler avec des monarchistes dans la première équipe rédactionnelle de son Dictionnaire de pédagogie et d'instruction primaire ${ }^{8}$, Daguet a pu, globalement, s'appuyer sur l'homogénéité idéologique de ses collaborateurs, au nombre de trois cents sous sa période rédactionnelle. Dans cet environnement essentiellement masculin, une poignée d'éducatrices vont jouer un rôle déterminant dans la circulation de savoirs pédagogiques spécifiques et méritent de ce fait une attention particulière.

\section{Caroline Progler et la diffusion de l'« évangile fröbelien »}

Énumérer les collaboratrices de L'Éducateur dans la période rédactionnelle d'Alexandre Daguet relève de l'anecdotique. Outre la notice

8. Voir Patrick Dubois, « Le Dictionnaire de F. Buisson et ses auteurs (1878-1887), Histoire de l'éducation, 85/2000, p. 25-47; du même, « La pédagogie catholique dans le « Dictionnaire de Pédagogie » de Ferdinand Buisson », in Pédagogie chrétienne, pédagogues chrétiens, colloque international d'Angers de septembre 1995, Paris, Éditions Don Bosco, 1996, p. 323-333. 
sur Les grandes difficultés de l'éducation morale d'Hortense Ray, décédée tragiquement en 1865 ou quelques rares poèmes de la neuchâteloise Amélie Pernod, les femmes et leurs revendications demeurent clairement au second plan lors de la phase initiale de la revue (1865-1889). Plusieurs arguments sont avancés par les instituteurs eux-mêmes: l'un pointe le manque d'aptitude, l'autre évoque la faiblesse féminine... Il faut dire que l'angoisse pernicieuse d'une féminisation du métier traîne ici et là, amères revendications que l'on retrouve sporadiquement dans le courrier des lecteurs:

Comment peut-on admettre, d'une manière générale, que l'enseignement de l'arithmétique, de la géométrie, de la comptabilité, de l'agriculture, des sciences naturelles, de l'instruction civique, du dessin linéaire, soit bien donné dans les écoles mixtes par des régentes, du reste toujours dévouées. Nous admettrons des exceptions en faveur de quelques personnes du sexe très bien douées au point de vue de l'intelligence et de la didactique. Mais faire de l'exception la règle, c'est mettre la charrue devant les bœufs, c'est placer ces demoiselles dans une fausse et cruelle position, les habituer à un enseignement superficiel ou les obliger parfois à faire fi de certaines branches importantes du programme pour lesquelles ces dames ne sauraient avoir les aptitudes nécessaires. Nous n'entendons nullement par là les exclure de l'enseignement, hâtons-nous de le dire. Nous plaignons le sort de celles qui sont ainsi placées, et nous demandons pour elles, pour l'institutrice au cœur sensible et maternel, les degrés inférieurs de nos écoles mixtes trop peuplées 9 .

L'une de ces femmes va néanmoins réussir à émerger de ce groupe, pour faire connaître et populariser un système pédagogique germanique en Suisse romande. Caroline Progler (?-1886) représente la plume genevoise qui intervient le plus souvent dans L'Éducateur, avec trente-sept contributions entre 1868 et 1884 . Entièrement dévouée à la diffusion de l'œuvre de Fröbel, elle a trouvé dans ce périodique une plateforme particulièrement appropriée pour diffuser la doxa fröbelienne en Suisse occidentale. On notera que c'est Henri-Frédéric Amiel qui, en novembre 1865, a alerté son ami Daguet sur les qualités de l'œuvre de l'éducateur allemand: "Pourquoi ne parle-t-on pas de Fröbel dans l'Éducateur? J'ai toujours cru et dis que les trois ou quatre premières années de la vie sont les plus importantes, et c'est la vue capitale de ce pédagogue, un des plus pénétrants qu'il y ait eu ${ }^{10}$. » Malgré cette invi-

9. L'Éducateur, 4/1880, p. 54.

10. Lettre de H.-F. Amiel à Daguet, Genève, 17 novembre 1865 , Bibliothèque publique de Genève, salle des manuscrits, Archives Amiel 92, Ms fr 3092, p. 212. 
tation, Daguet restera d'abord sceptique à l'idée d'ouvrir ses colonnes aux méthodes du Pestalozzi allemand, notamment en raison de leur caractère particulièrement onéreux.

L'histoire de l'éducation préscolaire et la diffusion de la pédagogie de Friedrich Fröbel en Suisse romande ont été remarquablement traitées par Michèle Schärer ${ }^{11}$. On doit toutefois s'interroger sur le régime circulatoire de la méthode fröbelienne. Il faut souligner le rôle de self-service que la Suisse a joué dans la diffusion des principes du pédagogue thuringien. En 1861, Édouard Raoux, fondateur du premier jardin d'enfants frobélien à Lausanne en 1860, lance une revue mensuelle intitulée L'éducation nouvelle ou méthode Frobel, dans le but de répandre la méthode en Suisse et en Europe. Il s'entoure de collaborateurs européens prestigieux, parmi lesquels on trouve la baronne prussienne von Marenholtz-Bülow, le Dr Karl Schmidt et le Dr Diesterweg de Berlin ${ }^{12}$. S'agissant de Bertha von Marenholtz-Bülow (1810-1893), nous savons qu'elle profita de l'appui d'Edgar Quinet et de Jules Barni - les deux irréconciliables exilés en Suisse - afin d'approcher la tribune du congrès de Berne de 1865 et d'y exposer les principes du Kindergarten. Elle y rencontra « le professeur Desor, le savant géologue neuchâtelois, l'historien Daguet et quelques autres, mais elle [fut] déçue, choquée surtout par les diverses professions de foi matérialistes qui lui [firent] qualifier le congrès de "foire des idées" 13 ".

On ne saurait trop souligner que la diffusion européenne de Fröbel fut réalisée en grande partie par des femmes et que Genève y tient une place de choix. "Découragé, voyant que les pédagogues de profession ne l'accueillaient avec défiance, que les hommes de science refusaient de le prendre au sérieux, que les pouvoirs publics restaient indifférents, Fröbel résolut de s'adresser dorénavant aux femmes, et de remettre sa cause entre leurs mains ${ }^{14}$.» Ces ambassadrices se sentirent investies d'une responsabilité incontestable. Elles se muèrent en missionnaires afin de faire tomber les préjugés qui couraient sur l'œuvre de Fröbel. Ne pouvait-on pas lire dans le dictionnaire pédagogique de Max Ricci:

11. Voir Michèle E. Schärer, Friedrich Froebel et I'éducation préscolaire en Suisse romande : 1860-1925, Lausanne, Les Cahiers de l'ÉÉSP, 2008.

12. Voir Félix Guérig, « Recension de L'éducation nouvelle ou méthode de Frœbel », L'Éducateur, 12/1865, p. 190-191.

13. Marcel Du Pasquier, Edgar Quinet en Suisse. Douze années d'exil (1858-1870), Neuchâtel, Éditions de la Baconnière, 1959, p. 216.

14. James Guillaume : «Fröbel », Nouveau Dictionnaire de pédagogie et d'instruction primaire publié sous la direction de F. Buisson, Paris, Hachette, 1911. 
«Jardin d'enfants: serre chaude pour le développement prématuré de l'enfance ${ }^{15}$ " ? Daguet contribua d'ailleurs à colporter un certain nombres d'idées préconçues, concernant notamment l'aspect ludique des Kindergarten, là où les adeptes préféraient parler de travail déguisé. Voilà d'ailleurs pourquoi Caroline Progler, malgré une maladie qui la rongeait, se démultiplia pour populariser la méthode fröbelienne en Suisse.

La dynamique interculturelle et l'extrême mobilité de ces femmes ont ainsi largement favorisé le prêche de ce que l'on appelait, selon le mot de Michelet, l' " évangile fröbelien ». À s'en tenir aux données biographiques, rappelons par exemple que la baronne Adele von Portugall (1828-1910) après avoir étudié la méthode Fröbel à Dresde, se rendit à Liverpool avant de s'installer à Genève en 1864 ; après dix ans passés à diriger les écoles de Chantepoulet, elle partit pour Mulhouse vers la fin 1873, revint sur les bords de l'Arve en 1876 pour prendre la direction des écoles enfantines de Genève avant de s'exiler à Naples en 1884. Un article qui a paru dans le Journal de Genève en août 1911 fait remarquer que " pour comprendre les pérégrinations de Mme de Portugall, il ne faut pas oublier qu'elle est un apôtre; elle en a l'énergie, la conviction et l'autorité, elle en a le tempérament migrateur et remuant ${ }^{16}{ }$.

Bien qu'il subsiste encore de nombreuses zones d'ombre dans le parcours de Caroline Progler ${ }^{17}$, les sources connues laissent entrevoir les grandes lignes de son œuvre de médiation. Elle rencontre Adele von Portugall à Genève en 1867. En 1875, lorsqu'elle s'engage à rédiger un rapport sur les écoles enfantines pour le futur congrès de Fribourg, elle dirige un jardin d'enfants à Mulhouse. Est-ce Mme de Portugall qui l'entraîne avec elle à Genève, écourtant son exil alsacien pour prendre la direction des écoles enfantines des bords de l'Arve? À l'automne 1876, Caroline Progler ouvre des cours de français, d'arithmétique, de géographie, d'histoire, de sciences naturelles, d'allemand, d'anglais et d'ouvrages à l'aiguille (méthode Kettiger-Schaldenfeld) qu'elle donne chez elle, 8 place du Molard ${ }^{18}$. Nous l'avons vu, en 1884, les deux éducatrices s'installent à Naples afin d'y établir des jardins d'enfants.

15. Cité par Caroline Progler dans « Le Centenaire de Frédéric Frœbel », L'Éducateur, 5/1882, p. 66.

16. Journal de Genève du 09.08.1911, p. 4. Sur la baronne Adele von Portugall (1828-1910), on lira Manfred Berger, « Frauen in der Geschichte des Kindergartens: Baronin Adele von Portugall 》, version online (http://www.kindergartenpaedagogik.de/431.html).

17. Voir L'Éducateur 23/1875, p. $353 ; 18 / 1876$, p. $283 ; 8 / 1886$, p. 113.

18. Journal de Genève du 13.09.1876, p. 4. 
Elles apportent ainsi leur coopération à l'œuvre de Mme Schwab, fondatrice d'une vaste institution de jeunes filles placée sous l'égide de la reine d'Italie ${ }^{19}$. Caroline Progler y meurt le 19 janvier 1886, des suites d'une longue maladie ${ }^{20}$.

L'itinéraire de Caroline Progler, en tant que passeuse transnationale de l'œuvre de Fröbel, s'avère particulièrement significatif. Mais on ne saurait l'y réduire. Habituée des rendez-vous internationaux, elle se retrouve dans les lieux d'évaluation de la production pédagogique, notamment à Paris lors de l'Exposition universelle de 1878. À la demande de Daguet, elle établit une série de notes comparatives sur les diverses nations présentes à Paris qu'elle expose en neuf articles dans L'Éducateur ${ }^{21}$. On peut donc penser que C. Progler se fait remarquer à Paris, d'autant qu'elle avait préalablement envoyé un mémoire sur l'enseignement géographique au Manuel général de l'instruction primaire dirigé alors par Charles Defodon. La sous-commission de l'Exposition universelle le gratifie d'un prix, séduite qu'elle est par les fondements germaniques de sa méthode:

$\mathrm{M}^{\text {lle }}$ Progler voudrait que les études géographiques ainsi comprises fussent préparées par des notions se rapportant à l'histoire naturelle. Suivant elle, c'est à cette préparation qu'il faut attribuer la supériorité des Allemands dans cette branche si importante de l'instruction. «De 5 à 10 ans, dit $\mathrm{M}^{\text {lle }}$ Progler, ce n'est pas la description de la terre, pas même celle de son pays natal que le petit élève doit apprendre; encore moins une kyrielle de noms étrangers qui ne dise rien à son esprit et sont loin d'être la nourriture que réclame sa jeune intelligence. Ce qu'il doit apprendre, c'est à voir, à comparer, à tirer des conclusions, à juger par lui-même. Son esprit d'observation doit être éveillé, il doit apprendre à aimer la nature qui l'entoure, et pour cela il doit la connaître ${ }^{22}$.

Cet exemple, parmi tant d'autres, nourrit l'hypothèse selon laquelle l'école helvétique aurait endossé le rôle d'espace de contournement du modèle scolaire prussien. Les cadres de l'école de la $\mathrm{III}^{\mathrm{e}}$ République vont tout du moins largement puiser dans ce réservoir romand, lui-même constitué par absorption d'un grand nombre de références pédagogiques germaniques. Si la diffusion opérée par Caroline Progler dans L'Éducateur

19. Journal de Genève du 09.08.1911, p. 4.

20. Voir le faire-part dans le Journal de Genève du 23.01.1886, p. 4.

21. Voir L'Éducateur 1879, p. 4, 50, 108, 115, 163, 193, 337 ; 1880, p. 35, 134.

22. L'Éducateur, 22/1878, p. 343. Mentionnons que le rapport du prix porte la signature des principaux acteurs de l'école républicaine: Buisson, Jost, Berger, Cocheris, Defodon, etc. 
se révèle tout à fait visible, certains emprunts demandent une lecture plus attentive, du fait surtout de la construction identitaire qui tend à dévaloriser certains transferts pour privilégier les aspects du cru.

\section{Crispations interrégionales et circulations dissimulées}

Comment évoluèrent, à moyen terme, les relations avec les frères d'outre-Sarine ${ }^{23}$ ? Sur la base d'une étude sur les relations confédérales dont on peut retracer le fil à partir de L'Éducateur et des comptesrendus de congrès, on peut affirmer qu'il existe, dans les années consécutives à la fondation de la SIR, une réelle volonté d'échange et de rapprochement. En 1865, le landammann Vigier, de Soleure, adresse une invitation à assister au congrès du Lebrerverein dans sa ville. Il marque par là " son désir de voir la Suisse romande s'associer à la Suisse allemande pour traiter d'un commun accord les questions diverses posées par le programme du congrès ${ }^{24}$ ". Daguet s'empresse de répondre que " tout en ayant à cœur de s'affirmer et de faire acte d'autonomie, dans le domaine pédagogique et intellectuel en général, la Suisse romande tient aussi à honorer et regarde comme un devoir de rester fermement unie à la Suisse allemande, sa sœur aînée en liberté et en patriotisme ${ }^{25}$ ». Une vingtaine d'instituteurs romands y prend part, comme à celui de Saint-Gall en 1867.

Pourtant, à y regarder de plus près, les coopérations et les échanges, notamment lors des congrès respectifs, s'avèrent peu nourries, malgré d'innombrables appels à l'union confédérale. Dans L'Éducateur, on trouve déjà quelques mouvements d'humeur dès $1869^{26}$. En 1871, Daguet déplore publiquement la piètre qualité des relations interrégionales: "L'isolement, un isolement déplorable continue à peser d'un point de vue intellectuel surtout entre les Suisses de langues diffé-

23. La Sarine partage non seulement la ville bilingue de Fribourg, mais également la Suisse allemande de la Suisse romande. On appelle également cette frontière le Röstigraben (littéralement le « fossé de röstis »).

24. Alexandre Daguet, « Congrès des instituteurs suisses à Soleure », L'Éducateur, 4/1865, p. 59.

25. Ibid.

26. « Nos frères allemands ont brillé par leur absence aux congrès scolaire de Fribourg (1866) et de Lausanne (1868) [...]. Notre étonnement a été grand en voyant que les considérations les plus propres à toucher nos frères allemands et les appels les plus chaleureux eussent trouvé si peu d'écho et eussent à peine excité l'attention dédaigneuse des journalistes et des hommes d'école de la Suisse allemande » (L'Éducateur, 14/1869, p. 218-219). 
rentes. Cet isolement est la plaie de la Suisse. La politique seule semble avoir le privilège de mettre en contact la Suisse allemande et la Suisse romande $^{27}$. » Médiateur, comme Eugène Rambert et trait d'union entre les deux berges de la Sarine, Daguet tente lors du congrès de la SIR de 1879 à Lausanne, d'insuffler une nouvelle dynamique aux relations pédagogiques confédérales qui se résument à une courtoise indifférence réciproque: «Et parmi nous, Messieurs, combien en est-il qui nourrissent l'idée fausse que tout ce qui vient d'outre-Rhin, même d'outreReuss, est nécessairement obscur et nébuleux ${ }^{28}$. " Avant de conclure sur le rôle défensif et tout à fait singulier de la Suisse allemande:

Non! Messieurs, il n'en est pas ainsi, et si les Allemands font bien d'imiter la clarté de notre langage, la brièveté relative de nos discours, nous avons beaucoup à gagner au contact de nos frères de la Suisse allemande pour la persévérance et le sérieux avec lesquels ils traitent les questions d'école. C'est aussi en vue du patriotisme, car le berceau de la liberté helvétique, où est-il ? sinon dans cette Suisse allemande dont nous parlons quelquefois avec tant de sans façon et qui est encore le rempart le plus fort contre les envahisseurs du dehors. L'Éducateur, depuis quinze ans qu'il existe, et son rédacteur, depuis qu'il a su tenir une plume, n'ont cessé de travailler au rapprochement et à l'union de la Suisse allemande, de la Suisse romande et de la Suisse italienne, sur le double terrain du patriotisme et de la culture, et il a vu avec peine, comme un obstacle à cette union, les tendances d'une partie du corps enseignant de Zurich et d'autres cantons [...]. J'en conclus, non qu'il faut se séparer de la Suisse allemande, où les tendances de cette nature trouvent d'ailleurs une opposition spiritualiste que nous pouvons renforcer, mais, au contraire, travailler avec eux au perfectionnement, au progrès, entretenir avec eux des relations patriotiques, fraternelles, nous associer à tout ce qui se fait chez eux de bien, d'utile (en dépit de certaines théories), mais sans sacrifier aucune de nos convictions et sachant au besoin les défendre avec énergie ${ }^{29}$.

Malgré cela, les rapports avec la Suisse allemande deviennent toujours moins importants, noyés dans la masse des échanges internationaux. À l'heure du bilan, Daguet conclut en 1886 que:

Depuis la fondation de L'Éducateur, nous avons constamment eu en vue de servir de trait d'union entre les confédérés des trois langues et travaillé au rapprochement, à l'échange des idées, sans toujours y parvenir.

27. Alexandre Daguet, « Nécrologie de Joseph-Antoine Henne », L'Éducateur, 6/1871, p. 87.

28. Compte-rendu du VIle congrès scolaire de la Société des instituteurs de la Suisse romande, Lausanne, Imprimerie Adrien Borgeaud, 1879, p. 80.

29. Ibid., p. 80-81. 
Nos frères allemands eux-mêmes, qui nous accusent parfois de tiédeur et se plaignent qu'on n'assiste pas en nombre à leur Lebrertag, viennentils beaucoup aux nôtres? Je traduis ou j'extrais souvent leurs articles; traduisent-ils ou extraient-ils les nôtres ${ }^{30}$ ?

Voici pour le discours dominant. Pourtant, dans les faits, la place accordée à la Suisse allemande pédagogique dans L'Éducateur ne semble pas si maigre et effacée qu'il n'y paraît dans le discours. Ainsi, entre 1865 et 1889, on dénote quelque cent trente entrées (articles de fond ou chroniques scolaires) spécifiquement consacrées à la Suisse alémanique. Certes, on recense un nombre important d'articles rédigés sur les divers synodes du canton de Berne par Henri Gobat. Toutefois, on relate toujours les temps forts des Lehrertag. De plus, Daguet publie plusieurs biographies d'éducateurs alémaniques. On remarquera d'abord une notice sur le Thurgovien Johann Jakob Wehrli ${ }^{31}$ ainsi que sur l'éducateur démocrate appenzellois Heinrich Grunholzer (18191873). Daguet sauve également Josef Anton Federer (1794-1868), Thomas Scherr (1801-1870) et Johann Rudolf Steinmüller (17721835) d'un oubli certain, en faisant partager leurs trajectoires aux régents romands. C'est dans ce même souci de conservation nationale que le rédacteur de L'Éducateur soumet, en 1885 un Coup d'œil sur les Pédagogues et Écrivains pédagogiques de la Suisse allemande 32 .

Néanmoins et malgré cette présence alémanique réduite mais stable dans L'Éducateur, on peut affirmer qu'à trop vouloir exiger son autonomie, il est probable que la SIR et sa revue se soient peu à peu distancées des projets initiaux d'union, se satisfaisant d'inviter les confrères d'outre-Sarine à participer à leurs congrès, ou de réhabiliter de temps à autre quelques figures de la pédagogie alémanique. Si Lausanne était au XVIII ${ }^{\mathrm{e}}$ siècle la plus cosmopolite des villes suisses pour appartenir à l'Europe plutôt qu'à Berne, peut-être que L'Éducateur s'ouvrit à l'international pour se départir d'une "majorité germanique [qui] ferait sentir à la minorité welsche le poids de sa force numérique et d'une culture supérieure à certains égards ${ }^{33}$ ». On ne saurait trop souligner,

30. Compte-rendu du $X^{e}$ congrès scolaire de la Société des instituteurs de la Suisse romande réuni à Porrentruy les 8, 9 et 10 août 1886, Porrentruy, V. Michel, 1886, p. 74.

31. Alexandre Daguet, « Biographie populaire des pédagogues suisses. Wehrli, l'éducateur thurgovien, le père de l'école des pauvres », L'Éducateur, 23/1876, p. 353-356 ; 24/1876, p. 369-373 et $1 / 1877$, p. 4-7.

32. Voir L'Éducateur, 18/1885, p. 281-283, 19/1885, p. 297-299 et 20/1885, p. 313-315.

33. Alexandre Daguet, « Union de la Suisse française et de la Suisse allemande », L'Éducateur, 14/1869, p. 219. 
en regard de ce constat, qu'il s'agit d'être particulièrement attentif aux périodes durant lesquelles les échanges semblent au premier abord inenvisageables, car c'est le plus souvent lorsque les espaces pédagogiques se critiquent et se dévalorisent mutuellement que les importations se révèlent les plus fécondes.

\section{Une histoire romande de la pédagogie française}

Comme l'a mentionné Daguet, c'est souvent au travers des revues que l'on entre en relation avec les pays voisins ou plus lointains. C'est également par ce canal que les instituteurs se forgent une représentation des systèmes éducatifs de ces pays. La présence d'une grande quantité de matériaux français dans L'Éducateur a retenu notre attention. Il est ainsi possible de restituer une mémoire pédagogique de la France, compilée et commentée sous la plume des collaborateurs romands. Ces derniers ont dressé leur histoire romande de la pédagogie française en trois temps: une période initiale de rejet, de dévalorisation, suivie d'un tournant donnant naissance à une troisième phase, caractérisée par l'arrivée de Ferdinand Buisson à la tête de l'enseignement primaire en 1879. Dès lors, on remarque que la République va clairement déborder sur la Suisse romande scolaire. Bien entendu, la France sous l'Empire n'était pas la même que sous la République autoritaire, qui diffère ellemême de la République de Ferry et de Buisson. Au demeurant, ce n'est pas toujours l'histoire et ses faits intangibles qui guident le propos. Christophe Charle a bien montré l'écart entre l'enthousiasme des professeurs qui rentraient de leur séjour allemand et les rapports beaucoup plus retenus que l'on publiait dans la presse officielle. En effet, " on se met[tait] à l'école de l'Allemagne à cette époque non pour reconnaître sa supériorité mais pour la battre sur son terrain tout en gardant ses propres atouts ${ }^{34} »$. Dans cette perspective, il est intéressant de s'attacher à l'évolution progressive de la perception de la pédagogie française par L'Éducateur en lien avec le processus structurel et identitaire de la SIR. Car son processus d'autonomie passe, on l'a vu, par une phase de prise de distance avec la Suisse allemande et de dévalorisation, voire d'exclusion de l'Allemagne et de la France. La revue à peine lancée, Jules Paroz publie un article sur le germanisme en pédagogie sous le titre évocateur de «Où allons-nous? ":

34. Christophe Charle, « L'élite universitaire française et le système universitaire allemand (18801900) » in Michel Espagne et Michael Werner, Les relations interculturelles dans I'espace francoallemand (XVIII'-XIXe siècles), Paris, Éditions Recherche sur les Civilisations, 1988, p. 345-258. 
L'Allemagne arrive cependant toujours la dernière: c'est dans sa nature. Son principal mérite a consisté et consiste jusqu'à ce jour à élaborer avec une patience extraordinaire et une profondeur de pensée remarquable les grandes idées nées sur un autre sol. Mais l'Allemand n'est pas pratique. C'est ce que tout le monde répète et c'est aussi la première impression qui frappe un pédagogue suisse qui parcourt l'Allemagne. Un ami qui a visité les écoles normales de la Prusse y a trouvé des choses que le bon sens populaire et pratique de notre peuple rejetterait sans hésiter. Ne nous engouons donc pas trop de l'Allemagne. C'est un tort qu'on a eu en Suisse, en particulier à Berne et à Zürich, où l'on a accordé des honneurs et une prépondérance à des éléments qu'il eût fallu repousser. Mais les yeux s'ouvrent; on commence à réclamer en faveur de l'élément national, trop longtemps méprisé, et à flétrir nos adultères pédagogiques $^{35}$.

Lorsque les instituteurs commencent à souligner le manque d'exercices pratiques et proposent de calquer la revue sur le modèle de L'École normale de Pierre Larousse, Daguet répond " que la Suisse romande n'est pas Paris et que l'imitation pure et simple tuerait l'organe de l'instituteur suisse plus sûrement que sa direction actuelle ${ }^{36}$ ». Il ajoute que "L'Éducateur n'appartient pas, Dieu merci, à cette tendance trop répandue dans certaines régions officielles, où ce qui vient de Paris doit nécessairement éclipser tout ce qui peut être fait de meilleur dans notre pays ${ }^{37}$. " Globalement, l'image que l'on donne de la pédagogie française dans L'Éducateur des années 1865-1870 est plutôt désavantageuse, d'autant qu'elle est entretenue par une série d'articles peu valorisants :

Un autre défaut de l'éducation française, c'est le peu d'attention accordée aux langues et aux littératures étrangères. Il est vrai que depuis quelques années l'étude des langues anglaise et allemande s'est introduite en France, mais plutôt toujours par désir de briller que par suite d'un besoin sérieux. Chose singulière, ni à Paris, ni dans la province, je n'ai rencontré un enfant désireux d'acquérir une langue étrangère. À quoi cela tient-il ? Je me suis expliqué cette énigme par le dédain que l'on professe en général pour tout ce qui n'est pas français. Rien n'échappe aux enfants, et on manque son but en voulant leur enseigner ce qu'on vingt fois déprécie devant eux. Et puis, le grand tort des Français est de ne pas croire à la supériorité

35. Jules Paroz, « Où allons-nous ? Un mot sur le germanisme en pédagogie », L'Éducateur, 11/1865, p. 163.

36. L'Éducateur, 2/1869, p. 30.

37. L'Éducateur, 23/1867, p. 366. 
intellectuelle de leurs voisins. Ils ont eu, jusqu'à présent du moins, l'intime conviction que le monde civilisé fini aux frontières de la France, et qu'il est inutile de savoir ce qui se passe au-dehors. J'ai vu des hommes distingués ignorer sur notre pays ce que tout le monde sait du leur. Comme c'est à peine si les Français connaissent les principaux faits de l'histoire nationale, il ne faut pas leur demander d'être forts sur celle des autres pays. Le tort d'une pareille insouciance est palpable, et je n'ai pas besoin d'ajouter que les événements récents viennent de prouver aux Français la nécessité de connaître les peuples voisins, ainsi que de s'associer au développement d'idées et de lumière qui pourrait se trouver ailleurs que chez eux. Je n'irai pas plus loin. Je n'ai pas prétendu entreprendre une critique sérieuse et complète; je n'ai voulu tracer qu'une exquise à grands traits, abandonnant à d'autres, plus habiles que moi, le soin de faire ressortir plus en détail les vices qui caractérisent l'éducation française et dont l'existence persistante a tant contribué à porter atteinte à la gloire et à l'avenir de cette nation, grande quand même ${ }^{38}$.

Lorsque Daguet commente l'histoire de la pédagogie française dans un article de $1872^{39}$, il relève le mérite des hommes d'école qui ont servi sous le Premier Empire. C'est le cas de Georges Cuvier, auquel Daguet voue une grande estime. Celui-ci relève la fondation de la première école normale primaire, créée en 1810 par Adrien de LezayMarnésia, préfet du Bas-Rhin qui s'est exilé en Suisse sous le Directoire. Mais c'est « la loi du 28 juin 1833 [qui] a été réellement la charte de l'instruction primaire dans ce grand pays ${ }^{40}$ ». À son sujet, Daguet relève néanmoins que:

pour être complètement libéral et assurer l'indépendance de l'instituteur, cette loi eût dû lui faire une position meilleure matériellement et moralement parlant. Encore aujourd'hui, l'instituteur, dans bien des localités, est le très humble valet, l'esclave-né de la commune, du maire et du curé, et on serait tenté de rire ou plutôt de pleurer en lisant ce mot d'indépendance accolé à celui de maître d'école, surtout quand on a lu l'histoire de celui dont Erckmann-Chatrian nous a fait la poignante et trop réelle peinture dans un de ses derniers livres ${ }^{41}$.

Daguet attribue à Victor Cousin les premiers combats pour la gratuité et l'obligation, poursuivis ensuite par son disciple Jules

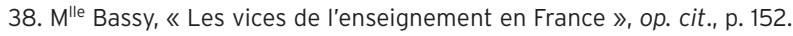

39. Alexandre Daguet, « L'instruction populaire et la littérature pédagogique de la république française », L'Éducateur, 14/1872, p. 217-222.

40. Ibid., p. 218.

41. Ibid., p. 218. 
Simon. Il souligne également que Victor Duruy s'y essaya et « échoua devant l'opposition combinée du clergé et des grands propriétaires qui payèrent plus volontiers pour la caserne que pour l'école ${ }^{42}$ ». Globalement et malgré les efforts remarqués de Duruy, la représentation de la France pédagogique demeure peu flatteuse:

La France, par exemple, qui, à tant d'autres égards, donne le ton et tient le sceptre de la puissance et de l'autorité, est restée, dans le domaine de l'instruction populaire, bien en arrière d'autres nations dont le poids, dans la balance de la civilisation générale, est bien inférieure au sien. Pour s'en convaincre, il suffit de jeter un regard sur la Carte de l'instruction publique en France, qui a été publiée ces derniers temps par différentes revues et journaux illustrés; on verra combien les ténèbres, et même parfois les plus épaisses, l'emportent encore sur la lumière ${ }^{43}$.

Dès les années 1870, lorsque l'identité pédagogique de la SIR est devenue stable et que L'Éducateur s'est forgé une place dans le giron national puis européen - et n'a donc plus d'intérêt à dévaloriser les systèmes étrangers - le discours sur la pédagogie française se modifie substantiellement. Les récentes avancées opérées par Jules Simon laissent à penser qu'il vaut mieux entretenir de bonnes relations avec cette nation qui fait preuve d'un zèle certain dans la rénovation de son système d'instruction:

Le pays voisin que nous sommes le plus porté à étudier et à imiter, c'est toujours la France, la France dont nous parlons et écrivons la langue avec amour sinon toujours avec pureté et élégance. La France d'ailleurs, quoique l'éducation populaire n'y ait jamais été organisée ni pratiquée comme en Allemagne et en Suisse, n'a pas laissé de nous éclairer, de nous instruire ces dernières années, d'abord par ses excellents journaux, parmi lesquels nous citerons le Manuel général de l'instruction primaire de M. Charles Defodon [...]. La pédagogie française fait en partie les frais de cette rubrique de L'Éducateur, sans parler des articles de fond consacré à ceux de ces ouvrages qui offrent le plus d'actualité et d'intérêt pour nous ${ }^{44}$.

De ce fait, du langage d'exclusion des années 1865 , on passe à une dynamique collégiale: "C'est par la France que nous commencerons notre tableau de la presse universelle, par cette France qui fait tant pour

42. Ibid., p. 219.

43. Auguste Biolley, « L'école par Jules Simon », L'Éducateur, 5/1867, p. 65-66.

44. Alexandre Daguet, « Rapport sur la marche de l'Éducateur, organe de la Société pédagogique de la Suisse romande », L'Éducateur, 15/1874, p. 238. 
se relever intellectuellement aussi bien que politiquement, et dont nous, Suisses français, nous sommes tributaires à tant d'égards ${ }^{45}$ ».

Avec l'accession de Jules Ferry au ministère de l'Instruction publique (4 février 1879) et le mandat de Ferdinand Buisson les données s'inversent et les références à cette France qui se modernise et rattrape son retard s'amplifient considérablement. Avec les écrits de Gabriel Compayré (Histoire critique de l'éducation en France, recensée en 1880), la pédagogie française s'impose dans L'Éducateur et monopolise dès lors la revue romande jusqu'à l'éviction de Daguet en $1889^{46}$. Si la pédagogie républicaine est globalement encensée par Daguet l'Histoire critique de Compayré " est à la fois un événement et un monument ${ }^{47}$ »- la science de l'éducation de Herbert Spencer constitue une sorte d'anti-modèle. Daguet attaque avant tout l'utilitarisme et le positivisme de la théorie éducative de Spencer et d'Alexander Bain dans une série de trois articles parus en 1880. Plusieurs raisons expliquent cette alliance avec les républicains français. Il s'agit d'abord, pour des théoriciens comme Daguet et Compayré de s'associer pour lutter contre l'utilitarisme qui hante la pédagogie de la seconde moitié du XIx ${ }^{\mathrm{e}}$ siècle. À cet égard, Patrick Dubois rappelle que le spectre de l'utilitarisme traverse certaines contributions du Dictionnaire de pédagogie et qu'il s'agit de combattre la séduction croissante des doctrines positivistes qui remettent en cause, au nom du réalisme l'éducation traditionnelle des élites et des humanités ${ }^{48}$. Ensuite, il s'agit de lutter contre l'ennemi commun, l'ultramontanisme, et le réseau européen mis en place au travers de la presse permet de relayer une doxa éclectique dans le but de neutraliser la pédagogie de systèmes.

Enfin, on peut dire que dès les années 1880, la pédagogie de la République déborde sur la Suisse romande, au point de se demander si L'Éducateur ne devient pas une revue française. L'alliance entre Buisson et Daguet fait de la revue romande une espèce d'arrièreboutique des éditions Hachette et Delagrave. Une collaboration se met

45. Alexandre Daguet, « Revue de la presse pédagogique en Europe et aux États-Unis et relations de l'Éducateur à l'étranger », L'Éducateur 19/1876, p. 291.

46. On dénote, entre autres, quatre articles sur la pédagogie à l'usage de l'enseignement primaire de Paul Rousselot en 1882, un article substantiel sur l'Histoire de la pédagogie de Compayré en 1883, quatre sur son Cours de 1886, un article sur la méthode active de Henri Marion en 1888.

47. Alexandre Daguet, « Histoire critique de l'éducation en France, de Gabriel Compayré », L'Éducateur, 1/1880, p. 4.

48. Patrick Dubois, Le Dictionnaire de Ferdinand Buisson : aux fondations de l'école républicaine (1878-1911), Berne, Peter Lang, 2002, p. 85 sq. 
en place entre L'Éducateur et Hachette, par l'entremise de Ferdinand Buisson, et institutionnalise l'envoi d'ouvrages en Suisse:

Votre journal est bien connu de la maison Hachette. Mais avant de quitter cette librairie, j'ai tenu à recommander de nouveau L'Éducateur en particulier pour les envois de livres scolaires. Vous en recevrez une première expédition demain ou après-demain. Mais je ne doute pas que si quelque article de L'Éducateur est consacré à l'un ou à l'autre de ces petits livres, vous ne manquerez pas d'en recevoir d'autres et d'être tenu ainsi au courant des publications Hachette ${ }^{49}$.

Ainsi, Daguet, pour qui « aucune librairie de France ne l'emporte en publications utiles et importantes sur celles de la maison Hachette ${ }^{50}$ ", multiplie les recensions et les présentations d'ouvrages provenant de cette prestigieuse maison d'édition parisienne ${ }^{51}$. Les instituteurs romands suivent ainsi régulièrement l'avancement de la publication du Dictionnaire de Buisson, de celui de Vivien et plus encore celui de la Nouvelle géographie universelle d'Élisée Reclus ${ }^{52}$, tous trois publiés chez Hachette. Plus encore, l'école de Ferry devient un exemple. Lorsque ce dernier décrète la création d'instituteurs suppléants pour cas de maladie, Daguet souhaite décliner cette idée en Suisse romande: " Il y a là un bel exemple donné par la France à la Suisse, où une pareille institution rendrait de grands services ${ }^{53}$ ".

Au terme de son mandat de rédacteur en chef (1865-1889), Daguet a donc réussi son pari d'ouverture, qui demeure le résultat de plus de vingt ans d'échanges progressifs, de rapprochements et de coopérations entre L'Éducateur et les principales feuilles pédagogiques occidentales. Les chroniques helvétiques côtoient toutes sortes d'informations relatives à l'enseignement pratiqué à l'étranger. Néanmoins, on remarquera qu'à l'exception d'articles dévolus aux deux Amériques, les références étrangères qui circulent dans L'Éducateur sont essentiellement eurocentrées. En regard de ce caractère hybride, la revue avait pour les uns

49. Lettre de F. Buisson à Daguet, sans lieu ni date, AEN, Fonds Daguet.

50. Alexandre Daguet, « Pédagogie et bibliographie françaises », L'Éducateur, 7/1881, p. 101.

51. Voir Jean-Yves Mollier, Louis Hachette, Paris, Fayard, 1999.

52. Recensions dans L'Éducateur, 11/1875, p. 172-173; 17/1875, p. 266-267; 1/1876, p. 7-8; $11 / 1876$, p. $170-171 ; 15 / 1877$, p. $234 ; 13 / 1878$, p. $199 ; 4 / 1879$, p. 58 ; 8/1880, p. 114-115; 7/1881, p. 101-102; 4/1883, p. 49-50; 3/1884, p. 39-20. Voir Federico Ferretti, « Géographie, éducation libertaire et établissement de l'école publique entre le $X I X^{e}$ et le $X X^{e}$ siècle: quelques repères pour une recherche », Cartable de Clio, n 13, 2013, p. 187-199 et du même auteur, Élisée Reclus, Pour une géographie nouvelle, Paris, Éditions du CTHS, 2014.

53. L'Éducateur, 1881, p. 202. 
perdu son caractère romand et suisse, pour les autres activé une sorte de missionnariat pédagogique:

Votre revue pédagogique, si dignement dirigée, si savamment rédigée au grand avantage des apôtres de la sainte mission de l'enseignement, se peut bien nommer décidément plus internationale que suisse, et en effet elle parcourt, dans son voyage d'irradiation comme la lumière, nombre de pays non seulement en Europe, mais encore au-delà de l'Océan ${ }^{54}$.

Daguet se défendit de cette ouverture: "Malgré la part assez grande faite à la pédagogie étrangère dans nos colonnes, la place la plus considérable, la place d'honneur, on peut dire, n'en appartient pas moins toujours à la pédagogie suisse ${ }^{55}$ » assure-t-il en 1882 .

En interrogeant les pratiques et savoirs étrangers qui ont circulé dans L'Éducateur, en questionnant la fonction nodale de ses passeurs et médiatrices, on remarque que la structure pédagogique proposée par L'Éducateur s'est constamment nourrie de l'altérité dont une des fonctions principales fut de légitimer les réformes projetées par les cadres romands. Cette perspective d'une « pensée métisse ${ }^{56}$ » invite les chercheurs en sciences de l'éducation à suivre la trajectoire des idées présentes dans les revues pour déconstruire et décloisonner les modèles nationaux. Plus qu'une recherche des différences, cette démarche cherche à reconstruire les inclusions et les branchements ${ }^{57}$ et de les considérer comme autant de témoins d'une construction collective de la pédagogie occidentale.

54. Lettre de Louis Zuccaro, abonné à L'Éducateur, à Alexandre Daguet, envoyée de Milan le 12 mars 1880, L'Éducateur, 8/1880, p. 116-117.

55. Alexandre Daguet, « Rapport sur la marche de l'Éducateur 1880, 1881 et 1882 », L'Éducateur, 17/1882, p. 260.

56. Serge Gruzinski, La pensée métisse, Paris, Fayard, 1999.

57. Jean-Loup Amselle, Branchements: Anthropologie de I'universalité des cultures, Paris, Flammarion, 2005. 
TROISIÈME PARTIE

$$
\begin{gathered}
\text { RÉINTERPRÉTER } \\
\text { AD USUM GALLIAE }
\end{gathered}
$$





\section{7 \\ Transférer la morale de la nation}

Dans son hommage à James Guillaume, Ferdinand Buisson rappelle au sujet de son collaborateur que:

Les précieuses, les savantes pages qu'il y écrivit sur le mouvement scolaire à l'étranger contribuèrent singulièrement à faire notre éducation, à nous apprendre enfin à jeter les yeux par-dessus la frontière, à comparer, à juger, à choisir et finalement à faire œuvre originale en transposant $a d$ usum Galliae tout ce que l'expérience d'autres peuples nous offrait de meilleur ${ }^{1}$.

On comprend mieux, à la lumière de ces lignes, les modalités selon lesquelles Buisson considérait l'emprunt, qui dans sa transposition ad usum Galliae devenait une œuvre originale. Pour autant, quels furent les disciplines et les savoirs dont les éducateurs français ont privilégié le transfert? Nul hasard dans leur choix, puisque comme l'on pouvait s'en douter, les républicains cherchèrent en premier lieu à accéder aux disciplines constitutives de la nation qui avaient, tout le moins en apparence, si bien tenu leur promesse dans l'espace germanophone ainsi qu'en Suisse romande: gymnastique et chant scolaires, corps de cadets, instruction civique et morale, colonies de vacances. C'est pourquoi cette dernière partie ${ }^{2}$ sera consacrée à l'analyse d'une série

1. Ferdinand Buisson, « Hommage à James Guillaume », Vie ouvrière, 20 février 1914, p. 212.

2. Certains développements de cette dernière partie (et de la conclusion) ont fait l'objet de publications: «Pedagogia como transferência cultural no espaço franco-suíço. Mediadores e reinterpretações de conhecimento (1850-1900) », Revista História da Educação (traduction de Maria Helena Camara Bastos) 18/42, p. 187-207; « La pédagogie comme transfert culturel. Passeurs, métissages et resémantisations de savoirs scolaires dans l'espace franco-romand (1850-1900) 》, in R. Hofstetter \& J. Droux (éds), Les savoirs dans le champ éducatif: circulations, transformations, implémentations. Pour une histoire sociale de la fabrique internationale des savoirs en éducation $x x^{E}-x x^{e}$ siècles, Rennes, PUR, 2015. 
de transferts éducationnels opérés entre la Suisse et la France. En regard de la notion de transfert culturel, on s'interrogera d'abord sur les besoins spécifiques et les ambitions du contexte d'accueil. On étudiera ensuite les vecteurs ou véhicules sociologiques du transfert, pour conclure par une analyse du processus de resémantisation qui accompagne l'emprunt. Cette notion de resémantisation nous paraît tout à fait adéquate, et préférable à celle d'influence, qui pourrait tendre à dévaloriser le résultat du transfert. En effet, comme l'indique Michel Espagne, la représentation de l'influence, ou du rayonnement, s'avère problématique, car le terme porte en lui une dimension magique et met entre parenthèses la question de la médiation ${ }^{3}$.

\section{Pestalozzi l'incompris vs Girard maître de la morale}

Quel bilan peut-on tirer de la réception pestalozzienne en France? À l'instar du père du mouvement spirite Allan Kardec ${ }^{4}$, une poignée de notables et d'éducateurs convaincus tente d'introduire son système pédagogique. Pour autant, Girard explique à son propos que « la forme n'avait rien d'engageant pour une nation qui, plus que tout autre, aime l'esprit et la grâce $^{5}$ ". On l'a déjà vu, Marc-Antoine Jullien se fit le grand promoteur des idées de Pestalozzi, qu'il s'appliqua à résumer dans l'Exposé de la méthode de $1812^{6}$ au sujet duquel Daguet mentionne:

le programme des aspirations ambitieuses de l'Institut d'Yverdon, plutôt que le tableau réel de l'enseignement qui s'y donnait et que son ignorance de la langue allemande empêchait Jullien d'observer par ses propres yeux. Cet homme de lettres a rendu de meilleurs services à la diffusion des lumières par la publication de la Revue encyclopédique ${ }^{7}$.

Michel Soëtard, spécialiste et biographe du pédagogue suisse, a donc raison de souligner que «Pestalozzi est plus utilisé et exploité que

3. Michel Espagne, Les transferts culturels franco-allemands, Paris, PUF, 1999, p. 20 et 32.

4. Voir Guillaume Cuchet, Les voix d'outre-tombe : tables tournantes, spiritisme et société au $X I X^{e}$ siècle, Paris, Seuil, 2012, p. 132 sq.

5. Gabriel Compayré, Le P. Girard et l'éducation par la langue maternelle, Paris, Paul Delaplane, 1906, p. 55.

6. Marc-Antoine Jullien de Paris, Esprit de la méthode d'éducation de Pestalozzi : suivie et pratiquée dans l'établissement d'éducation d'Yverdun (sic), Milan, Imprimerie Royale, 1812.

7. Alexandre Daguet, « Coup d'œil sur I'histoire de la pédagogie depuis les temps anciens jusqu'à aujourd'hui », L'Éducateur, 4/1871, p. 52-53. 
vraiment compris pour lui-même ${ }^{8}$ ". Pierre Ognier relève que James Guillaume estimait son influence en France plus que réduite, malgré l'existence à Bergerac d'une école pestalozzienne fondée par le philosophe Maine de Biran (1766-1824) ${ }^{9}$. D'ailleurs, le ministre des arts et des sciences suisse Philipp Albert Stapfer écrivit à Pestalozzi pour lui confier que, d'une part, Maine de Biran n'avait pas parfaitement compris la méthode ni su la faire appliquer convenablement et que, d'autre part, Fourcroy, alors directeur général de l'Instruction publique, n' [y] compren [ait] rien ${ }^{10}$. Singulier problème en vérité que la langue allemande, qui demeurait un obstacle de taille pour l'essentiel des savants français, qui de facto préférèrent taxer le système pestalozzien de nébuleuse germanique. Ainsi, un Destutt de Tracy soupçonnait « la nouvelle méthode de n'être pas encore bien débrouillée dans la tête de son auteur ${ }^{11}$ ». On a par ailleurs souvent reproché à Pestalozzi son incapacité à organiser son institut, alors que Girard, à l'inverse, pour avoir été l'élève du prince-évêque Franz Ludwig von Erthal (17301795 ) à Wurtzbourg, en avait reproduit le génie organisationnel.

Globalement, l'historiographie de l'éducation situe Girard dans l'ombre de Pestalozzi. Pourtant, dans les faits, il semble que ce soit davantage dans l'œuvre du moine cénobite que la France scolaire ait puisé. Pierre Boutan fait observer que «de la Restauration à l'installation de la III ${ }^{\mathrm{e}}$ République, c'est bien Girard qui en France disposa d'une notoriété considérable, tant il fut l'objet de l'attention des hauts responsables successifs de l'instruction publique ${ }^{12}$ ». Ainsi, le pédagogue français Michel Charbonneau (1817-1870) fit plus d'un emprunt à Girard qu'il admirait et dont il diffusa la pensée dans son Cours théorique et pratique de pédagogie aux multiples rééditions. Rappelons également que l'inspecteur Bonaventure Bergern défendit une conception très girardienne de l'enseignement de la langue maternelle lors des conférences de la Sorbonne de 1878, soulignant que " c'est à deux livres de la Suisse que je dois les plus justes idées que je

8. Michel Soëtard, Pestalozzi, Lucerne et Lausanne, Éditions René Coeckelberghs, 1987, p. 135.

9. Pierre Ognier, L'école républicaine française et ses miroirs, Berne, Peter Lang, 1988, p. 203. Cette école fut instituée en 1808 grâce à l'envoi en France du Vaudois Barrault, collaborateur de Pestalozzi à Yverdon.

10. Ibid., p. 206-207.

11. Ibid., p. 207.

12. Pierre Boutan, «Langue(s) maternelle(s) : de la mère ou de la patrie ? », Ela. Études de linguistique appliquée, 2/2003, nº 130, p. 142. 
me suis faites de l'enseignement de la langue, soit le Cours de Girard et la Chrestomathie de Vinet ${ }^{13}$ ". En outre, le républicain Jules Steeg réhabilita l'œuvre du moine fribourgeois dans la Revue pédagogique de mai 1896, en allant jusqu'à proposer un retour à son système:

En nos temps de programmes touffus, où toutes les sciences se livrent bataille sur le dos de nos écoliers qui n'échappent aux dangers de l'ahurissement que par la bienfaisante intervention de l'indifférence et de l'oubli, il ne serait peut-être pas mauvais de revenir un peu, dans notre enseignement primaire et dans notre enseignement " moderne », au système pédagogique du Père Girard ${ }^{14}$.

Enfin, Gabriel Compayré (1843-1913), principal théoricien de la pédagogie républicaine, lui consacra une étude dans sa collection "Les grands éducateurs » en $1906^{15}$. Il faut toutefois également mentionner le pèlerinage pestalozzien effectué par Compayré à l'automne $1901^{16}$. Parti de Zurich, il visita les différentes "Mecque » occupées par le pédagogue, en passant par Stanz, Burgdorf et Yverdon. Cette expérience aboutira à une réhabilitation des idées de Pestalozzi dans le monde pédagogique francophone.

On ne peut donc ignorer ces multiples emprunts. Toutefois, Daniel Hameline évoque à juste titre la notion de figure paradoxale pour caractériser les liens entretenus entre Girard et la France ${ }^{17}$. Car si Girard fonda son action morale sur les enseignements de Jésus, il n'en fut pas moins célébré par les théoriciens d'une III $^{\mathrm{e}}$ République que l'on voulait laïque. Pourquoi donc cet attrait des cadres de l'école française pour Girard? Esquissons quelques réponses. Girard est l'auteur d'une sociologie scolaire qui se fonde sur le respect de la paix sociale.

13. Bonaventure Berger, « Conférence pédagogique sur l'enseignement de la langue maternelle », in Les Conférences pédagogiques faites aux instituteurs délégués à l'exposition universelle de 1878, Paris, Delagrave, 1880, p. 71.

14. Jules Steeg, « Le Père Girard », Revue pédagogique, n 5, mai 1896, p. 409.

15. Gabriel Compayré, Le P. Girard et l'éducation par la langue maternelle, Paris, Paul Delaplane, 1906.

16. C'est dans un souci de préparer la rédaction de son étude sur Pestalozzi qui paraîtra un an plus tard dans la collection Les grands Éducateurs, que Gabriel Compayré se rendit en Suisse à l'automne 1901 (Gabriel Compayré, Pestalozzi et l'éducation élémentaire, Paris, P. Delaplane, 1902). Sous le titre de Note de voyage d'un pèlerinage pestalozzien, il retrace son séjour helvétique dans le Manuel général de l'instruction primaire $\left(n^{\circ} 42\right.$, 17 octobre 1901, p. 657-661). Le récit de ce pèlerinage sera d'ailleurs repris in extenso dans L'Éducateur, 45/1901, p. 677-679; 46/1901, p. 690-691; 48/1901, p. 724-725).

17. Daniel Hameline, « Grégoire Girard (1765-1850) », in Jean Houssaye, Nouveaux pédagogues. Pédagogues de la modernité, t. I, Paris, Fabert, 2007, p. 115. 
Partant du principe que " c'est par un esprit d'insubordination que pèche maintenant la société européenne ${ }^{18}$ " il souligne que "l'école doit apprendre aux enfants l'obéissance, la première vertu de l'état social $^{19}$ ". Ainsi, le respect des lois et sa morale sous-jacente légitime de facto son adhésion au mutualisme, créateur d'ordre et de soumission:

L'utilité morale de ce moyen opportun [l'enseignement mutuel] se montre sous tous les rapports. Il donne à l'enfant l'habitude du travail, en répandant des charmes sur ses études. Au lieu de le plier momentanément par la force, il l'amène au sentiment de l'ordre et de la soumission. Il lui apprend à commander en homme, au surplus, il le place à l'école de la charité qui aime mieux à donner qu'à recevoir, il présente donc à l'éducation morale une ressource infiniment précieuse ${ }^{20}$.

Ce qu'il est important de saisir, c'est que l'ensemble de l'œuvre de Girard s'articule autour de la diffusion d'une morale d'inspiration chrétienne amalgamée à une lecture personnelle de Kant et entendue comme un ciment de la paix sociale. Dans ce sens, la pensée girardienne converge avec celle d'un Félix Pécaut, le grand maître de la morale scolaire républicaine. Gabriel Compayré ne s'y trompe pas lorsqu'il fait du moine pédagogue de Fribourg "un Pécaut catholique, préoccupé, avant tout, comme lui, de l'éducation morale, et, pour en établir les fondements, faisant appel, comme lui, à la conscience personnelle ${ }^{21}$ ». Victor Cousin est le premier qui, en France, a cerné tout l'avantage de la pédagogie girardienne comme outil de moralisation de l'écoliercitoyen et ce n'est donc pas surprenant qu'il se soit engagé dès 1837 à importer l'œuvre maîtresse de Girard en France.

\section{La resémantisation contrastée du Cours de Girard en France}

Dans le prolongement de son voyage en Hollande de septembre 1836, Cousin visite l'école normale de Lausanne, avant de se rendre à Fribourg. Suite à sa rencontre avec Girard, Cousin aurait lancé: "Quel homme vous avez là sous le froc ${ }^{22}$ ! " C'est que Cousin, comme le souligne

18. Discours de clôture prononcés par le R. P. Grégoire Girard (1805-1822), Fribourg, Société fribourgeoise d'éducation, 1950 [1820], p. 83.

19. Ibid, p. 82.

20. Ibid, p. 86.

21. Gabriel Compayré, op. cit., p. 6.

22. Alexandre Daguet, Le Père Girard et son temps, op. cit., t. II, p. 199. 
Compayré, qui poursuivait alors son rêve de l'alliance de l'Université et de l'Église, de la réconciliation de la philosophie avec la foi, avait, pour ainsi dire, trouvé son homme dans le Père Girard ${ }^{23}$. Cousin consulta le Cours de langue maternelle et promit à son auteur non seulement de le faire imprimer en France, mais également de l'introduire dans les écoles. La proposition ne pouvait mieux tomber, tant Girard désespérait de voir ce travail de longue haleine publié en Suisse. Toutefois, en se mettant au service de la France, Girard dut remodeler l'ensemble de son Cours qu'il avait originellement conçu pour l'enseignement mutuel. Sur le conseil du Lyonnais de Borgnes, le cordelier adapta la totalité de l'œuvre à la forme simultanée qui contrairement au mutualisme ordonne l'école afin que tous les élèves reçoivent l'enseignement du maître. Ce brusque changement heurta son entourage, particulièrement son ami François-MarcLouis Naville, un des plus fidèles partisans de l'enseignement mutuel tel que l'avait organisé Girard. Il faut rappeler qu'à cette époque, Cousin s'était totalement détourné du mutualisme, le Hollandais Van den Ende ayant probablement achevé sa conversion ${ }^{24}$ :

Pour moi, philosophe et moraliste, je regarde l'enseignement simultané, à défaut de l'enseignement individuel, qui est impossible, comme la seule méthode qui convienne à l'éducation d'une créature morale; mais, je dois l'avouer, l'enseignement mutuel jouit encore, en France, d'une popularité déplorable [...]. Sous la Restauration, le gouvernement tendait à remettre l'instruction primaire entre les mains du clergé. L'opposition se jeta dans l'extrémité contraire. Quelques hommes bien intentionnés, mais superficiels et tout à fait étrangers à l'instruction publique, ayant été par hasard en Angleterre dans des villes de fabriques à demi barbares, où, à défaut de mieux, on est encore trop heureux d'avoir des écoles lancastériennes, prirent pour un chef-d'œuvre ce qui était l'enfance de l'art, et se laissèrent éblouir par le spectacle de classes innombrables gouvernées par un seul maître, à l'aide de petits moniteurs pris parmi les élèves. Ce gouvernement d'enfants par des enfants ressemblait à une sorte de self-government, et paraissait un utile apprentissage de l'esprit démocratique. De plus, l'instruction chrétienne était impossible avec cette méthode, car il n'y avait pas de moniteur, eut-il même

\footnotetext{
23. Gabriel Compayré, op. cit., p. 99.
}

24. L'inspecteur général de l'instruction primaire Van den Ende interpella Cousin lors de sa visite à Harlem les 19 au 20 septembre 1836 : « Et votre enseignement mutuel, qu'en faitesvous? Espérez-vous qu'avec un pareil enseignement l'instruction primaire puisse former des hommes? [...] Ce n'est pas que nous ignorions l'enseignement mutuel. Nous l'avons étudié, et c'est parce que nous l'avons étudié que nous le rejetons » (Victor Cousin, De l'instruction publique en Allemagne, en Prusse et en Hollande, op. cit., p. 247-248). 
douze ans, qui puisse enseigner la religion et la morale: on se trouvait donc conduit à réduire à peu près à rien l'instruction religieuse, à moins qu'on ne donne ce nom à la récitation matérielle du catéchisme [...]. Et puis, l'œil était charmé de cet ordre matériel et du mécanisme des exercices. Les enfants s'y mouvaient au geste d'un autre enfant, comme dans une fabrique les diverses parties d'un métier par l'impulsion d'une simple manivelle. Ce fut cet enseignement tout matériel qu'on opposa aux écoles ecclésiastiques de la restauration. Ainsi, une extrémité précipite dans une autre; la théocratie et le despotisme poussent à l'esprit de licence. Malheureusement l'enseignement mutuel a survécu aux luttes qui précédèrent $1830^{25}$.

Étonnant revirement, quand on sait qu'au début de la Restauration, Guizot et ses amis philanthropes - dont Victor Cousin - s'étaient engagés en faveur de l'introduction de l'enseignement mutuel en France par la création de la Société pour l'instruction élémentaire. Pourtant, dès son accession au ministère de l'Instruction publique en 1832, c'est bien l'enseignement simultané que Guizot promulgua au titre de méthode pédagogique officielle ${ }^{26}$, tirant un trait définitif sur le mutualisme.

Girard s'adjoignit deux éducateurs français qui devaient jouer les intermédiaires entre Fribourg et Paris et suivre le processus d'édition. Jean-Jacques Rapet (1805-1882) avait étudié l'allemand et l'anglais au collège Louis-le-Grand. Présenté par Eugène Rendu à Guizot, ce dernier le plaça dès 1833 à la tête de l'école normale de Périgueux, véritable creuset des idées de Girard. Quant à Louis Michel (1795-1874), il appliqua le système de Fribourg à son école de Lyon dès 1823 et diffusa une analyse détaillée du système de Fribourg dans son Journal d'éducation. Girard avait convenu avec ses deux adjoints de la forme que devait prendre les six volumes du Cours éducatif de langue maternelle en France: "Il leur avait donné pleins pouvoirs en ce qui concernait son style, qu'il savait n'être pas pur, être souvent plus allemand que français. Mais au style, à l'expression, s'arrêtait leur compétence ${ }^{27}$. » Pourtant, Girard allait connaître une série de désillusions lors du transfert de son Cours vers Paris.

Il s'attela d'abord à l'écriture d'un ouvrage préliminaire qui renfermait la théorie et devait servir d'introduction au Cours lui-même, qu'il

25. Ibid.

26. Sur le « paradoxe Guizot », on lira Christian Nique, Comment l'école devint une affaire d'État?, Paris, Nathan, 1990 et Claude Lelièvre, L'école obligatoire, pourquoi faire?, Paris, Retz, 2004.

27. Alexandre Daguet, Le Père Girard et son temps, op. cit., t. II, p. 258. 
intitula De l'enseignement régulier de la langue maternelle ${ }^{28}$. Eugène Rendu invita Girard à refondre une grande partie de cet ouvrage préliminaire et à faire des additions au reste du texte, afin d'obtenir l'approbation de l'Université. Deux membres du Conseil royal adressèrent une remarque fort curieuse sur la doctrine morale et religieuse du livre rédigé par le moine de Fribourg: "Ils lui trouvaient une teinte pélagienne et protestante et parlaient de retranchements et d'adjonctions nécessaires si on voulait faire pénétrer l'ouvrage dans les écoles de l'Universitée ${ }^{29}$. " Afin de contourner ces difficultés, Michel et Rapet décidèrent de se passer de l'approbation du clergé et de l'Université. Finalement, Michel prit la publication à sa charge et De l'enseignement régulier de la langue maternelle parut chez Dezobry et Magdeleine au printemps $1844^{30}$. L'ouvrage fut honoré du prix Montyon, prix de vertu obtenu non sans l'aide de Cousin qui bricola une origine française à Girard, celui-ci n'étant remis qu'aux citoyens français.

La publication du Cours commença quelques mois plus tard. Mais, malgré les invectives de Girard, Michel et Rapet décidèrent d'un nombre important d'aménagements sur le plan grammatical, sans l'aveu de l'auteur ${ }^{31}$. Excédé, Girard s'en expliqua longuement à Cousin:

Une circonstance aussi fâcheuse qu'inattendue me force à recourir à vous. Veuillez vous rappeler que c'est vous qui m'avez décidé à rédiger ce Cour éducatif de langue maternelle, et que c'est encore à vous que je dois le prix qui a été décerné par l'académie au livre qui lui sert d'introduction.

MM. Michet et Rapet avaient longuement ambitionné de soigner l'édition du Cours de langue dont les premières feuilles sont imprimées. Je leur ai donné une procuration qui les chargeait de redresser toutes les fautes de langue qui aurait pu échapper à l'auteur ou à ses copistes. Quant à l'ouvrage même, ils ne devaient se permettre aucun changement sans mon aveu.

Ces messieurs qui à ce que je vois n'ont aucune idée d'un enseignement progressif, basé sur le développement de l'esprit pour arriver au cœur,

28. Grégoire Girard, De l'enseignement régulier de la langue maternelle dans les écoles et les familles, Paris, Dezobry et Magdeleine, 1844.

29. Ibid.

30. On sait que le fouriériste Édouard de Pompéry s'était également proposé pour assurer financièrement l'édition du Cours et de l'ouvrage préliminaire.

31. On trouve la liste complète de ces aménagements, relevés et annotés par Girard dans sa correspondance à Cousin, BSFC, MSVC 231 : correspondance générale, t. XVIII. 
ces messieurs, dis-je, m'ont demandé en décembre dernier de nombreuses suppressions que je n'ai pas pu leur accorder pour des raisons que j'ai pris la liberté de vous soumettre le 31 janvier. Depuis lors ils ont voulu de nouvelles concessions. Deux fois j'y ai souscrit. Dernièrement j'ai été forcé de refuser. Ce dernier refus a irrité $M$. Rapet au point qu'il a écrit à M. Naville de Genève une incroyable lettre pour m'être communiquée. Il y déclare au nom de M. Michel comme au sien, qu'ils ne s'occupent de l'édition qu'avec dégoût et répugnance, qu'ils ont la triste perception de voir échouer mon travail et d'y perdre au surplus leur réputation.

Dès le lendemain j'ai délié ces messieurs, et je les ai priés d'arrêter l'impression. Hier j'ai fait la même demande à M. Dezobry. Cette suppression était d'autant plus nécessaire que les deux éditeurs se sont permis sans mon aveu des changements qui n'étaient pas de leur compétence.

Ils ont eu l'ambition d'entrer de suite dans toutes les écoles de France et comme ils croyaient de plus en plus que cela était impossible dans l'état actuel de l'enseignement, ils ont éprouvé des regrets et ils ont pris de l'humeur. Ce n'est pas ma faute, car j'ai toujours combattu cette ambition et ce qui pouvait se cacher derrière. Dans la circonstance où je me trouve, je me suis rappelé qu'à la fin de son rapport sur mon livre, M. Villemain m'a invité à publier les livres élémentaires, et qu'il a dit ces paroles, sans doute trop flatteuses pour moi: Il n'est pas d'écrit qui mérite autant d'être offert à la France, et qui, en répondant à la constitution générale de l'enseignement primaire dans notre pays, puisse donner à cet enseignement de plus sage et de plus utile conseils. En pesant ces paroles du Ministre de l'Instruction publique, je me suis demandé si je ne ferais pas bien d'offrir mes manuscrits au Conseil royal. Il en disposerait à son gré après un examen fait par des hommes capables de porter un jugement sur mon travail.

Je suis sans doute bien loin d'avoir atteint mon idéal, mais d'un bout à l'autre, j'ai été fidèle aux principes énoncés dans mon ouvrage préliminaire et je crois avoir fréquemment réussi dans leur application. Le Cours éducatif de langue maternelle est une œuvre susceptible d'un perfectionnement indéfini: je l'ai écrit pour la France et je désire qu'elle en fasse son profit. Voilà mon ambition, je n'en ai pas d'autre ${ }^{32}$.

Si, selon Gabriel Compayré, l'adaptation à la France du Cours de Girard s'est faite au prix d'une complète trahison ${ }^{33}$, nous sommes en réalité en présence d'un transfert somme toute ordinaire, qui ne peut se passer d'une inévitable transformation sémantique lorsque l'objet

32. Lettre de Girard à V. Cousin, Fribourg, 10 juin 1845, BSFC, MSVC 231 : correspondance générale, t. XVIII.

33. Gabriel Compayré, op. cit., p. 96. 
passe d'un contexte à l'autre. La méprise de Girard aura été ici de ne pas admettre que les deux médiateurs étaient obligés d'adapter sa grammaire pour le contexte français, plus encore quand on sait le poids et l'aura dont jouissait la grammaire de Noël et Chapsal en France. Ainsi, alors que Girard s'était autorisé, dans sa reformulation personnalisée du mutualisme de Bell et Lancaster, à ne pas suivre « strictement les pratiques et les procédés de la méthode de Madras » pour opérer une déviation nécessaire ${ }^{34}$, il renâcla à accepter ce même mécanisme d'acculturation pour son propre Cours. Il était pourtant inconcevable, pour Michel et Rapet et malgré les recommandations appuyées de Girard, d'importer le Cours terme à terme dans le contexte hexagonal.

D'ailleurs quelques années plus tard, les deux médiateurs français s'attelèrent à une autre utilisation de la grammaire de Girard en France, cette fois à des fins politiques. On rappellera que Girard préconisait une grammaire orale, sans aucun manuel afin d'éviter que l'élève n'apprenne par cœur et ne récite gauchement la leçon. Or, sous le Second Empire, c'est précisément dans cette direction que le ministre de l'Instruction publiques et des Cultes Gustave Rouland promulgua son instruction de 1857. À l'évidence, il faut voir dans cette manœuvre une tentative de briser l'enseignement de la grammaire pour faire place à l'enseignement roi, l'orthographe et sa dictée. C'est ce que soutient Pierre Boutan, qui a par ailleurs montré que dès 1856, Rapet mène dans le journal pédagogique du ministère, le Bulletin de l'instruction primaire, une féroce campagne contre l'enseignement grammatical, le grand ennui des écoles et contre l'utilisation d'un manuel de l'élève. Exaltant les ouvrages du Père Girard, il récuse l'abus de l'analyse grammaticale ou l'insuffisance de l'analyse logique ${ }^{35}$. Pourtant, dix ans plus tôt et au grand dam du cordelier fribourgeois, Rapet et Michel publiaient un Manuel de l'élève rédigé sous la direction et avec les conseils $d u$ R. P. Girard ${ }^{36}$. On notera enfin que ces deux médiateurs ne furent pas les seuls à chercher l'inspiration en matière de morale scolaire du côté de Fribourg. Edgar Quinet s'engagea dans la réinterprétation d'un manuel d'instruction civique suisse qui devint le premier Manuel du citoyen français (1872).

34. Alexandre Daguet, Le Père Girard et son temps, op. cit., t. 1, p. 348.

35. Pierre Boutan, « L'usage du manuel en question : une tradition en matière d'apprentissage des langues », Ela. Études de linguistique appliquée, 1/2002, n 125, p. 19-22

36. Cours éducatif de langue maternelle à l'usage des écoles et des familles. Manuel de l'élève : rédigé sous la direction et avec les conseils du R. P. Girard, Paris, Dezobry et Magdeleine, 3 vol., 1847-1848. 


\section{Le manuel suisse du citoyen français}

Lors de leur séjour dans le repli suisse, les proscrits du 2 décembre se montrèrent particulièrement attentifs à l'enseignement de l'instruction civique ainsi qu'à la diversité des manuels en usage. Il s'agissait de préparer la conversion des Français à leur rôle de citoyen républicain et d'assurer l'unité civique de la nation. Nul hasard si Ferdinand Buisson se plaît à souligner, dans sa conférence donnée à Neuchâtel en 1916, que " notre école primaire sous la troisième République s'est largement inspirée de la vôtre ${ }^{37}$ ", avant de rajouter:

Savoir lire, écrire et compter ne suffit pas, tout le monde en convient, mais que faut-il ajouter? D'abord sans doute des éléments d'instruction civique, car le peuple n'est souverain que si le citoyen est éclairé. La Suisse y a pourvu dès longtemps, et c'est le premier emprunt que nous lui avons fait ${ }^{38}$.

L'enseignement civique apparaît en Suisse sous l'impulsion du ministre Philipp Albert Stapfer qui l'inclut dans son programme national conçu sous la République helvétique (1798-1803). Ce projet ambitieux, abandonné suite à la promulgation de l'Acte de médiation (1803), fut toutefois poursuivi par le Père Girard ${ }^{39}$. Le moine pédagogue s'était fait une spécialité de cet objet d'étude conçu dans sa doxa comme un pilier de l'enseignement républicain.

Un semblable idéal républicain explique sans doute, toutes choses égales par ailleurs, que l'ancien conventionnel Lazare Carnot (17531823 ) ait été le seul ministre à vouloir introduire, sous la Restauration, un enseignement comprenant "la connaissance des devoirs et des droits de l'homme et du citoyen, le développement des sentiments de liberté et d'égalité ${ }^{40}$ ». Carnot, promoteur de l'enseignement de l'instruction civique en France et de ce fait initié aux travaux de Girard, éduqua son fils Hippolyte (1801-1888) avec le Cours de langue du cordelier fribourgeois et se fit l'apôtre de ses idées pédagogiques durant les Cent-Jours ${ }^{41}$.

37. Ferdinand Buisson, Souvenirs (1866-1916). Conférence faite à I'Aula de I'université de Neuchâtel le 10 janvier 1916, Paris, Librairie Fischbacher, 1916, p. 22.

38. Ibid., p. 24.

39. Voir Pierre Bovet, « Les origines fribourgeoises de l'enseignement moral et civique », Revue de théologie et de philosophie, Lausanne, 20/1932, p. 211-228.

40. Cité dans Philippe Marchand, « L'instruction civique en France. Quelques éléments d'histoire », Spirale-Revue de Recherches en Éducation, 7/1992, p. 9-10.

41. Voir Alexandre Daguet, « Le Père Girard jugé par l'auteur de Nos fils », L'Éducateur, 11/1888, p. 186-187. 
Pierre Bovet considère le Projet d'éducation publique pour la République helvétique adressé par le Père Girard au ministre Stapfer en août 1798 comme l'acte fondateur de cet enseignement civique. Si la proclamation de l'Acte de médiation (1803) devait balayer la République scolaire centralisée de Stapfer, les idées émises par Girard furent réactivées par son plus fidèle disciple. Ainsi, lorsqu'Alexandre Daguet prit la direction de la très progressiste école cantonale de Fribourg en 1848, instaurée par le nouveau gouvernement radical suite à la conflagration du Sonderbund, l'obligation d'une instruction civique figurait dans l'article premier de son règlement:

C'est par l'instruction civique que l'enfant, qui sera demain le citoyen, apprend quels sont les droits qu'il aura bientôt à exercer et quels sont aussi les devoirs qu'il aura à remplir. Autrement l'exercice de la souveraineté serait illusoire pour lui. C'est assez dire que, dès sa plus tendre enfance, on doit commencer à initier le futur citoyen aux nécessités et aux exigences du rôle qu'il sera appelé plus tard à jouer dans la société. Ce but ne peut être atteint que par l'instruction civique ${ }^{42}$.

Peu avant le retour des conservateurs et la suppression de l'enseignement civique à Fribourg, Louis Bornet publiait en 1856 un Cours gradué d'instruction civique pour l'école, la famille et le citoyen ${ }^{43}$, bientôt décliné pour les cantons protestants romands, puis remanié pour les besoins de l'école de la III ${ }^{\mathrm{e}}$ République naissante. Il est intéressant de constater que l'ouvrage de cet avocat de métier, façonné originellement dans l'esprit de Girard pour les écoles du canton catholique de Fribourg, a subi un nombre important de modifications pour être approprié aux écoles du canton de Neuchâtel en 1864, puis à celles du canton de Vaud en 1871, tous deux réformés. Les bons manuels jouissaient donc d'une diffusion transcantonale, mais en passant par une étape de remodelage permettant aux contenus d'être acclimatés à leur nouveau contexte local. Ces transpositions, dont il n'est pas toujours aisé d'éclairer l'ensemble des étapes souvent dissimulées, garantissaient également, à terme, une certaine standardisation des moyens d'enseignement.

On doit l'idée d'une reformulation laïcisée du Cours de Bornet à Edgar Quinet, établi, comme on l'a vu, dans les environs de Montreux

42. Alexandre Daguet, « Recension du Cours gradué d'instruction primaire de Bornet 》, 3e édition, L'Éducateur, 7/1879, p. 120. Notons que les conservateurs abandonneront l'enseignement de l'instruction civique à leur retour au pouvoir en 1858 (Voir L'Éducateur, 17/1875, p. 264).

43. Louis Bornet, Cours gradué d'instruction civique : manuel de l'école, de la famille et du citoyen, Fribourg, Imprimerie Ch. Marchand, 1856. 
dès 1858. À cet égard, il importe de souligner l'ascendance de l'expérience scolaire suisse sur les idées éducatives de Quinet, qui se posait continuellement en spectateur attentif:

Dans cette Suisse républicaine où nous avons trouvé si longtemps un refuge, j'ai souvent admiré au village, les petits résumés que l'enfant rapportait de l'école; car ils formaient un Manuel du Citoyen suisse. Les traditions qui font l'homme libre étaient déjà l'objet des dictées de ces citoyens de dix à douze ans. Elles s'établissaient d'elles-mêmes dans ces esprits naissants. Mêlées aux premières impressions rustiques du petit paysan, écrites sur la page encore blanche du livre de la vie, rien ne pourra les effacer! Pourquoi, me disais-je, ne verrions-nous pas quelque chose de semblable en France? La vraie notion de liberté ne se déracine si facilement chez nous que parce qu'elle est semée trop tard, à la surface, dans les intelligences, et seulement par les tempêtes. Faisons qu'elle se confonde avec nos premières notions: elle sera pour nous une des racines de l'existence; enfouissons le bon grain plus profondément: les vents ne l'emporteront plus ${ }^{44}$.

Pour Quinet, la renaissance de la France devait obligatoirement passer par l'introduction d'un cours d'enseignement civique. Aussi chargea-t-il un autre proscrit, l'Alsacien Georges Joseph Schmitt (1813-1875), de fournir un Manuel du citoyen français, d'inspiration helvétique... à la France:

Vous souvenez-vous de notre exil? Dans les moments où nous venait l'espoir de revoir un jour la France, nous nous proposions d'introduire un enseignement élémentaire de politique dans les écoles. Ce devait être là, suivant nous, une des premières conditions de renaissance. À personne, il n'appartenait mieux qu'à vous, de réaliser le vœu que nous formions ensemble au pied des Alpes. Il est bon, il est utile que nous tenions de la main d'un Alsacien tel que vous, notre Manuel de civisme. Soyez sûr que la France l'accueillera avec joie. Elle fera épeler à ses enfants ce premier alphabet du Patriotisme tracé par vous de l'autre côté des Vosges ${ }^{45}$.

Schmitt avait commencé sa carrière comme instituteur à Mulhouse. Intellectuellement, il s'intéressait aux thèses des phalanstériens ainsi qu'à Proudhon découvert par lui en 1845. Correspondant de Cabet, il avait lu Considerant et Owen. Au moment du coup d'État du 2 décembre 1851, il se consacrait à la rédaction de l'hebdomadaire Die Volksrepublik à

44. Edgar Quinet, « Introduction au Manuel du Citoyen français », in Georges Joseph Schmitt et Louis Bornet, Essai d'instruction morale et civique à l'usage des familles et des écoles. Manuel du citoyen français, Paris, A. Le Chevalier, 1872, p. XVI.

45. Edgar Quinet, op. cit., p. XV. 
Colmar. Condamné à l'expulsion du territoire français, il franchit la frontière et arrive le 10 décembre à Bâle, avant de se rendre dans la capitale helvétique. Protégé par le conseiller fédéral radical Henry Druey, Schmitt s'installe pour un temps à Aarau, dans des conditions particulièrement difficiles pour lui et sa famille ${ }^{46}$. Aussi, après un premier refus et dans la nécessité de trouver un emploi, il accepte d'assumer la rédaction du journal fribourgeois Le Confédéré. C'est depuis un des bastions catholiques de la Suisse que s'organisa dès lors la résistance républicaine... « L'idéal du journaliste républicain existe encore quelque part en 1869 [...] Il vit en exil. - Où ? - Au centre du foyer de la réaction catholique, cléricale, à Fribourg. Le rédacteur en chef du Confédéré rédige à lui seul cet excellent journal (véritable Moniteur de la proscription) ${ }^{47}$ " écrivait Hermione Quinet dans ses Mémoires d'exil. Marc Vuilleumier a souligné que les républicains français prirent progressivement les rênes du journal à partir de la défaite des radicaux fribourgeois de décembre 1856. Dès lors, on recruta des correspondants parmi les amis de Jean-BaptisteAdolphe Charras: Quinet, Victor Schoelcher ou Ledru-Rollin acceptèrent de livrer des articles ${ }^{48}$. Comme de juste, Schmitt se tenait en relations étroites avec les républicains alsaciens regroupés autour de Quinet, tels Marc Dufraisse et Victor Chauffour-Kestner ${ }^{49}$.

Au moment de s'atteler au Cours de Bornet, Schmitt n'en était pas à son coup d'essai en matière d'ouvrage pédagogique. Il avait déjà édité un petit livre intitulé Utopie, dans lequel il formulait un projet de loi sur l'instruction publique élémentaire ${ }^{50}$. Du Cours de Bornet de 1856 au Manuel du citoyen français de 1872, on remarquera que la principale resémantisation relève de la doctrine. Dans la préface, Schmitt indique avoir "évité, avec un soin attentif, de toucher, même par la voie de l'allusion la plus lointaine, aux questions dogmatiques et confessionnelles ${ }^{51}$ ». Ainsi, l'Alsacien écarta systématiquement les items religieux présents chez Bornet (Père Girard, Providence, Dieu,

46. Voir Marc Vuilleumier, « Georges Joseph Schmitt, Le Confédéré de Fribourg et les Républicains français. Documents inédits », Revue suisse d'histoire, 24/1974, p. 67-70.

47. Hermione Quinet, Mémoires d'exil. L'amnistie (Suisse orientale et bords du Léman), Paris, Armand le Chevalier Éditeur, 1870, p. 255.

48. Marc Vuilleumier, op. cit., p. 73.

49. Voir Cédric Krattinger, L'idéologie de Georges Joseph Schmitt dans Le Confédéré (18541869). Entre radicalisme républicain et socialisme associationniste, mémoire de licence, université de Fribourg, 1997, p. 17-20.

50. Ibid., p. 16.

51. Georges Joseph Schmitt et Louis Bornet, op. cit., p. VIII. 
Église, religion, paroisse, Jésus, etc.). En revanche, la graduation chère à Girard et la division en quatre cours adoptée par Bornet furent intégralement conservées. Au-delà de la rédaction même d'un manuel, il s'agissait en ces lendemains du traumatisme de 1870 de convaincre, preuves à l'appui, du bien-fondé de l'enseignement civique. On peut dire, de ce point de vue, que l'expérience étrangère - et celle de la Suisse en particulier - fut largement utilisée par Schmitt pour légitimer et précipiter le mouvement en France: "Cet enseignement se donne dans les États libres. En Suisse, l'enseignement civique est une matière obligatoire dans toutes les écoles, et notre Manuel, adapté aux institutions locales, est en usage dans plusieurs cantons. "Schmitt ajoute " qu'en Allemagne, le grand Diesterweg a réclamé cet enseignement dès 1833 »; ainsi, en France, " la question est donc arrivée à maturité. Il faut réaliser l'idée en l'appliquant à la fois en haut et en bas, surtout en bas $^{52}$ ».

C'est justement dans cette même perspective d'initiation à la république pour le peuple que Gambetta, arrivé en ballon à Tours le 9 octobre 1870, chargea une autre de nos connaissances, le philosophe Jules Barni de s'employer à la rédaction du Bulletin de la République ${ }^{53}$. Ce journal de propagande, nous dit Barni, «était destiné à éclairer les populations des campagnes, comme des villes, non seulement sur les actes du gouvernement de la défense nationale, mais aussi sur les institutions républicaines, qui seules peuvent relever la France $^{54}$ ». En d'autres termes, il s'agissait «d'insérer, dans chaque numéro, sous le titre de Manuel républicain, un court chapitre où je m'efforçais de mettre à la portée de toutes les intelligences les notions fondamentales qui constituent l'esprit même de la république ». En la personne de Barni, rappelé de son exil genevois dès la proclamation du gouvernement de la défense nationale, Gambetta disposait d'un intellectuel-clé qui avait étudié les institutions helvétiques avec assiduité et intérêt: en attestent les multiples références à la Suisse présentes dans son Manuel. Convaincu du rôle de l'éducation et de la morale laïque comme unique moyen d'accéder au self-government, Barni privilégiait la constitution de mœurs républicaines pour assurer la pérennité des institutions.

\section{Ibid., p. XII-XIII.}

53. Ce Bulletin devait remplacer le Moniteur des communes demeuré enfermé dans Paris.

54. Jules Barni, Manuel républicain, Paris, Librairie Germer Baillière, 1872, p. V. Notons que le texte de Barni fut d'abord diffusé par épisodes dans le Bulletin de la République. 
À la vérité, les manuels de Schmitt et de Barni ne jouirent que d'une faible diffusion. Ils n'en ont pas pour le moins attiré l'attention de l'élite sur cette nécessité de l'enseignement civique et fourni un patron helvétisé en référence auquel se façonneront les ouvrages de $1882^{55}$. Comme l'a souligné Émile Boutroux:

L'enseignement moral et civique, après avoir prospéré en France sous la République, ne tarda pas à s'éteindre. Cependant, il s'établit, dans le courant de ce siècle, en d'autres pays, notamment en Suisse, où les proscrits de 1851 furent frappés de le voir en pleine vigueur. Edgar Quinet raconte que pendant son séjour dans ce pays, il admirait les petits résumés que les enfants rapportaient de l'école, et qui formaient un véritable manuel du citoyen suisse. Parmi les livres servant à cet enseignement, nous citerons le Cours gradué d'instruction civique, manuel de l'école, de la famille et $d u$ citoyen, par Louis Bornet, professeur, ouvrage conçu dans un esprit chrétien. L'exemple de la Suisse contribua sans doute à réveiller dans l'esprit des républicains français le souvenir des traditions de la première République en matière d'enseignement moral et civique; et dès la fin de l'Empire, ils conçurent avec précision l'idée d'organiser un tel enseignement ${ }^{56}$.

Michèle Alten signale que sous la III $^{e}$ République, "la musique devient un auxiliaire de la morale et se réduit à la mémorisation de chants édifiants ${ }^{57}$ ». Le chant scolaire, tout comme la dictée d'ailleurs, engage l'écolier-citoyen dans un processus d'absorption symbolique de la morale républicaine. Il n'est donc pas étonnant que ce soit son principal théoricien, Félix Pécaut, qui ait signé l'article consacré à la musique dans le Dictionnaire de pédagogie et d'instruction primaire de

55. L'instruction civique est instituée en France par Jules Ferry (loi d'obligation du 28 mars 1882). On trouve dès lors une profusion de manuels, parmi lesquels Paul Bert, L'instruction civique à l'école, Paris, Picard-Bernheim et C C ${ }^{\text {ie }}$ 1882; Pierre Laloi (Ernest Lavisse), La Première Année d'instruction civique, Paris, Armand Colin et C $C^{\mathrm{ie}}, 1882$; Henriette Massy, Notions de morale et d'éducation civique à l'usage des jeunes filles, Paris, Picard-Bernheim et $C^{i e}, 1883$. Voir l'étude des manuels français d'Alain Mougniotte, Les débuts de l'instruction civique en France, Lyon, Presses universitaires de Lyon, 1991, p. 69-138, et surtout son analyse de l'article de Boutroux, p. 123-130. Sur l'émergence de l'objet d'étude « instruction civique », on lira Georges Bensoussan et Antoine Laugère, «L'instruction civique: ses buts, ses agents, ses discours », Raison présente, 74/1985, p. 7-23. Voir également Laurent Gutierrez (dir.), Éduquer au patriotisme par l'illustration. L'apport de Lucien Métivet. Recueil de dessins commentés parus dans la revue scolaire L'Ecole et la Vie entre le 15 septembre 1917 et le 19 octobre 1918, Paris, Art Négatif, 2014.

56. Émile Boutroux, « Les récents manuels de morale et d'instruction civique », Revue pédagogique, 15 avril 1883 (et non le 15 août comme l'indique Pierre Bovet), p. 290.

57. Michèle Alten, « Un siècle d'enseignement musical à l'école primaire », Vingtième siècle. Revue d'histoire, n 55, juillet-septembre 1997, p. 5. 
Buisson. Là encore, la Suisse n'est pas étrangère à l'instauration et à la consolidation de la discipline dans l'espace français.

\section{L'éducation musicale: de Niedermeyer à Schneeberger}

Au début du long siècle, les éducateurs n'avaient pas encore clairement identifié le chant comme un objet d'étude susceptible de prendre place dans les programmes des écoles primaires françaises. Pourtant, le Concordat du 15 juillet 1801 et la réouverture des églises laissaient entrevoir un renouveau de la musique religieuse. Porté par les initiateurs de la Société pour l'instruction élémentaire - le baron de Gérando connaissait la portée du chant dans les écoles d'Allemagne - l'enseignement musical parisien s'institua lentement grâce à des figures majeures comme Guillaume-Louis Bocquillon, dit Wilhem ${ }^{58}$ (1781-1842) et Alexandre Choron (1772-1834). En 1815, Choron ouvrit une école normale de musique (institution privée) et décida de développer ses méthodes pour le plus grand nombre. Georges Favre précise que « son idée dominante consistait à faire passer le goût de la bonne musique dans toutes les classes; pour y parvenir, il fit des essais en grand sur des masses d'enfant pris dans les écoles de charité et le succès alla audelà de toutes ses espérances ${ }^{59}$ ". Malgré cela, privé de subventions dès l'avènement de la monarchie de Juillet, Choron mourut désespéré le 29 juin 1834. Et c'est un compositeur vaudois, Louis Niedermeyer ${ }^{60}$, qui réorganisa l'école de Choron et redynamisa la musique religieuse en France. Protestant né sur les bords du Lac Léman à Nyon, Niedermeyer se passionna pour la liturgie catholique et se fit le promoteur, au moyen notamment de sa revue La Maîtrise, d'une réflexion théorique sur la musique sacrée catholique. Avec l'appui d'Hippolyte Fortoul, qui intercèdera auprès de l'ensemble des évêques de France pour les prier de soutenir son projet, Niedermeyer ouvrit son école le $1^{\text {er }}$ décembre 1853. Camille Saint-Saëns y enseigna dès 1861 et compta parmi ses élèves

58. Au sujet de l'itinéraire de Wilhem, un des premiers promoteurs de l'enseignement du chant dans les écoles primaires françaises, voir Claire Fijalkow, Deux siècles de musique à I'école. Chroniques de I'exception parisienne 1819-2002, Paris, L'Harmattan, 2003, p. 11-29 et Charles Defodon, « Wilhem », NDP.

59. Georges Favre, Histoire de l'éducation musicale, Paris, La pensée universelle, 1980, p. 122. 60. Louis Niedermeyer (1802-1861), initié à la musique par son père, il se rend ensuite à Vienne et suit des cours de piano chez Ignaz Moscheles et étudie la composition avec Emmanuel Alois Förster. II se perfectionne ensuite en Italie, et s'installe à Paris dès 1823. II y deviendra célèbre grâce à sa mélodie composée sur Le lac de Lamartine. 
le jeune Gabriel Fauré, André Messager, Albert Périlhou ou Eugène Gigout. Les événements de la Commune provoquèrent l'installation à Lausanne de l'école de Niedermeyer, dirigée depuis la mort du Vaudois par Gustave Lefèvre, bientôt rejoint par Fauré.

Sous la Troisième République, c'est l'influent Albert Dupaigne, ancien élève de l'école normale supérieure puis inspecteur primaire à Paris, qui fut le grand instigateur de la musique scolaire. En 1878, lors des fameuses conférences données aux instituteurs délégués lors de l'Exposition universelle, Dupaigne laissa entrevoir ses orientations en matière d'enseignement musical. Il considérait le chant comme un puissant levier contre le matérialisme et " un moyen précieux d'élever le niveau des âmes auxquelles s'adresse la langue musicale ${ }^{61}$ ». L'ennemi désigné était le café-concert, " la ruine de la musique [...] et une institution aussi antimusicale qu'antisociale ». On le voit, dans la France républicaine comme dans toute l'Europe des nations, la musique scolaire prit pour double fonction d'éveiller les consciences au patriotisme et de servir de complément à la morale civique. Le conférencier déplorait également que « les artistes, les compositeurs et les éditeurs ne s'occupent que du monde des salons ». Dans le droit fil de Choron, il estimait urgent que " le bon goût et la véritable instruction musicale se trouve [nt] transportés des classes aisées dans les classes populaires ${ }^{62}$ ».

Lors des conférences, Dupaigne présenta une série de recueils publiés en français aux instituteurs présents, parmi lesquels on trouve les Chants d'école à l'usage de la Suisse française, du Neuchâtelois Kurz, publiés en deux volumes chez Sandoz et Fischbacher. À ce propos, Dupaigne ajouta «qu'on a souvent reproché à plusieurs de ces chants d'être d'origine allemande. C'est une erreur: ils sont plus souvent d'origine suisse, ce qui est bien différent. Naegeli, Schultz, Kurz, et d'autres compositeurs illustres, auteurs de la musique de ces chants, sont Suisses et non Prussiens ». Dupaigne conclut en rappelant " qu'en fait d'instruction primaire, nous avons beaucoup à apprendre de la Suisse. C'est un pays ami, qui ne nous reprochera pas nos emprunts $^{63}$ ».

61. Albert Dupaigne, «Conférence sur le chant dans les écoles (29 août 1878) 》, Les Conférences pédagogiques faites aux instituteurs délégués à l'Exposition universelle de 1878 [3 $3^{\mathrm{e}}$ édition], Paris, Charles Delagrave, 1880, p. 284. Cette conception semble assez largement répandue en Europe, et notamment en Allemagne, voir Alexandre Daguet, « L'affaiblissement du chant populaire et des moyens de le relever », L'Éducateur, 9/1876, p. 136-137.

62. Ibid, p. 302.

63. Ibid, p. 306. 
Le 27 juillet 1882, Jules Ferry inscrivait le chant comme douzième et dernière matière obligatoire de l'éducation intellectuelle. Michèle Alten explique qu'en l'absence de tradition et de méthodes, il incomba au législateur de fonder un programme de toutes pièces. Les pédagogues optèrent notamment pour la méthode Galin-Paris-Chevé, spécialement conçue pour les débutants non musiciens ${ }^{64}$. On doit ce système au Bordelais Pierre Galin (1786-1822), qui s'appliqua en autodidacte à théoriser la musique comme une langue, pour l'approprier au plus grand nombre sous une forme chiffrée. Malgré plusieurs tentatives de diffusion à Bordeaux puis à Paris, son œuvre n'obtint point le succès escompté. C'est son élève et disciple Aimé Paris (1798-1866) qui sauva la méthode de l'oubli, pour la propager avec l'aide de sa sœur Nanine, l'épouse d'Émile Chevé (1804-1864).

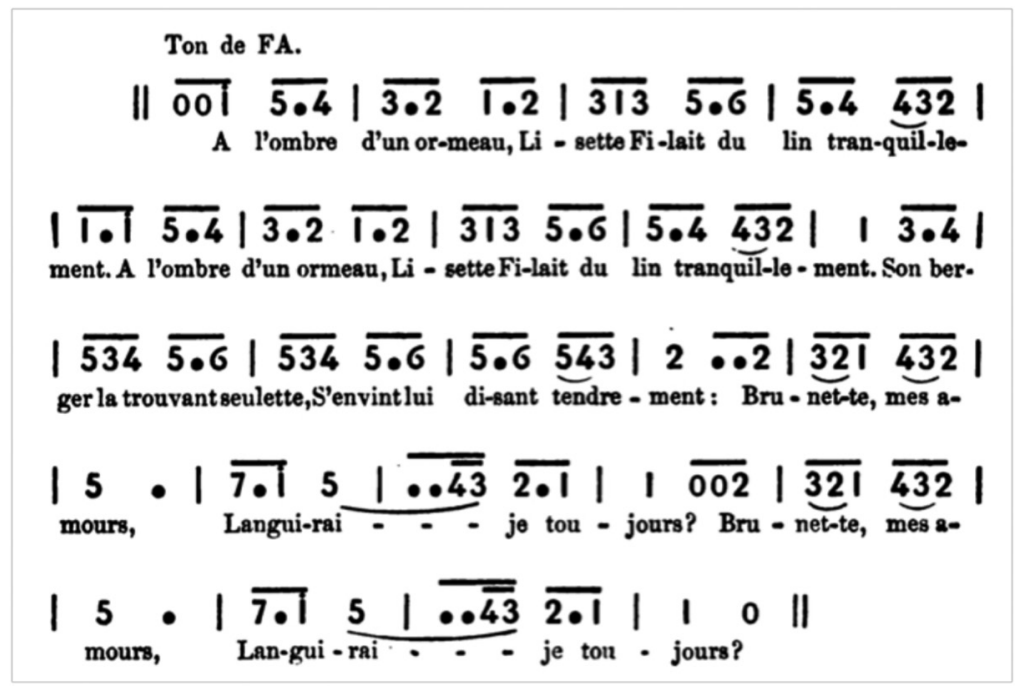

Languirai-je toujours? Musette du XVII siècle selon la méthode Galin-Paris-Chevé, tiré de Alphonse Pagès, La méthode Galin-Paris-Chevé. Exposé historique, Paris, Librairie de l'écho des feuilletons, 1860, p. 32.

Il est intéressant de noter que ce système fit l'objet d'une intense propagande en Suisse romande dans les années 1860. C'est Alphonse Meylan (1834-1917) qui assura la translation de la méthode en Suisse

64. Michèle Alten, « Musique scolaire et société dans la France de la III république », Tréma [en ligne], 25/2005, p. 9. 
occidentale. Après des études à Genève, Meylan devint graveur, puis maître de musique au collège de Genève. Dès 1867, L'Éducateur lui donna carte blanche pour populariser la méthode chiffrée, que Meylan utilisait depuis plusieurs années ${ }^{65}$, puisque le Conseil d'État genevois l'avait adoptée en 1861. D'abord sceptiques, puis convertis par Émile Chevé lui-même, les politiciens genevois se montrèrent satisfaits " des résultats obtenus en fort peu de temps, et cela sans fatigue pour les maîtres et sans travail ingrat et aride pour les enfants ${ }^{66}$ ". Ce satisfecit hâta d'ailleurs son introduction dans les écoles du canton de Vaud sous le gouvernement Ruchonnet ${ }^{67}$. À noter: comme on peut s'y attendre, dans son passage d'un contexte culturel à un autre, la méthode subit une transformation sémantique. Meylan s'attacha en effet à ressusciter la rationalité du système musical prôné par Jean-Jacques Rousseau, qui servit de base au système perfectionné ensuite par Galin-Paris-Chevé, mais qui avait été plus ou moins dissimulé par les deux spécialistes français. En 1869, Meylan fit paraître sa déclinaison de la méthode dans un Cours de musique chiffrée et portée ${ }^{68}$, adopté par les directions de l'Instruction publique des cantons de Vaud, Genève et Neuchâtel.

On peut raisonnablement penser que d'autres méthodes de musique scolaire circulaient dans l'espace franco-romand. Par une lettre de Ferdinand Buisson à Friedrich Schneeberger ${ }^{69}$, on apprend que ce maître de chant au progymnase de Bienne souhaitait voir adopter sa méthode en France:

J'ai reçu la lettre que vous m'avez fait l'honneur de m'écrire, à la date du 10 février courant, et par laquelle vous me manifestez le désir de voir adopter et même rendre obligatoire en France une méthode de

65. La musique scolaire et la méthode Galin-Paris-Chevé jouirent d'une bonne visibilité dans la revue romande, puisque Meylan expose ses vues dans une série de douze articles répartis dans L'Éducateur de 1867 et de 1868.

66. Alphonse Meylan, « Musique populaire », L'Éducateur, 3/1867, p. 40.

67. Selon I'arrêté du Conseil d'État du 31 octobre 1868, la méthode Galin-Paris-Chevé était adoptée comme base de l'enseignement du chant dans les écoles normales, ainsi que dans les écoles primaires et secondaires du canton de Vaud. Voir « Introduction de la musique chiffrée dans les écoles du canton de Vaud», L'Éducateur, 22/1868, p. 363-364 et « La musique chiffrée », L'Éducateur, 16/1889, p. 255-256.

68. Alphonse Meylan, Cours de musique chiffrée et portée. Essai théorique, pratique et pédagogique des principes de l'école de J.-J. Rousseau-Galin-Paris-Chevé, Lausanne, Bridel, 1869.

69. Friedrich Schneeberger (1843-1906), maître de chant à Aarberg, suivit les cours du « père de tous les chanteurs » de l'époque, Gustav Weber. En 1872, il fut engagé au Progymnase de Bienne. II inventa une méthode élémentaire d'apprentissage de la musique, qu'il chercha à populariser en France (Le Journal du Jura, 7 juin 2006, p. 4). 
chant dont vous êtes l'auteur. Je ne doute pas que votre méthode ne contribue à faciliter l'enseignement du chant, mais je ne dois point vous laisser ignorer que le ministre n'a plus, aux termes des règlements, à recommander ou à approuver les méthodes destinées aux écoles. Il suffit pour qu'elles puissent être introduites dans les établissements scolaires qu'elles n'aient été l'objet d'aucune interdiction. Je ne puis donc que vous exprimer le regret que mon intervention ne puisse être d'aucune utilité à la propagation de votre œuvre ${ }^{70}$.

Les études de cas auxquelles nous nous sommes livrés dans ce chapitre montrent comment les éducateurs français et les cadres de l'école de la III $^{\mathrm{e}}$ République ont transféré et réinterprété des éléments de morale laïque de l'espace helvétique vers la France. L'enjeu de cette morale républicaine s'est peu à peu cristallisé sur « la dimension sacrée $\mathrm{du}$ politique et la dimension politique du sacré », la morale laïque s'étant peu à peu substituée à la morale religieuse dans un jeu de double transfert ${ }^{71}$.

70. Lettre de F. Buisson à F. Schneeberger, Paris, 19 février 1880, AN, F17/12340.

71. Voir Sarah Scholl, « "Soyez courageux et dociles!". Les normes religieuses comme vecteur d'éducation au patriotisme en Suisse (1870 - 1914) 》, Revue suisse d'histoire, 3/2013, p. 343363; Pierre Ognier, Une école sans Dieu? 1880-1895. L'invention d'une morale laïque sous la III République, Toulouse, Presses universitaires du Mirail, 2008. 



\section{8 \\ Transférer le corps de la nation}

Dans le Nouveau dictionnaire de pédagogie et d'instruction primaire publié sous la direction de Ferdinand Buisson en 1911, on peut lire que « la gymnastique fait partie de l'éducation générale et est inséparable de l'éducation morale et intellectuelle ${ }^{1}$ ». Il faut dire que l'éducation du et au corps fut l'une des composantes essentielles du processus de fabrication des États-nations européens. Jean-Claude Bussard rappelle que "l'éducation physique soumet les corps aux strictes règles de l'obéissance, de la subordination aux impératifs sociaux et l'enferme dans le carcan rigide de certaines pratiques gymnastiques ${ }^{2} »$.

\section{Passeurs et caractère hybride d'une gymnastique scolaire connectée}

Sauf en Allemagne, il vaut de le constater, l'implantation de la gymnastique scolaire en Europe demeure essentiellement le fait d'éducateurs étrangers. Jacques Defrance et Yves Joseleau y voient le résultat de l'adaptation aux lois d'un marché de la gymnastique marqué très tôt par l'opposition et la concurrence de grands promoteurs ${ }^{3}$. Defrance souligne encore que "pour s'occuper de gymnastique dans la première moitié du $\mathrm{XIX}^{\mathrm{e}}$ siècle, il faut posséder un esprit d'entrepreneur, construire sa position, gagner des appuis parmi les puissants, faire de la propagande et des démonstrations gratuites, ce qui suppose une certaine

1. NDP, «Gymnastique », 1911, p. 1. Je remercie Véronique Czáka de m'avoir guidé dans ces développements inhérents à la gymnastique scolaire.

2. Jean-Claude Bussard, L'éducation physique suisse en quête d'identité (1830-1930), Paris, L'Harmattan, 2007.

3. Jacques Defrance et Yves Joseleau, « Phokion Heinrich Clias (1782-1854) », in Pierre Arnaud, Le militaire, l'écolier, le gymnaste. Naissance de l'éducation physique en France (1869-1889), Lyon, Presses universitaires de Lyon, 1991, p. 175-185. 
aisance matérielle ${ }^{4}$ ». Le Suisse Phokion Heinrich Clias (1782-1854) est un des organisateurs de la gymnastique dans les écoles parisiennes de la Restauration. Né en Amérique du nord, élevé en Hollande, Clias enseigne son art à l'institut privé Gottstatt près de Bienne. Officier d'artillerie, il introduit avec succès les exercices corporels parmi les soldats. Installé en France au début de la Restauration, il se charge de l'organisation de l'enseignement de la gymnastique dans les écoles de la ville de Paris, en rivalité avec le colonel espagnol Francesco Amoro ${ }^{5}$. $\mathrm{Au}$ sujet de ce dernier, Jacques Ullmann souligne que ses méthodes relevaient d'une acclimatation française des gymnastiques du père de la gymnastique scolaire moderne Friedrich Ludwig Jahn (1778-1852) et de Pestalozzi ${ }^{6}$. C'est d'autant plus crédible qu'on sait qu'Amoros profita de la création d'un institut à Madrid, à l'initiative de Charles IV qui fit venir de Suisse plusieurs pestalozziens ${ }^{7}$. Revenons à Clias : grâce à ses Éléments de la gymnastique (Aufangsgründe der Gymnastik), une copie partielle des thèses du Saxon GutsMuths ${ }^{8}$, ses méthodes s'institutionnalisérent dans la plupart des cantons suisses et le firent connaître en Angleterre. En 1822, il obtient la place de surintendant en chef des exercices gymnastiques de l'armée britannique. À nouveau installé dans la Suisse de la Régénération, Clias, en compétition avec le théologien hessois Spiess ${ }^{9}$, retente sa chance en France vers 1841. Il s'installe à Coppet en 1849, et donne jusqu'à sa mort des leçons de gymnastique à des adolescents genevois ${ }^{10}$.

4. Jacques Defrance, «Phokion-Heinrich Clias (1782-1854) : callisthénie ou somascétique naturelle appropriée à l'éducation physique des jeunes filles », in Anthologie commentée des textes historiques de l'éducation physique et du sport, Paris, Revue EP. S, 2001, p. 47.

5. Voir Marcel Spivak, « Colonel François Amoros y Ondeano (1770-1848) : manuel d'éducation physique, gymnastique et morale », in G. Vigarello (éds.), Anthologie commentée des textes historiques de l'éducation physique et du sport, Paris, Revue EPS, 2001, p. 13-17.

6. Relevé par Jean-Claude Bussard, op. cit., p. 63.

7. Voir Alfred Morel-Fatio, « Don Francisco Amoros, marquis de Sotelo, fondateur de la gymnastique en France (fin) », Bulletin Hispanique, t. 27, 1/1925, p. 36-78.

8. Jean-Claude Bussard indique que Clias copia plusieurs passages de La Gymnastique de la jeunesse, la traduction française de I'ouvrage du Saxon Johann Christoph Friedrich GutsMuths, avant de les retraduire en allemand dans son propre ouvrage. Voir Jean-Claude Bussard, op. cit. p. 88.

9. Adolph Spiess (1810-1858) étudia les méthodes du Prussien Jahn - le père de la gymnastique européenne - qu'il revisita dans ses écoles de Giessen. Le gouvernement décida de fermer son gymnase, jugé trop libéral, et Spiess s'établit en Suisse, où il diffusa ses préceptes à Berthoud (où enseignait Fröbel) ainsi qu'à l'école normale de Münchenbuchsee (1835-1843), puis à l'école des jeunes filles de Bâle avant de se fixer à Darmstadt.

10. Voir la notice biographique de Clias dans le Journal de Genève du 28.11.1854, p. 3. 
La mise en place de la gymnastique scolaire se double d'une "bataille pour l'hygiène ${ }^{11}$ ". Dès l'été 1871 - et donc bien avant l'arrivée des républicains aux affaires scolaires - une mission dirigée par Jean-Baptiste Fonssagrives est dépêchée pour étudier les conditions sanitaires dans plusieurs établissements suisses ${ }^{12}$ :

L'organisation des écoles enfantines y est remarquablement avancée et j'ai éprouvé plus d'une fois un sentiment de regret envieux, en comparant ces écoles spacieuses, bien aérées, amplement munies de soleil, ayant souvent un mobilier luxueux, richement dotées de toutes les ressources de l'enseignement intuitif, aux conditions dans lesquelles trop souvent chez nous s'administre le premier enseignement, si décisif pourtant pour l'instruction comme pour la santé à venir.

Fonssagrives, professeur d'hygiène à l'université de Montpellier, insiste par ailleurs sur les conditions spécifiques dévolues à la gymnastique scolaire:

Je ferai la même remarque sur la façon vraiment intelligente dont la pédagogie suisse entend l'enseignement et les pratiques de la Gymnastique. Nous sommes, en ce qui concerne l'éducation physique, dans un état d'infériorité que je soupçonnais mais dont je n'avais pas la mesure. Malgré les efforts louables qui ont été tentés dans ces dernières années, la gymnastique éducative n'existe pas chez nous. Incomplète dans les lycées, elle manque à peu près complètement à l'enseignement primaire libre ou public; et on peut affirmer que l'éducation des filles en est absolument déshéritée. J'ai visité les Gymnases principaux de la Suisse; j’ai interrogé les gymnasiarques les plus habiles; j’ai assisté à leurs leçons; j'ai rapporté des reproductions photographiques de gymnases de petites villes, et je suis arrivé à cette conclusion: que tout en France, ou peut s'en faut, était à faire en matière de gymnastique d'écoles. Il ne me sera pas difficile de le démontrer dans le travail que je prépare ${ }^{13}$.

11. Jean-François Chanet, Vers l'armée nouvelle. République conservatrice et réforme militaires, 1871-1879, Rennes, PUR, 2006, p. 225-244. Voir également Anne Rasmussen, «L'hygiène en congrès 1852-1912: circulations et configurations internationales 》, in P. Bourdelais (dir.), Les hygiénistes. Enjeux, modèles, pratiques (XVIIIe-XXe siècles), Paris, Belin, 2001, p. 213-239.

12. Durant un mois, Fonssagrives visite les écoles ou gymnases de Genève, Lausanne, Neuchâtel, Winterthur, Bâle, Schaffhouse, Zurich, Küsnacht, Wettingen, Saint-Gall, Fribourg, Lucerne, Berne, Burins, Rolle et conclut son voyage par Genève où il avait plusieurs sujets d'étude à compléter.

13. Lettre de Jean-Baptiste Fonssagrives au ministre Jules Simon, Montpellier, 17 octobre 1871, AN, F17-12340. 
En France, par la loi du 27 janvier 1880, l'enseignement de la gymnastique $^{14}$ devient obligatoire pour les garçons, notamment par l'enseignement régulier d'exercices militaires élémentaires. Jules Ferry fait paraître un Manuel de gymnastique et des exercices militaires pour les élèves des écoles primaires (1881) qui s'inspire largement du premier manuel scolaire publié sur le thème par la Confédération suisse en $1876^{15}$. Tous deux se caractérisent par la prédominance des valeurs martiales et des exercices militaires (deux-tiers du manuel) sur les jeux ${ }^{16}$.

Véronique Czáka a montré en outre que certains expatriés suisses ont joué un rôle déterminant dans la promotion de la gymnastique en France. C'est le cas du Fribourgeois Léon Galley, qui s'installe à Reims (1877-1880) puis à Arras (1880-1887). Durant ces dix ans, il publie une terminologie de gymnastique, codirige le premier cours français de formation pour moniteurs, réforme les règlements des rencontres de gymnastique sur le modèle suisse et impulse la participation de sociétés suisses aux fêtes françaises de gymnastique ${ }^{17}$.

\section{Des corps de cadets suisses aux bataillons scolaires}

Suite à la défaite de Sedan, on assiste en France à un mouvement général de militarisation des consciences ainsi qu'à l'installation d'un attachement indéfectible au dévouement patriotique. La volonté d'instruire militairement l'écolier est patente: faut-il y voir, comme cela a été longtemps le cas, les racines d'un mouvement qui devait aboutir à la revanche de 1914? Eugène Paz, directeur du lycée Condorcet à Paris, déclare dans sa Gymnastique obligatoire " qu'il est temps de tremper nos enfants dans le Styx ». S'agissait-il de façonner des hommes pour préparer, comme le souhaitait un Paul Déroulède, la

14. Au sujet de la relation entre gymnastique, armée et école républicaine, on lira Eugen Weber, «Gymnastique et sport en France à la fin du XIX siècle: opium des classes? 》, Recherches, 43/1980, p. 185-220; Pierre Arnaud, Le militaire, l'écolier, le gymnaste: naissance de l'éducation physique en France (1869-1889), Lyon, Presses universitaires de Lyon, 1991; Pierre Arnaud (sld), Les Athlètes de la républiques: Gymnastique, sport et idéologie républicaine (1870-1914), Paris, L'Harmattan, 2000.

15. L'école de gymnastique pour l'instruction militaire préparatoire de la jeunesse suisse de I'âge de 10 à 20 ans, Berne, Imprimerie R.-F. Haller-Goldschach, 1876.

16. Jean-Claude Bussard, op. cit., p. 99-104.

17. Voir Véronique Czáka, Éduquer les corps et les âmes. Histoire sociale et genrée de l'éducation physique en Suisse romande (xIx ${ }^{e}$-début $x x^{e}$ siècle), université de Lausanne, Faculté des Lettres, thèse de doctorat, 2015. 
revanche française? Au-delà des mots, il conviendrait de s'interroger sur les finalités et enjeux réels des intentions proclamées; n’importaitil pas avant tout de se prémunir de toute agression en préparant physiquement et mentalement une jeunesse à la défense d'un territoire qu'on voulait inviolable? Sans prétendre entrer dans le détail d'un débat éminemment complexe, la translation des corps de cadets suisses ${ }^{18}$ en bataillons scolaires français apporte quelques éléments de réponse.

Albert Bourzac souligne en effet que " le modèle suisse a exercé une influence certaine dans la constitution des bataillons scolaires ${ }^{19}$ ", créés par décret en 1882. À preuve, après une mission dans la Confédération, l'officier de réserve Auguste Frette conclut en 1879 qu'il « serait à souhaiter que nous eussions une organisation analogue à celle des Cadets suisses ${ }^{20}$ ». Huit ans plus tôt, en octobre 1871, Jean-Baptiste Fonssagrives vantait déjà les avantages de cette institution à son ministre Jules Simon:

L'introduction de la vie militaire, de son esprit et de ses exercices dans les Gymnases, qui correspondent à nos collèges ou lycées, et même dans les divisions supérieures de l'enseignement primaire, m'a fourni un sujet d'études qui m'a intéressé au plus haut point. Aussi ai-je étudié avec soin l'institution des Cadets en Suisse, cette pépinière de la milice nationale, et je n'hésiterai pas à en conclure à la nécessité urgente d'introduire dans nos collèges cette institution si pleine d'attraits et d'utilité en même temps et qui donne, à la fois tant de garanties à la vigueur physique, à la pureté, et à l'instruction militaire des jeunes gens. Les exercices que font nos enfants dans l'intérieur des lycées n'ont rien qui puisse remplacer cette vie en plein air, ces exercices entourés d'un véritable appareil militaire et ces excursions où toute la jeunesse d'une école, rompue aux exercices à feu du fusil et même du canon, s'en va, musique en tête, faire une reconnaissance stratégique ou simuler une attaque. La Santé, la gaité et les muscles s'en trouvent bien; l'instruction (l'expérience est là

18. Sur I'histoire des corps de cadets en Suisse, voir Édouard Secrétan, L'instruction militaire préparatoire, les corps de cadets, Lausanne, Imprimerie A. Borgeaud, 1882; Fritz Jung, Corps des cadets et musique scolaire, 1850-1950, Annales locloises, 8/1950; Louis Burgener, « Les cadets en Suisse », Revue militaire suisse, Pully, 12/1986, p. 574-581; André de Giuli, « Les Cadets veveysans », Vibiscum, 8/2000, p. 256-274; Yves Clément, Les Cadets de Vevey: un patrimoine social et culturel plus que centenaire, mémoire de licence, université de Lausanne, 2001.

19. Albert Bourzac, Les bataillons scolaires 1880-1891. L'éducation militaire à l'école de la République, Paris, L'Harmattan, 2004, p. 21.

20. Auguste Frette, À propos de l'organisation de l'armée et des Cadets en Suisse, Paris, Librairie militaire de J. Dumaine, 1879, cité dans Albert Bourzac, op. cit., p. 19. 
pour le démontrer) n'en souffre nullement. On fait des hommes de cette façon; et, en même temps qu'on les trempe vigoureusement au physique et au moral, ou surexcite chez eux le sentiment national en les associant déjà aux idées de patriotisme et de défense du pays.

Les événements calamiteux que nous venons de traverser, la probabilité d'une refonte complète de notre système militaire donneraient à cette réforme une opportunité plus particulière. L'opinion l'accepterait en ce moment et une fois entrée dans nos mœurs, elle serait d'un incalculable avantage pour le pays ${ }^{21}$.

S'il a fallu une dizaine d'années pour assurer ce transfert de savoirs entre la Suisse et la France ${ }^{22}$, il convient de s'interroger sur l'usage, au point de départ, de ces corps dans le contexte culturel suisse. Bien qu'il ne soit pas obligatoirement représentatif de l'ensemble des corps de cadets en Suisse romande, un retour sur celui qui avait été mis en place par Alexandre Daguet s'avère intéressant à plus d'un titre. Quelques mois après l'ouverture de l'école cantonale de Fribourg à l'automne 1848, Daguet décide en effet l'introduction d'un corps militaire, avec cinq heures de gymnastique, dont trois d'exercices militaires. Comme le rappelle Geneviève Heller, Daguet, inspiré par le colonel Amoros, faisait fond sur les potentialités militaires de la gymnastique scolaire:

La gymnastique embrasse la pratique des exercices qui tendent à rendre l'homme plus courageux, plus intrépide, plus intelligent, plus fort, plus adroit, plus industrieux, plus véloce, plus souple, plus agile et qui le dispose à résister aux intempéries des saisons, aux variations du climat, à supporter les privations de la vie, à vaincre les difficultés, à triompher des dangers et des obstacles, à rendre enfin des services signalés à l'État et à l'humanité ${ }^{23}$.

Il souhaitait ainsi renouer avec la tradition: il cite l'exemple du couvent de Bellelay près de Porrentruy où « les exercices et l'uniforme qui en est le complément obligé exista [ient] avant la Révolution ${ }^{24}$ ». Très vite attaqué par les ultramontains fribourgeois pour cette introduction de ces exercices militaires, Daguet s'en défendit en invoquant la filiation qui les unissait à l'antique Confédération :

21. Lettre de Jean-Baptiste Fonssagrives au ministre Jules Simon, op. cit.

22. Les emprunts faits à I'Allemagne sont également à considérer.

23. Alexandre Daguet, « Manuel de pédagogie ou d'éducation 》, L'Éducateur, 20/1865, p. 309, cité par Geneviève Heller, « Tiens-toi droit ! ». L'enfant à l'école au XIX siècle : espace, morale et santé. L'exemple vaudois, Lausanne, Éditions d'en bas, 1988, p. 214.

24. Alexandre Daguet, Rapport sur l'école cantonale du 20 juillet 1857, Fribourg, p. 4. 
Mais les exercices militaires sont aussi anciens en Suisse que la Confédération elle-même; ils remontent au berceau des Alliances éternelles et datent de ce temps de foi religieuse et patriotique, exprimé par la belle devise: Dieu et Patrie [...]. Mais les exercices militaires ne sont autre chose que la conséquence et la mise en action de ce principe fondamental de la vieille Suisse: "Tout Suisse est soldat. " De là l'introduction du maniement des armes dans presque tous les collèges de l'Helvétie, et l'institution de ces corps de cadets ${ }^{25}$.

$\mathrm{Au}$ passage, on remarquera que les républicains français usèrent également de l'argument de l'ancrage et de la continuité historique au moment de la mise en place des bataillons scolaires. En 1882, Aristide Rey prenait la plume dans la Revue pédagogique afin de «vaincre les dernières résistances ». Il s'agissait de montrer à ceux qui " considér [ai] ent l'institution comme une séduisante fantaisie " que les bataillons « [avaient] été l'œuvre de nos pères, qu'ils nous sont imposés par notre tradition nationale, qu'ils sont une institution nécessaire de la République $^{26}$ ».

On ne saurait trop souligner que l'introduction des exercices militaires à Fribourg répond avant tout à un besoin de discipline devenu urgent, dans une école cantonale rongée par l'insubordination. Les cahiers du directeur ${ }^{27}$ rendent clairement compte des efforts quotidiens exercés par l'ensemble du corps enseignant pour mater une jeunesse peu docile: fréquentation des cabarets, abus d'alcool, grossièreté envers les passants, etc. À l'ordre du jour du 25 novembre 1849, on découvre " que les exercices militaires commenceront dimanche à 9 heures. Les élèves se rendront immédiatement après l'office sur la place du lycée pour y être organisé en pelotons. Tout élève qui n'aura pas pour les ordres du chef le respect convenable sera exclu du corps et ne recevra pas d'armes ${ }^{28}$ ". Dans celui du 17 juin 1850, Daguet indique que « la promenade [de Bulle] se fera militairement, c'est-à-dire avec les $\operatorname{armes}^{29}$ ». Pour autant, rien ne serait plus inexact que de considérer Daguet comme un militariste forcené. Rappelons qu'il fut, dès les années 1867, l'un des leaders de la contestation romande contre le projet Welti, qui prévoyait une coopération resserrée entre l'école et

25. Ibid., p. 3.

26. Aristide Rey, « Les bataillons scolaires et la Révolution française », Revue pédagogique, juillet-décembre 1882, p. 552.

27. AEF, Fonds de l'école cantonale, carton 1, livres du directeur (1849-1856).

28. AEF, Fonds de l'école cantonale, carton 1, cahiers du directeur (1849-1850).

29. Ibid. 
l'armée. "Moi aussi j’ai fait introduire les exercices des cadets à l'école cantonale, dont j'étais le recteur à Fribourg en 1848, et j'ai présidé aux fêtes de corps. S'ensuit-il que je devrais prôner et recommander le système qui relie et subordonne en quelque sorte la caserne à l'école $(s i c)^{30}$ ? » répond-il à ses détracteurs en 1874. Daguet martèle " qu'il n'y a rien de plus contraire à l'idée d'un éducateur que celle d'un caporal ou sergent instructeur, apportant au milieu des enfants, pour lesquels il doit être un ami et un second père, des habitudes de discipline militaire ". Criant à la " militairomanie ", l'acceptation de cette loi eût été selon lui « une mesure funeste à l'école, à son caractère essentiellement pédagogique, pacifique, intellectuel, moral, humanitaire ${ }^{31}$ ». On assiste à une véritable passe d'armes entre enseignants romands et alémaniques lors du Lehrertag de Bâle en octobre 1869; il est intéressant de constater, à ce sujet, que les quarante délégués français qui assistent à ce congrès " étaient, sauf trois, l'expression fidèle du sentiment général de leurs concitoyens romans $(s i c)^{32}$ ». S'il ne fait nul doute que Buisson partageait les idées pacifistes de son ami Daguet, celui-ci correspondait également avec Frédéric Passy ${ }^{33}$. De plus, ses conceptions iréniques étaient relayées dans la presse parisienne, comme ici dans la Revue bleue:

On sait qu'il existe en Suisse un parti dont le programme est l'agrandissement territorial de la Confédération helvétique, et que ce parti n'a jamais pardonné à la France de ne point avoir accordé à ses réclamations, lors de l'acquisition de la Savoie, certains districts de la province annexée. M. Daguet s'est élevé contre ce qu'il appelle le patriotisme cosmopolite, un des ennemis les plus dangereux du vrai patriotisme, et il a cité à ce propos un vers de Lamartine à un officier suisse qui s'était fait auprès de lui l'interprète des partisans des conquêtes ${ }^{34}$.

Aussi, sans minimiser l'action de Paul Déroulède et sa Ligue des patriotes de 1882, il est concevable que cet esprit revanchard étant

30. Journal de Genève du 7 octobre 1874, p. 3.

31. Charles Châtelain, « Considérations nouvelles sur le projet fédéral relatif à l'obligation du service militaire pour tout instituteur », L'Éducateur, 8/1869, p. 115.

32. Journal de Genève, 20 octobre 1869, p. 1.

33. Frédéric Passy (1822-1912) partage en décembre 1901 le premier prix Nobel de la paix avec Henri Dunant. Ce pacifiste reçut en 1868 I'autorisation du gouvernement impérial français de tenir une assemblée de la Ligue internationale permanente de la paix qu'il venait de fonder en mai 1867 et qui était de fait en concurrence avec la Ligue internationale de la paix et de la liberté fondée à Genève (voir Les États-Unis d'Europe. Organe de la Ligue internationale de la paix et de la liberté, $n^{\circ} 23,7$ juin 1868, p. 1).

34. Revue politique et littéraire (Revue bleue), Paris, XIV/1878, p. 668. 
dépassé, c'est dans cette même perspective helvétique - physique, disciplinaire et surtout civique - que Paul Bert et les membres de sa commission de l'éducation militaire (instituée le 21 janvier 1882) réfléchissent à l'instauration des bataillons. Accusé tout comme Daguet en Suisse romande de vouloir développer le militarisme, Paul Bert répond:

L'éducation militaire me paraît le plus puissant moyen, je ne dis pas de relever, mais de maintenir le niveau moral, par l'enseignement de l'obéissance raisonnée et des sacrifices légitimes. On a dit déjà et l'on dira encore que notre tâche tend à ramener au militarisme, cette espèce d'automatisme du corps et de l'esprit tant admiré par les grands exploiteurs d'hommes. C'est là une erreur profonde: l'éducation militaire, au contraire, est la plus sûre protection contre le militarisme. Elle développe non les tendances serviles mais les qualités de l'homme vraiment libre, car la liberté n'est plus troublée ni entravée, mais bien assurée et consacrée par l'obéissance à la règle, à la loi ${ }^{35}$.

On peut certes persister à penser que la translation des cadets suisses en France se resémantisa autour d'une fonction martiale à visée revancharde. Mais la présence de Ferdinand Buisson dans la commission de l'éducation militaire - lui qui naguère avait comparé l'uniforme militaire à une ignominieuse livrée ${ }^{36}$, lui qui recevra le prix Nobel de la paix en 1927 - laisse supposer, comme le suggère Jean-François Chanet, que c'est bien la "paix plutôt que la revanche ${ }^{37}$ " que l'élite scolaire de la III ${ }^{\mathrm{e}}$ République tenta de favoriser au travers de ses programmes, malgré certains propos fort ambigus:

À cette minute, un mot dit tout, il le semble du moins: la " revanche ", mot qu'il ne faudrait pas juger avec les idées et les sentiments qu'on aura trente ans plus tard. Il faut se demander ce qu'eût été le moral d'un peuple chez qui n'aurait pas vibré instantanément, au lendemain du désastre, ce cri de révolte, ce cri d'espoir quand même, poignant, farouche, brutal. On manquerait de justice envers les premiers disciples de Fichte comme envers les premiers manifestants de la « Ligue des patriotes » en leur reprochant la véhémence de certains propos, l'outrance de certaines attitudes. Que plus tard le nationalisme ait parfois dénaturé, parfois exploité pour des fins politiques les généreux emportements de la pre-

35. Allocution de Paul Bert devant la commission de l'éducation militaire, cité dans Albert Bourzac, op. cit, p. 93.

36. Discours de Ferdinand Buisson, Bulletin officiel du congrès de la paix et de la liberté de 1869, Lausanne, Association typographique, 1869, p. 42.

37. Jean-François Chanet, op. cit., p. 24-29. 
mière heure, qu'importe? À leur heure, il y a des exaspérations qui sont la sagesse même sous les dehors de la folie ${ }^{38}$.

Pour bien cerner la vision de Buisson, il faut mesurer le poids qu'il attachait non pas à la guerre, mais à la capacité des citoyens à se lever pour défendre le pays et être résolu à sacrifier, in fine, leur propre existence. C'est à l'aune de cette disposition au sacrifice que l'on peut calculer la valeur réelle et le succès de l'enseignement moral républicain. C'est ce que le même Buisson expliquera, en pleine guerre de 14, s'enorgueillissant de ce que cette fois-ci le citoyen français, élevé par la laïque, n'a pas failli et que l'enseignement moral républicain l'a mené à l'union sacrée:

Quand ces hommes, que tout séparait, éducation, croyances, opinions, intérêts, furent jetés pêle-mêle dans la fournaise, en face du péril suprême, tous ont obéi, comme d'instinct, à un même ordre que chacun entendait au fond de lui-même [...] Le juif et le chrétien, le prêtre et le libre penseur, le camelot du roi, le syndicaliste révolutionnaire n'ont pas seulement versé leur sang ensemble, ils ont ensemble communié dans l'héroïsme, disons, comme eux, simplement dans le devoir ${ }^{39}$.

Corroborant ce point de vue, Michèle Alten souligne que si les Chants patriotiques de Déroulède furent largement diffusés dans les écoles suite au désastre de 1871, il n'en est pas moins vrai que cette recrudescence de l'inspiration nationaliste fit place bientôt, dans le contexte de l'école publique, à un humanisme républicain soucieux de progrès social et de paix ${ }^{40}$. Les exercices physiques avaient pour fonction première de fortifier les corps, tout comme le souhaitait par ailleurs le concepteur - suisse - des colonies de vacances.

\section{D’Appenzell à Paris, les colonies de vacances}

Bien avant le développement des colonies de vacances, plusieurs institutions avaient été créées afin de soigner les enfants rachitiques et scrofuleux ${ }^{41}$. Mais aucune n'avait obtenu d'aussi bons résultats en termes d'hy-

38. Ferdinand Buisson, « L'école et la nation en France », L'Année pédagogique, 1913, p. 3.

39. Ferdinand Buisson, Souvenirs (1866-1916). Conférence faite à l'Aula de l'université de Neuchâtel le 10 janvier 1916, Paris, Fischbacher, 1916, p. 34-35.

40. Michèle Alten, « Musique scolaire et société dans la France de la ॥ république », Tréma [en ligne], 25/2005, p. 5.

41. On pense notamment aux caravanes scolaires, aux voyages à la Töpffer ou aux hospices comme celui de Berck-sur-Mer. 
giène préventive que n'en donnèrent les Ferien-Kolonien, conçues par le pasteur thurgovien Hermann Walter Bion (1830-1909), descendant de huguenots émigrés suite à la révocation de l'édit de Nantes. Bion consacra son existence à l'assistance, chez lui d'abord en créant l'hôpital de Trogen dans le canton d'Appenzell Rhodes-Extérieures, puis en fondant la maison des sœurs de la Croix-Rouge à Zurich-Fluntern. Au printemps 1876, il accompagna quelques écoliers valétudinaires dans les montagnes d'Appenzell et constata une amélioration rapide de leur état de santé. Cette expérience concluante donna le coup d'envoi d'un succès philanthropique mondial, propagé en Allemagne par le Dr Warrentrapp, en Belgique par le Dr Kopps puis sur l'ensemble du continent et aux États-Unis grâce au pasteur William Parsons ${ }^{42}$.

Comme l'indique James Guillaume dans la Revue pédagogique, « la France a attendu quelques années avant d'entrer à son tour dans la voie où plusieurs pays étrangers l'avaient précédée ${ }^{43}$ ". La déclinaison française fut le résultat du zèle d'une poignée d'individus. On citera d'abord Edmond Cottinet (1824-1895), qui le premier a cherché à naturaliser l'idée du pasteur Bion, qu'il découvrit vraisemblablement dans la Revue pédagogique de novembre 1879. Dans les mois suivants, Cottinet se rendit en Suisse et ce séjour le décida à propager le concept à Paris, dans ses écoles primaires du IX ${ }^{\mathrm{e}}$ arrondissement ${ }^{44}$. Globalement, il s'agissait d'envoyer, sous le contrôle de maîtres ou maîtresses, "les plus pauvres entre les plus débiles, les plus méritants entre les plus pauvres " à l'école normale de Chaumont (garçons) et à l'école primaire de Luxeuil (filles), inoccupées durant les vacances d'été. Le succès ${ }^{45}$ de l'entreprise permit à Cottinet d'entrevoir une application à l'échelle nationale. En effet, dès lors que Ferdinand Buisson, convaincu par Cottinet du bien-fondé des colonies pour la jeunesse

42. Sur l'établissement des colonies de vacances en Europe et aux États-Unis, voir PhilippeAlexandre Rey-Herme, Colonies de vacances. Origines et premiers développements (18811906), Paris, chez l'auteur, 1954, p. 97-162 ; Laura Downs, Histoire des colonies de vacances de 1880 à nos jours, Paris, Librairie académique Perrin, 2009.

43. James Guillaume, «Les colonies de vacances et les écoles du IX $X^{e}$ arrondissement de Paris », Revue pédagogique, janvier-juin 1885, p. 308.

44. II s'agit de la version de Rey-Herme. Dans le NDP de Buisson, Maurice Pellisson explicite que Cottinet s'est inspiré des colonies du pasteur parisien Lorriaux, le fondateur de l'œuvre des Trois-Semaines, et de celles de Mme de Pressensé, qui avait ajouté une colonies de vacances à son CEuvre de la Chaussée du Maine (M. Pellisson, « Vacances (colonies de) », NDP, 1911).

45. Les 18 enfants de la première année devinrent 100 dès l'année suivante, puis 109 et 120 en 1886 (P.-A. Rey-Herme, op. cit., p. 215). 
française, décida d'institutionnaliser l'expérience, l'intelligentsia républicaine joua de l'argument du retard sur l'international pour légitimer une action rapide: "Aussi l'institution s'est-elle répandue rapidement dans tous les pays de l'Europe. Nous ne saurions rester en arrière de ce mouvement ${ }^{46}$ " scande le normalien Francisque Sarcey dans la Revue pédagogique. Par ailleurs, il faut souligner le rôle de Buisson, qui convoqua le 26 mai 1887 une commission pour la propagation et l'encouragement des colonies de vacances en France ${ }^{47}$. Comme l'indique Philippe-Alexandre Rey-Herme, en à peine six mois et grâce à l'ardeur conjuguée de Cottinet et Buisson, " les colonies scolaires de vacances avaient terminé leurs enfances expérimentales pour entrer par la grande porte dans le domaine des institutions reconnues ${ }^{48}{ }$. On usa également de l'argumentaire civique, puisqu'il s'agissait de faire, « avec des enfants dont le sang a été vicié comme l'âme par le séjour malsain de Paris, de fiers soldats et de bons patriotes ${ }^{49}$ ".

Du contexte originel suisse au contexte culturel français, les colonies de vacances générèrent une transformation sémantique tout à fait singulière. L'école républicaine instrumentalisa le concept pour aboutir à une version presque antagonique au schéma développé par le pasteur Bion. Cette posture constitue à nos yeux une manifestation de ce que Jean Houssaye résume sous le terme de déviation scolaire. Il explicite que le projet originel de Bion avait pour but de sortir les enfants du cadre scolaire et de lutter ainsi contre l'excès intellectualiste de l'éducation. Or, dans la version républicaine, la fonction scolaire va se substituer à la fonction sanitaire et sociale: "La pédagogie de ces colonies va donner naissance à une véritable déviation scolaire, transformant parfois les centres en gigantesques leçons de choses dans un cadre réglementaire très rigoureux ${ }^{50}$. " D'ailleurs, à Paris, on remarqua très tôt la valeur éducative et scolaire des colonies:

46. Francisque Sarcey, « Les colonies de vacances », Revue pédagogique, janvier-juin 1887, p. 198.

47. Buisson réunit des personnalités de premier plan. Le comité central de cette commission fut présidé par Octave Gréard, vice-recteur de l'académie de Paris et avait pour membre MM. Mézières, de l'académie française et Carriot, directeur de l'enseignement primaire du département de la Seine. Edmond Cottinet, fondateur des colonies de vacances du IXe arrondissement, prit la charge de secrétaire général.

48. Philippe-Alexandre Rey-Herme, op. cit., p. 239.

49. Francisque Sarcey, op. cit., p. 197.

50. Jean Houssaye, « Vouloir la coéducation, une fausse bonne idée ? », in Philippe Maubant et Lucie Roger (dir.), De nouvelles configurations éducatives. Entre coéducation et communautés d'apprentissage, Québec, Presses de l'université du Québec, 2010. p. 14-16. 
Le corps n'avait pas gagné seul [...] Ces petits Parisiens, ils n'avaient jamais rien vu que le chemin qui mène de leur rue à l'école; l'horizon de leurs pensées était borné à cet étroit espace. On s'imagine que le gamin parisien connaît Paris. Quelques-uns sans doute ont vagabondé à travers la grande ville. C'est le petit nombre. La plupart sont en quelque façon serfs du logis que leur père habite, et hors duquel il n'a pas le loisir de les promener. Cottinet en a vu qui, à l'âge de douze ans, passant dans le Palais-Royal, demandaient ce que c'était, et s'émerveillaient à regarder le Louvre, dont ils n'avaient pas même entendu parler. À plus forte raison ne savaient-ils rien de la campagne. Ils étaient sur ce point d'une ignorance crasse, et n'auraient pas distingué un champ de blé d'un champ d'avoine ${ }^{51}$.

Houssaye conclut qu'au final c'est l'enfant qui y perd, « lui [qui] se trouvera avant tout contraint dans la forme scolaire, à l'école et en vacances ». On le voit, la question centrale se cristallise sur le choix de la forme de la colonie, qui est double: on avait la possibilité d'envoyer les enfants comme pensionnaires uniques dans des familles montagnardes, ou alors en colonies estivales dans des écoles vides et sous la responsabilité d'un-e enseignant-e. On sait que cette question a attiré l'attention des spécialistes européens réunis lors d'une conférence à Berlin en novembre 1881. Les intervenants Schoost de Hambourg et Reddersen de Brême penchaient clairement pour le système du placement dans les familles «qui donne à l'enfant plus de liberté, tandis que dans les colonies il se trouve constamment sous la contrainte de la discipline scolaire $^{52}$ ». S'il pensa en premier lieu suivre le schéma de Bion qu'il avait observé en Suisse, et placer les enfants anémiques chez des paysans montagnards, Cottinet décida d'un ajustement pour la France en optant pour le système collectif ${ }^{53}$ :

Mais, entre l'annonce et l'exécution, une enquête supplémentaire avait révélé les risques de ce procédé séduisant. On avait vu les colons, disséminés dans les villages du Jura, sans surveillance suffisante, subir les conditions trop souvent défectueuses d'hôtes mal fournis ou rapaces... On préféra réunir les pupilles par petits groupes, dans les mains d'un

51. Francisque Sarcey, op. cit., p. 197.

52. James Guillaume, op. cit., p. 307.

53. Voir « L'instruction pour la formation et le fonctionnement des colonies de vacances » publiée par Edmond Cottinet dans la Revue pédagogique, juillet-décembre 1887, p. 44-59. On notera également que selon le fonctionnement des colonies proposé par le Journal de la Société vaudoise d'utilité publique de 1883 (p. 153), les enfants se retrouvaient également sous le contrôle de régents et régentes dans le canton de Vaud (G. Heller, op. cit., p. 256). 
maître connu d'eux, et leur chercher pour asile quelque école vidée par les vacances, où la nourriture leur serait donnée à forfait ${ }^{54}$.

$\mathrm{Au}$ premier congrès international des colonies de vacances de Zurich en août 1888, la délégation française ${ }^{55}$, emmenée par Jules Steeg, trancha radicalement en indiquant que "de toute manière, les Français entendent rester fidèles à leur forme de colonie, qui est la colonie collective ". Aux logiques internes se mêlaient dès lors des revendications nationales. D'ailleurs, à l'occasion des toasts, Steeg « crut ajouter que rien n'était capable de nous faire oublier qui nous sommes, qu'il n'y aurait aucun mérite à ces rencontres internationales si nous ne gardions pas jalousement notre sentiment national, et qu'à travers tout nous restons des patriotes irréductibles ${ }^{56}{ }$.

\section{Quelques considérations sur l'emprunt}

On impose à toute une population un ersatz quelconque, et en un laps de temps très court l'authentique, le produit d'origine, disparait totalement.

William Morris, L'âge de l'ersatz, 1894, p. 123.

Quand bien même la majorité des transferts de savoirs résulte davantage d'un désir d'importation que d'une volonté d'exportation, l'emprunt ne va pas de soi. En effet, emprunter aux nations concurrentes comporte certains risques, comme celui d'afficher son retard et de paraître de ce fait trop évidemment perfectible. Si l'emprunt ne semble pas poser un réel problème jusqu'à la moitié du XIX ${ }^{\mathrm{e}}$ siècle, la fabrication et la cristallisation des structures nationales modifient les représentations. Tout le paradoxe réside dans le fait d'imiter ses semblables dans la construction collective d'un espace clos tout en feignant de ne constituer que du particulier, du propre à soi. Les nations sont désormais engagées dans une intense concurrence pour la meilleure maîtrise du même. Il n'est plus possible de rester en retard sur quelque point que ce soit, le risque de déclassement pesant dans

54. Philippe-Alexandre Rey-Herme, op. cit., p. 212.

55. Cette délégation se composait de M. Jacoulet, directeur de l'école normale primaire de Saint-Cloud, de Pauline Kergomard, inspectrice générale des écoles maternelles, d'Edmond Cottinet, le promoteur des colonies de vacances du IX ${ }^{e}$ arrondissement de Paris et de M. Thomas, maire du XIII arrondissement.

56. Jules Steeg, « Congrès international de Zurich (colonies de vacances et hygiène scolaire) », La Revue pédagogique, juillet-décembre 1888, p. 221. 
tous les domaines constitutifs de l'identité nationale. Nul hasard si le culte du modèle et le comparatisme s'instituent de manière agressive à la suite des premières expositions universelles. On comprend dès lors mieux le recours aux nettoyages qui permettent, lors du processus de transfert, de relativiser ou de se défaire d'une origine de l'emprunt parfois bien encombrantes, il suffit de penser à la relation franco-germanique. Rappelons le constat de l'inspecteur Dupaigne, qui engage ses conférenciers à se servir des livres et manuels de chants scolaires mis à leur disposition parce qu'ils sont d'origine suisse et non allemande. Il est intéressant de constater que Dupaigne établit une différenciation morale entre la Prusse et la Suisse allemande. Le chant, considéré par erreur comme prussien, devient tolérable lorsqu'on apprend qu'il est d'origine suisse, ce qui montre que ce pays a potentiellement joué un rôle de contournement de l'Allemagne en matière pédagogique. On remarquera d'autre part que, des propos de Dupaigne, se détache en filigrane l'idée d'une realpolitik des emprunts. Emprunter aux nations concurrentes comportait certains enjeux de taille, comme celui, a-t-on rappelé, d'afficher son retard et l'on remarque dans les faits un présupposé psychologique non négligeable qui sous-tend un certain déshonneur à emprunter chez le voisin, à s'identifier à ses productions. D'où l'émergence d'une certaine forme de discours basé sur le dédain de la copie servile. J'y vois trois raisons principales. Il s'agit premièrement de dévaloriser le transfert en convoquant la thèse du particularisme et de la singularité locale. C'est par exemple le cas à Fribourg lorsque l'instituteur Félix Guérig souhaite importer la pratique des bibliothèques populaires pensées par Jean Macé pour l'Alsace. Guérig s'empresse de clamer qu'il serait "impensable de procéder à une copie servile des enseignements de la société du Haut-Rhin car nous avons nos mœurs, nos habitudes, nos goûts particuliers; conformons-y nos institutions ${ }^{57}$ ». Une autre manière de dédramatiser l'emprunt consiste à le légitimer par comparaison internationale. C'est également l'argument des superlatifs (meilleur, premier, etc.) qui cherche à hâter l'emprunt en surexposant la valeur et le succès de l'idée ou de la pratique dans son contexte d'origine. Rappelons le cas des autorités du canton de Vaud qui vers les années 1830 décident de naturaliser plusieurs pratiques pédagogiques bataves en suivant les préceptes établis par la société hollandaise d'utilité publique introduits en Suisse par Evert van Muyden-Porta :

57. Félix Guérig, « Des bibliothèques communales », L'Éducateur, 8/1865, p. 121. 
Les écoles primaires hollandaises occupent peut-être aujourd'hui le premier rang parmi celles de l'Europe. Il sera donc intéressant d'entendre un homme instruit et qui connaît bien ces écoles nous entretenir de la marche qui y est suivie. Son intention n'est aucunement de prescrire une marche pareille aux écoles du Canton de Vaud, mais de faire connaître ce qui peut se faire et ce qui se fait ailleurs, afin qu'on suive ce qui parâ̂tra de bon exemple ${ }^{58}$.

Enfin, un troisième argument relève d'une certaine déviance dans la copie. On retrouve cette rhétorique chez Ferdinand Buisson qui, de retour à Neuchâtel en 1916, confesse lors d'une conférence s'être inspiré de l'école suisse "non pas par voie de copie servile, mais par l'élan des mêmes forces de liberté et de raison ${ }^{59}$ ". Ainsi, le problème particulier de l'emprunt réside dans la difficulté d'assumer sa provenance et son transfert. On le remarque plus particulièrement dans le cas helvétique, où la proximité avec la France pour la Suisse romande et de l'Allemagne pour la Suisse alémanique n'est pas sans poser problème dans l'usage des méthodes, surtout lorsqu'il s'agit de valoriser les productions locales ou nationales. Au moment d'envoyer des ouvrages à l'exposition de Vienne en 1873 , le directeur du bureau suisse de la statistique, Johann Jacob Kummer, communique dans une circulaire que "nous aurions mauvaise façon à nous présenter à Vienne avec des ouvrages publiés en France, tout comme la Suisse allemande avec des manuels venus de l'Allemagne. Il y a plus: le nombre des ouvrages de provenance française étant très considérable, on pourrait croire en Allemagne que Paris forme notre jeunesse ${ }^{60}$ ".

Ce souci de se démarquer de l'habitus du voisin dans le processus de transfert ne doit cependant pas nous détourner de l'idée d'une standardisation silencieuse des savoirs et des pratiques scolaires. Ainsi que nous avons tenté de le montrer, des disciplines comme l'instruction civique, la morale, la gymnastique ou le chant scolaires ou des pratiques comme les colonies de vacances se diffusent grâce à l'action des médiateurs-connecteurs qui se chargent ensuite de les réinterpréter au gré de contingences locales. Au demeurant, il pourrait être fort utile de consacrer une étude d'envergure à la construction transnationale des disciplines scolaires en Europe et dans le monde, tant leur élaboration

58. Journal d'éducation, 1829, p. 49.

59. Ferdinand Buisson, Souvenirs (1866-1916), op. cit., p. 12.

60. Alexandre Daguet, « Troisième Bulletin de l'Exposition scolaire de Vienne », L'Éducateur, 2/1873, p. 32. 
semble suivre des logiques similaires de circulations et de retraductions nationales ou régionales. Rappelons brièvement que l'introduction des travaux manuels dans les écoles primaires européennes se pense collectivement et par jeu de domino gagne l'ensemble des pays occidentaux. En 1866, la Finlande consacre le travail manuel comme branche obligatoire dans les programmes scolaires. Puis suivent les autres pays scandinaves, la Hollande et l'Allemagne où est fondée une Société pour l'encouragement de l'industrie domestique à Berlin en 1876. De l'Allemagne, le mouvement entre en Suisse par Bâle où quelques pionniers, emmenés par l'instituteur Samuel Rudin, fondent en 1882 le premier atelier de travaux manuels destiné à des garçons. Les expositions universelles et plus particulièrement celles de Vienne (1873) et de Paris (1889), avec leurs innombrables stands consacrés à l'enseignement industriel, assurent une diffusion à très grande échelle. C'est le cas en France qui à son tour institutionnalise le travail manuel dans les écoles primaires du pays, qui devient obligatoire par la loi du 28 mai 1882 et jouera un rôle important dans les colonies ${ }^{61}$.

61. Sur le développement des travaux manuels en France, voir Renaud D'Enfert, « L'introduction du travail manuel dans les écoles primaires de garçons, 1880-1900 », Histoire de l'éducation, n 113, janvier 2007, p. 31-67. 

CONCLUSION 



\title{
Remettre la figure de l'étranger au centre du débat
}

\author{
"Les idées font de curieux voyages et on les retrouve \\ souvent bien loin de leur point de départ" \\ Jules Paroz, L'Éducateur, 1870, p. 152
}

En dressant ce panorama des circulations de savoirs scolaires entre la Suisse (romande) et la France, nous avons cherché à montrer de quelle manière ces deux espaces se sont nourris d'appropriations réciproques. Étudier certaines références helvétiques de l'école républicaine française révèle par ailleurs une série de médiations et de retraductions locales, ainsi qu'une multitude d'entreprises collectives rendues possibles grâce à la mise en place de réseaux qui ont favorisé l'importation massive de méthodes et de pratiques pédagogiques élaborées à l'international. Les sciences de l'éducation, dont les acteurs rencontrés dans cet ouvrage constituent des pionniers, sont donc pourvoyeuses de transferts culturels. Malgré des résistances de façade, dues essentiellement à l'émergence des rivalités étatiques et à un certain attachement à la tradition, il n'est plus possible de douter du caractère hybride de nos systèmes pédagogiques.

Cela dit, comment concilier l'histoire reformulée de cette matrice pédagogique commune composée de bigarrures multiples avec la structure compartimentée sous lesquelles nos systèmes scolaires sont traditionnellement décrits depuis le second $\mathrm{XIX}^{\mathrm{e}}$ siècle? Dès 1874 , la constitution fédérale helvétique mentionne dans son article 27 que " les Cantons pourvoient à l'instruction primaire » alors qu'en France, si l'instruction publique est gérée par un ministère dès 1828 , elle ne deviendra graduellement une affaire d'État qu'à la fin du XIX ${ }^{\mathrm{e}}$ siècle pour se muer en éducation nationale sous le gouvernement Herriot en 1932. Voilà pourquoi il est intéressant de réfléchir au poids que ces divisions cantonale et nationale ont indirectement joué sur la manière 
de considérer et d'écrire l'histoire de l'éducation de ces deux pays. Une étude récente consacrée à l'analyse des thèses françaises et romandes des vingt dernières années met en lumière que les phénomènes d'internationalisation et de circulations de savoirs demeurent le parent pauvre de la recherche en histoire de l'éducation française, puisque seuls $3 \%$ des investigations sont consacrées à des thématiques transnationales (sur quelque cinq cents recherches doctorales) ${ }^{1}$. En privilégiant l'étude basée sur le cadre national, n'a-t-on pas délaissé d'autres formes d'interrelations et de temporalités qui ont fini par se distendre et se rompre avec le temps? Il faut dire que le chercheur qui s'attache à l'étude des transferts pédagogiques se heurte aux normes de classement mises en œuvre par l'administration, faites pour conforter les aspects de la mémoire nationale ou cantonale bien davantage que l'analyse des constructions communes et des emprunts ${ }^{2}$. Pourtant les innovations circulent, transitent, se mêlent et se déclinent à tel point que leurs origines mêmes s'égarent et renforcent par là même l'hypothèse d'une standardisation silencieuse des savoirs scolaires.

\section{Le modèle: un concept clos?}

Aussi, au regard de ce constat est-il intéressant d'interroger la portée du concept de modèle - qu'il soit national, cantonal, provincial ou régional - dans le sens où cette représentation dévalue des réalités et des dynamiques d'échanges qui dépassent largement la sphère nationale ou cantonale. Le concept de modèle tend à figer les circulations et laisse à penser que l'espace considéré comme tel se retrouve en quelque sorte immunisé de toute contamination. Cette posture déterministe empêche d'appréhender les hybridations pédagogiques et culturelles et ne rend pas pleinement compte de la réalité des échanges. De plus, considérer un espace en tant que modèle tend à déprécier son historicité, vraisemblablement constituée d'emprunts pluriels, pour se focaliser sur la situation qui correspond au moment du nettoyage des emprunts et à leur acculturation, ce qui tend à occulter les racines étrangères de son système évolutif.

1. Rita Hofstetter, Alexandre Fontaine, Solenn Huitric, Emmanuelle Picard, « Mapping the discipline History of Education », Paedagogica Historica, 50 (6), 2014, p. 871-880. Voir également le recensement des thèses françaises (http://rhe.ish-lyon.cnrs.fr/?q=carto-theses-list) ainsi que http://kartografy.wordpress.com

2. Voir Gérard Noiriel, « Transferts culturels: l'exemple franco-allemand. Entretien avec Michel Espagne », Genèses, 8/1992, p. 146. 
Nous assistons depuis quelques années en Europe à l'émergence d'une littérature consacrée aux modèles nationaux qui auraient su tirer leur épingle du marasme actuel ${ }^{3}$. On peut s'en réjouir. Toutefois, la tentation de sauver la peau du continent par l'exaltation de l'un et la péjoration de l'autre contribue à enfouir encore plus profondément l'idée forte d'une construction collective de l'Europe. Car dans ces écrits, rares sont les auteurs, à l'instar de Patrick Aebischer, qui relèvent le rôle central de l'altérité dans la lente élaboration de la nation érigée en modèle:

L'histoire du succès économique de la Suisse rappelle constamment la dépendance de ce petit pays à l'égard de l'Autre: les clients de tous les continents, les travailleurs étrangers qui ont de tous temps apporté leurs compétences à la machine économique suisse, les chercheurs venus exercer ici leur esprit d'initiative. La tradition d'accueil de la Suisse s'inscrit dans la même logique: la Suisse n'est forte, sur le plan économique ou politique, que si elle vit en symbiose avec le monde ${ }^{4}$.

Quitte à provoquer, nous pourrions affirmer qu'il n'existe pas de modèles puisque les systèmes dits nationaux ne sont de facto que le résultat de déclinaisons de motifs conçus, pensés collectivement et remaniés selon des contingences locales. Ainsi, il y a de tout dans l'un. Au milieu des années 1990, Sandrine Kott et Thierry Nadau pointaient déjà ce paradoxe en affirmant que l'on est " conduit à mettre en cause la notion même de modèle, non par principe mais en montrant comment ces modèles se sont historiquement constitués ${ }^{5}$ ». Ainsi, une patiente reformulation des circulations et des emprunts à l'échelle globale reste à écrire, en suivant les retraductions opérées par

3. Magnus Falkehed, Le modèle suédois. Santé, services publics, environnement: ce qui attend les Français, Paris, Payot, 2005; Mogens Lykketoft, Le modèle danois. Chronique d'une politique réussie, Paris, Esprit ouvert, 2006; François Garçon, Le modèle suisse. Pourquoi ils s'en sortent beaucoup mieux que les autres, Paris, Perrin, 2008; Paul Robert, La Finlande: Un modèle éducatif pour la France? Les secrets de la réussite, Paris, ESF éditeurs, 2010; Damiano Matasci, « Jalons pour une histoire de la circulation internationale du "modèle" scolaire suisse à la fin du XIXe siècle », in Y. Decorzant, A. Heiniger, S. Reubi, A. Vernat (éds.), Le Made in Switzerland: mythes, fonctions et réalités, Bâle, Schwabe, 2012, p. 177-190; Alain Bournazel, Le défi finlandais: Pour un modèle éducatif, économique et culturel, Paris, Sefi-Arnaud Franel, 2012; Guillaume Duval, Made in Germany: Le modèle allemand au-delà des mythes, Paris, Seuil, 2013; R. James Breiding, Swiss made: Tout ce que révèle le succès du modèle suisse, Genève, Éditions Slatkine, 2014; Christophe Blot, Sabine Lebayon, Odile Chagny, Faut-il suivre le modèle allemand?, Paris, Documentation française, 2015.

4. Patrick Aebischer, «Préface » de R. James Breiding, Swiss made : Tout ce que révèle le succès du modèle suisse, op. cit., p. 8-9.

5. Sandrine Kott, Thierry Nadau, « Pour une pratique de I'histoire sociale comparative. La France et l'Allemagne contemporaine », Genèses, 17/1994, p. 107. 
les passeurs, en retraçant les trajectoires multiples des pratiques et des savoirs scolaires afin de rattacher des espaces bien plus connectés qu'il n'y semble ${ }^{6}$. Voilà pourquoi il est crucial de déconstruire les modèles scolaires nationaux contemporains afin d'en reformuler les filiations occultées et les multiples références étrangères qui les alimentent.

\section{Comparatisme et regard sur l'altérité}

L'acte comparatif favorise-t-il la rencontre et la connaissance de l'altérité ? Est-il besoin de le préciser, tenter de répondre à cette question n'implique nullement une critique frontale de l'éducation comparée. Il s'agit plutôt de s'interroger sur la manière dont Alexandre Daguet et ses contemporains ont éprouvé l'acte comparatif. Globalement, on peut affirmer que les pédagogues de la seconde moitié du XIX ${ }^{\mathrm{e}}$ siècle considéraient l'étude comparative comme utile et instructive. Daguet voyait dans l'observation des moyens d'instruction des occasions " propres à nous éclairer sur nos écarts et à nous fournir de nouvelles sources d'amélioration et de perfectionnement ${ }^{7}$ ". D'un autre côté, il faut également témoigner d'une fonction plus ambiguë, caractérisée par la nécessité de s'approprier les innovations des voisins pour assurer la performance de son propre système. Lorsque le comité central de la Société des instituteurs de la Suisse romande entre en relation avec le Conseil fédéral afin de recevoir un subside pour aller étudier l'Exposition universelle de Paris en 1867, le prédéfini concurrentiel de la comparaison est manifeste:

Mais, excitées par l'exemple des grands pédagogues de la Suisse et instruites par leurs propres expériences, les autres nations ont marché, et il est à prévoir que notre pays ne pourra conserver le rang élevé qu'il a conquis dans la pédagogie européenne, qu'en s'appropriant les conquêtes intellectuelles des autres peuples et leurs progrès dans l'art d'instruire et d'élever des hommes ${ }^{8}$.

6. Voir notamment Mathias Middell (éds.), Cultural Transfers, Encounters and Connections in the Global 18th Century, Leipzig, Leipziger Universitätsverlag, 2013; Eckhardt Fuchs et Benedikt Stuchtey (éds.), Across Cultural Borders: Historiography in Global Perspective, New York \& Oxford, Rowman \& Littlefield Publishers, 2013; Sanjay Subrahmanyam, Aux origines de I'histoire globale, Paris, Collège de France/Fayard, 2014; Serge Gruzinski, L'histoire, pour quoi faire?, Paris, Fayard, 2015.

7. Alexandre Daguet, « La Réforme scolaire dans les divers États de l'Europe », L'Éducateur, 4/1865, p. 50.

8. Lettre de la Société des instituteurs de la Suisse romande au Haut Conseil fédéral datée du 24 février 1867, L'Éducateur, 7/1867, p. 99. 
Par ailleurs, les historiens suisses de l'éducation ont mis en avant une conséquence inattendue des examens de recrues, imposés dans chacun des cantons dès les années 1870 afin de mesurer les acquis scolaires des confédérés. Au-delà des éléments positifs de cette expertise, les classements générés ont eu l'effet d'attiser les rivalités entre les cantons et de nourrir des rancœurs contre l'État fédéral ${ }^{9}$. Les pédagogues et les rédacteurs de revues, en convoquant l'Europe dans leurs publications respectives, ont-ils pour autant incité leur lectorat à davantage de compréhension envers l'altérité ? L'exemple de Ferdinand Buisson demeure à cet égard particulièrement significatif, lui qui a, plus que tout autre, hâté le mouvement de rénovation de l'école publique en France en instituant de gigantesques machines à comparer. On le retrouve à l'origine du musée pédagogique et surtout du fameux Catalogue noir, institué sur le modèle des catalogues du British Museum et qui recense dès 1886 les documents pédagogiques en vigueur sur le globe. Dès lors, c'est donc le monde qui se retrouve consigné dans les catalogues de la rue d'Ulm. Y a-t-il meilleure méthode pour rattraper son retard que de compiler, dans un relatif secret, les procédés et les innovations de ses concurrents?

La statistique comparative s'invite rapidement dans les pages de L'Éducateur et notamment au travers de grands tableaux comparatifs qui deviennent légion dans le domaine pédagogique. Ces tables s'instituent dans le sillage des travaux d'Émile Levasseur. Toutefois, on notera que c'est à l'économiste socialiste belge Émile de Laveleye (1822-1892) que l'on doit la première étude comparative d'envergure dévolue aux divers systèmes éducatifs en vigueur sur la planète ${ }^{10}$. À dire vrai, ces classements n'ont pas manqué de froisser les susceptibilités. Ainsi, chaque nation se mit à produire ses propres statistiques, afin de venger son honneur comme ce fut le cas dans la péninsule ibérique:

Nous empruntons au Magisterio Espanol, de Madrid, du novembre (1878), un tableau statistique de l'instruction publique en Europe, qui a été dressé par ordre du ministre de l'Intérieur (Fomente) qui est en même temps directeur de l'instruction publique. L'auteur de ce tableau est M. Valin, directeur d'une institution qui porte le nom du cardinal Cisneros. Le but spécial de cette statistique est de venger l'honneur de la péninsule

9. Werner Lustenberger, Les examens pédagogiques des recrues: une contribution à I'histoire de l'école en Suisse, Coire et Zürich, Rüegger, 1997 ; Véronique Czáka, Mathilde Freymond, Valérie Lussi Borer, « A Necropolis of Numbers : data production in Switzerland's decentralised education system », in Martin Lawn et Valérie Lussi Borer (éds), Governing Education Systems by Shaping Data, European Educational Research Journal, 12 (1), p. 99-112.

10. Émile de Laveleye, L'instruction du peuple, Paris, Hachette, 1872. 
de la note d'ignorance extrême que lui a infligée la fameuse carte Manier et que certaines feuilles américaines ont dernièrement fait valoir d'une manière pénible pour l'amour-propre castillan ${ }^{11}$.

Dans leur synthèse historique de l'éducation comparée, Antonio Novoa et Tali Yariv-Mashal distinguent quatre jalons, quatre cycles d'une quarantaine d'années qui ont modelé la discipline: "connaissance de l'autre ", " désir de paix et de coopération internationale ", " construction de l'autre à travers l'exportation de modèles » et " effort de mesurer l'autre " sont autant de constantes structurantes d'un " effort de nous comparer à l'autre, dans un jeu de miroirs qui construit une "pensée mondiale»». En résumé, les auteurs argumentent que "le recours à un regard sur l'autre nous permettrait de laisser de côté nos propres habitudes et croyances, en ouvrant ainsi des possibilités jusqu'alors inconnues ${ }^{12}$ ». L'idée que le comparatisme permette une épokhè, une suspension phénoménologique définie par Henri-Irénée Marrou comme le moyen privilégié d'aller à la rencontre de l'autre en s'oubliant soi-même, s'avère séduisante ${ }^{13}$. Mais, au demeurant, n'est-ce pas là privilégier une perception biaisée, voire fantasmée de la démarche comparatiste? Est-ce que l'acte de comparer s'avère réellement porteur d'altruisme, ou inversement ne se conditionne-t-il pas dans un acte syncrétique? Avec Michel Espagne, nous pensons plutôt que: "L'histoire du comparatisme depuis le début du $\mathrm{XIX}^{\mathrm{e}}$ siècle montre qu'il n'a jamais été question de se nier grâce au principe de comparaison, mais au contraire de défendre indirectement un point de vue national ${ }^{14}$. " Aussi, lorsque l'on s'intéresse aux relations pédagogiques dans l'espace francophone entre 1850 et 1900, on remarque combien la comparaison internationale, stimulée principalement par les expositions universelles, a généré l'angoisse persistante de se retrouver dans une logique de concurrence permanente avec ses voisins, au risque d'être fustigé au travers de tables comparatives au fondement statistique d'ailleurs fort discutable. Aujourd'hui, cette logique de l'émulation s'est établie dans le monde de l'entreprise comme dans

11. Alexandre Daguet, « Statistique de I'instruction publique en Europe », L'Éducateur, 24/1878, p. 377.

12. Antonio Novoa, Tali Yariv-Mashal, « Le comparatisme en éducation : mode de gouvernance ou enquête historique ? », in Pierre Laderrière et Francine Vaniscotte, L'éducation comparée : un outil pour l'Europe, Paris, L'Harmattan, 2003, p. 59.

13. Henri-Irénée Marrou, De la connaissance historique, Paris, Le Seuil, 1954, p. 84 sq.

14. Michel Espagne, « Sur les limites du comparatisme en histoire culturelle », Genèses, 17/1994, p. 113. 
celui de l'école. Rankings et benchmarking se sont imposés, vraisemblablement dans le sillage du mouvement comparatiste qui se structure lors du XIX ${ }^{\mathrm{e}}$ siècle $^{15}$. A-t-on de ce fait pris le chemin tant redouté d'un Daguet, qui a désigné l'utilitarisme et son soubassement mercantiliste comme la cible d'un combat permanent légitimé par la hantise d'une emprise positive et financière sur le monde éducatif et culturel:

Quand dans un pays la haute culture littéraire et scientifique vient à manquer, on ne tarde pas à en éprouver les effets fâcheux pour l'état intellectuel, moral et même matériel du pays où les lumières vont diminuant et où le demi-savoir prend la place de la vraie instruction, où le niveau des intelligences baisse, où les compilateurs suppléent aux écrivains, où la dégradation du goût ne permet pas de distinguer les œuvres dignes d'encouragement, des productions médiocres ou pitoyables, où un sordide et inintelligent mercantilisme a toute chance de se faire passer pour l'expression du bon sens et d'un calcul habile, quand il est au contraire attesté par l'histoire qu'un utilitarisme excessif abaisse matériellement, intellectuellement et moralement les nations qu'il cherche à faire prospérer ${ }^{16}$.

Voici dans tous les cas de nouveaux paris pour les sciences de l'éducation ${ }^{17}$. Celui de ne faire l'économie d'une analyse des références étrangères d'espaces que l'historien a l'habitude d'appréhender dans des cadres restrictifs. Celui de ne pas se satisfaire d'une réalité compartimentée mais plutôt de chercher à éclairer les inclusions et retracer les multiples resémantisations des idées et des savoirs scolaires. Enfin, celui de tendre l'oreille vers le vieux moine pédagogue de Fribourg et de résister comme lui à la tentation du cloisonnage culturel:

Hommes de prévention et de scrupule, ne chiffrez plus désormais: vos chiffres sont arabes et mahométans. Gardez-vous bien de lire et d'écrire, car on dit que vos caractères viennent de l'idolâtre Phénicie. Ne touchez, ni or, ni argent, de peur que des mains païennes ne les aient tirés des entrées de la terre. Défendez-vous même de respirer l'air; car assurément, avant d'arriver à vous, il est passé sur des pagodes et des mosquées ${ }^{18}$.

15. Voir Jean-Yves Mollier, Jean-François Sirinelli, François Vallotton (éds.), Culture de masse et culture médiatique en Europe et dans les Amériques (1860-1940), Paris, PUF, 2006.

16. Alexandre Daguet, « Un établissement d'instruction supérieure est-il un objet de luxe pour un pays démocratique ? », L'Éducateur, 12/1876, p. 181.

17. Voir Rita Hofstetter et Bernard Schneuwly (éds), Le pari des sciences de l'éducation, Bruxelles, De Boeck, 2001; Michèle Hofmann, « History of education in Switzerland: Historic development and current challenges », Encounters, Encuentros, Rencontres on Education, 15/2014, p. 223-237. II va de soi que les départements qui s'occupent d'éducation interculturelle sont familiarisés avec ces questions.

18. Libelle de Girard contre les ultramontains fribourgeois, cité dans Gabriel Compayré, Le Père Girard et l'éducation par la langue maternelle, Paris, Paul Delaplane, 1906, p. 72-73. 



\section{ABRÉVIATIONS}

AEF Archives de l'État de Fribourg

AEG Archives de l'État de Genève

AEN Archives de l'État de Neuchâtel

AF Annales fribourgeoises

AIT Association internationale des travailleurs (I ${ }^{\text {ère }}$ Internationale)

AN Archives nationales de France

BNF Bibliothèque nationale de France

BPUG Bibliothèque publique et universitaire de Genève

BPUN Bibliothèque publique et universitaire de Neuchâtel

BSFC Bibliothèque de la Sorbonne - Fonds Cousin

DHS Dictionnaire historique de la Suisse

DP Dictionnaire de pédagogie et d'instruction

EF Étrennes fribourgeoises

MSVC Manuscrits de Victor Cousin

NAF Nouvelles acquisitions françaises

NDP Nouveau dictionnaire de pédagogie et d'instruction (1911)

NEF Nouvelles étrennes fribourgeoises

SIR Société des instituteurs de la Suisse romande 

ANNEXES 



\section{Annexe I \\ Repères biographiques \\ d'Alexandre Daguet (1816-1894)}

\section{6-1843 : formation}

1816 Naissance à Fribourg.

1823 École primaire à Fribourg.

1824 Mort de son père Jacques Nicolas Daguet, huissier et vitrier.

1827 Externe au collège des jésuites de Fribourg jusqu'en 1835.

1834 Fréquente le Père Girard, de retour de Lucerne.

1836 Études de droit chez le professeur libéral Jean-Marcellin Bussard.

1837 Maître d'histoire à l'école moyenne centrale de Fribourg. Co-fondateur de la Société d'histoire de la Suisse Romande.

1838 Fonde la Société d'études des bords de la Saane, future Société d'études.

1840 Co-fondateur de la Société cantonale d'histoire et de la Société générale d'histoire de la Suisse. Membre du congrès historique de Besançon, y rencontre Marc-Antoine Jullien de Paris.

1841 Fonde L'Émulation (1841-1846 et 1852-1856).

1842 Membre du congrès historique de Strasbourg.

1843 Directeur de l'école normale du Jura bernois à Porrentruy.

1846 Décline l'appel du gouvernement vaudois à la chaire d'histoire de l'académie.

1847 Co-fondateur de la Société jurassienne d'Émulation à Porrentruy. 


\section{8-1866: retour à Fribourg}

1848 Prend part à la réorganisation des études à Fribourg, au côté du Père Girard. Nommé directeur de l'école cantonale, de l'école normale et recteur des cours académiques à Fribourg, vice-président de la commission permanente des études pour le canton, enseigne l'histoire de la philosophie aux cours académiques, l'histoire générale et nationale, la littérature française au gymnase et la pédagogie à l'internat.

1849 Élu au Grand Conseil fribourgeois jusqu'en 1857.

1850 Appel pour l'érection d'un monument au Père Girard, inauguré en 1860.

1851 Histoire de la Nation suisse en 2 volumes.

1854 Mort de Françoise Daguet, mère d'Alexandre. Élu associé de l'académie royale de Turin.

1856 Délégué au congrès historique d'Annecy.

1857 Les conservateurs reviennent au pouvoir à Fribourg. Le conseiller d'État genevois Tourle s'emploie à faire nommer Daguet à l'école polytechnique de Zurich.

1858 Directeur de l'école secondaire des jeunes filles jusqu'en 1866.

1861 Histoire de la Suisse, depuis les temps anciens jusqu'à nos jours. Élu chevalier de l'ordre de Saint-Maurice et Lazare par le roi Victor-Emmanuel, pour son Histoire de la Confédération suisse.

1863 Membre de la Société d'histoire et d'archéologie de Genève.

1864 Refuse la direction des écoles primaires et industrielles de la Chaux-de-Fonds.

Premier président de la Société des instituteurs romands (SIR).

1865 Dirige L'Éducateur, organe de la SIR, de 1865 à 1889.

Membre honoraire de l'assemblée historique de Palerme, sur la proposition du duc Lanza di Brolo. 


\section{6-1896: le pédagogue à Neuchâtel}

1866 Préside le premier congrès de la SIR à Fribourg.

Professeur d'histoire nationale à l'académie de Neuchâtel. Nommé en même temps que Ferdinand Buisson, Cyprien Ayer et Édouard Desor. Devient Docteur honoris causa de l'université de Berne.

1868 Membre de la commission des Quinze, nommée par l'assemblée de Genève, pour s'occuper du perfectionnement des hautes études dans la Suisse romande. Associé étranger de la Société pour l'enseignement élémentaire de Paris.

1870 Adhère, avec son beau-père l'avocat Alexandre Favrot, à l'Église vieille-catholique.

1871 Manuel d'éducation ou de pédagogie.

1872 Devient franc-maçon (Loge La Bonne Harmonie à Neuchâtel).

1875 Décline la direction d'une école à Bruxelles.

1878 Élu par le conseil fédéral membre suppléant du jury de l'Exposition de Paris pour le groupe II d'enseignement et gratifié de la médaille frappée à cette occasion. Eugène Rambert lui est préféré pour rédiger le compte-rendu de l'Exposition universelle.

1879 Fait officier d'académie de la République française sous le ministre Bardoux.

Pense pour un temps s'établir à Paris, alors que Ferdinand Buisson l'appelle à l'y rejoindre pour publier une " œuvre internationale d'éducation ». Son ami Amiel l'en dissuade.

Membre du comité central du congrès international de l'enseignement à Bruxelles.

1885 Obtient son entrée en sommeil de la loge maçonnique La Bonne Harmonie.

1889 Éviction de Daguet de L'Éducateur.

1893 Part en retraite et s'installe à Couvet.

1894 Décès d'Alexandre Daguet à Couvet chez sa fille Élisa.

1896 Le Père Girard et son temps. Histoire de la vie, des doctrines et des travaux de l'éducateur suisse publié à titre posthume chez Fischbacher à Paris grâce à l'appui de Ferdinand Buisson et Jules Steeg. 



\section{Annexe II}

\section{Autobiographie inédite d'Alexandre Daguet}

L'auteur de ces lignes Jean-Alexandre Daguet est né à Fribourg le 12 mars 1816, d'une famille patricienne mais devenue pauvre et dont la situation présentait à la fin du régime de la Restauration cette particularité curieuse que tandis que le père d'Alexandre comme son grandpère paternel exerçait les fonctions subalternes d'huissiers d'État, l'un de ses oncles paternels signait Pierre de Daguet et siégeait au Grand Conseil aristocratique qui tombait en 1830. Privé de son père à l'âge de sept ans et sans fortune, Alexandre Daguet dut au système de gratuité qui régnait au collège et lycée de Fribourg l'avantage de pouvoir faire toutes ses études. C'était les jésuites qui dirigeaient le collège. Mais de bonne heure l'amour de la patrie, de l'humanité et du Dieu d'amour que lui inculquèrent successivement un jésuite exceptionnel le Père Lückmeyer - originaire de la principauté de Lippe-Detmold - et le Père Girard rentré à Fribourg en 1834, après 10 ans d'exil volontaire, le préservèrent des écarts de l'intolérance. L'étude de nos grands écrivains nationaux et les leçons du philosophe et publiciste Troxler achevèrent de donner à son esprit une direction nationale, humanitaire et vraiment religieuse. À l'âge de 21 ans (1837) Daguet était entré dans la vie pratique comme professeur de langues et d'histoire à l'école moyenne centrale (cantonale). Il enseigna 7 ans dans cette école où avec le feu sacré mais aussi avec l'inexpérience de la jeunesse il chercha à enflammer les jeunes gens pour les idées qu'il croyait salutaire au pays; il fonda une société d'études, publia une revue littéraire et d'utilité publique (L'Émulation) et d'autres écrits, agissait au congrès scientifique de Strasbourg où il vengeait l'honneur suisse d'un oubli offensant et d'attaques déloyales, comme on peut le voir dans les actes de ce 
congrès (1842 publié en 2 volumes chez Silbermann à Strasbourg). Il correspondit avec le Nouvelliste, l'Helvétie, rédigea une adresse des libéraux à l'Avoyer Neuhaus, et s'attira la haine du parti ultramontain au point qu'il jugea à propos d'accepter les fonctions de directeur de l'école normale du Jura bernois qui lui avaient été offertes par Neuhaus sur la recommandation du Père Girard (1843).

De 1843 à 1848, Daguet dirigea l'école normale mixte en religion du Jura, dans le sens des idées du Père Girard, chercha à répandre le patriotisme suisse en opposition aux tendances séparatistes, rédigea l'Helvétie en 1847, écrit dans la Revue suisse sur l'histoire littéraire et se voyait en 1846 appelé par Druey et le Conseil d'État de Vaud à la Chaire d'histoire à l'académie de Lausanne, qu'il commit la faute de refuser par suite de circonstances de famille, pour accepter en 1848 la tâche difficile de travailler à la réorganisation de l'Instruction publique à tous les degrés dans le canton de Fribourg comme recteur de l'école cantonale et vice-président du conseil de l'instruction publique. De 1848 à 1857, c'est-à-dire au milieu des éclairs et des tonnerres de l'insurrection, Daguet est à la brèche et dirige l'école cantonale (progymnase, gymnase, école normale, cours académiques), 24 professeurs et 250 élèves. Mais entrainé par la politique militante, il commet une seconde faute, celle de se laisser porter au Grand Conseil par la société patriotique dont il est président (1849). Les insurrections se multipliant et le sang ayant coulé, en 1851, le professeur député fait une motion de conciliation qui n'avait d'autre résultat que de le désigner à la vengeance de la garde civique qui l'appelle transfuge et veut le tuer à la sortie du Grand Conseil et à celle du pouvoir exécutif qui, sous un prétexte habile, mais déloyal lui retranche net la moitié de son traitement (1852).

L'année suivante, Daguet toujours recteur de l'école cantonale et habitant le collège avec sa famille est fait prisonnier par les paysans insurgés (22 avril 1853). J'eus l'honneur d'être arrêté par le chef même des insurgés, le fameux Carrard qui me dit poliment du reste: "N'ayez pas peur Monsieur, dans deux heures tout sera fini ", sans douter le malheureux que c'était lui qui devait deux heures après tomber sous les balles devant la porte du collège en faisant une sortie avec ses gens. Je restais à la tête de l'école cantonale jusqu'à sa chute en 1857 et au milieu des agitations continuelles qui avaient leur contre-coup (sic) parmi la jeunesse et le corps enseignant surtout. J'eus le bonheur de conserver assez de liberté d'esprit pour composer une histoire de la Suisse qui en est aujourd'hui à sa $6^{\mathrm{e}}$ édition et qui a été traduite en 
allemand et en italien; et plusieurs autres ouvrages littéraires et historiques. Bonheur plus grand encore! J'ai pu coopérer activement à l'érection de la statue du Père Girard dont j'ai composé les inscriptions et à l'inauguration de laquelle j'ai prononcé un discours qui a paru dans le Confédéré. C'est même sur mon initiation que le jour de sa mort (6 mars 1850) le Grand Conseil de Fribourg vota que ce grand homme avait bien mérité du pays et que son portrait serait placé dans toutes les écoles du canton.

Au milieu des tribulations de cette époque j'eus la consolation d'être agrégé pour mes travaux à plusieurs académies et sociétés savantes de Genève, de Savoie, Turin, Palerme. Les membres du congrès historiques d'Annecy parmi lesquels se trouvaient 15 Suisses romands me chargèrent de complimenter en leur nom et en leur présence l'évêque Dupanloup alors disgracié à Rome et qui venait d'être nommé membre de l'académie française (août 1856). Il me serait impossible d'accepter aujourd'hui une pareille mission après ce qui s'est passé au Concile du Vatican. La société d'histoire de mon canton me fit président deux fois de suite. La société d'utilité publique et la société économique m’appelèrent également à leur tête. La réaction de 1856-7 m'avait éliminé comme recteur et même comme professeur. Je fus déclaré impossible par l'évêque et dus me suffire quelques mois par un travail de plume. C'est alors que j'écrivis l'ouvrage de circonstance intitulé: De l'enthousiasme de la Suisse pour la cause de Neuchâtel qui n'avait que le mérite d'être une édition fort augmentée et très adoucie d'un écrit allemand de courte haleine et très violent sur l'histoire politique de ce canton émancipé de la Prusse. Le conseil communal de Fribourg ayant décidé de rétablir l'école supérieure des filles, supprimée par le gouvernement cantonal, me plaça à la tête de cet Établissement auquel le gouvernement rendu ensuite son caractère primitif. Je dirigeai cette école de 1848 à 1866, continuant mes travaux qui, en 1861, me firent donner la Croix de l'ordre de Saint-Maurice et Lazare par Victor-Emmanuel sur la proposition de l'historien et ministre d'État Cibrario. Je sais qu'une distinction de ce genre ne donne aucun mérite, mais l'ayant reçue à une époque où le régime ultramontain me tenait à l'écart et me déclarait impossible pour la seconde fois, je me fis un plaisir de braver l'insolence de ceux qui disaient que je n'oserais pas la porter.

En 1865, je pris part au congrès social de Berne où mon discours sur la morale indépendante excita un orage parmi les hôtes français du congrès qui me trouvaient trop évangélique. L'année suivante, je présidais un congrès pédagogique de 600 instituteurs de la Suisse 
romande dans la salle du Grand Conseil; je devenais rédacteur en Chef de L'Éducateur qui est entré dans sa huitième année et je recevais de l'université de Berne le titre de docteur honoraire pour mon histoire de la Suisse (15 novembre 1866). De la fin de cette année date mon appel à l'académie de Neuchâtel où j'enseigne depuis 6 ans. En 1867 je fus envoyé à l'Exposition universelle de Paris comme président de la délégation suisse et je signais la publication des rapports rédigés par mes collègues de l'enseignement primaire et secondaire qui a paru en brochure. Depuis mon séjour à Neuchâtel j'ai publié entre autres plusieurs abrégés d'histoire pour les écoles, un Manuel d'éducation, une vie de Troxler, plusieurs articles dans le Musée neuchâtelois et je continue un grand travail intitulé "Grégoire Girard et son temps » que j'espère livrer au public ainsi que d'autres ouvrages si Dieu me prête vie.

C'est là une esquisse très rapide quoique trop longue peut-être pour mes lecteurs, de la carrière que j'ai parcourue pendant le demi-siècle et plus que j'ai vécu. Je puis me rendre le témoignage que j'ai toujours aimé Dieu, l'humanité, la Patrie, le Peuple d'un amour ardent, sincère et profond; que j'ai toujours soutenu les petits, les malheureux, les opprimés contre l'injustice, que je n'ai jamais reculé quand j'étais sûr de la bonté de ma cause et que j'ai fait les plus grands sacrifices à mes convictions. Mais j'ai eu l'imagination trop vive, trop ardente, trop impressionnable et j'ai payé mon large tribut aux erreurs et aux faiblesses de l'humanité, ce qui m'a rendu indulgent pour toutes celles des autres qui ne tentent pas la méchanceté, la vileté (sic) et la bassesse; car je crois à la conscience, à la responsabilité humaine, à la fraternité universelle devant le Père Céleste ${ }^{1}$.

1. Je remercie M. Daniel Hess, le secrétaire de la Loge La Bonne Harmonie de Neuchâtel, qui a autorisé la publication de cette biographie rédigée par Daguet pour son entrée dans la Loge, tirée des Archives de la BPUN, Fonds de la Loge, La Bonne Harmonie, Correspondances FF. Décédés M. Daguet Doc II E Plan I. 


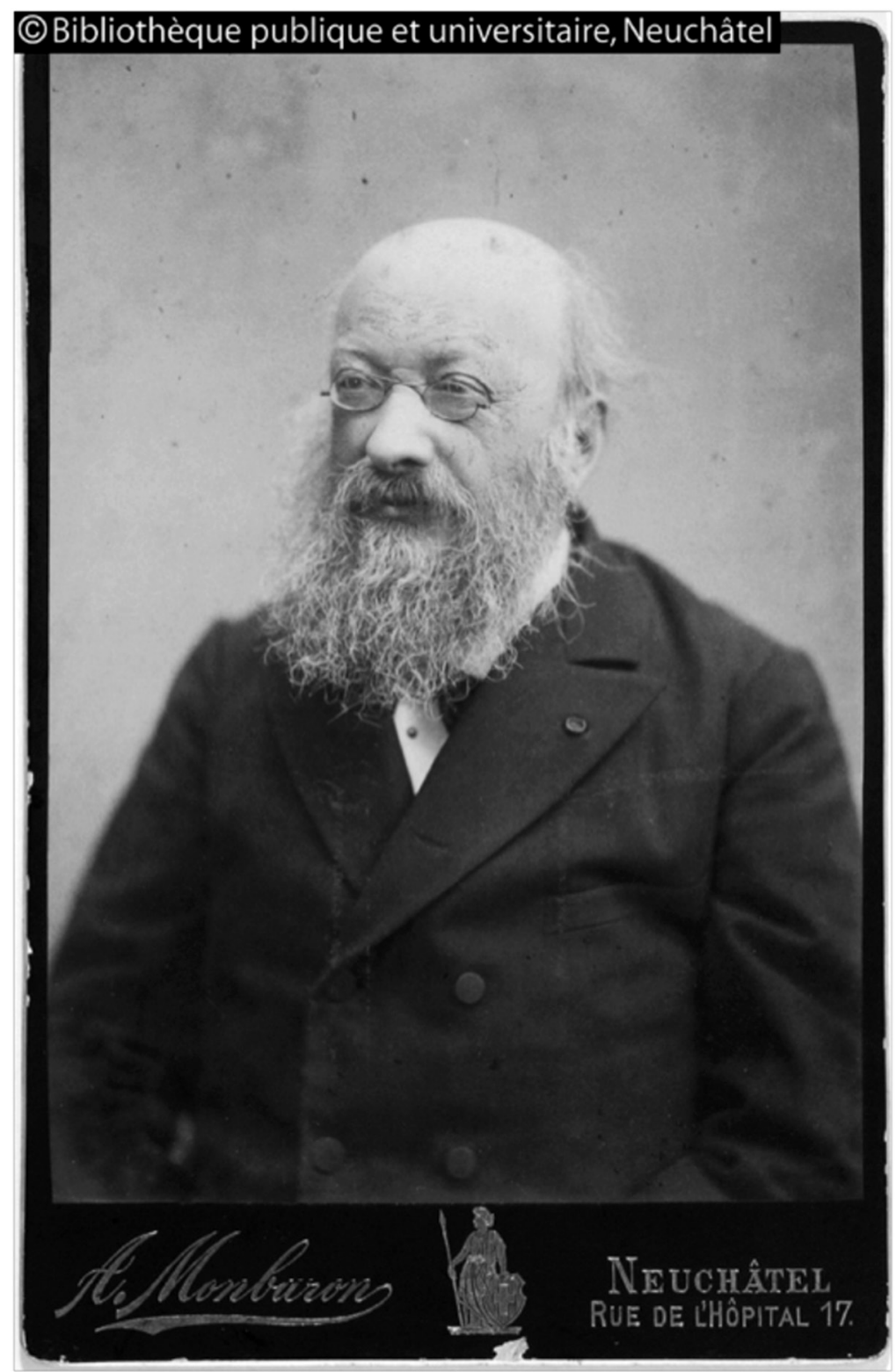

Alexandre Daguet (1816-1894), BPU Neuchâtel. 



\section{Annexe III}

\section{Chronologie de la pédagogie franco-romande}

\section{Français-e-s en Suisse (romande) \\ Fin du $X \mathrm{VII}{ }^{e}$ siècle \\ Plus de 60000 huguenots se réfugient \\ en Suisse, notamment à Genève.}

1792

La France tente d'envahir Genève.
Suisses (romand-e-s) en France

1790

Fondation du club helvétique à Paris.

1792

Massacre des gardes suisses aux Tuileries (10 août).

\section{8}

Les troupes françaises envahissent la Suisse au début de l'année.

Naissance de la République helvétique une et indivisible sur le modèle de la constitution française (28 mars).

Albert Stapfer nommé ministre des sciences et des arts.

\section{9}

Madame Guizot, rousseauiste, emmène son fils François à Genève, où il fait son éducation jusqu'en 1805 .

\section{2}

Napoléon Bonaparte impose l'Acte de Médiation. La Suisse devient un protectorat français.

\section{5}

Girard découvre la méthode mutuelle grâce à l'ouvrage de Lasteyrie Nouveau système d'éducation pour les écoles primaires.
1815

Clias organise les écoles de gymnastique de la ville de Paris. 


\begin{tabular}{ll} 
Français-e-s en Suisse (romande) & Suisses (romand-e-s) en France \\
\hline $\begin{array}{l}1816 \\
\text { Jullien de Paris et Casimir Perier visitent } \\
\text { les écoles du Père Girard à Fribourg. }\end{array}$ & \\
$\begin{array}{ll}1817 \\
\text { Charles Louis Napoléon Bonaparte se } \\
\text { réfugie au château d'Arenenberg en } \\
\text { Thurgovie avec sa mère. }\end{array}$ & $\begin{array}{l}1817 \\
\text { Girard reçu membre honoraire de la } \\
\text { Société pour l'enseignement élémentaire. }\end{array}$ \\
& $\begin{array}{l}1823 \\
\text { Louis Michel applique le système de Girard } \\
\text { dans son institution de Lyon. }\end{array}$ \\
$\begin{array}{ll}1830 & 1830 \\
\text { A Thoune, le général Dufour se charge de } \\
\text { l'éducation militaire du futur Napoléon III, } \\
\text { jusqu'en 1836. }\end{array}$ & $\begin{array}{l}\text { Juste Olivier complète sa formation } \\
\text { pait la connaissance d'Hugo, de Vigny, de } \\
\text { Lamartine et se lie avec Sainte-Beuve qu'il }\end{array}$ \\
& $\begin{array}{l}\text { attire à Lausanne. } \\
\end{array}$
\end{tabular}

\section{4}

Max Buchon étudie au collège Saint-

Michel de Fribourg, jusqu'en 1837.

\section{7}

Sainte-Beuve commence le 6 novembre son cours sur Port-Royal à l'académie de Lausanne, qu'il conclut le 25 mai 1838. En septembre, Victor Cousin visite l'école normale de Lausanne, puis les écoles du Père Girard à Fribourg.

1838

Affaire Louis-Napoléon Bonaparte exilé en Suisse avec sa mère dès 1817.

\section{0}

Jullien de Paris visite les écoles du Père Girard à Fribourg en septembre.

\section{2}

Le socialiste Édouard de Pompéry, rédacteur de la Démocratie pacifique, propose de financer le Cours de Girard et visite ses écoles à Fribourg.

\section{9}

Louis Michel publie une analyse détaillée de la méthode Girard dans son Journal d'éducation (Paris).

\section{0}

En avril, Henri-Frédéric Amiel est introduit auprès de Victor Cousin par Adolphe Pictet, qui lui demande de le recommander à ses amis berlinois.

Girard nommé chevalier de l'ordre royal de la Légion d'honneur (5 mai).

En septembre, Daguet assiste avec I'historien Vuilleumier et Jacques Porchat au Congrès historique de Besançon et rencontre Marc-Antoine Jullien de Paris.

\section{2}

En septembre, Daguet et Naville père assistent au Congrès de Strasbourg et rencontrent Enrico Mayer. 
Français-e-s en Suisse (romande)

\section{4}

Rapet à Fribourg pour convenir des arrangements de la publication du Cours de langue de Girard (25 septembre).
Suisses (romand-e-s) en France

\section{4}

Première édition de l'Enseignement régulier de la langue maternelle. Girard reçoit le prix Montyon.

Victor Cousin nomme Girard membre de I'Institut de France, suite à la mort de Fellenberg (21 novembre). Le Vaudois Adam Vuillet dirige l'école normale protestante de Paris jusqu'en 1858.

\section{5}

Eugène Rambert enseigne à Paris.

\section{6}

Victor Considérant s'arrête à Genève le 19 septembre. II tient 8 conférences à Lausanne du 23 septembre au 3 octobre. Le 7 octobre, il est au Locle. Du 15 au 28 octobre, il donne des conférences à Genève.

\section{6}

Frédéric Gauthey devient le directeur de l'école normale protestante de Courbevoie jusqu'à sa mort en 1864.

Seconde édition de l'Enseignement régulier de la langue maternelle de Girard chez Dezobry et Magdeleine (mai). À la suite de la révolution radicale vaudoise, Juste Olivier s'installe à nouveau à Paris où il va vivre jusqu'au début de la guerre franco-prussienne.

\section{9}

Daguet devient membre de l'Institut catholique Athénée universel de Paris.

\section{0}

Xavier Marmier est à Fribourg pour I'inauguration de la statue du Père Girard.

\section{0}

Lettre de Daguet à Cousin pour trouver un professeur de philosophie pour l'école cantonale de Fribourg.

\section{1}

Georges Joseph Schmitt passe la frontière et arrive à Bâle le 10 décembre, avec quelques proscrits alsaciens. Max Buchon se réfugie trois mois chez Daguet à Fribourg, puis s'installe à Berne.

\section{2}

Georges Joseph Schmitt s'installe à Aarau le 31 mai (sa famille le rejoint le 30 juin).

Quinet refuse la direction de la chaire d'histoire de la philosophie à l'académie de Genève. Propose la candidature au gendre de Michelet, Dumesnil.

\section{3}

Le Vaudois Louis Niedermeyer réorganise l'école parisienne d'Alexandre Choron. 


\section{Français-e-s en Suisse (romande) Suisses (romand-e-s) en France}

\section{4}

Georges Joseph Schmitt est reçu au

Cercle littéraire et du commerce de

Fribourg, présenté par Jullien Schaller

(14 décembre). II remplace Cyprien Ayer

à la rédaction du Confédéré de Fribourg,

I'organe des républicains français en

Suisse (Schmidt rentre à Mulhouse en

1869).

Gustave Courbet visite Buchon à Berne

en septembre.

\section{5}

Recommandé par Quinet au conseiller genevois radical Tourte, Marc Dufraisse devient professeur de législation comparée à l'école polytechnique fédérale de Zurich nouvellement créé. Y enseigne durant 15 ans.

Champfleury visite Buchon à Berne en juin.

\section{6}

Daguet est délégué au Congrès historique d'Annecy.

\section{7}

Premier séjour des Quinet en Suisse allemande, durant l'été (Bâle, Olten, Lucerne, ascension du Rigi, Amsteg, col du Gothard, Altdorf, Engelberg, Thoune, Interlaken et Bâle)

\section{8}

Second séjour des Quinet en Suisse allemande (Schaffhouse, Winterthur, Saint-Gall, Appenzell et Toggenbourg). Ils passent ensuite trois semaines à Zurich proches de Flocon et Dufraisse. Au lieu de rentrer en Belgique, ils mettent le cap sur le Léman, sur les conseils de Michelet et Dufraisse.

Les Quinet passent quelques semaines à Amphion, puis s'installent à Veytaux le ler novembre 1858, leur lieu d'exil durant dix ans (accueillis par Merlin de Thionville, Bétant et Charles Gleyre). Pierre Larousse visite Jules Paroz à Berne. Fusion de L'Éducateur populaire avec L'école normale.

\section{9}

Premier passage des Quinet à Genève. Dès 1861 , ils y font régulièrement un ou deux séjours par an.

Quinet refuse pour la seconde fois la direction de la chaire d'histoire de l'académie de Genève.

\section{8}

Juste Olivier enseigne à l'école de la Chaussée-d'Antin, un établissement de jeunes filles protestantes. II reçoit SainteBeuve, Aimé Steinlen, Charles Gleyre, Eugène Rambert ou Adam Mickiewicz dans sa maison parisienne. 


\section{Français-e-s en Suisse (romande) Suisses (romand-e-s) en France}

\section{1}

Premier des douze séjours genevois entre 1861 et 1870 pour les Quinet ( 3 semaines à un mois). Fréquentent Ernest Naville, Adolphe Pictet, Jules Pictet de la Rive, Alphonse Favre, Auguste de la rive, etc. Jules Barni vient s'installer à Genève, et devient titulaire de la chaire d'histoire générale.

Émile-Joseph-Maurice Chevé est à

Genève pour faire publicité de la méthode musicale chiffrée Galin-Paris-Chevé.

\section{2}

Séjour genevois des Quinet remplacé par une visite à Zurich, Berne et Fribourg. Charles Bergeron s'établit à Lausanne. Sa demeure est le rendez-vous des exilés, notamment de Flocon, Brückner, Tamisier, Leroux et Schmidt de Fribourg.

\section{3}

Jules Barni est reçu au Cercle littéraire et du commerce de Fribourg, présenté par G. J. Schmitt (29 juin).

Henri Bordier passe par Fribourg pour se rendre à Munich.

\section{4}

Ferdinand Flocon est reçu au Cercle littéraire et du commerce de Fribourg, présenté par G. J. Schmitt (29 juin). Sur la recommandation de Jules Ferry, Antonin Proust visite Quinet le 17 août. Charras et Clémenceau visitent Quinet à Veytaux (3 octobre).

\section{5}

Charras meurt à Bâle le 23 janvier. Clémenceau assiste aux funérailles. Congrès de l'Association internationale pour le progrès des sciences sociales à Berne (28 août au 2 septembre). Jules Ferry y participe. Première visite de Bakounine à Veytaux.

\section{6}

Mort de Ferdinand Flocon à Lausanne le 15 mai.

Première visite de Jules Ferry à Veytaux en septembre.

F. Buisson est engagé comme professeur de philosophie à l'académie de Neuchâtel. Rencontre avec Daguet.

Durant l'hiver, Barni donne une série de conférences à Fribourg, sous les auspices du Cercle littéraire et du commerce. 
Français-e-s en Suisse (romande)

\section{7}

Pierre Leroux, sans le sou, se trouve à Lausanne et fréquente Charles Secrétan (épaulé par F. Buisson).

Gabriel Monod visite Quinet à Veytaux le 5 juin. Visite de Barni à Veytaux le 11 août.

Congrès de I'AIT à Lausanne (2-8 septembre).

$1 e^{r}$ Congrès de la Ligue de la paix et de la liberté à Genève, 9-12 septembre, organisé et présidé par Jules Barni. Bakounine en est une des vedettes. Edmond Stahr et Fanny Lewald fréquentent les Quinet à Veytaux jusqu'au milieu de I'an 1868.

\section{8}

$2^{\mathrm{e}}$ Congrès de la Ligue de la paix et de la liberté à Berne, 21-25 septembre.

\section{Suisses (romand-e-s) en France}

\section{7}

En Sorbonne, Alexandre Daguet propose la création d'une Association pédagogique universelle (22 août).

La délégation romande est reçue par le ministre Duruy, marié à une Suissesse.

\section{9}

Séjour de Quinet à Genève, rencontre Alexandre Herzen (10 mai au 11 juin).

$3^{e}$ Congrès de la Ligue de la paix et de la liberté à Lausanne, 14-18 septembre. J. Ferry y rencontre F. Buisson, son futur collaborateur au ministère de I'Instruction publique.

Seconde visite de Ferry à Veytaux. Visite d'Etienne Vacherot à Veytaux.

\section{0}

Jean Macé se réfugie à la Neuveville et rencontre Daguet à Neuchâtel.

Charles Defodon et Jean-Magloire

Baudoin assistent au III ${ }^{\mathrm{e}}$ congrès de la SIR à Neuchâtel (20-21 juillet).

\section{1}

Mission de Jean-Baptiste Fonssagrives en Suisse (hygiène scolaire).

Le normalien Georges Renard s'exile en Suisse après la Commune et arrive à Vevey où il enseigne. Devient titulaire d'une chaire à l'académie de Lausanne jusqu'en 1900, date à la quelle il est nommé professeur au Collège de France (Maggetti).

\section{2}

Charles Defodon et Jean-Georges Hoffet assistent au IV ${ }^{\mathrm{e}}$ congrès de la SIR à Genève (29-31 juillet).

Élisée Reclus arrive en Suisse et s'établit en mars à Lugano.

\section{8}

Daguet est nommé membre associé de la Société pour l'instruction élémentaire de Paris.

\section{0}

La guerre franco-prussienne contraint Juste Olivier à rentrer en Suisse. La SIR organise une collecte pour les orphelins de guerre.

\section{1}

Internement de l'armée Bourbaki. Les cantons suisses organisent des cours pour les soldats français (février-mai). Début de la correspondance Daguet-Passy.

\section{2}

Histoire de la pédagogie de Jules Paroz chez Delagrave à Paris. 


\begin{tabular}{ll} 
Français-e-s en Suisse (romande) & Suisses (romand-e-s) en France \\
\hline 1873 & \\
$\begin{array}{l}\text { Charton visite Daguet à Neuchâtel et } \\
\text { quelques écoles de Suisse romande. }\end{array}$ & \\
1874 & 1874 \\
Gustave Courbet est reçu au Cercle & Le Fribourgeois Victor Tissot se fixe à \\
littéraire et du commerce de Fribourg & Paris. \\
(20 mai). &
\end{tabular}

\section{5}

Après un bref passage chez Courbet, Élisée Reclus s'installe à Vevey le 7 septembre 1875 (il y reste jusqu'au 2 octobre 1879).

\section{5}

Voyage au pays des milliards de Victor Tissot.

Victor Cherbuliez s'installe à Paris. II y incarne le prototype du romancier brillant et salonard; devenu citoyen français, il est reçu à l'académie française en 1881 (Maggetti).

\section{8}

James Guillaume arrive à Paris le $1^{\text {er }}$ mai, jour d'ouverture de l'Exposition universelle.

\section{9}

Daguet est nommé Officier d'académie de la République française sous le ministre Bardoux (3 janvier).

Daguet pense à un établissement à Paris. Son ami Amiel I'en dissuade.

Édouard Rod s'établit à Paris.
M. Bertrand est le délégué du Ministère de l'instruction publique au VII ${ }^{\mathrm{e}}$ Congrès de la SIR à Lausanne (14-15 juillet) Jules Gourdault s'installe à Saxon en Valais pour la composition de sa Suisse pittoresque.

\section{0}

Lettre de Gabriel Compayré à Daguet, pour s'abonner à L'Éducateur (5 janvier). Edmond Cottinet se trouve en Suisse pour étudier les colonies de vacances. Bonaventure Berger assiste au Lehrertag de Soleure.

\section{1}

Mission de Gustave Vapereau en Suisse.

\section{2}

Guillaume Jost assiste au Lehrertag de Bâle.

Nouvelle excursion des maîtres-élèves en Suisse romande, dirigée par Quénard et Laporte d'Amiens.

\section{4}

Charles Defodon assiste au IX ${ }^{e}$ congrès de la SIR à Genève (5-7 août). 


\begin{tabular}{|c|c|}
\hline Français-e-s en Suisse (romande) & Suisses (romand-e-s) en France \\
\hline \multicolumn{2}{|l|}{$\begin{array}{l}1886 \\
\text { Ferdinand Buisson et Félix Pécaut } \\
\text { assistent au Xe Congrès de la SIR à } \\
\text { Porrentruy ( } 8-10 \text { août). }\end{array}$} \\
\hline & $\begin{array}{l}1887 \\
\text { Samuel Cornut s'installe à Paris et y vit } \\
\text { jusqu'en 1916, en donnant des cours et en } \\
\text { écrivant. }\end{array}$ \\
\hline \multicolumn{2}{|l|}{$\begin{array}{l}1888 \\
\text { Jules Steeg, Edmond Cottinet et Pauline } \\
\text { Kergomard assistent au I }{ }^{\text {er }} \text { congrès } \\
\text { international des colonies de vacances } \\
\text { à Zürich. }\end{array}$} \\
\hline & $\begin{array}{l}1891 \\
\text { Victor Tissot devient rédacteur au Figaro, } \\
\text { jusqu'en } 1893 .\end{array}$ \\
\hline $\begin{array}{l}1901 \\
\text { Gabriel Compayré effectue un pèlerinage } \\
\text { Pestalozzi en septembre (Zurich, Stans, } \\
\text { Yverdon, Lausanne). }\end{array}$ & \\
\hline
\end{tabular}


SOURCES 



\title{
Sources manuscrites
}

\section{Archives publiques}

\author{
A. Archives de l'État de Fribourg \\ Fonds Alexandre Daguet (1816-1894) \\ Papiers personnels \\ Généalogie Schneuwly \\ Généalogie de Gottrau \\ Fonds de l'école cantonale
}

\section{B. Bibliothèque publique et universitaire de Neuchâtel} Fonds de la Loge La Bonne Harmonie

Correspondance, FF. Décédés M. Daguet. Doc II E Plan. I

\section{Bibliothèque publique et universitaire de Genève Fonds Amiel}

MS 3092, f 124-195: 36 lettres de Daguet à Henri-Frédéric AMIEL (1849-1877)

MS 3092, f 197-222: extraits de lettres d'AMIEL à Daguet (1849-1880)

Correspondance de Daguet

MS 6135, f 3-10 h 3 lettres à Henri BORDIER (1872-1881)

MS 5531, f 233-251: 10 lettres à François-Marc-Louis NAVILLE (1839-1845)

\section{Archives nationales de France, site de Paris CARAN}

F17*2272-73 Procès-verbaux de la commission des missions, 1874-1889

F17 2924-28 Service des voyages et missions, 1842-1919 
F17 2962 Missions scientifiques et littéraires, 1828-1894, dossiers individuels

F17 9397 Dépenses du musée pédagogique 1877-1890

F17 11623-24 Conférences pédagogiques, 1874-1892

F17 11625-29 Congrès pédagogiques, 1880-1899

F17 11635-45 Gymnastique, tir, exercices militaires, 1843-1899

F17 $12338 \quad$ Échanges avec l'étranger de renseignements sur l'école primaire; affaires particulières avec des étrangers ou des français résidant à l'étranger 1843-1886: Allemagne

F17 12340 Idem avec Grèce, Italie, Luxembourg, Madagascar, Pays-Bas, Portugal, Roumanie, Russie, Livonie, Suède, Suisse, Tunisie, Turquie, Uruguay

F17 $13052 \quad$ Service des missions, 1884-1903

F17 14312-13 Orphelinat Prévost à Cempuis (Oise): affaire Robin (1878-1912)

F18 549 Presse étrangère. Dossiers des journaux introduits en France 1850-86: Suisse

$71 \mathrm{AJ} 1$ à 90 Musée pédagogique

71AJ1 Brochures, pièces et dossiers (Histoire du musée pédagogique)

71AJ4 Revue pédagogique (comités, procès-verbaux des réunions 1882-92)

71AJ 69-76 Archives de Ferdinand Buisson

71AJ75 Bataillons scolaires: presse (38 coupures) rassemblée à l'occasion de la publication au Journal officiel d'un décret et d'un règlement sur l'organisation des bataillons scolaires, juillet 1882

71AJ78 Conférences cantonales pour les instituteurs et conférences pédagogiques

\section{E. Département des manuscrits de la Bibliothèque de la Société pour l'histoire du protestantisme français, Paris}

Fonds Buisson - Papiers personnels

022Y.1.04 Ferdinand Buisson, professeur à Neuchâtel (1866-1871)

022Y.1.05 soutenance de thèse

022Y.1.11 livre de raison (1858-1922)

Fonds Buisson - Correspondance

022Y.2.05 Jules BARNI (2) 1869

022Y.2.59 Philippe GODET (2) 1916 


$\begin{array}{ll}\text { 022Y.2121 } & \text { Edgar QUINET (3) non daté } \\ \text { 022Y.2136 } & \text { Jules SIMON (7) 1870-1891 } \\ \text { 022Y.2137 } & \text { Jules STEEG (4) 1869-1896 }\end{array}$

Fonds Buisson - Production intellectuelle

022Y.4.03 Ferdinand Buisson et la librairie Hachette 1876-1919

022Y.4.15 Bureau international de l'éducation, non daté

\author{
F. Manuscrits de la Bibliothèque de la Sorbonne, Paris \\ Manuscrits de la bibliothèque Victor Cousin \\ MSVC 64 notes et documents sur l'instruction publique I. En France \\ MSVC 65 notes et documents sur I'instruction publique II. En Allemagne \\ MSVC 66 notes et documents sur I'instruction publique III. En Italie, \\ Suisse, etc. \\ MSVC 67 notes et documents sur l'instruction publique IV. En Prusse \\ MSVC 68 notes et documents sur l'instruction publique V. En Prusse \\ MSVC 214 CG, tome I, 1 lettre de Henri-Frédéric AMIEL, 1844 \\ MSVC 224 CG, tome XI, 1 lettre d'Alexandre DAGUET, 15.08.1850 \\ MSVC 225 CG, tome XII, 1 lettre de DIESTERWEG, 26.04.1839 \\ MSVC 226 CG, tome XIII, 3 lettres de Victor DURUY, 1863-1865 \\ MSVC 228 CG, tome XV, 1 lettre d'Emmanuel de FELLENBERG, 1822 \\ MSVC $229 \quad$ CG, tome XVI, 1 lettre de Théodore FRITZ, 1841 \\ MSVC 231 CG, tome XVIII, 4 lettres d'André GINDROZ, 1837 \\ MSVC 231 CG, tome XVIII, 10 lettres du Père GIRARD, 1838-1849 \\ MSVC 235 CG, tome XXII, 1 lettre de Frédéric-César de LA HARPE, 1837 \\ MSVC 235 CG, tome XXII, 1 lettre de Raffaello LAMBRUSCHINI, 1837 \\ MSVC $241 \quad$ CG, tome XXVIII, 1 lettre d'Ernest NAVILLE \\ MSVC 241 CG, tome XXVIII, 2 lettres de François-Marc-Louis NAVILLE, 1853 \\ MSVC $244 \quad C G$, tome XXXI, 1 lettre de Valentin-Louis PRAT, 1843 \\ MSVC $244 \quad$ CG, tome XXXI, 4 lettres d'Edgar QUINET, 1828 \\ MSVC 249 CG, tome XXXVI, 11 lettres de Philipp Albert STAPFER, 1826-1836
}

\title{
G. Département des manuscrits de la Bibliothèque nationale de France
}

NAF 11825 à 11837: volumes I-XIII, Mémorial d'exil (1861-1875) par Hermione Quinet

NAF 15507 à 15510: lettres adressées à Edgar Quinet

NAF 24328: recueil de lettres (F. 64-70 F. Buisson) 


\section{Archives privées}

\section{A. Fonds Daguet (Archives de l'État de Neuchâtel)}

35 lettres d'Henri-Frédéric AMIEL, 1849-1880

1 lettre de I'ASSOCIATION florimontane d'Annecy, 1857

10 lettres d'Auguste BACHELIN, 1867-1890

2 lettres de la BIBLIOTHÈQUE publique de Besançon, A. CASTAN, 1868-1874

4 lettres de Carlo BONCOMPAGNI, 1854-1858

1 lettre de La BONNE HARMONIE, 1885

4 lettres d'Henri BORDIER, 1863-1881

5 lettres de Louis BORNET, 1857-1872

5 lettres de Félix BOVET, 1861-1890

30 lettres de Max BUCHON, 1841-1868

34 lettres de Ferdinand BUISSON, 1868-1892

1 lettre de Mariano CARDERERA, 1870

18 lettres d'Édouard CHARTON, 1873-1883

7 lettres de Joël CHERBULIEZ, 1850-1867

1 lettre de Gabriel COMPAYRÉ, 1880

1 lettre du CONGRÈS international d'instituteur du Havre, 1885

6 lettres de Gustave COURBET, 1841-1871

2 lettres de Charles DEFODON, 1874

3 lettres de Charles DELAGRAVE, 1872-1880

19 lettres d'Édouard DESOR, 1864-1878

7 lettres de Numa DROZ, 1884-1887

12 lettres de Xavier DUCOTTERD, 1874-1886

1 lettre de Clovis LAMARRE, école Sainte-Barbe, Paris, 1878

1 lettre de Frédéric GODET, 1892

16 lettres de Philippe GODET 1882-1891

3 lettres de Jules GOURDAULT, 1879-1880

2 lettres d'Angelo de GUBERNATIS, 1887-1888

1 lettre de James GUILLAUME, 1883

3 lettres de Louis GUILLAUME, 1863-1889

18 lettres de Roger de GUIMPS, 1859-1879

1 lettre de I'INSTITUT catholique de Paris, 1849

3 lettres de I'INSTITUT impérial de France, 1867-1868 
1 lettre de I'INSTRUCTION publique, Paris, Jules Cambon, 1871

6 lettres d'Henri JACOTTET, 1892-1894

23 lettres de Xavier KOHLER, 1852-1888

1 lettre de Pierre LAROUSSE, non daté

1 lettre de la LÉGATION suisse à Paris, 1871

9 lettres de Charles LOYSON, dit Hyacinthe, 1873-1874

2 lettres de Charles MENN, congrès international de la paix de Genève, 1867-1873

2 lettres du MINISTÈRE de I'Instruction publique de Paris, 1879-1887

2 lettres du MUSÉE pédagogique, Paris, Martel et Berger, 1882-1887

50 lettres d'Ernest NAVILLE, 1843-1893

3 lettres de Jules PAROZ, 1865-1892

5 lettres de Frédéric PASSY, 1870-1882

1 lettre de Félix PÉCAUT, non daté

4 lettres de Louis-Valentin PRAT, 1842-1848

1 lettre de Caroline PROGLER, 1881

6 lettres de Jean-Jacques RAPET, 1861-1878

2 lettres de Jules SANDOZ, 1865-1866

15 lettres d'Eulalie de SENANCOUR, 1846-1854

1 lettre de Jules STEEG, 1894

4 lettres d'Édouard TALLICHET, 1866-1882

50 lettres de Victor TISSOT, 1866-1888

22 lettres d'Ignace Paul Vital TROXLER, 1838-1851

12 lettres de Gustave VAPEREAU, 1868-1882

39 lettres de Louis VULLIEMIN, 1837-1857

\section{B. Archives familiales}

FAVARGER Pierre, Chronique de famille commencée en l'an de grâce 1905 par Pierre Favarger, avocat à Neuchâtel, don de M. Laurent de Weck, arrière-petitfils d'Alexandre Daguet. 



\section{Sources publiées}

\section{A. Publications d'Alexandre Daguet}

DAGUET Alexandre, «Les Troubadours ou les Minnesänger suisses », Congrès scientifique de France, huitième session, Besançon, septembre 1840.

-, « Gottrau-Treyfaye, ou les francs-maçons de 1763. Épisode de I'histoire fribourgeoise », Album de la Suisse romande, Genève, juin 1843.

-, Quelques idées pour la réorganisation de I'Instruction publique dans le Canton de Fribourg, Fribourg, L.-J. Schmidt, 1848.

-, Histoire de la Nation suisse d'après Zschokke. Les principaux écrivains nationaux et quelques sources originales, Fribourg, B. Galley Éditeur, 1850.

-, Histoire de la Confédération suisse depuis les premiers temps jusqu'en 1860, Neuchâtel et Paris, Leidecker, 1861 (7 rééditions et plusieurs traductions).

-, Histoire abrégée de la Confédération suisse à l'usage des écoles et des familles, Neuchâtel, C. Leidecker, 1863 (16 rééditions).

-, Jost Alex, ou Histoire des souffrances d'un protestant fribourgeois de la fin du xvI ${ }^{e}$ siècle, racontée par lui-même, traduite de l'allemand et précédée d'une introduction par Alexandre Daguet, Genève, J.-G. Fick, 1864.

-, Rapport sur l'exposition scolaire de Paris en 1867, Lausanne, Imprimerie J.-L. Borgeaud, 1868.

-, Manuel de pédagogie ou d'éducation à l'usage des personnes qui enseignent ou qui désirent se vouer à l'enseignement, Neuchâtel, Imprimerie G. Guillaume, 1871 (5 rééditions).

-, Le Père Girard et son temps. Histoire de la vie, des doctrines et des travaux de l'éducateur suisse (1765-1850), 2 tomes, Paris, Fischbacher, 1896.

Pour une liste exhaustive des travaux de Daguet, voir https://unige.academia. edu/AlexandreFontaine 


\section{B. Correspondances}

CHARTON Édouard, Correspondance générale (1824-1890), 2 vol., éditée et annotée par Marie-Laure Aurenche, Paris, Honoré Champion Éditeur, 2008.

COURBET Gustave, Correspondance établie, présentée et annotée par Petra TenDoesschate Chu, Paris, Flammarion, 1996.

RECLUS Élisée, Correspondances, Tome // (1870-1889), Paris, Librairie Schleicher, 1911.

\section{Sources imprimées ( $\mathrm{XIX}^{\mathrm{e}}$ siècle)}

AMIEL Henri-Frédéric, Du mouvement littéraire dans la Suisse romane, et de son avenir, sans lieu, 1849.

BARNI Jules, Manuel républicain, Paris, Librairie Germer-Baillière, 1862.

-, Ce que doit être la République, Amiens, Publication de I'Union républicaine de la Somme, 1872.

-, L'Instruction républicaine, Paris, Imprimerie A. Le Chevalier, 1872.

-, La morale dans la démocratie, Paris, Éditions Kimé, 1992.

BAUD-BOVY Daniel, Le Château d'amour, Genève, 1897.

-, La colonie, Genève, 1897.

-, Les séjours de Corot en Suisse, Genève, 1922.

BAUDOIN Jean-Magloire, Rapport sur l'état actuel de l'enseignement spécial et de l'enseignement primaire en Belgique, en Allemagne et en Suisse, Paris, Imprimerie impériale, 1865.

BERGER Bonaventure, Conférence pédagogique sur l'enseignement de la langue maternelle (19 août 1978), Paris, Imprimerie de A. Chaix, 1879.

BERT Paul, L'instruction civique à l'école, Paris, Picard-Bernheim et Cie, 1882.

BLANC Samuel, Essai d'un Cours d'instruction civique et d'économie politique, Lausanne, S. Blanc libraire-éditeur, 1862.

BORNET Louis, «Les Tsévreis: conto gruérin », L'Émulation, Fribourg, $\mathrm{n}^{\circ} 8$, p. 7-8, 1841-1842.

-, Cours gradué d'instruction civique: manuel de l'école, de la famille et du citoyen, $3^{e}$ édition approuvée et adoptée pour les écoles par le Département de I'Instruction publique du Canton de Vaud, Fribourg, Ch. Marchand, 1856.

-, Manuel d'instruction civique: traité scolaire sur les droits et les devoirs de I'homme et du citoyen, Neuchâtel, J. Attinger, 1864.

BOUTROUX Émile, «Les récents manuels de morale et d'instruction civique », Revue pédagogique, 15 avril 1883, p. 289-342.

BRIDEL Philippe-Sirice, Poésies helvétiennes, Lausanne, Librairie Mourer, 1792. 
BRÉAL Michel, Quelques mots sur l'instruction publique en France, Paris, Hachette, 1872.

BUCHON Max, Poésies allemandes: Hebel, Körner, Uhland, Heine, Salins, 1846.

-, «Comment Joggeli va chercher femme », L'Émulation, 1/1852, p. 74-91 [traduction de Gotthelf, Wie Joggeli eine Frau sucht], 1841.

-, Hebel et Auerbach. Scènes villageoises de la Forêt-Noire, Paris, Borrani et Droz, Berne, Dalp, 1853.

-, Le réalisme: discussions esthétiques recueillies et commentées par Max Buchon, Neuchâtel, Imprimerie de J. Attinger, 1856.

-, Scènes franc-comtoises, Bruxelles, Labroue, 1858.

-, CEuvres choisies, I, Paris, Sandoz et Fischbacher, 1878.

BUISSON Ferdinand, L'Orthodoxie et l'Évangile dans l'Église réformée, réponse à M. Bersier, Paris, Imprimerie L. Tinterlin, 1864.

-, De l'Enseignement de l'histoire sainte dans les écoles primaires, conférences données à Genève au Palais électoral, le 25 février 1869 à Neuchâtel, Paris, Theolib, 2014 [1869].

-, L'Enseignement primaire supérieur et professionnel en France, conférence faite à l'assemblée générale de la Société protestante du travail, tenue le 13 juin 1887, à la mairie du 1er arrondissement, Paris, Fischbacher, 1887.

-, Conférences et causeries pédagogiques, Paris, C. Delagrave, 1888.

-, Cours de science de l'éducation: leçon d'ouverture faite à la Sorbonne, le 3 décembre 1896, Paris, Delagrave, 1896.

- La Religion, la Morale et la Science. Leur conflit dans l'éducation contemporaine, quatre conférences faites à l'aula de l'université de Genève (avril 1900),

Paris, Theolib, 2013 [1901].

-, Libre-pensée et protestantisme libéral, Paris, Fischbacher, 1903.

-, « L'Instruction et l'éducation internationale, par Ferdinand Buisson », La Grande Revue, 1905.

-, « L'école et la nation en France », extrait de L'Année pédagogique de 1913, Theolib: Ferdinand Buisson, Souvenirs et autres écrits, 2012, p. 73-86.

-, Souvenirs. 1866-1916. Conférence, faite à l'Aula de l'université de Neuchâtel, le 10 janvier 1916, Paris, Fischbacher, 1916.

-, Leçons de morale à l'usage de l'enseignement primaire, Paris, Hachette, 1926.

CLARIS Jean-Aristide, La proscription française en Suisse 1870-1871, Genève, Imprimerie Blanchard, 1872.

COMPAYRÉ Gabriel, Histoire critique des doctrines de l'éducation en France, depuis le xvI siècle, Paris, Hachette, 1879.

-, Cours de morale théorique et pratique, Paris, P. Delaplane, 1887.

-, Félix Pécaut et l'éducation de la conscience, Paris, Paul Mellottée, 1904.

-, Le P. Girard et l'éducation par la langue maternelle, Paris, Paul Delaplane, 1906.

-, Histoire de la pédagogie, Paris, Elibron Classics, 2002 [1886]. 
DEFODON Charles, Promenade à l'Exposition de 1867, Hachette, 1868.

-, Les expositions scolaires départementales de 1868, Paris, 1869.

DUFAURE-ROSEN Sophie, «État de l'enseignement à Genève », L'Éducateur, 1871, p. 152-184.

-, L'éducation devant le dogme ancien et la philosophie moderne. Conférence faite à Seignelay (Yonne), Paris, Librairie de la Société d'études psychologiques, 1882.

DULON Rudolph, Aus Amerika über Schule, deutsche Schule, amerikanische Schule und deutsch-amerikanische Schule, Leipzig und Heidelberg, C. F. Winter, 1866.

DUPAIGNE Albert, « Conférence sur le chant dans les écoles (29 août 1878), Les Conférences pédagogiques faites aux instituteurs délégués à l'Exposition universelle de 1878 [3édition], Paris, Charles Delagrave, 1880.

FONSSAGRIVES Jean-Baptiste, Entretiens familiers sur l'hygiène ( $2^{\mathrm{e}}$ édition), Paris, Hachette, 1869.

-, L'éducation physique des garçons, ou Avis aux familles et aux instituteurs sur l'art de diriger leur santé et leur développement, Paris, C. Delagrave, 1870.

FONTAINE Charles-Aloyse, Un mot sur la tolérance religieuse, d'après les Lumières de la raison, Fribourg, chez L. B. Piller, 1800.

FRETTE Auguste, À propos de l'organisation de l'armée et des Cadets en Suisse, Paris, Librairie militaire de J. Dumaine, 1879.

FRITZ Théodore, Esquisse d'un système complet d'instruction et d'éducation et de leur histoire: avec indications des principaux ouvrages qui ont paru sur les différentes branches de la pédagogie, surtout en Allemagne, 3 volumes, Strasbourg, Schmidt et Grucker, 1841-1843.

GAUTHEY Louis-François-Frédéric, Des changements à apporter au système de I'instruction primaire dans le Canton de Vaud, Lausanne, Imprimerie des Frères Banchard, 1833.

-, Des droits et des devoirs des citoyens vaudois ou essai d'instruction civique, Lausanne, M. Ducloux, 1844.

-, Le livre du jeune citoyen ou notions élémentaires d'instruction civique à I'usage de la jeunesse vaudoise, Lausanne, J. Chantrens et G. Bridel, 1845.

GIRARD Grégoire, Rapport sur I'Institut de M. Pestalozzi à Yverdon, présenté à S.E. Mr, le Landamman et à la haute Diète des dix-neuf cantons de la Suisse, Fribourg, Beat-Louis Piller, 1810.

-, Discours de clôture prononcés par le R. P. Grégoire Girard, préfet des écoles de Fribourg 1805-1822, Fribourg, Imprimerie Saint Paul, 1950.

-, Grammaire des campagnes, à l'usage des écoles rurales du canton de Fribourg, Fribourg, François-Louis Piller, 1821.

-, Cours éducatif de langue maternelle à l'usage des écoles et des familles, Paris, Dezobry, E. Magdeleine \& Cie, 1847. 
-, Père Grégoire Girard. Quelques souvenirs de ma vie avec des réflexions, Fribourg, Imprimerie Saint Paul, 1948.

-, Projets d'éducation publique, Fribourg, Imprimerie Saint Paul, 1950 [1798].

-, Rapport sur I'Institut Pestalozzi à Yverdon, Fribourg, Imprimerie Saint Paul, 1950 [1810].

-, Méthodes et procédés d'éducation, Fribourg, Imprimerie Saint Paul, 1953.

-, Traités pédagogiques, sociologiques et philosophiques, Fribourg, Société fribourgeoise d'éducation, Imprimerie Saint Paul, 1954.

GUILLAUME James, Esquisses historiques: études populaires sur les principales époques de I'histoire de l'humanité, Neuchâtel, Imprimerie Borel, 1874-1875.

-, Idées sur I'organisation sociale, La Chaux-de-Fonds, Imprimerie Courvoisier, 1876.

-, « Les colonies de vacances et les écoles du IXe arrondissem ent de Paris », Revue pédagogique, janvier-juin 1885, p. 305-315.

-, Pestalozzi. Études biographiques, Paris, 1890.

-, L'internationale: documents et souvenirs (1864-1878), Paris, Société nouvelle de librairie et d'édition puis Stock, 4 volumes, 1905-1910.

HAMEL Joseph, L'enseignement mutuel ou Histoire de l'introduction et de la propagation de cette méthode par les soins du Dr Bell, de J. Lancaster et d'autres, Paris, L. Colas, 1818.

JOST Guillaume, Les congrès des instituteurs allemands, Paris, C. Delagrave, 1880.

-, De l'enseignement manuel et professionnel en Allemagne et dans les pays du nord. Rapport à M. le ministre de I'Instruction publique sur une mission relative à l'enseignement du travail manuel dans divers pays étrangers; notes sur quelques écoles professionnelles d'Allemagne, Paris, C. Delagrave, 1887.

JULLIEN DE PARIS Marc-Antoine, Essai général d'éducation physique, morale et intellectuelle: suivi d'un plan d'éducation pratique pour l'enfance, l'adolescence et la jeunesse, Paris, s.n., 1808.

-, Esprit de la méthode d'éducation de Pestalozzi: suivie et pratiquée dans I'Institut d'éducation d'Yverdun [sic] en Suisse, Milan, Imp. royale, 1812.

-, Exposé de la méthode d'éducation de Pestalozzi telle qu'elle a été suivie et pratiquée sous sa direction pendant dix années (1806-1816) dans l'institut d'Yverdun (sic) en Suisse, Paris, L. Hachette, 1842.

-, Esquisse et vues préliminaires d'un ouvrage sur l'éducation comparée entrepris d'abord pour les vingt-deux cantons de la Suisse et pour quelques parties de l'Allemagne; susceptible d'être exécuté plus tard, d'après le même plan, pour tous les États d'Europe; et Modèle de tables comparatives d'observations, à l'usage des hommes qui, voulant se rendre compte de la situation actuelle de l'éducation et de l'instruction publique dans les différents pays d'Europe, seront disposés à concourir au travail d'ensemble dont on expose ici le plan et le but, Paris, L. Colas, 1817. 
LAVELEYE Émile (de), Du progrès des peuples anglo-saxons, Bruxelles, Imprimerie

E. Guyot, 1859.

-, De l'instruction du peuple, Paris, Hachette, 1872.

-, Le socialisme contemporain, Bruxelles, Imprimerie C. Muquardt, 1881.

LEMONNIER Camille, Gustave Courbet à la Tour-de-Peilz, Paris, Alphonse Lemerre, 1868.

MACÉ Jean, Petit catéchisme républicain, Paris, Garnier frères, 1848.

-, Discours d'un vrai Républicain, Paris, Imprimerie de Claye et Taillefer, 1848.

-, Profession de foi d'un communiste, Paris, Imprimerie de A. Lacour, 1848.

-, Histoire d'une bibliothèque communale, Colmar, Imprimerie de C. Decker, 1863.

-, Conseils pour l'établissement des bibliothèques communales, Paris, Hetzel, 1865.

-, Proposition de loi sur la préparation militaire de la jeunesse française, Paris, Imprimerie de L. Mouillot, 1888.

MAILLARD Frédéric, Jacques Dubar, ou le respect de la propriété, Lausanne, Corbaz \& Cie, 1868.

-, Manuel d'instruction civique, Lausanne, H. Mignot, 1874.

MANGET Jean-Louis, Histoire de la Suisse, par H. Zschokke, traduit de l'allemand, Paris, Genève, Barbezat et Delarue, 1828.

MEYLAN Alphonse, « Musique populaire », L'Éducateur, 3/1867, p. 39-41.

-, Cours de musique chiffrée et portée. Essai théorique, pratique et pédagogique des principes de l'école de J.-J. Rousseau-Galin-Paris-Chevé, Lausanne, Bridel, 1869.

MICHEL Louis, Notice sur la vie et les ouvrages du P. Girard et études sur les doctrines pédagogiques et sur sa méthode d'enseignement, Paris, Magdeleine et Dezobry, 1840.

MICHELET Jules, Nos Fils, Paris, Nabu Press, 2010.

MIÉVILLE Antoine, Manuel du citoyen vaudois à l'usage des campagnes et des écoles, Lausanne, Vincent, 1846.

MORRIS William, « L'âge de l'ersatz », in L'âge de l'ersatz et autres textes contre la civilisation moderne, Paris, Éditions de l'encyclopédie des nuisances, 1996 [1894], p. 121-140.

MUYDEN-PORTA Jacob Evert van, Mémoire sur la Société hollandaise d'utilité publique, présenté à la Société vaudoise d'utilité publique, dans sa séance du 2 août 1827, Lausanne, Imprimerie de Hignou Aîné, 1827.

NAVILLE François-Marc-Louis, De l'éducation publique, Paris, Dufort, 1833.

-, Quels moyens pourrait-on employer dans l'enseignement public pour développer dans les élèves l'amour de la patrie suisse? Genève, 1839.

-, « Histoire de l'éducation et de la pédagogie par Théodore Fritz», Bibliothèque universelle, Genève, 1843. 
-, De la culture de l'esprit et du cœur par l'étude de la grammaire: analyse raisonnée de l'ouvrage du P. Girard, Lyon, 1845.

NIEMEYER August Hermann, Grundsätze der Erziehung und des Unterrichts für Eltern, Hauslehner und Schulmänner, $5^{\mathrm{e}}$, verbesserte mit dem dritten Teil vermehrte Ausgabe, Halle, Weisenhaus-Buchhandlung, 1805-1806.

-, Essai sur l'éducation intellectuelle et morale de l'enfance. Extraits des « Principes d'éducation », traduits de I'allemand par E.-P.-H. Durivau, Paris, L. Colas, 1832.

-, Principes d'éducation, traduits par Lochmann, Paris, Librairie du Commerce chez Renard, 1837-1842.

OWEN Robert, Institution pour améliorer le caractère du peuple, Paris, Elibron Classics, 2005 [1819].

PAGÈS Alphonse, La méthode Galin-Paris-Chevé. Exposé historique, Paris, Librairie de l'écho des feuilletons, 1860.

PAROZ Jules, Vie et voyages de William Dampier: ouvrage dédié aux enfants (d'après l'allemand de Frédéric Körber), Berne-Paris, E. Mathey, 1855.

-, Des avantages de l'instruction primaire, des progrès qui lui restent à faire en France, et des moyens propres à les réaliser, Montbéliard, H. Barbier, 1862. -, La Bible en éducation: réponse à la «Réforme urgente» de M. le Professeur Buisson, conférence donnée à Neuchâtel le 18 janvier 1869, Neuchâtel, S. Delachaux, 1869.

-, Du développement historique de la liberté religieuse en Suisse: son passé, son présent, son avenir. Étude faite en vue de la situation ecclésiastique actuelle dans le canton de Neuchâtel, Lausanne, L. Meyer, 1885.

-, Histoire universelle de la pédagogie, Paris, Kessinger, 2009 (1883).

PÉCAUT Félix, Le Christ et la conscience, lettres à un pasteur sur l'autorité de la Bible et celle de Jésus-Christ, Paris, J. Cherbuliez, 1859.

-, De l'avenir du protestantisme en France, Paris, J. Cherbuliez, 1865.

-, Le Christianisme libéral et le miracle. Quatre conférences prononcées à Nîmes, Neuchâtel et Paris, Paris, J. Cherbuliez, 1869.

-, De l'usage et de l'abus de la pédagogie, Paris, Imprimerie de Chaix, 1882.

-, L'éducation publique et la vie nationale, Paris, 1897.

PESTALOZZI Heinrich, Léonard et Gertrude. Un livre pour le peuple (trad. intégrale de Léon Van Vassenhove), 2 tomes, Boudry (NE), La Baconnière, 1947.

PRAT Louis-Valentin, « La culture de la sériculture », L'Émulation, 7/1841, p. 1-2.

PROGLER Caroline, « Méthode de lecture », L'Éducateur, 1868, p. 249.

-, «Quatrième congrès de l'Association pédagogique universelle », L'Éducateur, 1875, p. 355, 375.

-, « Protection de l'enfance malheureuse », L'Éducateur, 1875, p. 206.

-, « L'école à l'Exposition universelle de Paris (1878), L'Éducateur, 1879, p. 4, 50, 108, 115, 163, 193, 337. 
-, « L'école à l'Exposition universelle de Paris (1878) 》, L'Éducateur, 1880, p. 35,134 .

-, « Le congrès international de l'enseignement à Bruxelles », L'Éducateur, 1880, p. 368-386.

-, « Le centenaire de Frœbel », L'Éducateur, 1882, p. 65.

-, « Les jardins d'enfants », L'Éducateur, 1884, p. 265.

PROUDHON Pierre-Joseph, Qu'est-ce que la propriété?, Paris, Le livre de poche, 2009 [1840].

QUINET Hermione, Mémoires d'exil. L'amnistie (Suisse orientale et bords du Léman), Paris, Armand le Chevalier Éditeur, 1870.

QUINET Edgar, L'enseignement du peuple, Paris, Hachette, 2001 [1850].

-, Histoire de mes idées, Paris, Flammarion, 1972 [1858].

-, La Révolution, Paris, Belin, 2009 [1865].

RAMBERT Eugène, L'avenir de l'instruction supérieure dans la Suisse française, Genève, H. Georg, 1869.

-, Exposition universelle de Paris 1878 : Suisse, éducation et enseignement, enseignement supérieur, classe 8, Rapport, Zurich, Orell \& Füssli, 1879.

RECLUS Élisée, Du sentiment de la nature dans les sociétés modernes, Paris, Gascogne, 2005 [1866].

-, L'Anarchie, Mille et une nuits, 2009 [1896].

-, L'Évolution, la Révolution et l'idéal anarchique, Paris, Labor, 2006 [1898].

REY Aristide, « Les bataillons scolaires et la Révolution française », Revue pédagogique, juillet-décembre 1882, p. 552-580.

REYBAUD Louis, Études sur les réformateurs contemporains ou socialistes modernes: Saint-Simon, Fourier, Owen, Paris, Librairie Guillaumin, 1839.

ROUSSEAU Jean-Jacques, Émile ou de l'éducation, Paris, Flammarion, 2009.

SAINT-FERRÉOL Amédée, Impressions d'exils à Genève, Brioude, Imprimerie et Librairie D. Chouvet, 1877.

SAINT-SIMON Claude-Henri, (de) Lettres d'un habitant de Genève à ses contemporains, Paris, 1803.

SARCEY Francisque, «Les colonies de vacances », Revue pédagogique, janvierjuin 1887, p. 193-198.

SCHMITT Georges Joseph et BORNET Louis, Essai d'instruction morale et civique à l'usage des familles et des écoles. Manuel du citoyen français avec une introduction de M. Edgar Quinet, Paris, Armand le Chevalier Éditeurs, 1872.

SIMON Jules, Victor Cousin, Paris, Hachette, 1887.

STEEG Jules, « congrès international de Zurich (colonies de vacances et hygiène scolaire) », Revue pédagogique, juillet-décembre 1888, p. 211-222.

-, « Le Père Girard », Revue pédagogique, nº 5, mai 1896, p. 398-415. 
STIRNER, Max, L'Unique et sa propriété, Paris, La Table Ronde, 2000 [1845-1844].

TÖPFFER Rodolphe, Voyages et aventures du docteur Festus, Lausanne chez Ledouble et Paris chez A. Cherbuliez, 1840.

-, Voyages en zigzag, ou, Excursions d'un pensionnat en vacances dans les cantons suisses et sur le revers italien des Alpes, illustrés d'après des dessins de l'auteur et ornés de 12 grands dessins par M. Calame, Paris, Lacrampe, 1842.

TRISTAN Flora, Promenades dans Londres, General Books, 2012 [1840].

TROUBAT Jules, Une amitié à la d'Arthez, Champfleury, Courbet, Max Buchon, Paris, Lucien Duc Éditeur, 1900.

UHLAND Ludwig, Walter von der Vogelweide, ein alt deutscher Dichter, Tübingen et Stuttgart, Cotta, 1822.

\section{Rapports divers et comptes rendus de congrès}

Recueil des Discours prononcés à la Distribution des prix de l'école Cantonale de Fribourg depuis sa fondation en 1848-9 jusqu'à sa clôture en l'année scolaire 1856-7, par M. Alexandre Daguet, directeur de cet Établissement, Fribourg, Bibliothèque cantonale et Universitaire.

Le congrès scolaire de Fribourg. Rapport sur la deuxième session de l'assemblée générale des Instituteurs de la Suisse romande réunis le 6 août, Fribourg, Imprimerie Ch. Marchand, 1866.

Rapport sur l'Exposition scolaire de Paris en 1867 adressé aux gouvernements cantonaux et à la Société des Instituteurs de la Suisse romande par les délégués des cantons et de la Société: MM. Chapuis-Vuichoud, Maillard, Favre, Biolley, Paroz, Fromaigeat et Guerne/rapports complétés, mis en ordre et précédés d'une introduction par A. Daguet, Lausanne, Imprimerie J.-L. Borgeaud Wyss, 1868.

Le congrès scolaire de Lausanne. Rapport sur la troisième session de l'assemblée générale des Instituteurs de la Suisse romande réunis les 5 et 6 août 1868, Lausanne, Imprimerie Charles Borgeaud, 1868.

Compte-rendu du congrès pédagogique de Neuchâtel en 1870, et Rapport sur l'exposition scolaire de la Suisse romande, Neuchâtel, Imprimerie G. Guillaume Fils, 1870.

Compte-rendu du congrès pédagogique de Genève en 1872 et Rapport sur l'exposition scolaire de la Suisse romande, Genève, 1872.

Compte-rendu du cinquième congrès scolaire de la Société des Instituteurs de la Suisse romande tenu à Saint-Imier les 20, 21 et 22 juillet 1874, Saint-Imier, Imprimerie Ernest Grossniklaus, 1874. 
Sixième congrès de la Société des instituteurs de la Suisse romande tenu à Fribourg en septembre 1877 et Rapport sur les trois questions mises à l'étude par le comité central, Lausanne, Imprimerie Borgeaud, 1877.

Compte-rendu du VII congrès scolaire de la Société des Instituteurs de la Suisse romande à Lausanne les dimanches 13, lundi 14 et mardi 15 juillet 1879, Lausanne, Imprimerie Adrien Borgeaud, 1879.

Compte-rendu du VIII congrès scolaire de la société des instituteurs de la Suisse romande à Neuchâtel tenu les 25 et 26 juillet 1882, Neuchâtel, Imprimerie L.-A. Borel, 1882.

Compte-rendu du IXe congrès scolaire de la société des instituteurs de la Suisse romande réuni à Genève les 5, 6 et 7 août 1884, Genève, Imprimerie Taponnier et Studer, 1884.

Compte-rendu du congrès international d'instituteurs et d'institutrices tenu au Havre du 6 au 10 septembre 1885, Paris, 1885.

Compte-rendu du $X^{e}$ congrès scolaire de la Société des instituteurs de la Suisse romande réuni à Porrentruy les 8,9 et 10 août 1886, Porrentruy, V. Michel, 1886.

Compte-rendu du XI congrès scolaire de la Société des instituteurs de la Suisse romande à Lausanne, 14, 15 et 16 juillet 1889, Lausanne, Imprimerie Ch. ViretGenton, 1889.

Éducation et instruction. Rapport présenté au Haut conseil fédéral sur le groupe I de I'Exposition universelle à Paris en 1900, par François Guex, Lausanne, Payot, 1903.

\section{E. Revues et périodiques}

Conteur vaudois. Journal de la Suisse romande, 1860-1870, http://retro.seals.ch

Le Catalogue noir, dir. F. Buisson dès 1883, http://www.inrp.fr/numerisations

Le Confédéré de Fribourg, dir. G.-J. Schmitt

Le Dictionnaire de pédagogie et d'instruction, dir. F. Buisson, http://www.inrp.fr/ numerisations

L'École normale, dir. Pierre Larousse, 1858-1866

L'Éducateur populaire, journal pédagogique pour les écoles et les famille, dir. J. Paroz, 1850-1859, ensuite absorbé par L'École normale de Larousse

L'Éducateur, dir. A. Daguet, 1865-1889, http://retro.seals.ch

L'Émancipation, organe du christianisme libéral pour la Suisse romande, 18691872

L'Émulation de Fribourg, 1841-1846 et 1852-1856 
Les États-Unis d'Europe, organe de la Ligue internationale de la paix et de la liberté, 1868, http://gallica.bnf.fr

La Gazette de Lausanne, 1830-1950, http://www.letempsarchives.ch

Le Journal d'éducation à l'usage des instituteurs et des pères de famille, 1829-1831

Le Journal de Genève, 1830-1950, http://www.letempsarchives.ch

Le Journal des Instituteurs et Institutrices, 1858-1896, http://www.inrp.fr/numerisations

La Morale indépendante, 1865-1870

Le Narrateur fribourgeois, dir. A. Daguet, 1854

Le Progrès de Bruxelles, revue pédagogique, gérant J.-J. Campion, 1870-1890

La Revue bleue, 1878, version électronique, Gallica

La Revue des Deux Mondes, 1854 \& 1867, http://fr.wikisource.org

La Revue pédagogique, 1878-1900, bibliothèque des lettres, ENS-UIm Paris

La Revue suisse, 1853-1861

Histoire de l'éducation, http://histoire-education.revues.org

Manuel général de l'instruction primaire, 1860-1900, http://www.inrp.fr/numerisations

Revue germanique internationale, http://rgi.revues.org 

BIBLIOGRAPHIE 



\section{Recherche sur les transferts culturels et histoire globale}

AMSELLE Jean-Loup, « Métissage, branchement et triangulation des cultures », Revue germanique internationale, PUF, 21/2004, p. 41-52.

-, Branchements. Anthropologie de l'universalité des cultures, Paris, Flammarion, 2005.

BÉNAT-TACHOT Louise, GRUZINSKI Serge, Passeurs culturels. Mécanismes de métissage, Paris, Maison des Sciences de l'Homme, 2001.

BERTRAND Romain, L'Histoire à parts égales, Paris, Seuil, 2011.

BOUCHERON Patrick, DELALANDE Nicolas, Pour une histoire-monde, Paris, PUF, 2013.

BOUDROT Pierre, L'écrivain éponyme, Paris, Armand Colin, 2012.

BUTLER Judith, SPIVAK Gayatari Chakravorty, L'État global, Paris, Payot, 2009.

CHARLE Christophe, « Histoire globale, histoire nationale? Comment réconcilier recherche et pédagogie », Le Débat, 3/2013, p. 60-68.

CLIFFORD Geertz, Routes. Travel and Translation the Late Twentieth Century, Cambridge, Harvard University Press, 1997.

DÉCULTOT Élisabeth, ESPAGNE Michel, LE RIDER Jacques (éds.), Dictionnaire du monde germanique, Paris, Bayard, 2007.

DIGEON Claude, La crise allemande de la pensée française, 1870-1914, Paris, PUF, 1959.

DOUKI Caroline, MINARD Philippe, « Histoire globale, histoires connectées: un changement d'échelle historiographique? », Revue d'histoire moderne et contemporaine, 5/2007, p. 7-21.

ESPAGNE Michel, WERNER Michael (éds.), «La construction d'une référence allemande en France, 1750-1914. Genèse et histoire culturelle », Annales ESC, juillet-août 1987, p. 969-992.

-, Transferts. Les relations interculturelles dans l'espace franco-allemand, Paris, Éditions Recherche sur les civilisations, 1988.

-, Philologiques III. Qu'est-ce qu'une littérature nationale?, Paris, Maison des sciences de I'homme, 1994.

ESPAGNE Michel, «Sur les limites du comparatisme en histoire culturelle », Genèses, 17/1994, p. 112-121.

-, « La fonction de la traduction dans les transferts culturels franco-allemands aux XVIII ${ }^{e}$ et $\mathrm{XIX}^{\mathrm{e}}$ siècles. Le problème des traducteurs germanophones », Revue d'histoire littéraire de la France, 3/1997, p. 413-427.

-, Les transferts culturels franco-allemands, Paris, PUF, 1999.

-, Le creuset allemand. Histoire interculturelle de la Saxe XVIII'-XIXe siècles, Paris, PUF, 2000. 
-, En deçà du Rhin. L'Allemagne des philosophes français au XIXe siècle, Paris, Cerf, 2004.

-, L'histoire de l'art comme transfert culturel. L'itinéraire d'Anton Springer, Paris, Belin, 2009.

-, « La notion de transfert culturel », Revue Sciences/Lettres, 1/2013.

-, L'Ambre et le fossile. Transferts germano-russes dans les sciences humaines XIXe-XXe siècles, Paris, Armand Colin, 2014.

FUCHS Eckhardt, STUCHTEY Benedikt (éds.), Across Cultural Borders: Historiography in Global Perspective, New York \& Oxford, Rowman \& Littlefield Publishers, 2013.

GLISSANT Édouard, Traité du Tout-Monde. Poétique VI, Paris, Gallimard, 1997.

GRATALOUP Christian, Faut-il penser autrement I'histoire du monde?, Paris, Armand Colin, 2011.

GRUZINSKI Serge, La pensée métisse, Paris, Fayard, 1999.

-, Les quatre parties du monde. Histoire d'une globalisation, Paris, La Martinière, 2004.

-, « Faire de I'histoire dans un monde globalisé », Annales. Histoire, Sciences Sociales, 4/2011, p. 1081-1091.

-, L'histoire, pour quoi faire?, Paris, Fayard, 2015.

HALBWACHS Maurice, La mémoire collective, Paris, Albin Michel, 1997.

HANNERZ UIf, Transnational Connections. Culture, People, Places, Londres, Routledge, 1996.

JOYEUX Béatrice, «Les transferts culturels. Un discours de la méthode », Hypothèses 1/2002, p. 149-162.

LOMBEZ Christine, VON KULESSA Rotraud (éds.), De la traduction et des transferts culturels, Paris, L'Harmattan, 2007.

LÜSEBRINK Hans-Jürgen, REICHARDT Rolf, « Histoire des concepts et transferts culturels, 1770-1815. Note sur une recherche », Genèses, 14, 1994, p. 27-41.

LÜSEBRINK Hans-Jürgen « Liminaire », Tangence, 72/2003, p. 5-10.

MAUREL Chloé, «La World/Global History. Questions et débats 》, Vingtième Siècle. Revue d'histoire, 4/2009, p. 153-166.

MIDDELL Mathias, ESPAGNE Michel (éds.), Von der Elbe bis an die Seine. Kulturtransfer zwischen Sachsen und Frankreich im 18. und 19. Jahrhundert, Leipzig, Leipziger Universitätsverlag, 1993.

MIDDELL Matthias, « Méthodes de I'historiographie culturelle », Revue germanique internationale [En ligne], 10/1998, mis en ligne le 26.09.2011, http://rgi. revues.org/689

-, «La Révolution française et l'Allemagne: du paradigme comparatiste à la recherche des transferts culturels », Annales historiques de la Révolution française, 317/1999, p. 427-454. 
-, « Histoire universelle, histoire globale, transfert culturel », Revue germanique internationale [En ligne], 21/2004, mis en ligne le 19.09.2011, http://rgi. revues.org/1015.

MIDDELL Matthias (éds.), Cultural Transfers, Encounters and Connections in the Global 18th Century, Leipzig, Leipziger Universitätsverlag, 2013.

MINARD Philippe, «Globale, connectée ou transnationale: les échelles de I'histoire », Esprit, 12/2013, p. 20-32.

MOINE Caroline, BOUVIER Yves, PALMER Michael, « Espaces européens et transferts culturels », Le temps des Médias, n 11, hiver 2008-2009, p. 5-181.

NERLICH France, La peinture française en Allemagne: 1815-1870, Paris, Maison des sciences de I'homme, 2010.

NOIRIEL Gérard, ESPAGNE Michel, « Transferts culturels: I'exemple franco-allemand. Entretien avec Michel Espagne », Genèses, 8/1992, p. 146-154.

OLÉRON-EVANS Émilie, Transferts culturels et historiographie de l'art: le cas de Nikolaus Pevsner (1902-1983), thèse de doctorat, universités de Paris 3 et de Queen Mary, 2014.

RABAULT-FEUERHAHN Pascale, Théories intercontinentales. Voyages du comparatisme postcolonial, Paris, Demopolis, 2014.

RABAULT-FEUERHAHN Pascale, FEUERHAHN Wolf, La fabrique internationale de la science. Les congrès scientifiques de 1865 à 1945, Revue germanique internationale, 12/2010.

SPIVAK Gayatari Chakravorty, En d'autres mondes, en d'autres mots: essais de politique culturelle, Paris, Payot, 2009.

SUBRAHMANYAM Sanjay, Comment être un étranger. Goa-Ispahan-Venise, XVI XVIII ${ }^{e}$ siècle, Paris, Alma, 2013.

-, Aux origines de l'histoire globale, Paris, Collège de France/Fayard, 2014.

THIESSE Anne-Marie, La création des identités nationales. Europe XVIII XIXe siècle, Paris, Seuil, 1999.

TURGEON Laurier, DELAGE Denys, OUELLET Réal, Transferts culturels et métissages. Amérique/Europe $X V l^{e}-X X^{e}$ siècle, Les Presses de I'université Laval, 1996.

TURGEON Laurier, Regards croisés sur le métissage, Les presses de l'université Laval, 2003.

-, « Les mots pour dire les métissages: jeux et enjeux d'un lexique », Revue germanique internationale, PUF, 21/2004, p. 11-16.

WERNER Michael, « Transferts culturels », Le Dictionnaire des sciences humaines, Paris, PUF, 2006, p. 1189-1192. 


\section{Transferts éducationnels, éducation comparée et circulations des savoirs pédagogiques}

AUBIN Paul, « La pénétration des manuels scolaires de France au Québec. Un cas-type: Les frères des écoles chrétiennes, $\mathrm{XIX}^{\mathrm{e}} \mathrm{XX} \mathrm{X}^{\mathrm{e}}$ siècles $\gg$, Histoire de l'éducation, 85/2000, p. 3-24.

BAGCHI Barnita, FUCHS Eckhardt, ROUSMANIERE Kate (éds.), Connecting Histories of Education: Transnational and Cross-Cultural Exchanges in (Post-) Colonial Education, Oxford \& New York, Berghahn Books, 2014.

BEECH Jason, « The theme of Educational Transfer in Comparative Education: a view over time », Research in Comparative and International Education, Vol. 1, 1/2006, p. 2-13.

CARUSO Marcelo, TENORTH Heinz-Elmar (éds.), Internationalisierung: Semantik und Bildungssystem in vergleichender Perspektive, Frankfurt am Main, Peter Lang, 2002.

CARUSO Marcelo, ROLDAN VERA Eugenia, Pluralizing Meanings: The monitorial system of education in Latin America, Paedagogica Historica, 6/2010

CARUSO Marcelo, KOINZER Thomas, MAYER Christine, PRIEM Karin (éds.), Zirkulation und Transformation. Pädagogische Grenzüberschreitungen in historischer Perspektive, Böhlau Verlag, 2014.

CHARLE Christophe, SCHRIEWER Jürgen, WAGNER, Peter (éds.), Transnational Intellectual Networks. Forms of Academic Knowledge and the Search for Cultural Identities, Frankfurt et New York, Campus Verlag, 2004.

DITTRICH Klaus, Experts going transnational: education at world exhibitions during the second half of the nineteenth century, PhD Thesis, University of Portsmouth, 2010.

-, «Appropriation, Representation and Cooperation as Transnational Practices: The Example of Ferdinand Buisson » in I. Löhr et R. Wenzlhuemer, The Nation State and Beyond. Governing Globalization Processes in the Nineteenth and Early Twentieth Centuries, Heidelberg, Springer Verlag, 2013, p. 149-176.

DOGAN Mattei, KAZANCIGIL Ali, Comparing Nations, Oxford \& Cambridge, Blackwell, 1994.

DREWEK Peter, FUCHS Eckhardt, ZIMMER-MULLER Michael, Internationale Rezeption in pädagogischen Zeitschriften im deutsch-amerikanischen Vergleich 1871-1945/50, Bestandsverzeichnisse zur Bildungsgeschichte, DIPF, 2010.

DROUX Joëlle, HOFSTETTER Rita (éds.), Internationalisation in Education: Issues, Challenges, Outcomes, Paedagogica Historica, 50/1-2, 2014. 
EISEMON Thomas, «Educational transfer: The implications of foreign educational assistance », Interchange, 4/1974, volume v, p. 53-61.

FERRETTI Federico, «Géographie, éducation libertaire et établissement de l'école publique entre le $X I X^{e}$ et le $X X^{e}$ siècle: quelques repères pour une recherche », Cartable de Clio, n 13, 2013, p. 187-199.

FONTAINE Alexandre, Transferts culturels et déclinaisons de la pédagogie européenne. Le cas franco-romand au travers de l'itinéraire d'Alexandre Daguet (1816-1894), universités de Fribourg \& de Paris 8, thèse de doctorat, 2013.

-, «Entre ambitions universalistes et concurrences internationales. Retour sur le pari manqué de I'Association pédagogique universelle (1863-1900) », Histoire de l'éducation, n 139, septembre-décembre 2013.

-, «Pedagogia como transferência culturalno espaço franco-suíço. Mediadores e reinterpretações de conhecimento (1850-1900) », Revista História da Educação, 2014, 18 (42), p. 187-207.

-, « Une revue à I'affût du monde (1865-1890)? L'Éducateur comme relais des transferts et métissages pédagogiques en Suisse romande », Revue suisse des sciences de l'éducation, 2014, 36 (1), p. 17-34.

-, «La pédagogie comme transfert culturel. Passeurs, métissages et resémantisations de savoirs scolaires dans l'espace franco-romand (1850-1900) », in R. Hofstetter \& J. Droux (éds), Les savoirs dans le champ éducatif: circulations, transformations, implémentations. Pour une histoire sociale de la fabrique internationale des savoirs en éducation $x I x^{e}-x x^{e}$ siècles, Rennes, PUR, 2015.

FONTAINE Alexandre, MATASCI Damiano, «Centraliser, exposer, diffuser: les musées pédagogiques et la circulation des savoirs scolaires en Europe (18501900) 》, Revue germanique internationale, CNRS Éditions, 20/2015.

FRASER, Stewart E, Jullien's plan for comparative education 1816-1817, New York, Teachers College, Columbia University, 1964.

FRIJHOFF Willem, «Sur l'utilité d'une histoire comparée des systèmes éducatifs nationaux », Histoire de l'éducation, 12-13/1982, p. 29-44.

FUCHS Eckhardt, «Educational Science, Morality and Politics: International Educational Congresses as Mode of Institutionalization and Politicization of Education in the Early Twentieth Century », Paedagogica Historica, 2004, 40 (5-6), p. 757-784.

-, « Networks and the History of Education », Paedagogica Historica, 2007, 43 (2), p. 185-197.

FUCHS Eckhardt (éds.), Bildung international: historische Perspektiven und aktuelle Entwicklungen, Würzburg, Ergon, 2006.

GONON Philipp, «Learning from European Neighbours: The role of the State in Defining of Institutional Policies - The Case of Switzerland », in A. Heikkinen 
(éds.), Vocational Éducation and Culture-European Prospects from Theory and Practise, 1995, p. 22-36.

GOUBET Jean-François, Des maîtres philosophes? La fondation de la pédagogie générale par l'Université allemande, Paris, Garnier, 2012.

HANS, N., « Exportation of Educational Ideas », Journal of Educational Sociology, volume XXIX, number 7, March 1956, p. 274-281.

HOFSTETTER Rita, FONTAINE Alexandre, HUITRIC Solenn \& PICARD Emmanuelle, « Mapping the Discipline « History of Education », Paedagogica Historica, 50 (6), 2014.

HOUSSAYE Jean, « Pédagogies: import-export », Revue française de pédagogie [En ligne], 155/avril-juin 2006, mis en ligne le 21.09.2010, http://rfp.revues. org/240.

KAELBLE Hartmut, SCHRIEWER Jürgen (éds.), Vergleich und Transfer. Komparatistik in den Sozial-, Geschichts- und Kulturwissenschaften, Frankfurt/ Main, Campus, 2003.

KAELBLE Hartmut, « Les mutations du comparatisme international », Les cahiers Irice, 1/2010, $\mathrm{n}^{\circ}$ 5, p. 9-19.

KEINER Edwin, Erziehungswissenschaft 1947-1990. Eine empirische und vergleichende Untersuchung zur kommunikativen Praxis einer Disziplin, Weinheim, Deutscher Studien Verlag, 1999.

KEMNITZ Heidemarie, « Un regard allemand sur I'histoire de l'école en Suisse », in R. Hofstetter, C. Magnin, L. Criblez, C. Jenzer (éds.), Une école pour la démocratie. Naissance et développement de l'école primaire en Suisse au XIXe siècle, Berne, P. Lang, 1999, p. 325-342.

KOTT Sandrine, « Les organisations internationales, terrains d'étude de la globalisation. Jalons pour une approche socio-historique », Critique internationale, 52/2011, p. 9-16.

KOTT Sandrine, DROUX Joëlle, Globalizing social rights: The International Labour Organization and Beyond, Palgrave MacMillan, 2012.

LAWN Martin (éds.), An Atlantic Crossing? The Work of the International Examination Inquiry, its Researchers, Methodes and Influence, Cambridge University Press, 2008.

LAWN Martin, NOVOA Antonio, L'Europe réinventée. Regards critiques sur l'espace européen de l'éducation, Paris, L'Harmattan, 2005.

MAGNIN Charles, ZOTTOS Éléonore (2005), «Enseignement secondaire et «transferts » de modèle éducatif: le cas de la Conférence internationale de l'éducation (Cie) 1934-1986, in N. Bottani, C. Magnin, E. Zottos (éds.), L'enseignement secondaire à l'échelle mondiale: bilans et perspectives, Genève, Service de la recherche en éducation, 2005, p. 179-199. 
MATASCI Damiano, «Le système scolaire français et ses miroirs, Les missions pédagogiques entre comparaison internationale et circulation des savoirs », Histoire de l'éducation, nº 125, 1/2010, p. 35-51.

-, L'école républicaine et l'étranger. Une histoire internationale des réformes scolaires en France, 1870-1914, Lyon, ENS Editions, coll. « Sociétés, Espaces, Temps », 2015.

MAYER Christine, « Female education and the cultural transfer of pedagogical knowledge in the eighteenth century », Paedagogica Historica, 48/4, 2012, p. 511-526.

McINTOSH Christopher, «The Perils of Educational Transfers », International Review of Education, Volume 53, 2/2007, p. 219-242.

MEURIS Georges, DE COCK Geneviève (éds.), Éducation comparée. Essai de bilan et projet pour l'avenir, Bruxelles, De Boeck Université, 1997.

NGUYEN Thuy Phuong, « The rivalry of the French and American educational missions during the Vietnam War », Paedagogica Historica, vol. 50, 1-2/2014, p. 27-41.

NOAH Harold J., ECKSTEIN Max A., Toward a science of Comparative Education, London, Macmillan, 1969.

NOVOA Antonio, YARIV-MASHAL Tali, «Le comparatisme en éducation: mode de gouvernance ou enquête historique? », in P. Laderrière et F. Vaniscotte (éds.), L'éducation comparée: un outil pour l'Europe, L'Harmattan, 2003, p. 57-82.

PERRY Laura B., TOR Geok-hwa, « Understanding educational transfer: theoretical perspectives and conceptual frameworks », Prospects, vol. 38, 4/2008, p. 509-526.

PHILLIPS David, «Aspects of educational transfer», Springer International Handbooks of Education, vol. 22, 1/2009, International Handbook of Comparative Education, section vII, p. 1061-1077.

PHILLIPS David, OCHS Kimberly, Educational Policy Borrowing: historical perspectives, Oxford, Symposium Books, 2004.

PORCHER Louis, L'éducation comparée: Pour aujourd'hui et pour demain, Paris, L'Harmattan, 2008.

RAPPLEYE Jeremy, « Theorizing Educational Transfer: toward a conceptual map of the context of cross-national attraction », Research in Comparative and International Education, volume I, 3/2006, p. 223-240.

RAPPLEYE Jeremy, IMOTO Yuki, HORIGUCHI Sachiko, «Towards "thick description" of educational transfer: understanding a Japanese institution's "import" of European language policy », Comparative Education, 2011. 
ROLDAN VERA Eugenia, The British Book Trade and Spanish American Independence. Education and Knowledge Transmission in Transcontinental Perspective, Aldershot, Ashgate Publishing Limited, 2003.

SAUNIER Pierre-Yves, «Circulations, connexions et espaces transnationaux », Genèses, 4/2004, p. 110-126.

SADLER Michael, «How Far Can we learn anything of practical value from the study of foreign systems of Education? Address given at the Guilford Educational Conference on Saturday 20 October 1900, in J. Higginson (éds.), Selections from Michael Sadler: studies in world citizenship, Liverpool, Dejall et Meyorre, 1979.

SCHRIEWER Jürgen, «Système mondial et réseaux d'interrelation. L'internationalisation de la pédagogie, un problème des sciences comparées de l'éducation », in G. Meuris, G. De Cock (éds.), Éducation comparée. Essai de bilan et projets d'avenir, Paris et Bruxelles, De Boeck \& Larcier, 1997, p. 107-139.

-, «L'éducation comparée: un programme ambitieux face à de nouveaux défis », in P. Laderrière, F. Vaniscotte, L'éducation comparée: un outil pour I'Europe, Paris, L'Harmattan, 2003, p. 21-49.

STEINER-KHAMSI Gita, Multikulturelle Bildungspolitik in der Postmoderne, Opladen, Leske \& Budrich, 1992.

-, The global politics of educational borrowing and lending, New York, Teachers College Press, 2004.

STEINER-KHAMSI Gita, QUIST Hubert O., « The Politics of Educational Borrowing: Reopening the Case of Achimota in British Ghana », Comparative Education Review, vol. 44, n³, août 2000, p. 272-299.

STEINER-KHAMSI Gita, STOLPE Ines, Educational Import: Local Encounters with Global Forces in Mongolia, New York, Palgrave Macmillan, 2006.

STEINER-KHAMSI Gita, WALDOW Florian, Policy Borrowing and Lending in Education, Londres et New York, Routledge, 2012.

TANAKA Masahiro, The Cross-cultural Transfer of Educational Concepts and Practices: a comparative study, Oxford, Symposium Books, 2005.

WALDOW Florian, « Undeclared imports: silent borrowing in educational policymaking and research in Sweden », Comparative Education, volume 45, $n^{\circ} 4$, novembre 2009 , p. 477-494. 


\section{Littératures nationales, construction culturelle, identités nationales et régionales}

ASSIMA Georges, «L'exception culturelle suisse ou l'émergence d'une Confédération multiculturelle dans sa relation historique avec la France », Migrations Société, vol. 15, 87-88/2003, p. 169-174

-, La France et la Suisse. Une histoire en partage, deux patries en héritage, Paris, L'Harmattan, 2012

ALLAZ André, L'helvétisme, péril national, Fribourg, 1914.

ANDERSON Benedict, L'imaginaire national. Réflexions sur l'origine et l'essor du nationalisme, Paris, La Découverte, 2002.

ANDREY Georges, La Suisse romande, une histoire à nulle autre pareille! Pontarlier, Éditions du Belvédère, 2012.

BAYLY Christopher Alan, La naissance du monde moderne (1780-1914), Paris, Les Éditions de l'Atelier, 2007 [2004].

BEYRIE Jacques, Qu'est-ce qu'une littérature nationale? Écriture, identité, pouvoir en Espagne, Toulouse, Presses universitaires du Mirail, 1994.

BERCHTOLD Alfred, La Suisse romande au cap du XXe siècle. Portait littéraire et moral, Lausanne, Payot, 1966.

BERTRAND Michel, CABANEL Patrick, DE LAFARGUE Bertrand, La fabrique des nations. Figures de l'État-nation dans l'Europe du XIXe siècle, Paris, Les Éditions de Paris, 2003.

BICHSEL Peter, La Suisse du Suisse, Lausanne, Éditions La Cité, 1970.

BLOCH Peter André (éds.), La Suisse romande et sa littérature, Poitiers, La Licorne, 1989.

BONDALLAZ Paul, « Le mouvement littéraire en pays fribourgeois vers 1850 », $A F, 1 / 1919$, p. 1-28.

BRIDEL Yves, FRANCILLON Roger, La Bibliothèque universelle (1815-1924). Miroir de la sensibilité romande au XIXe siècle, Lausanne, Payot, 1998.

CABANEL Patrick, La Question nationale au XIXe siècle, Paris, La Découverte, 1997.

-, Le Tour de la nation par des enfants. Romans scolaires et espaces nationaux (XIXe-XXe siècles), Paris, Belin, 2007.

-, «École et nation: l'exemple des livres de lectures scolaires (XIX et première moitié du XXe siècles) », Histoire de l'éducation, n 126, avril-juin 2010, p. 33-54.

CANDAUX Jean-Daniel, « Rodolphe Töpffer a-t-il inventé les "Voyages en zigzag" » ? », in L. Boissonnas et alii, Töpffer, Genève, Skira, 1996, p. 189-199. 
CARRETERO Mario, ASENSIO Mikel, RODRIGUEZ-MONEO Maria, « History Education and the Construction of National Identities », International Review of History Education, Information Age Publishing, 2012.

CASANOVA Pascale, La République mondiale des Lettres, Paris, Seuil, 1999.

CITRON Suzanne, Le Mythe national, Paris, Éditions ouvrières, 1980.

CLAVIEN Alain, Les Helvétistes. Intellectuels et politiques en Suisse romande au début du siècle, Lausanne, SHSR et Éditions d'en bas, 1993.

DEMAZIÈRE Didier et GADÉA Charles (éds.), Sociologie des groupes professionnels: acquis récents et nouveaux défis, Paris, La Découverte, 2009.

DESCHAMPS Jean-Claude, MOLINER Pascal, L'identité en psychologie sociale: des processus identitaires aux représentations sociales, Paris, Colin, 2008.

DIECKHOFF Alain, La nation dans tous ses états. Les identités nationales en mouvement, Paris, Flammarion, 2000.

ELIAS Norbert, Qu'est-ce que la sociologie, Paris, Pocket, 2003.

-, La civilisation des mœurs, Paris, Pocket, 1974.

-, La dynamique de I'Occident, Paris, Pocket, 1975.

-, La société des individus, Paris, Fayard, 2001.

FELBER Jean-Pierre, De I'Helvétie romaine à la Suisse romande, Genève, Slatkine, 2006.

FONTAINE Alexandre, « Des livres pour fabriquer des Romands. Littérature scolaire, transferts culturels et élaboration collective des identités européennes au XIX siècle », in P. Bühler, T. Bühler, M. Helfenberger \& F. Osterwalder (éds.), Erziehung in der europäischen Literatur des 19. Jahrhunderts, Prisma 21, Beiträge zur Erziehungswissenschaft aus historischer psychologischer und soziologischer Perspektive, Bern, Haupt Verlag, 2014, p. 233-250.

-, «Alexandre Daguet (1816-1894): une histoire pour les Fribourgeois. La fabrication d'un romand cantonal », Annales Fribourgeoises, 76/2014, p. 47-56.

FRANCILLON Roger, JAKUBEC Doris (éds.), Littérature populaire et identité suisse. Récits populaires et romans littéraires: évolution des mentalités en Suisse romande au cours des cent dernières années, Lausanne, L'Âge d'Homme, 1991.

FRANCILLON Roger, Histoire de la littérature en Suisse romande. I/ De Töpffer à Ramuz, Lausanne, Payot, 1997.

-, De Rousseau à Starobinsky. Littérature et identité suisse, Lausanne, Presses polytechniques et universitaires romandes, 2011.

GELLNER Ernest, Nations and Nationalism, Oxford, 1983.

GIRAULT René, Peuples et nations d'Europe au xix siècle, Paris, Hachette, 1996.

GODET Philippe, Histoire littéraire de la Suisse romande, Neuchâtel et Paris, Delachaux et Fischbacher, 1890. 
HALPERN Catherine, Identité(s): L'individu, le groupe, la société, Paris, Éditions sciences humaines, 2009.

HELLER Geneviève, «L'école vaudoise: entre l'identité suisse et l'identité cantonale » in Auf dem Weg zu einer schweizerischen Identität, Fribourg, Universitätsverlag, 1987, p. 245-271.

-, «Tiens-toi droit! ». L'enfant à l'école primaire du XIX siècle: espace, morale, santé, Lausanne, Éditions d'en bas, 1988.

HELLER Geneviève et alii, D'un pays et du monde: comment l'école a contribué à développer le sentiment d'appartenance au pays et au monde à travers 150 ans de matériel scolaire, Yverdon-les-Bains, Association du musée de l'école et de l'éducation, 1993.

HOBSBAWN Eric, RANGER Terence, The Invention of Tradition, Cambridge, Cambridge University Press, 1983.

HOBSBAWN Eric, Nations et nationalisme depuis 1780, Paris, Gallimard, 1992 [1990].

JEISMANN Michael, La patrie de l'ennemi. La notion d'ennemi national et la représentation de la nation en Allemagne et en France de 1792 à 1918, Paris, CNRS-Éditions, 1997.

LEVRAT Nicolas, La construction européenne est-elle démocratique?, Paris, La Documentation française, 2012.

LÖFGREN Orvar, « The Nationalization of Culture, National Culture as Process », réédition de Ethnologia Europaea, XIX, 1/1989.

MAGGETTI Daniel et MUELLER Dieter, Bonnes lectures. Textes populaires de Suisse Romande 1880-1990, Lausanne, Éditions Zoé, 1992.

MAGGETTI Daniel, L'Invention de la littérature romande 1830-1910, Lausanne, Payot, 1995.

MAUSS Marcel, «Nations, nationalités, internationalisme», CEuvres, Paris, Minuit, 1969.

MAALOUF Amin, Les identités meurtrières, Paris, Grasset, 1998.

MOECKLI-CELLIER Maurice, La révolution française et les écrivains suissesromands 1789-1815, Neuchâtel, Éditions Victor Attinger, 1931.

MÜTZENBERG Gabriel, «Rodolphe Töpffer et le sentiment national », Revue suisse d'histoire, 27/1977, p. 121-132

PAVILLON Monique, La femme illustrée des années vingt: essai sur l'interprétation de l'image des femmes dans la presse illustrée, 1920-1930, Lausanne, Histoire et Société contemporaine, 1986.

PERROCHON Henri, «Le Franc-Comtois Max Buchon à Fribourg (1834-1869), d'après des correspondances inédites », AF, 1936, p. 12-27. 
-, « Un ami d'Alexandre Daguet et de Félix Bovet: Max Buchon », Musée neuchâtelois, 1936, p. 205-214

PIGNAT Valérie, L'expression du sentiment patriotique dans la presse de l'Helvétique de 1798, Genève, 1994.

POMIAN Krzysztof, L'Europe et ses nations, Paris, Gallimard, 1990.

REFFET Michel (éds.), La littérature suisse. Les masques de l'identité, Strasbourg, Presses universitaires, 1999.

RÉGNIER Philippe, VAILLANT Alain, BERTRAND Jean-Pierre, Histoire de la littérature française du XIXe siècle, Paris, Nathan 1998.

REICHLER Claude, Le voyage en Suisse: anthologie des voyageurs français et européens de la Renaissance au XXe siècle, Paris, R. Laffont, 1998.

-, La découverte des Alpes et la question du paysage, Genève, Georg, 2002.

RESZLER André, Mythes et identité de la Suisse, Genève, Georg, 1986.

-, Les Suisses (s'ils existent)... L'identité suisse et sa relation à l'Europe, Genève, Georg, 2008.

REYNOLD Gonzague (de), « Le doyen Bridel et I'influence de l'école zuricoise (sic) dans la Suisse romande », Bibliothèque universelle et revue suisse, Lausanne, t. 43,1906 , p. 524-553; t. 44, 1906, p. 43-64.

-, Deux Conférences: La Suisse romande, I'unité de la Suisse, Zurich, Rascher et Cie Éditeurs, 1915.

-, « Notre romantisme», La vie romantique au pays romand, Lausanne, Éditions Freudweiler-Spiro, 1930. Défense et illustrations de l'esprit suisse, Boudry, La Baconnière, 1939.

ROSSEL Virgile, Histoire littéraire de la Suisse romande I et II, Genève, Georg, 1891.

-, Littérature française hors de France, Paris, Fischbacher, 1897.

ROUGEMONT Denis (de), L'aventure occidentale de I'homme, Paris, Albin Michel, 1957.

-, Vingt-huit siècles d'Europe. La conscience européenne à travers les textes d'Hésiode à nos jours, Paris, Payot, 1961.

-, La Suisse ou I'histoire d'un peuple heureux, Lausanne, L'Âge d'homme, 1989.

RUEDIN Pascal, Beaux-arts et représentation nationale: la participation des artistes suisses aux expositions universelles de Paris (1855-1900), Bern. Peter Lang, 2010.

SAPIRO Gisèle, L'espace intellectuel en Europe. De la formation des États-nations à la mondialisation XIXe-XXI siècle, Paris, La Découverte, 2009.

-, La responsabilité de l'écrivain. Littérature, droit et morale en France (XIXe$X X^{e}$ siècle), Paris, Seuil, 2011. 
SEMMIG Hermann, Kultur- und Litteratur-Geschichte der französischen Schweiz und Savoyens, Zurich, Th. Schröter, 1884.

SCHNYDER Peter (éds.), Visions de la Suisse. À la recherche d'une identité: projets et rejets, Strasbourg, Presses universitaires de Strasbourg, 2005.

SCHULZE Hagen, État et Nation dans I'histoire de I'Europe, Paris, Seuil, 1996.

THIESSE Anne-Marie, La création des identités nationales. Europe XVIII XIXe siècle, Paris, Seuil, 1999.

-, «Des fictions créatrices: les identités nationales», Romantisme, volume XXX, 110/2000, p. 51-62.

-, «Littérature et éducation au national », Le Français aujourd'hui, n 167, 4/2009, p. 19-26.

-, Faire les Français. Quelle identité nationale?, Paris, Stock, 2010.

-, «Rôle de la presse dans la formation des identités nationales», in M.-È. Thérenthy et A. Vaillant (éds.), Presse, nations et mondialisation au XIXe siècle, Nouveau Monde Éditions, 2010, p. 127-137.

-, (éds.), La culture des nations, La matière et l'esprit, 16/2010.

-, «Nations, internationalismes et mondialisation », Romantisme, $\mathrm{n}^{\circ} 163$, $1 / 2014$, p. $15-27$.

VERDELHAN-BOURGADE Michèle et alii, Les manuels scolaires, miroirs de la nation?, Paris, I'Harmattan, 2007, p. 13-24.

VUILLET Adam, Les poètes vaudois contemporains, Lausanne, Bridel Éditeurs, 1870.

ZELLWEGER Rudolph, Les débuts du roman rustique: Suisse, Allemagne, France, 1836-1856, Paris, E. Droz, 1941.

ZORN Fritz, Mars, Paris, Gallimard, 1982.

\section{Société et éducation en France}

AESCHIMANN Willy, La pensée d'Edgar Quinet. Études sur la formation de ses idées, Paris et Genève, Anthropos, 1986.

ALBERTINI Pierre, La France du XIXe siècle, Paris, Hachette, 2000.

ALTEN Michèle, «Un siècle d'enseignement musical à l'école primaire », Vingtième siècle. Revue d'histoire, nº 55, juillet-septembre 1997, p. 3-15.

-, « Musique scolaire et société dans la France de la III République », Tréma [en ligne], 25/2005, p. 1-12.

APRILE Sylvie, Le siècle des exilés: bannis et proscrits de 1789 à la Commune, Paris, CNRS Éditions, 2010.

ARNAUD Pierre, Le militaire, l'écolier, le gymnaste: naissance de l'éducation physique en France (1869-1889), Lyon, Presses universitaires de Lyon, 1991. 
ARNAUD Pierre (éds.), Les Athlètes de la républiques: Gymnastique, sport et idéologie républicaine (1870-1914), Paris, L'Harmattan, 2000.

AZOUVI François, BOUREL Dominique, De Königsberg à Paris. La réception de Kant en France (1788-1804), Paris, Vrin, 1991.

BAUBÉROT Jean, Laïcité 1905-2005, entre passion et raison, Paris, Seuil, 2004. -, Histoire de la laïcité en France, Paris, PUF, 2007.

-, La morale laïque contre l'ordre moral sous la III République, Paris, L'Harmattan, 2009.

BELHOSTE Bruno, Les Sciences dans l'enseignement secondaire français, textes officiels (1789-1914), Paris, INRP et Economica, 1995.

BELISSA Marc et COTTRET Bernard (éds.), Cosmopolitismes, patriotismes. Europe et Amériques 1773-1802, Rennes, Les Perséides, 2005.

BENJAMIN Walter, Paris, capitale du XIXe siècle, Paris, Allia, 2003.

BENSOUSSAN Georges et LAUGÈRE Antoine, « L'instruction civique: ses buts, ses agents, ses discours 》, Raison présente, 74/1985, p. 7-23.

BOUREL Dominique, Souvenirs d'Allemagne, Paris, CNRS Éditions, 2011.

BOURZAC Albert, Les bataillons scolaires 1880-1891. L'éducation militaire à l'éducation de la République, Paris, L'Harmattan, 2004.

BOUTAN Pierre, « Michel Bréal "ami des patois": linguistique, pédagogie, politique », Langages, 120/1995, p. 33-51.

-, « L'usage du manuel en question: une tradition en matière d'apprentissage des langues », Ela, Études de linguistique appliquée, 2001/1, nº 125, p. 11-24.

-, «Langue(s) maternelle(s): de la mère ou de la patrie?», Ela, Études de linguistique appliquée, 2003/2, n²130, p. 137-151.

BRUNET Martine, «La création du premier établissement d'éducation laïque: I'Orphelinat des Batignolles », Journée d'étude sur Ferdinand Buisson (30 mai 2000).

-, « Ferdinand Buisson, la guerre et la paix », Theolib: Ferdinand Buisson, Souvenirs et autres écrits, 2012, p. 119-142.

-, Ferdinand Buisson \& les socialistes libertaires, Clamecy, Nouvelle Imprimerie Laballery, 2014.

BRUTER Annie, L'Histoire enseignée au Grand siècle. Naissance d'une Pédagogie, Paris, Belin, 1997.

-, « L'enseignement de I'histoire de France vers 1900 », Centraliens. La revue mensuelle des Arts et Manufactures, n 558, décembre 2004, p. 32-33.

-, «Grandeur et décadence d'une matière d'enseignement: I'histoire sainte », in J. Lalouette, X. Boniface, J.-F. Chanet, I. Elliott, Les Religions à I'école. Europe et Amérique du nord, XIXe-XXI siècles, Paris, Letouzey et Ané, 2011, p. 259-274 
CABANEL Patrick, « Les nouvelles provinciales: Félix Pécaut et la formation de l'esprit républicain dans les années $1870 »$, Le Protestantisme dans les pays de l'Adour (1787-1905), Colloque d'Orthez, 22 au 23 septembre 1995, BSHPF, 4/1996, p. $755-774$.

-, Les Protestants et la république, Paris, Éditions Complexe, 2000.

-, « Un essai de vies parallèles: Ferdinand Buisson et Félix Pécaut », Journée d'étude sur Ferdinand Buisson, 30 mai 2000 (https: halshs.archives-ouvertes. $\mathrm{fr} /$ halshs-00177990).

-, Le Dieu de la République. Aux sources protestantes de la laïcité (18601900), Rennes, PUR, 2003.

CARRIVE Lucien, « Félix Pécaut d'après sa correspondance », Le Protestantisme dans les pays de l'Adour (1787-1905). Actes du colloque d'Orthez, 22 au 23 septembre 1995, Paris, Bulletin de la Société d'histoire.

CASPARD Pierre (dir.), La presse d'éducation et d'enseignement, XVIII' siècle-1940: répertoire analytique, 4 volumes, Paris, INRP-CNRS, 1981-1991.

CASPARD Pierre, «Presse pédagogique et formation continue des instituteurs (1815-1940) », Recherche et Formation (Paris), 23/1996, p. 105-117.

CHALMEL Loïc, Réseaux philanthropinistes et pédagogie au XVIII siècle, Berne, Peter Lang, 2004.

CHALOPIN Michel, L'enseignement mutuel en Bretagne de 1815 à 1850, université de Rennes, thèse de doctorat, 2008.

CHANET Jean-François, L'école républicaine et les petites patries, Paris, Aubier, 1996.

-, Vers I'armée nouvelle. République conservatrice et réforme militaire 18711879, Rennes, PUR, 2006.

CHAPOULIE Jean-Michel, L'école d'État conquiert la France. Deux siècles de politique scolaire, Rennes, PUR, 2010.

CHARLE Christophe, Les élites de la République (1880-1900), Paris, Fayard, 1987. -, Naissance des « intellectuels: 1880-1900, Paris, Les Éditions de Minuit, 1990.

-, La République des universitaires (1870-1940), Paris, Seuil, 1994.

-, Les intellectuels en Europe au XIXe siècle. Essai d'histoire comparée, Pairs, Seuil, 1996.

CHERVEL André, Histoire de l'enseignement du français du XVII au XXe siècle, Paris, Retz, 2006.

CLANCY-SMITH Julia, «L'école de la rue du Pacha à Tunis: I'éducation de la femme arabe et la plus "grande France" (1900-1914) », Clio. Histoire, femmes et sociétés, 12/2000, p. 33-55.

COMBES Jean, L'école primaire sous la III République, Luçon, Éditions SudOuest, 2002. 
COMPÈRE Marie-Madeleine, L'histoire de l'éducation en Europe. Essai comparatif sur la façon dont elle s'écrit, Paris et Berne, INRP et Lang, 1995.

CUCHET Guillaume, Les voix d'outre-tombe. Tables tournantes, spiritisme et société au XIXe siècle, Paris, Seuil, 2012.

DEFRANCE Jacques, JOSELEAU Yves, «Phokion Heinrich Clias (1782-1854)», in P. Arnaud, Le militaire, l'écolier, le gymnaste. Naissance de l'éducation physique en France (1869-1889), Lyon, Presses universitaires de Lyon, 1991, p. 175-185.

DELIEUVIN Marie-Claude, Marc-Antoine Jullien de Paris (1775-1848): théoriser et organiser l'éducation, Paris, L'Harmattan, 2003.

D'ENFERT Renaud, «L'introduction du travail manuel dans les écoles primaires de garçons, 1880-1900 », Histoire de l'éducation, n 113, janvier 2007, p. 31-67.

DEMEULENAERE-DOUYERE Christiane, « Une tentative pédagogique novatrice sous les auspices du Conseil général de la Seine: l'éducation intégrale à I'orphelinat Prévost de Cempuis (Oise) », 114e congrès national des Sociétés savantes, Paris, 1989, p. 465-475.

-, Paul Robin (1837-1912): un militant de la liberté et du bonheur, Paris, Publisud, 1994.

-, « Ferdinand Buisson et l'innovation pédagogique: I'exemple de l'Orphelinat Prévost de Cempuis », Journée d'étude sur Ferdinand Buisson, 30 mai 2000.

DENIS Daniel, KAHN Pierre (éds.), L'école républicaine et la question des savoirs. Enquête au cœur du Dictionnaire de Ferdinand Buisson, Paris, CNRS Éditions, 2003.

-, L'école de la III République en questions. Débats et controverses dans le Dictionnaire de Pédagogie de Ferdinand Buisson, Berne, Peter Lang, 2006.

DESBUISSONS Frédérique, BUCHON Max, Le réalisme. Discussions esthétiques recueillies et commentées, La Rochelle, Rumeurs des Âges, 2007.

DESROSIERES Alain, La politique des grands nombres. Histoire de la raison statistique, Paris, La Découverte, 2010.

DUBOIS Patrick, Le dictionnaire de pédagogie et d'instruction primaire de Ferdinand Buisson. Unité et disparité d'une pédagogie pour l'école primaire (1876-1911), université L. Lumière-Lyon 2, thèse de doctorat, 1994.

-, « L'historiographie composite du Dictionnaire de pédagogie de Ferdinand Buisson », Penser l'éducation, université de Rouen, laboratoire des sciences de l'éducation, 1/1996, p. 43-57.

-, «La pédagogie catholique dans le dictionnaire de pédagogie de Ferdinand Buisson », Pédagogies chrétiennes, pédagogues chrétiens. Actes du colloque d'Angers des 28 au 30 septembre 1995, Paris, Éditions Don Bosco, 1996, p. 323-333.

-, « Le Dictionnaire de F. Buisson et ses auteurs (1878-1887) », Histoire de l'éducation, 85/2000, p. 25-47. 
-, Répertoire des auteurs du Dictionnaire de pédagogie de Ferdinand Buisson, Paris, INRP, 2002.

-, Le Dictionnaire de Ferdinand Buisson. Aux fondations de l'école républicaine, Bern, Peter Lang, 2002.

DURKHEIM Émile, Éducation et sociologie, Paris, PUF, 2009 [1922].

ESPAGNE Michel, LAGIER Françoise, WERNER Michael, Le maître de langues. Les premiers enseignants d'allemand en France: 1830-1850, Paris, Éditions de la maison des sciences de I'homme, 1991.

FABRE Rémi, « Pécaut, Buisson, Steeg, le libéralisme protestant entre tolérance et laïcité », La Tolérance, Colloque international de Nantes (mai 1998), Rennes, PUR, 1999.

FALAIZE Benoît, HEIMBERG Charles, LOUBES Olivier (éds.), L'école et la nation, Paris ENS Éditions, 2013.

FAVRE Georges, Histoire de l'éducation musicale, Paris, La pensée universelle, 1980.

FREY Hugo, Max Buchon et son œuvre, Besançon, Imprimerie de I'Est, 1940.

FURET François, La Gauche et la révolution au milieu du XIXe siècle. Edgar Quinet et la question du jacobinisme, Paris, Hachette, 1986.

FURET François, OZOUF Jacques, Lire et écrire: I'alphabétisation des Français de Calvin à Jules Ferry, 2 tomes, Paris, Éditions de Minuit, 1977.

GAUTHERIN Jacqueline, «Marc-Antoine Jullien de Paris (1775-1848)», Perspectives: revue trimestrielle d'éducation comparée, vol. 23, 3-4/1993, p. $783-798$

GÉRARD Alice, « Le rôle des pédagogues protestants: I'exemple du Dictionnaire pédagogique », Les Protestants dans les débuts de la troisième République, p. 49-57.

GESLOT Jean-Charles, Victor Duruy, historien et ministre (1811-1894), Presses universitaires du Septentrion, 2009.

GIOLITTO Pierre, Histoire de l'enseignement primaire au XIXe siècle, Paris, Nathan, 1983-1984.

GO Henri Louis, RIONDET Xavier, À côté de Freinet, Nancy, PUN-Édulor, 2015.

GUEISSAZ Mireille, « Félix Pécaut et Ferdinand Buisson. Entre passion religieuse et raison politique: histoire d'une vocation $\gg$, Tumultes, Paris, 2-3/1993, p. 175204.

-, « Jules Barni (1818-1878) ou l'entreprise démopédique d'un philosophe républicain moraliste et libre-penseur », Les bonnes mœurs, actes du colloques tenu à Amiens en 1993, Paris, PUF, 1994, p. 215-244.

-, L'Image énigmatique de Ferdinand Buisson. La vocation républicaine d'un saint puritain, Villeneuve-d'Ascq, Presses universitaire du Septentrion, 1999. 
HAYAT, Pierre, Le dictionnaire de pédagogie et d'instruction primaire: extraits, Paris, Kimé, 2000.

-, « Ferdinand Buisson et l'individualisme », Archives de sciences sociales des Religions, n²124, octobre-décembre 2003, p. 5-18.

HOUSSAYE Jean (éds.), Premiers pédagogues: de l'Antiquité à la Renaissance, Paris, ESF, 2002.

-, Nouveaux pédagogues: pédagogues de la modernité (tome I), Paris, Fabert, 2007.

-, « Vouloir la coéducation, une fausse bonne idée? 》, in P. Maubant et L. Roger (éds.), De nouvelles configurations éducatives. Entre coéducation et communautés d'apprentissage, Québec, Presses de I'université du Québec, 2010, p. 13-21.

JOLIOT-ANGUENOT Janine, Max Buchon, romancier réaliste et régionaliste, université de Besançon, thèse de doctorat, 1980.

JOUAN Sylvie, «Enseignement mutuel et enseignement simultané. Quelle conception de l'apprentissage se cache derrière le choix pédagogique simultané par le Ministère Guizot en France? », mémoire de recherche, ISPEF Lyon, 2012.

LOEFFEL Laurence, Ferdinand Buisson, apôtre de l'école laïque, Paris Hachette, 1999.

-, La question du fondement de la morale laïque sous la III République (18701914), Paris, PUF, 2000.

LOMBEZ Christine, La traduction de la poésie allemande en français dans la première moitié $d u X I X X^{e}$ siècle. Réception et interaction poétique, Tübingen, Max Niemeyer Verlag, 2009.

LOUBES Olivier, L'école et la patrie. Histoire d'un désenchantement, Paris, Belin, 2001.

LUC Jean-Noël, La petite enfance à l'école, XIXe-XXe siècles. Textes officiels relatifs aux salles d'asile, aux écoles maternelles, aux classes et sections enfantines (1829-1981), Paris, Economica, 1982.

MARCHAND Philippe, « L'instruction civique en France. Quelques éléments d'histoire », Spirale-Revue de Recherches en éducation, 7/1992, p. 11-42.

MAURICE René, La fugue à Bruxelles. Proscrits, exilés, réfugiés et autres voyageurs, Paris, Éditions du Félin, 2003.

MAYEUR Françoise, Histoire de l'enseignement et de l'éducation, 1789-1930, tome III, Paris, Perrin, 1981.

-, L'éducation des filles en France au XIXe siècle, Paris, Perrin, 2008.

MIQUEL Pierre, Le second Empire, Paris, Perrin, 1998 [1992].

MOLE Frédéric, L'école laïque pour une République sociale. Controverses pédagogiques et politiques (1900-1914), Rennes, PUR, 2010. 
MOLLIER Jean-Yves, Louis Hachette (1800-1864). Le fondateur d'un empire, Paris, Fayard, 1999.

MOLLIER Jean-Yves, SIRINELLI Jean-François, VALLOTTON François (éds.), Culture de masse et culture médiatique en Europe et dans les Amériques (1860-1940), Paris, PUF, 2006.

MOMBERT Monique, L'enseignement de l'allemand en France 1880-1918. Entre «modèle allemand» et "langue de l'ennemi», Strasbourg, Presses Universitaires de Strasbourg, 2001.

MOREL-FATIO Alfred, « Don Francisco Amoros, marquis de Sotelo, fondateur de la gymnastique en France », Bulletin Hispanique, t. 27, 1/1925, p. 36-78.

MOUGNIOTTE Alain, Les débuts de l'instruction civique en France, Lyon, Presses universitaires de Lyon, 1991.

NICOLET Claude, L'idée républicaine en France (1789-1924), Paris, Gallimard, 1994 [1982].

NIQUE Christian, François Guizot. L'école au service du gouvernement des esprits, Paris, Hachette Éducation, 1999.

NOVOA Antonio Manuel, La construction du «modèle scolaire » dans l'Europe du Sud-Ouest (Espagne, France, Portugal) des années 1860 aux années 1920, Paris université Paris IV Sorbonne, thèse de doctorat d'histoire, mars 2006.

NOVOA Antonio, LAWN Martin, L'Europe réinventée: Regards critiques sur l'espace européen de l'éducation, Paris, L'Harmattan, 2005.

OGNIER Pierre, L'École républicaine française et ses miroirs. L'idéologie scolaire française et sa vision de l'école en Suisse et en Belgique à travers la revue pédagogique (1887-1900), Berne, Peter Lang, 1998.

-, Une école sans Dieu? 1880-1895. L'invention d'une morale laïque sous la III République, Toulouse, Presses universitaires du Mirail, 2008.

ONFRAY Michel, Les ultras des Lumières, Paris, Livre de poche, 2009. -, L'Eudémonisme social, Paris, Livre de poche, 2010.

OZOUF Jacques et FURET François, Lire et écrire: L'alphabétisation des Français de Calvin à Jules Ferry (2 tomes), Paris, Les éditions de Minuit, 1977.

OZOUF Mona, La République des instituteurs, Paris, Seuil, 2001.

-, L'École, l'Église et la République: 1871-1914, Paris, Seuil, 2007.

OZOUF Jacques et OZOUF Mona, La République des instituteurs, Paris, Seuil, 1992.

PICCO Dominique, « Le plan d'Ivan Betskoï pour I'Institut des demoiselles nobles de Smolny, modèle ou contre-modèle éducatif? », in F. Cadilhon, M. Combet \& M. Figeac-Monthus (éds.), Construire l'éducation de l'Ancien Régime à nos jours, Presses universitaires de Bordeaux, 2009, p. 101-128.

PLENEL Edwy, Dire non, Paris, Don Quichotte, 2014.

-, Pour les musulmans, Paris, La Découverte, 2014. 
PROST Antoine, Histoire de l'enseignement et de l'éducation, depuis 1930, tome IV, Paris, Perrin, 1981.

-, Histoire de I'enseignement en France 1800-1967, Paris, Colin, 1983.

-, Regards historiques sur l'éducation en France XIXe-XX siècles, Paris, Belin, 2007.

PROST Antoine, FALAIZE Benoît, « École, histoire et nation », Histoire de l'éducation, numéro thématique, n 126, avril-juin 2010.

PEILLON Vincent, Une religion pour la République. La foi laïque de Ferdinand Buisson, Paris, Seuil, 2010.

POUCET Bruno, « Petite histoire de l'enseignement mutuel: I'exemple du département de la Somme », Carrefours de l'éducation, 1/2009, n² 27, p. 7-18.

RASMUSSEN Anne, L'Internationale Scientifique (1890-1914), thèse d'histoire sous la direction de Jacques Julliard, EHESS, 1995, 2 volumes.

-, « L'hygiène en congrès 1852-1912: circulations et configurations internationales », in P. Bourdelais (dir.), Les hygiénistes. Enjeux, modèles, pratiques (XVIII ${ }^{e}-X X^{e}$ siècles), Paris, Belin, 2001, p. 213-239.

REY-HERME Philippe-Alexandre, Les colonies de vacances en France. Origines et premiers développements (1881-1906), Saint-Étienne, chez l'auteur, 1954.

RICHER Laurence, Edgar Quinet: I'aurore de la République, Bourg-en-Bresse, Musnier-Gilbert, 1999.

RIOUX Jean-Pierre, SIRINELLI Jean-François, Le temps des masses, le vingtième siècle, Paris, Collection Histoire culturelle de la France, Seuil, 2005.

RIVET Daniel, Le Maghreb à l'épreuve de la colonisation, Paris, Fayard, 2010 [2002].

ROGERS Rebecca, A Frenchwoman's Imperial Story: Madame Luce in NineteenthCentury Algeria, Stanford, Stanford University Press, 2013.

ROSANVALLON Pierre, Le moment Guizot, Paris, Gallimard, 1985.

-, Le sacre du citoyen, Paris, Gallimard, 1992.

-, Le peuple introuvable, Paris, Gallimard, 1998.

-, La démocratie inachevée: histoire de la souveraineté du peuple en France, Paris, Gallimard, 2000.

SCHROEDER-GUDEHUS Brigitte, RASMUSSEN Anne, Les fastes du progrès: le guide des expositions universelles, 1851-1992, Paris, Flammarion, 1992.

THEIS Laurent, François Guizot, Paris, Fayard, 2008.

TOMEI Samuel, Ferdinand Buisson (1841-1932): protestantisme libéral, foi laïque et radical-socialisme, 2 vol., Paris, Institut d'études politiques de Paris, 2004.

TRONCHOT Raymond, L'enseignement mutuel en France de 1815 à 1833, les luttes politiques et religieuses autour de la question scolaire, université de Lille, thèse de doctorat 1973. 
UPTON Dell, «Écoles lancastériennes, citoyenneté républicaine et imagination spatiale en Amérique au début du XX $X^{e}$ siècle », Histoire de l'éducation, 102/2004, p. 87-108.

VARGAS Pierre (de), «L'héritage de Marc-Antoine Jullien, de Paris à Moscou », Annales historiques de la Révolution française, 301/1995, p. 409-431.

VERNUS Michel, « La Révolution de 1848 à Salins et Arbois. La présence du fouriérisme dans le mouvement démocratique », Cahiers Charles Fourier, n 10 , décembre 1999.

VIARD Bruno, Pierre Leroux, penseur de I'humanité, Sulliver, 2009.

VINCENT Jean-Didier, Élisée Reclus. Géographe, anarchiste, écologiste, Paris, Robert Laffont, 2010.

WEBER Eugen, « Gymnastique et sport en France à la fin du XIX $X^{\mathrm{e}}$ siècle: opium des classes? », Recherches, 43/1980, p. 185-220.

WEILL Georges, Histoire du parti républicain en France, 1814-1870, Genève, Slatkine, 1980.

\section{Société et éducation en Suisse}

AEBY Viviane, « Patois contre français. La querelle des «Tsévreis »», Cahiers du musée gruyérien, 5/2005, p. 39-44.

ANDREY Georges, Les émigrés français dans le canton de Fribourg (1789-1815), Neuchâtel, Attinger, 1972.

-, Grégoire Girard, apôtre de l'école pour tous, Bière, Cabédita, 2015.

ASSIMA Georges, La France et la Suisse. Une histoire en partage, deux patries en héritage, Paris, L'Harmattan, 2012.

BANDELIER André, Des Suisses dans la République des Lettres. Un réseau savant au temps de Frédéric le Grand, Genève, Slatkine, 2007.

BATOU Jean, CERUTTI Mauro, HEIMBERG Charles, Pour une histoire des gens sans Histoire. Ouvriers, exclues et rebelles en Suisse $X I X^{e}-X X^{e}$ siècles, Lausanne, Éditions d'en Bas, 1995.

BIAUDET Jean-Charles, La Suisse et la Monarchie de Juillet, 1830-1838, Bibliothèque Historique Vaudoise, Lausanne, 1941.

BOURQUIN Julien, Des portes qui s'ouvrent ou la vue de Jules Paroz 1824-1903, Neuchâtel et Paris, Delachaux et Niestlé, 1954.

BOVET Pierre, « Les origines fribourgeoises de l'enseignement moral et civique », Revue de théologie et de philosophie, Lausanne, 20/1932, p. 211-228.

-, Écoles nouvelles d'autrefois: Louis Perrot et les débuts de l'enseignement mutuel en Suisse française, Genève, Institut J.-J. Rousseau, 1938. 
BUGNARD Pierre-Philippe, Le machiavélisme de village. La Gruyère face à la République chrétienne de Fribourg (1881-1913), Lausanne, Le Front université, 1983.

-, «Le Rapport Girard, un réquisitoire paradoxal», in Johann Heinrich Pestalozzi, Écrits sur la méthode. Volume 4 - La Méthode à l'épreuve de l'expertise officielle, Le Mont-sur-Lausanne, LEP Éditions Loisirs et Pédagogie, 2011.

-, Le Temps des espaces pédagogiques. De la cathédrale orientée à la capitale occidentée (seconde édition revue et augmentée), Nancy, Éditions universitaires de Lorraine, 2013.

BUSSARD Jean-Claude, L'éducation physique suisse en quête d'identité (18001930), Paris, L'Harmattan, 2007.

CALOZ-TSCHOPP Marie-Claire, Le tamis helvétique. Des réfugiés aux nouveaux réfugiés, Lausanne, Éditions d'En bas, 1982.

CASPARD Pierre, « Pourquoi l'État s'est-il intéressé à l'éducation? (1750-1830) 》, Musée neuchâtelois, juillet 1994, p. 93-105.

-, « Les miroirs réfléchissent-ils ? Esquisse d〉une étude comparée de la gratuité, de I>obligation et de la laïcité scolaires, en France et en Suisse », in R. Hofstetter, C. Magnin, L. Criblez, C. Jenzer (éds.): Une école pour la démocratie. Naissance et développement de l'école primaire en Suisse au XIXe siècle, Berne, P. Lang, 1999, p. 343-357.

-, « Un modèle pour Ferdinand Buisson? La religion dans la formation des maîtres à Neuchâtel (XIX siècle) », in J.-F. Condette, Éducation, religion, laïcité $\left(X V l^{e}-X X^{e}\right.$ s.). Continuités, tensions et ruptures dans la formation des élèves et des enseignants, Lille, Centre de gestion de l'Édition scientifique, 2010.

CHARRIÈRE Gonzague, L'école cantonale de Fribourg 1848-1857, mémoire de licence, université de Fribourg, 1985.

CHRIST Thierry, RIARD Sabine, Du réduit communal à l'espace national: le statut des étrangers dans le canton de Neuchâtel 1750-1914, Hauterive, G. Attinger, Société d'histoire et d'archéologie du canton de Neuchâtel, 2000.

CLAVIEN Alain, GULLOTTI Hervé, MARTI Pierre, La province n'est plus la province. Les relations culturelles franco-suisses à l'épreuve de la seconde guerre mondiale (1935-1950), Lausanne, Antipodes, 2003.

COLLIARD Michel, NICOULIN Martin, Étienne Eggis, poète et écrivain, 1830-1867, Fribourg, Éditions La Sarine, 1980.

DELAY Christophe, Les classes populaires à l'école. La rencontre ambivalente entre deux cultures à légitimité inégale, Rennes, PUR, 2011.

DÉVAUD Eugène, L'école primaire fribourgeoise sous la République helvétique 1798-1803, Fribourg, Imprimerie Saint-Paul, 1905.

DU BOIS Pierre, La guerre du Sonderbund. La Suisse de 1847, Paris, Alvik, 2002. 
DU PASQUIER Marcel, Edgar Quinet en Suisse: douze années d'exil (1858-1870), Neuchâtel, La Baconnière, 1959.

-, La Suisse romande terre d'accueil et d'échanges, Neuchâtel, La Baconnière, 1966.

EXTERMANN Blaise, Une langue étrangère et nationale. Histoire de l'enseignement de l'allemand en Suisse romande (1790-1940), Neuchâtel, Alphil, 2013.

FELBER Jean-Pierre, De I'Helvétie romaine à la Suisse romande, Genève, Slatkine, 2006.

FURRER Daniel, Gründervater der modernen Schweiz. Ignaz Paul Vital Troxler (1780-1866), université de Fribourg, thèse de doctorat, 2009.

GARÇON François, Le modèle suisse, Paris, Perrin, 2008.

GARIEL Philippe, Fribourg et le romantisme: Étienne Eggis (1830-1867), Fribourg, Imprimerie Saint-Paul, 1930.

-, «Eulalie de Senancour et ses amis fribourgeois, d'après sa correspondance inédite avec A. Daguet (1844-1857) », Revue de littérature comparée, 13/1933, p. 403-428.

GENOUD François, L'école fribourgeoise à l'époque de la Régénération (18301847), mémoire de licence, université de Fribourg, 1983.

GUEX François, Histoire de l'instruction et de l'éducation, Lausanne, Payot, 1913.

HAMELINE Daniel, L'éducation dans le miroir du temps, Lausanne, LEP, 2002.

-, « Grégoire Girard (1765-1850) », in J. Houssaye (éds.), Nouveaux pédagogues. Pédagogues de la modernité, tome I, Paris, Fabert, 2007, p. 115-153.

HASELBACH Philipp, Erziehung zu Menschenwürde. Das pädagogische Denken und Handeln bei Gregor Girard (1765-1850), Fribourg, Academic Press, 2007.

HELLER Geneviève, «Propre en ordre »: habitation et vie domestique (18501930). L'exemple vaudois, Lausanne, Éditions d'en bas, 1979.

-, « Tiens-toi droit! » L'enfant à l'école au XIX siècle. Espace, morale et santé, l'exemple vaudois, Lausanne, Éditions d'en bas, 1988.

HERMANN Irène, Les cicatrices du passé. Essai sur la gestion des conflits en Suisse (1798-1918), Bern, Peter Lang, 2006.

HOFMANN Michèle, « History of education in Switzerland: Historic development and current challenges », Encounters, Encuentros, Rencontres on Education, 15/2014, p. 223-237

HOFSTETTER Rita, Les lumières de la démocratie: histoire de l'école primaire publique à Genève au XIXe siècle, Bern, P. Lang, 1998.

-, «La Suisse et l'enseignement aux XIXe-XX siècles. Le prototype d'une "fédération d'États enseignants" ? 》, Histoire de l'éducation, n 134, avril-juin 2012, p. 59-80.

HOFSTETTER Rita, SCHNEUWLY Bernard (éds.), Le pari des sciences de l'éducation, Bruxelles, Éditions de Boeck université, 2001. 
-, (éds.), Émergence des sciences de l'éducation en Suisse à la croisée de traditions académiques contrastées, Bern, Peter Lang, 2007.

KAENEL Philippe, «Les voyages illustrés », in L. Boissonnas et alii, Töpffer, Genève, Skira, 1996, p. 201-252.

KAESER Marc-Antoine, « Une science universelle ou "éminemment nationale"? Les congrès internationaux de préhistoire (1865-1912) 》, Revue germanique internationale, 12/2010, p. 17-31

-, L'univers du préhistorien. Science, foi et politique dans l'œuvre et la vie d'Édouard Desor (1811-1882), Paris, L'Harmattan, 2004.

KRATTINGER Cédric, L'idéologie de Georges Joseph Schmitt dans Le Confédéré (1854-1869). Entre radicalisme républicain et socialisme associationniste, mémoire de licence, université de Fribourg, 1997.

LAU Thomas, «Stiefbrüder »: Nation und Konfession in der Schweiz und in Europa (1656-1712), Köln, Böhlau, 2008.

LUSSI BORER Valérie, Formations à l'enseignement et science de l'éducation. Analyse comparée des sites universitaires de Suisse romande (fin du XIXe - première moitié $d u X X X^{e}$ siècle), université de Genève, thèse de doctorat, 2008.

MAISSEN Thomas, "L'histoire de la Suisse à l'heure de la mondialisation », in Histoire de la Suisse, catalogue de l'exposition permanente au musée national de Zurich, 2009, p. 16-17.

MEUWLY Olivier, Histoire des sociétés d'étudiants à Lausanne, université de Lausanne, 1987.

-, «Louis-Henri Delarageaz ou le versant proudhonien du radicalisme vaudois », in O. Meuwly, Les Constitutions vaudoises 1803-2003. Miroir des idées politiques, Lausanne, Bibliothèque historique vaudoise, 123/2003, p. 327-351. Les penseurs politiques du xixe siècle. Les combats d'idées à l'origine de la Suisse moderne, Lausanne, Presses polytechniques et universitaires romandes, 2007.

-, Louis-Henri Delarageaz 1807-1891. Homme politique vaudois, ami de Proudhon, grand propriétaire foncier, Neuchâtel, Éditions Alphil Presses universitaires suisses, 2011.

MEUWLY Olivier (éds.), Henri Druey 1799-1855, Actes du colloque du 8 octobre 2005, Lausanne, Bibliothèque historique vaudoise, 2007.

MOREROD Jean-Daniel, BADOUD Nathan, Les Romands et la gloire, Actes du colloque de Lausanne du 17 novembre 2001, SHSR, 2006.

NICOULIN Martin, La genèse de Nova Friburgo: émigration et colonisation suisse au Brésil (1817-1827), Fribourg, Éditions universitaires, 1973.

PYTHON Francis, Mgr Étienne Marilley et son clergé à Fribourg au temps du Sonderbund 1846-1856, Fribourg, Éditions universitaires, 1987. 
-, « La société cantonale d'histoire et le souci de la mémoire fribourgeoise », Équinoxe, Lausanne, 10/1993, p. 145-157.

REINHARDT Volker, Schweiz und Liechtenstein, Stuttgart, A. Kröner, 1997.

-, Hauptwerke der Geschichtsschreibung, Stuttgart, A. Kröner, 1997.

-, Jacob Burckhardt und die Erfindung der Renaissance: ein Mythos und seine Geschichte, Bern, 2002.

-, Geschichte der Schweiz, München, Beck, 2006.

-, Die Tyrannei der Tugend: Calvin und die Reformation in Genf, München, Beck, 2009.

-, Die Geschichte der Schweiz: von den Anfängen bis heute, München, Beck, 2011.

-, Schweizer Mythen. Der Stoff, aus dem die Mythen sind - oder auch nicht. Illustrationen Martial Leiter, Zurich, Schriftenreihe Vontobel-Stiftung, 2014.

REYNOLD Gonzague (de) et alii, La vie romantique au pays romand, Lausanne, Éditions Freudweiler-Spiro, 1930.

ROSSELLO Pedro, Les précurseurs du Bureau international d'éducation, Genève, BIT, 1943.

ROSSIER-MENTHONNEX Michelette, «Élisée Reclus, géographe (1830-1905)», Vibiscum 9/2002, p. 76-113.

ROUGEMONT Denis (de), La Suisse ou l'histoire d'un peuple heureux, Lausanne, L'Âge d'homme, 1989.

RUFFIEUX Roland, Encyclopédie du canton de Fribourg, 2 vol., Fribourg, Office du Livre SA, 1977.

-, Idéologie et nécessité. Essai sur le régime radical fribourgeois (1847-1856), Fribourg, Éditions universitaires, 1957.

-, Fribourg sous le choc de la modernité. Aspects de l'Histoire fribourgeoise aux XIXe et $X X^{e}$ siècles, Lausanne, Formation continue des journalistes de Suisse romande, 1988.

-, Les idéaux du parti radical fribourgeois et leur application politique (18471856), université de Fribourg, thèse de doctorat, 1953.

SAVARY Ernest, La Société pédagogique de la Suisse romande (1864-1914): notice historique rédigée à l'occasion du jubilé cinquantenaire de la Société, Lausanne, Imprimeries réunies, 1914.

SCHÄRER Michèle E., Friedrich Frœbel et l'éducation préscolaire en Suisse romande: 1860-1925, Lausanne, EESP, 2008.

SCHOLL Sarah, " "Soyez courageux et dociles!". Les normes religieuses comme vecteur d'éducation au patriotisme en Suisse (1870-1914)», Revue suisse d'histoire, 3/2013, p. 343-363.

-, En quête d'une modernité religieuse. La création de l'Église catholiquechrétienne de Genève au cœur du Kulturkampf (1870-1907), Neuchâtel, Alphil, 2014. 
SOËTARD Michel, Johann Heinrich Pestalozzi. Le chant du cygne, le testament pédagogique du maître d'Yverdon, Paris, Éditions Fabert, 2009.

SQUILLANTE Geneviève, «Le Père Girard, cordelier (1765-1850): L'exil en récompense, pour l'un des promoteurs les plus éminents de l'enseignement mutuel en Europe », Pédagogies chrétiennes, pédagogues chrétiens. Actes du colloque d'Angers des 28 au 30 septembre 1995, Paris, Éditions Don Bosco, 1996, p. 227-238.

SUDAN Louis, L'école primaire fribourgeoise sous la Restauration, 1814-1830, Paris, E. de Boccard éditeur, 1934.

TORCHE Laurent, Peine de mort et exécutions dans le canton de Fribourg au $X I X X^{e}$ siècle. Formes, perceptions, signification, mémoire de licence, université de Fribourg, 1994.

TORNARE Alain-Jacques, L'Histoire des Fribourgeois et de la Suisse, Bière, Éditions Cabédita, 2012.

ULDRY Jean-Maurice, L'Émulation (1841-1846 et 1852-1856). Analyse de la première revue culturelle fribourgeoise, mémoire de licence, université de Fribourg, 2003.

VAJ Daniela, « Une pédagogue genevoise méconnue: Mathilde Calandrini et la diffusion de l'éducation populaire enfantine dans I'Italie du Risorgimento », Société genevoise d'études italiennes, 1999, p. 287-310.

VALLOTTON François, L'édition romande et ses acteurs (1850-1920), Genève, Éditions Slatkine, 2001.

VARGAS Philippe (de), Le congrès de la paix et de la liberté de 1869 à Lausanne, mémoire de licence, université de Lausanne, 1961.

VUILLEUMIER Marc, «Les proscrits de la Commune en Suisse (1871) 》, Revue suisse d'histoire, Zurich, 12/1962, p. 498-537.

-, «Quelques jalons pour une historiographie du mouvement ouvrier en Suisse », Cahiers Vilfredo Pareto, Genève, T. xı, 29/1973, p. 5-35.

-, «Victor Considerant et son expulsion du canton de Neuchâtel », Cahiers Vilfredo Pareto, Genève, T. 11, 29/1973, p. 96-100.

-, « Georges Joseph Schmitt, le "Confédéré" de Fribourg et les Républicains français: documents inédits », Revue suisse d'histoire, Basel, tome XXIV, 1974, fasc. 1, p. 66-97.

-, « James Guillaume et son rôle dans le mouvement syndicaliste révolutionnaire », Ricerche storiche, numero speciale: II sindicalismo rivoluzionario nella storia del movimento operaio internazionale, Firenze, Anno 11, 1/1981, p. 300-325.

-, Souvenirs de deux Communards réfugiés à Genève 1871-1873, Genève, Éditions d'En-Bas, 1987.

-, Immigrés et réfugiés en Suisse: aperçu historique, Zurich, Pro Helvetia, 1992. 
-, «Les correspondances de Proudhon en Suisse », Proudhon: sa correspondance et ses correspondants, Paris, Société P.J. Proudhon, 1994, p. 67-76. -, « Autour des conférences de Considerant à Genève (octobre 1846)》, Cahiers Charles Fourier, Besançon, 19/2008, p. 23-32.

-, Histoire et combats. Mouvement ouvrier et socialisme en Suisse 1864-1960, Genève, Éditions d'en bas et collège du travail, 2012.

WALTER François, Histoire de la Suisse. La création de la Suisse moderne (18301930), T. 4, Neuchâtel, Alphil, 2010.

WALZER Pierre-Olivier, Les pré-actes. Nouveau coup d'œil sur les origines de la Société jurassienne d'Émulation, Porrentruy, Société jurassienne d'Émulation, 1990.

WILLY Rahel, « Un regard sur la Russie », Cahiers du musée gruyérien, 5/2005, p. 51-56.

\section{Articles et études consacrés à Alexandre Daguet}

BÜCHI Albert, "Alexander Daguet », Freiburger Geschichtsblätter herausgegeben vom deutschen geschichtsforschenden Verein des Kantons Freiburg, Freiburg, Verlag des Universitätsbuchhandlung, 1894-1895, p. 106-107.

DESSONNAZ Jean-Daniel, «Alexandre Daguet (1816-1894)», 1700, Bulletin d'information de la ville de Fribourg, n 94, avril 1993, p. 29-34.

FONTAINE Alexandre, Alexandre Daguet (1816-1894): racines et formation d'un historien libéral-national oublié, mémoire de licence, université de Fribourg, 2005 (https:unige.academia.edu/AlexandreFontaine).

-, « Alexandre Daguet: naissance d'un historien. Un jeune homme ambitieux, républicain, hostile aux jésuites $\gg, A F$, Fribourg, 68/2006, p. 59-72.

-, « L'intellectuel fribourgeois Alexandre Daguet, un exemple de modération pour notre temps », Spectrum, Fribourg, mars 2010, p. 20-23.

-, «Alexandre Daguet (1816-1894): une histoire pour les Fribourgeois. La fabrication d'un Romand cantonal », Annales Fribourgeoises, 76/2014, p. 47-56.

-, «Schweizer Historiker und transnationaler Erzieher: der Freiburger Intellektuelle Alexandre Daguet (1816 - 1894) », Freiburger Geschichtsblätter, 2015.

GRANDJEAN Laetitia, Éducation civique et culture politique: les écrits historicopédagogiques d'Alexandre Daguet, université de Fribourg, Séminaire III, 2001.

GREMAUD Jean, «Examen de la défense de l'abrégé de l'Histoire de la Confédération suisse par M. Daguet publiée dans le Journal de Fribourg », L'Ami du peuple, Romont, 1868, p. 34-46.

HAMELINE Daniel, «L'Éducateur (1865-1885): compétence et légitimité », L'Éducateur, 8/1983. 
-, « Petite histoire édifiante d'un trait édifiant ou le jeu sans fin des donneurs de leçons », L'Éducateur, 3/188.

NIQUILLE Jeanne, Un portrait d'Alexandre Daguet, NEF, 62/1929, p. 204-208.

PFISTER Christoph, Beiträge zur Freiburger Historiographie des 18. und 19. Jahrhunderts: Guillimann-Alt-Berchtold-Daguet, Norderstedt, Books on Demand, Dillum, 2008.

REYFF Simone (de), «L'idéal favori d'Alexandre Daguet ou les pages littéraires de l'Émulation », Les Cahiers du musée gruyérien, Bulle, 5/2005, p. 22-38.

ROSSEL Virgile, Les correspondants jurassiens d'Alexandre Daguet, Actes de la Société jurassienne d'Émulation, 1923.

ROULLET Louis-Édouard, « Alexandre Daguet, un professeur fribourgeois à l'académie de Neuchâtel (1866-1894) », Passé Pluriel, 1991, p. 447-462.

RUFFIEUX Raphaël, Les moments forts de I'histoire fribourgeoise à travers les articles historiques de l'Émulation et les linéaments d'une identité cantonale, université de Fribourg, Séminaire III, 2003.

SCHORDERET Auguste, « Alexandre Daguet et son temps (1816-1894) » AF IX, n 1, janvier-février 1921, p. 1-14 \& AF IX, n 2-3, mars-juin 1921, p. 49-86.

SECRÉTAN Eugène, « Alexandre Daguet », La Famille, journal pour tous, Lausanne, Éditions Georges Bridel, 18/1894, p. 409-415. 
INDEX 

A

Addams, Jane: 107

Addison, Joseph: 64

Aebischer, Patrick: 217

Aeby, Viviane: 67

Agrippa, Heinrich Cornelius: 51

Alten, Michèle: 188, 191, 204

Amiel, Henri-Frédéric: 58, 84, 88, 136, 150, 157

Amoros, Francesco: 196, 200

Amselle, Jean-Loup: 170

Anderson, Benedict: 20, 125

Andrey, Georges: 52, 98

Anker, Albert: 89

Aprile, Sylvie: 88

Arnaud, Pierre: 195

Ascenzi, Anna: 42

Aubin, Paul: 21

Aurenche, Marie-Laure: 73

Ayer, Cyprien: 92, 145

Azouvi, François: 28

B

Bachelin, Auguste: 57

Bagchi, Barnita: 21

Bagutti, Giuseppe: 42

Bain, Alexander: 168

Bakounine, Mikhaïl: 107, 110, 137

Bandelier, André: 25

Barni, Jules: 13, 89, 90, 91, 99, 104, 105, 108, 158, 188

Barras, Jean-Marie: 113, 141

Barrault, François: 38

Basedow, Johann Bernhard: 26, 69

Batou, Jean: 85

Baud-Bovy, Auguste: 57

Baudouin, Jean-Magloire: 134

Beech, Jason: 16

Bell, Andrew: 36, 37, 39

Beneke, Friedrich Eduard: 28

Bensoussan, Georges: 188

Berchtold, Alfred: 58

Berger, Bonaventure: 74, 148, 149, 160

Bergeron, Charles: 86

Bert, Paul: 125, 188, 203

Biolley, Auguste: 156, 167

Bion, Hermann Walter: 205, 206, 207
Bitzius, Albert: 66, 82, 84

Blanc, Louis: 104, 137

Bocion, François: 89

Bocquillon, Guillaume-Louis dit Wilhem: 189

Bodmer, Johann Jacob: 64

Boileau, Nicolas: 64

Bonaparte, Louis-Napoléon: 13

Bondallaz, Paul: 54

Bonnet, Charles: 63

Bordier, Henri: 72

Borel, Eugène: 94,145

Bornet, Louis: 52, 66, 184, 186, 188

Bosson, Alain: 132

Bourbaki, Charles Denis: 70

Bourel, Dominique: 28, 44

Bourgarel, Gérard: 53

Bourqui, Alexis: 156

Bourzac, Albert: 199, 203

Boutan, Pierre: 182

Boutroux, Émile: 188

Bouvard, Vincent: 69

Bovet, Félix: 82, 96

Bovet, Pierre: 39, 40, 184

Breiding, R. James: 217

Breitinger, Johann Jacob: 64

Bridel, Philippe-Sirice: 59

Brunet, Martine: 104, 109

Buchon, Max: 22, 56, 57, 78, 79, 80, 81, $82,83,84,85$

Bühler, Patrick: 49, 121

Buisson, Ferdinand: 11, 12, 13, 22, 27, 72 , $75,76,90,91,92,93,94,95,96,97$, $99,108,109,110,111,122,123,124,125$, $127,128,135,137,139,140,141,143$, $144,145,147,148,154,156,168,183$, $192,202,203,204$

Bungener, Félix: 95, 96

Buoncompagni, Carlo: 42

Bussard, Jean-Claude: 195, 196

Bussard, Jean-Marcelin: 55

C

Caballero, Firmin: 70

Cabanel, Patrick: 14, 91, 93, 95, 97

Cabet, Étienne: 185

Calame, Georges: 145

Camara Bastos, Maria Helena: 173 
Campion, Jean-Joseph: 117, 126

Cantagrel, François-Jean-Félix: 76, 79

Carderera, Mariano: 121

Carnot, Hippolyte: 74, 183

Carnot, Lazare: 183

Caruso, Marcelo: 16, 36, 37, 43

Casanova, Pascale: 25

Caspard, Pierre: 97, 115, 153

Castelar, Emilio: 70

Castellion, Sébastien: 92

Catherine, Florence: 25

Cattaneo, Carlo: 105

Centlivres, Pierre: 149

Cerutti, Mauro: 85

Chalmel, Loïc: 12, 25, 31, 99

Chalopin, Michel: 31

Champfleury, Jules François Félix Husson dit: 82,84

Chanet, Jean-François: 68, 197

Chapoulie, Jean-Michel: 12

Charle, Christophe: 12

Charles, Hubert: 67

Charras, Jean-Baptiste-Adolphe: 79, 90, 98, 186

Charton, Édouard: 22, 73, 74

Chateaubriand, François-René de: 62, 63, 66

Chaudey, Gustave: 76,86

Chauffour, Victor: 79, 87

Cherbuliez, Victor: 88, 131

Chessex, Pierre: 57

Chevé, Émile: 191, 192

Choppin, Alain: 153

Choron, Alexandre: 189, 190

Cicconi, Luigi: 61

Clancy-Smith, Julia: 21

Claris, Jean-Aristide: 108

Clavien, Alain: 5, 131

Clemenceau, Georges: 13, 90

Clias, Phokion Heinrich: 196

Colliard, Michel: 62

Comenius, Amos: 144

Compayré, Gabriel: 22, 48, 128, 176

Condette, Jean-François: 97

Condorcet, Nicolas de: 14

Confalonieri, Federico: 42

Considerant, Victor: 56, 57, 80, 82, 185

Constant, Benjamin: 63
Coquerel, Athanase: 96

Corot, Jean-Baptiste: 57

Costa, Andrea: 138

Cottinet, Edmond: 205, 207

Courbet, Gustave: 22, 56, 57, 79, 80, 82

Cousin, Victor: $42,43,44,45,46,56$, $147,166,177,179,180$

Criblez, Lucien: 16

Cuchet, Guillaume: 174

Cuvier, Georges: 29, 45, 166

Czáka, Véronique: 198, 219

D

Daele, Henk van: 16,17

Daguet, Alexandre: 11, 21, 27, 47, 49, 50, $51,52,54,55,57,58,59,60,61,62$, $63,65,66,67,69,71,75,81,85,91$, $99,111,112,115,118,119,120,121,135$, $140,142,143,144,145,150,153,154$, $156,158,161,162,165,166,168,169$, 200, 218

Defodon, Charles: $74,75,116,123,147$, $154,160,167,189$

Delagrave, Charles: 75, 115, 134

Delieuvin, Marie-Claude: 29, 30

Demeulenaere-Douyère, Christiane: 110

Demkès, Auguste: 144

D'Enfert, Renaud: 211

Denis, Daniel: 140

Deribaucourt, Édouard: 91

Deribaucourt, Pauline Emma: 92

Déroulède, Paul: 202, 204

Derron, Marianne: 82

Desbuissons, Frédérique: 80

Desor, Édouard: 76, 92, 95, 145, 158

Destutt de Tracy, Antoine: 175

Diesterweg, Friedrich Adolph Wilhelm: 43, 158, 187

Digeon, Claude: 14, 133

Dinter, Gustav Friedrich: 69, 146

Dittrich, Klaus: 124

Dogan, Mattei: 17

Douki, Caroline: 19

Downs, Laura: 205

Droux, Joëlle: 173

Dubois, Patrick: 121, 140, 156

Ducotterd, Xavier: 141, 142, 156

Dufraisse, Marc: 79, 86, 87, 90, 186

Dumesnil, Georges: 149 
Dunant, Henri: 72

Dunoyer, Anatole: 90

Dupaigne, Albert: 190

Du Pasquier, Marcel: 88, 90, 99

Duprat, Pascal: 76, 79

Duruy, Victor: 115, 123, 134, 167

Duval, Guillaume: 217

\section{E}

Eggis, Étienne : 62

Elias, Norbert: 120

Épicure: 28

Espagne, Michel: 17, 18, 26, 81, 164, 216, 220

Euler, Leonhard: 25

Extermann, Blaise: 78

\section{F}

Falaize, Benoît: 21

Farré, Sébastien: 6

Fattori, Giuseppina: 42

Fazy, James: 89

Federer, Josef Anton: 163

Feder, Johann Georg: 28

Fellenberg, Philipp Emanuel von: 29, 35,145

Ferguson, Adam: 28

Ferretti, Federico: 169

Ferry, Jules: 12, 13, 91, 191, 198

Feuerhahn, Wolf: 103

Fichte, Johann Gottlieb: 28

Fijalkow, Claire: 189

Flocon, Ferdinand: 79, 87

Fonssagrives, Jean-Baptiste: 197, 199

Fontaine, Charles-Aloyse: 58

Fontius, Martin: 25

Fortoul, Hippolyte: 189

Fourier, Charles: 57, 137

Francillon, Roger: 58, 64, 131

Francke, August Hermann: 69

Frette, Auguste: 199

Frey, Hugo: 80, 83

Freymond, Mathilde: 219

Fritz, Théodore: 46, 47, 48

Fröbel, Friedrich: 157, 158, 159, 160

Fuchs, Eckhardt: 21, 218

Furer, Daniel: 55
G

Gaggero, Stéphane José: 71

Galin, Pierre: 191

Galley, Léon: 198

Garçon, François: 217

Garibaldi, Giuseppe: 104

Gariel, Philippe: 54, 62

Gautherin, Jacqueline: 29

Gauthey, Frédéric: 133

Geay, Bertrand: 130

Gellner, Ernest: 20

Gérando, Joseph-Marie de: 37

Gessner, Salomon: 65

Gindroz, André: 45

Girard, Grégoire: 27, 30, 33, 39, 40, 41, $42,43,47,50,52,54,58,69,74$, $99,115,143,155,175,179,180,183$, 184,221

Giuli, André de: 199

Glasson, Nicolas: 52, 59, 80

Gleyre, Charles: 89

Gobat, Henri: 163

Gobineau, Arthur: 77

Godet, Philippe: 96

Goegg, Armand: 104, 107

Goegg-Pouchoulin, Marie: 104, 107

Goethe, Johann Wolfgang von: 44

Gogol, Nicolas: 61

Gonon, Philippe: 15

Goody, Jack: 20

Gotthelf, Jeremias: 59, 61, 66, 82, 83, 84

Gottsched, Johann Christoph: 64

Goubet, Jean-François: 19

Gréard, Octave: 206

Gremaud, Jean: 59

Griset de Forell, Charles: 50

Grivet, Adrien: 61

Gruaz, Charles: 64

Grunholzer, Heinrich: 163

Gruzinski, Serge: 25, 170, 218

Gueissaz, Mireille: 89

Guérig, Félix: 158

Guerrier de Haupt, Adrien: 123

Guillaume, James: 70, 74, 76, 93, 94, $107,108,110,134,136,137,138,139$, 140, 144, 158, 205

Guillimann, Franz: 51 
Guizot, François: 44, 55, 99, 179

Gutierrez, Laurent: 188

Guyau, Georges: 97

\section{$\mathrm{H}$}

Hachette, Louis: 169

Haenggeli-Jenni, Béatrice: 121

Haller, Albrecht von: 51, 65

Hamel, Joseph: 37

Haupt, Heinz-Gerhard: 130

Hebel, Johann Peter: 66, 81, 83, 84

Hegel, Georg Wilhelm Friedrich: 44

Heimberg, Charles: 21, 85

Heine, Heinrich: 81, 82

Heller, Geneviève: 200, 207

Herbart, Johann Friedrich: 141, 142

Herder, Johann Gottfried von: 28

Herr, Lucien: 140

Herrmann, Irène: 32

Herzen, Alexandre: 89

Hetzel, Pierre-Jules: 87

Hirsch, Adolphe: 95

Hirzel, Hans Caspar: 32

Hoffet, Jean Georges: 148

Hofmann, Michèle: 221, 289

Hofstetter, Rita: 12, 39, 113, 216, 221

Holzhey, Helmut: 25

Horner, Raphaël: 114, 140, 143

Hornung, Joseph-Marc: 150

Houssaye, Arsène: 62

Houssaye, Jean: 15, 31, 206, 207

Hugo, Victor: 77, 86, 104, 108, 123

Huitric, Solenn: 216

Humbert, Aimé: 92, 93, 143, 144

Husser, Anne-Claire: 93

I

Izoulet, Jean: 125, 126

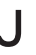

Jaccard, Auguste: 95

Jacobi, Friedrich Heinrich: 28

Jacotot, Joseph: 35

Jahn, Friedrich Ludwig: 196

Jakubec, Doris: 58

Jessen, Christian: 121
Joanne, Adolphe: 91

Jolissaint, Pierre: 109

Jomard, Edme François: 37

Joseleau, Yves: 195

Jost, Guillaume: 75, 118, 148, 149, 160

Jottrand, Lucien: 150

Jullien de Paris, Marc-Antoine: 16, 31, 39, 69, 105

\section{K}

Kaeser, Marc-Antoine: 145

Kahn, Pierre: 140

Kant, Immanuel: 13, 27, 90, 177

Kaufmann, Lionel: 34

Kazancigil, Ali: 17

Kinkelin, Hermann: 143

Klopstock, Friedrich Gottlieb: 46, 65

Köchly, Hermann: 137

Kohler, Xavier: 62

Kopp, Charles: 92, 94

Kott, Sandrine: 217

Krattinger, Cédric: 53, 186

Kropotkine, Pierre: 138

Kummer, Johann Jacob: 210

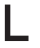

Laborde, Alexandre de: 37

La Harpe, Frédéric-César de: 32, 38

Lamarre, Clovis: 75

Lambruschini, Raffaello: 42

La Mettrie, Julien Offray de: 28

Lancaster, Joseph: 36, 37, 40

Larousse, Pierre: 114, 134, 165

Lasteyrie, Charles-Philibert de: 35, 37, 39

Laugère, Antoine: 188

Lau, Thomas: 64

Lavater, Johann Caspar: 25, 65

Lavisse, Ernest: 188

Lawn, Martin: 15, 219

Le Bars, Loïc: 128

Leclerc, Nicolas Gabriel: 26

Ledru-Rollin, Alexandre: 82

Lemonnier, Charles: 104

Leroux, Pierre: $76,79,89$

Le Roy, Albert: 117

Lessing, Gotthold Ephraim: 28, 46 
Levasseur, Émile: 128

Lezay-Marnésia, Adrien de: 166

Loeffel, Laurence: 140

Lombez, Christine: 81

Loubes, Olivier: 21

Loyson, Hyacinthe: 22

Lucas, Charles: 22

Luc, Jean-Noël: 12

Lückmeyer, Père: 55

Lussi Borer, Valérie: 140, 219

Lustenberger, Werner: 219

\section{M}

Macé, Jean: 22, 69, 70, 209

Madeline, Laurence: 57

Maggetti, Daniel: 58, 79, 145, 150

Magnin, Charles (écrivain): 83

Maine de Biran, Pierre: 38

Malardier, Pierre: 86

Mangin, Évariste: 104

Manique da Silva, Carlos: 36

Marchand, Philippe: 183

Marenholtz-Bülow, Bertha von: 158

Marion, Henri: 106, 168

Martin, Jean-Paul: 129

Marx, Karl: 104, 107

Matamoros, Manuel: 144

Matasci, Damiano: 12, 154, 217

Maurice, René: 87

Mauss, Marcel: 125

Mayer, Christine: 19, 36

Mayer, Enrico: 42

Mayer, Karl: 144

Merian, Johann Bernhard: 25, 28

Meuwly, Olivier: 32, 51, 78

Meylan, Alphonse: 191, 192

Michelet, Jules: 13, 72, 89, 159

Michel, Louis: 179, 182

Mickiewicz, Adam: 61, 88

Middell, Mathias: 218

Minard, Philippe: 19

Mole, Frédéric: 129

Moleschott, Jacob: 76

Mollier, Jean-Yves: 169, 221

Mombert, Monique: 19

Monod, Gabriel: 90

Morel-Fatio, Alfred: 196
Morerod, Jean-Daniel: 132

Moscheles, Ignaz: 189

Mougniotte, Alain: 188

Muller, Christian Alain: 39

Müller, Johannes von: 55, 65

Muyden-Porta, Jacob Evert van: 32, 34, 35, 209

\section{$\mathrm{N}$}

Nadau, Thierry: 217

Naville, Ernest: 88

Naville, François-Marc-Louis: 47, 178

Nicoulin, Martin: 53, 62

Niedermeyer, Louis: 189

Niemeyer, August Hermann: 46, 48, 69

Nique, Christian: 179

Niquille, Jeanne: 59

Noiriel, Gérard: 216

Nora, Pierre: 108

Novoa, Antonio: 15, 220

Oberlin, Jean-Frédéric: 34

Ochs, Kimberly: 16, 43

Ognier, Pierre: 14, 93, 193

Olivier, Juste: 136,150

Onfray, Michel: 40, 112

Ory, Pascal: 18

Osterwalder, Fritz: 49

Owen, Robert: 28, 40, 56, 185

$P$

Paris, Aimé: 191

Paroz, Jules: 48, 95, 96, 134, 156

Parsons, William: 205

Passy, Frédéric: 22, 72, 103, 202

Pautry, Paul: 71

Pécaut, Félix: 13, 76, 96, 97, 177

Peillon, Vincent: 93, 108

Pellisson, Maurice: 205

Périer, Casimir: 40

Pernod, Amélie: 157

Perrochon, Henri: 56, 82

Perrot, Louis: 40

Pestalozzi, Johann Heinrich: 28, 29, 38, $40,42,59,65,66,84,99,106,134$, 
155, 175, 196

Pharisa, François: 132

Phillips, David: 16, 43

Picard, Emmanuelle: 216

Picco, Dominique: 26

Pictet de Rochemont, Charles: 38, 40

Pillans, James: 40

Pivert de Senancour, Etienne: 50

Pompée, Pierre-Philibert: 115, 116, 117

Pompéry, Édouard de: 180

Porchat, Jean-Jacques: 150

Porta, Maurice: 98

Portugall, Adele von: 159

Poucet, Bruno: 43, 129

Prat, Louis-Valentin: 55

Progler, Caroline: 144, 159, 160

Proudhon, Pierre-Joseph: 82, 90, 137, 185

Python, Francis: 50

Q

Quinet, Edgar: 13, 76, 86, 87, 88, 89, 90, $91,97,99,104,111,158,184,188$

Quinet, Hermione: 87, 99

\section{$\mathrm{R}$}

Rabault-Feuerhahn, Pascale: 20, 103

Rambert, Eugène: 92, 136, 150, 162

Raoux, Édouard: 158

Rapet, Jean-Jacques: 154, 179, 180, 182

Rapp, Karl Moritz: 82

Rappleye, Jeremy: 16

Rasmussen, Anne: 12, 103, 115, 197

Ray, Hortense: 157

Reclus, Élisée: 104, 169

Reinhardt, Volker: 5, 18

Rendu, Eugène: 179, 180

Réville, Albert: 76, 96

Reybaud, Louis: 56

Reyff, Simone de: 61

Rey, Joseph: 156

Reynold, Gonzague de: 68

Ricci, Max: 158

Ridolfi, Cosimo: 42

Rivet, Daniel: 21

Rochow, Friedrich Eberhard: 69

Rod, Édouard: 131
Rogers, Rebecca: 21

Roldan Vera, Eugenia: 36

Rosanvallon, Pierre: 13, 100

Rossello, Pedro: 28

Rossi, Pellegrino: 78

Roth, Dorothea: 137

Rouland, Gustave: 182

Rousmaniere, Kate: 21

Rousseau, Jean-Jacques: 155, 192

Rousselle, André: 117

Rousselot, Paul: 168

Royer, Clémence: 76, 79, 106

Ruchonnet, Louis: 192

Ruffieux, Roland: 50

Ruiz de Salazar, Emilio: 121

\section{$\mathrm{S}$}

Sacchi, Giuseppe: 121

Sadler, Michael: 16

Saïd, Édouard: 18

Sailer, Johann Michael: 69

Sainte-Beuve, Charles-Augustin: 136

Saint-Saëns, Camille: 189

Saint-Simon, Claude Henri de Rouvroy comte de: 29

Sandoz, Jules: 135

Sarcey, Francisque: 206

Savary, Ernest: 113, 128

Savoie, Philippe: 12

Say, Jean-Baptiste: 37

Schärer, Michèle: 158

Schelling, Friedrich Wilhelm Joseph von: 28,44

Scherr, Thomas: 163

Schleiermacher, Friedrich: 28

Schmitt, Georges Joseph: 53, 79, 185, $186,187,188$

Schneeberger, Friedrich: 192

Schneuwly, Bernard: 221

Scholl, Sarah: 19, 193

Schorderet, Auguste: 52

Schriewer, Jürgen: 16, 17

Schroeder-Gudehus, Brigitte: 12

Schwarz, Friedrich Heinrich Christian: 48

Sciobéret, Pierre: 52

Secrétan, Charles: 89, 91

Secrétan, Eugène: 145

Semper, Gottfried: 90 
Senancour, Eulalie de: 54, 62

Simon, Jules: 73, 104, 117, 123, 167, 199

Sirinelli, Jean-François: 221

Snell, Ludwig: 78

Soëtard, Michel: 99, 174

Spencer, Herbert: 168

Spiess, Adolph: 196

Spivak, Marcel: 196

Staël, Germaine de: 63, 86

Stapfer, Philipp Albert: 183, 184

Steeg, Jules: 13, 22, 27, 76, 96, 97, 176, 208

Steiner-Khamsi, Gita: 15, 19

Steinmüller, Johann Rudolf: 163

Stoy, Karl Volkmar: 141, 143, 156

Stuchtey, Benedikt: 218

Subrahmanyam, Sanjay: 218

Sulzer, Johann Georg: 25, 65

$\mathrm{T}$

Taillandier, Saint-René: 77

Tallichet, Edmond: 92

Tamisier, Jean-Christophe: 6

Tartakowsky, Danielle: 128

Tenorth, Heinz-Elmar: 16

Tétard, Françoise: 128

Thiers, Adolphe: 13

Thiesse, Anne-Marie: 12, 20, 49, 59, 64, 68,112

Tinembart, Sylviane: 34

Tissot, Victor: 132

Tocqueville, Alexis de: 77

Töpffer, Rodolphe: 64,84

Tornare, Alain-Jacques: 50, 78

Tosato-Rigo, Danièle: 19, 26, 99

Tourte, Abraham Louis: 90

Tristan, Flora: 112

Tronchot, Raymond: 43

Troxler, Ignaz Paul Vital: 55

Turgeon, Laurier: 122

U

Uhland, Ludwig: 81, 82

Uldry, Jean-Maurice: 59

Ushinsky, Konstantin: 16

Usteri, Johann Martin: 59
V

Vaj, Daniela: 41
Vallotton, François: 64, 221
Van Driessche, Emmanuel van: 117
Vapereau, Gustave: 22, 72, 132
Vargas, Philippe de: 104
Vargas, Pierre de: 28, 30
Vergnon, Marie: 40
Versigny, Victor: $76,79,83,86,87$
Vésinier, Pierre: 86
Vieusseux, Giovan Pietro: 42
Vigarello, Georges: 196
Villemereux, Émile: 55
Vinet, Alexandre: 150
Vischer, Friedrich Theodor: 82, 137
Vogt, Carl: $76,89,107$
Vonlanthen, Roland: 67
Vuillemin, Louis: 89
Vuillet, Adam: 133
Vuilleumier, Marc: $57,76,78,89,90,137$,
140, 186

W

Waldow, Florian: 16, 19

Wehrli, Johann Jakob: 35, 163

Werner, Michael: 12, 164

Willi, Rahel: 61

Wynen, Pierre: 117

Y

Yariv-Mashal, Tali: 220

Z

Zellweger, Johann Caspar: 32, 35

Zellweger, Rudolph: 80

Zimmermann, Christian von: 82

Zschokke, Johann Heinrich Daniel: 51, 55,66

Zymek, Bernd: 15 



\section{Table des matières}

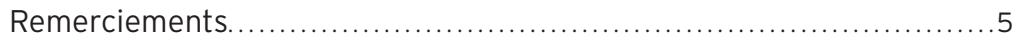

Préface .................................................................. 7

Introduction

La pédagogie comme transfert culturel ................................11

Repenser la standardisation silencieuse des savoirs scolaires..............14

Décloisonner les espaces pédagogiques pour reformuler des connexions

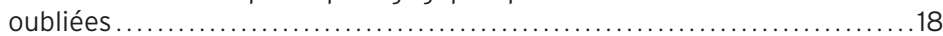

Alexandre Daguet: entre nationalisme et universalisme ................21

\section{PREMIÈRE PARTIE}

Relier les espaces pédagogiques .................................. 23

1. L'éveil d'une diplomatie scolaire ........................................ 25

Le nouvel horizon du Père Girard.......................................27

Le transfert manqué de Jullien de Paris............................. 28

L'école transnationale des philanthropes européens .....................31

De Madras à Fribourg: I'enseignement mutuel décliné .................. 36

Les Girardines à l'heure européenne ................................. 39

Les racines germaniques de l'éclectisme pédagogique francophone...... 44

2. Daguet et le « problème français $\gg \ldots \ldots \ldots \ldots \ldots \ldots \ldots \ldots \ldots \ldots \ldots . . . \ldots . . . \ldots 49$

Un milieu, des flux, une réaction...................................... 49

L'héritage culturel français de Fribourg............................. 52

Une littérature suisse, rien que suisse? ........................... 58

S'émanciper du modèle culturel français............................... 62

Absorber la littérature populaire alémanique.......................... 65

Daguet pédagogue... et la France fut....................................69 69

3. Des irréconciliables en Romandie .......................................77

Entre les rives, Max Buchon ...................................... 80

Autour d'un transfert triangulaire ................................. 83

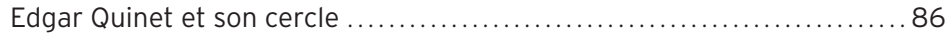

La Suisse française de Ferdinand Buisson .............................. 91

À la recherche du peuple introuvable ? .............................. 98 


\section{DEUXIÈME PARTIE}

Internationales de l'éducation et savoirs scolaires métissés ........ 101

4. Internationaliser, propager, contrôler................................ 103

La Ligue internationale de la paix et de la liberté...................... 103

Les États-Unis d'Europe et la question de l'éducation ................... 106

L'entrée de Ferdinand Buisson sur la scène internationale............... 107

Le pari manqué de l'Association pédagogique universelle ................111

L'association est morte, vive l'association!.......................... 120

Buisson et l'élaboration d'une pensée sur l'éducation internationale ....124

5. Connexions franco-romandes et bigarrures pédagogiques ........... 131

Quand la France recrutait du made in Switzerland ..................... 131

James Guillaume, un Neuchâtelois à Paris ............................137

Les Suisses du Dictionnaire de Buisson............................. 140

En mission dans les congrès suisses ................................ 146

Un trait d'union entre le Nord et le Midi ................................. 149

6. L'Éducateur et ses références pédagogiques mêlées..................153

Dieu-Humanité-Patrie ............................................ 154

Caroline Progler et la diffusion de l'« évangile fröbelien ».............. 156

Crispations interrégionales et circulations dissimulées ................. 161

Une histoire romande de la pédagogie française...................... 164

\section{TROISIÈME PARTIE}

Réinterpréter ad usum Galliae .................................. 171

7. Transférer la morale de la nation..................................173

Pestalozzi l'incompris vs Girard maître de la morale....................174

La resémantisation contrastée du Cours de Girard en France .............177

Le manuel suisse du citoyen français .............................. 183

L'éducation musicale: de Niedermeyer à Schneeberger................. 189

8. Transférer le corps de la nation .................................. 195

Passeurs et caractère hybride d'une gymnastique scolaire connectée... 195

Des corps de cadets suisses aux bataillons scolaires .................... 198

D'Appenzell à Paris, les colonies de vacances........................204

Quelques considérations sur l'emprunt..........................208

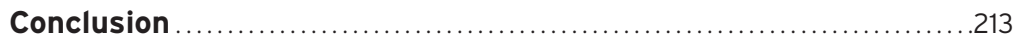

Remettre la figure de l'étranger au centre du débat................... 215

Le modèle: un concept clos? .................................... 216

Comparatisme et regard sur l'altérité ........................... 218

Abréviations ....................................................... 223 
Annexes

Annexe I

Repères biographiques d'Alexandre Daguet $(1816-1894) \ldots \ldots \ldots \ldots \ldots 227$

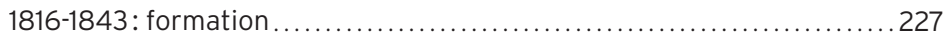

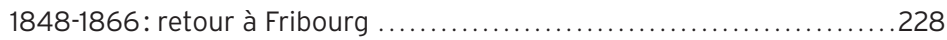

1866-1896: le pédagogue à Neuchâtel..............................229

Annexe II

Autobiographie inédite d'Alexandre Daguet...........................231

Annexe III

Chronologie de la pédagogie franco-romande.....................237

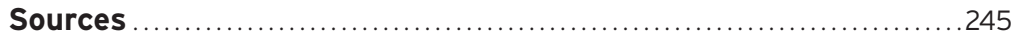

Sources manuscrites......................................... 247

Sources publiées.....................................................253

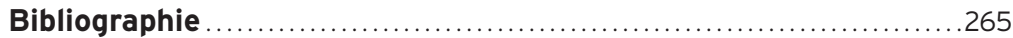

Recherche sur les transferts culturels et histoire globale ..............267

Transferts éducationnels, éducation comparée et circulations des

savoirs pédagogiques ........................................270

Littératures nationales, construction culturelle, identités nationales et

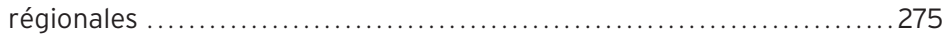

Société et éducation en France ....................................... 279

Société et éducation en Suisse ......................................287

Articles et études consacrés à Alexandre Daguet.....................293

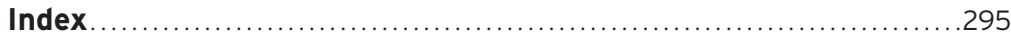




\section{Déjà parus aux éditions DEMOPOLIS}

Brossat, Alain

Abécédaire Foucault

Boltanski, Luc

Rendre la réalité inacceptable

Bourdieu, Pierre - Boltanski, Luc

La Production de l'idéologie

dominante

Césaire, Aimé - Malcolm X

Black revolution

Clover, Charles

Surpêche

Da Lage, Olivier (sous la dir. de)

Qatar: les nouveaux maîtres du jeu

Denord, François

Néo-libéralisme, version française

Duclert, Vincent

Occupy Gezi

Durpaire, François -

Richomme, Olivier

L'Amérique de Barack Obama

Obama face à la crise

Gaulard, Mylène

Karl Max à Pékin - Les racines de

la crise en Chine capitaliste

Garo, Isabelle

Foucault, Deleuze, Althusser et

Marx

Hobsbawm, Éric

Marx et I'histoire

Hroub, Khaled

Le Hamas

Jaurès, Jean

Le socialisme et la Révolution

française

Jennar, Raoul Marc Khieu

Samphan \& les Khmers rouges
Khaldy, Eddy - Fitoussi, Muriel

Main basse sur l'École publique

La République contre son école

Kalfon, Pierre

Chroniques chiliennes

Kamata, Satoshi,

Toyota: I'usine du désespoir

Mamdani, Mahmoud

La CIA et la fabrique

du terrorisme islamique

Labat, Séverine

Les islamistes tunisiens - entre

l'État et la mosquée

Latour, Bruno - Lippman, Walter

Le public fantôme

Lénine

Petit manuel pour rompre avec le capitalisme

Lénine

1914, repenser le nationalisme et

la guerre

Marx, Karl

Qu'est-ce que le capitalisme?

Les Crises du capitalisme

Le Capital financier

Mordillat, Gérard -

Prieur, Jérôme

De la crucifixion considérée

comme un accident du travail

Nsar, Vali

Le renouveau chiite

Pivert, Marceau

L'Église et l'École

Prochasson, Christophe

L'Empire des émotions:

les historiens dans la mêlée

Rebérioux, Madeleine

Vive la République 
Rodinson, Maxime

Islam et capitalisme

Sassen, Saskia

Critique de l'État

Saurin, Patrick

Les prêts toxiques: une affaire d'État

Shah, Sonia

Cobayes humains: le grand secret des essais pharmaceutiques

Uchitelle, Louis

Le salarié jetable

Wallerstein, Immanuel

L'Universalisme européen:

de la colonisation au droit

d'ingérence

Wilkinson, Richard

L'égalité, c'est la santé

\section{Collection « QUAERO »}

Cassin, Barbara et Wosny, Danièle (dir.)

Les intraduisibles du patrimoine en Afrique subsaharienne

Dawod, Hosham (dir.)

La constante «Tribu », variations

arabo-musulmanes

Ehrenfreund, Christian et

Schreiber, Jean-Philippe (dir.)

Les marranismes. De la religiosité

cachée à la société ouverte

Ghasarian, Christian

Rapa. île du bout du monde, île dans le monde

Niveleau, Charles-Édouard (dir.)

Vers une philosophie scientifique Le programme de Brentano

Rabault-Feuerhahn, Pascale (dir.)

Théorie intercontinentales

- Voyages du comparatisme postcolonial

Salamagne, Michèle- $\mathrm{H}$. et

Thominet, Patrick (dir.),

Accompagner. Trente ans de soins palliatifs en France 
"Quatrième tirage"

Achevé d'imprimer en France en 2015 dans les ateliers de Dupli-print à Domont (95)

Quatrième tirage en novembre 2015

$\mathrm{N}^{\circ}$ d'impression : 2015111472

Dépôt légal : mars 2015 


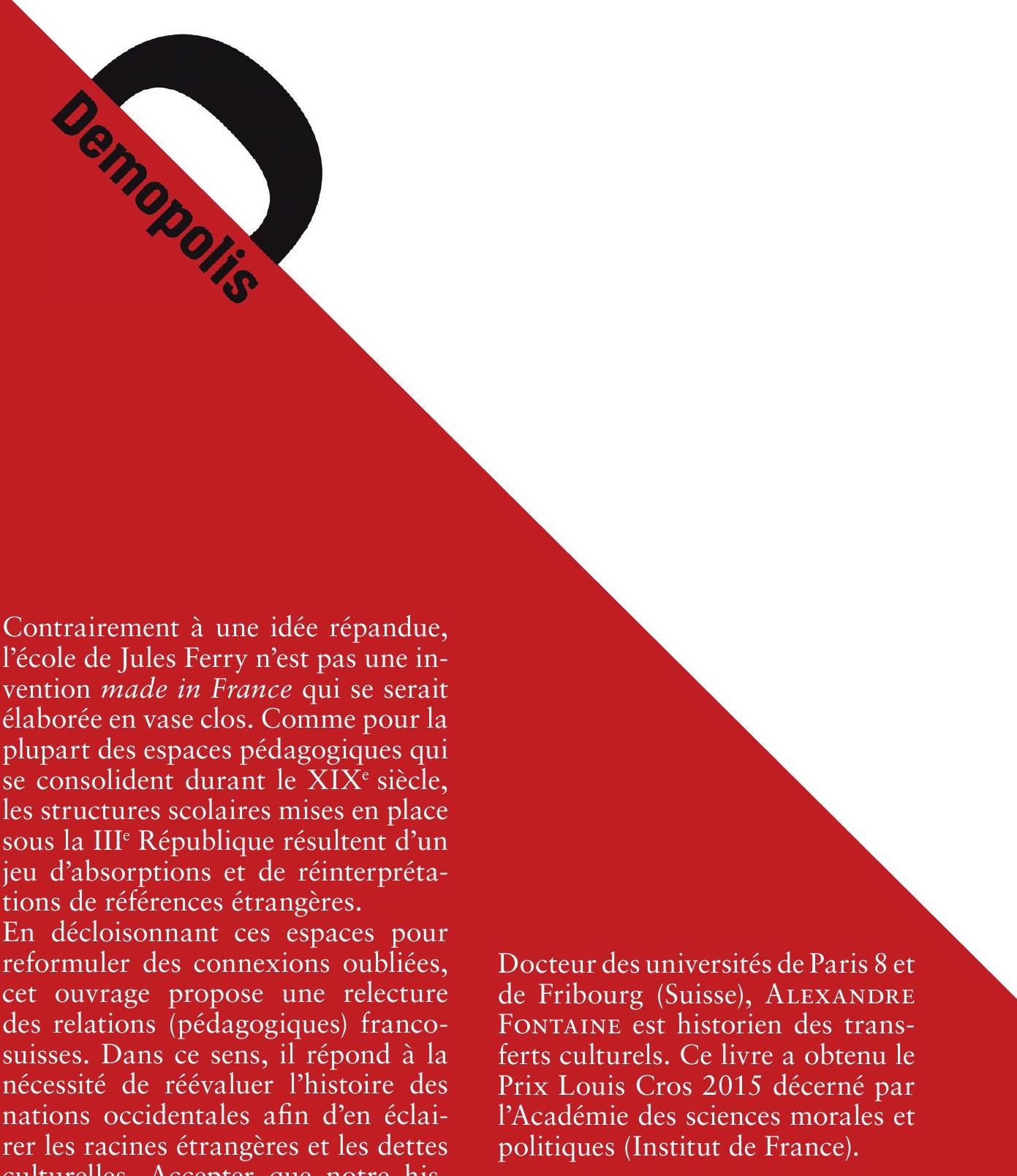
culturelles. Accepter que notre histoire soit aussi celle des autres constitue assurément un défi de taille pour l'ego-citoyen du XXI' siècle.
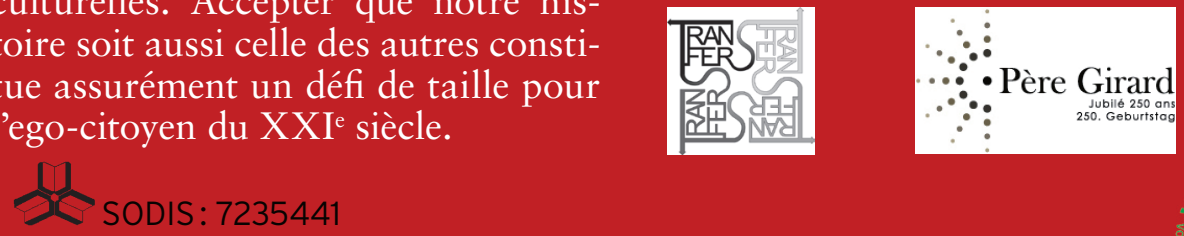

ISBN: 978-2-35457-071-2

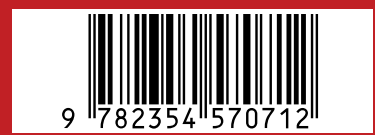

$29,50 €$

www.demopolis.fr 